\title{
Abstracts of the 41st Annual Meeting of THE JAPAN SOCIETY OF HUMAN GENETICS
}

October 23-25, 1996, Sapporo, Japan

President: Kiyotaro KONDO, M.D., D.M.Sc.

(Professor, Department of Public Health, Hokkaido University School of Medicine, Sapporo) 
List of invited papers and symposium

\section{Plenary Lectures}

PL-2 DNA Repair Defects in Mutagenesis and Carcinogenesis .......... Sekiguchi 27

PL-3 Human Genetics-Past, Present, and Future ................ Yanase 27

PL-4 Molecular Pathogenesis of Nonketotic Hyperglycinemia ............. S. Kure 28

PL-5 Molecular Basis of Zellweger Syndrome, $\beta$-Ketothiolase Deficiency and Mucopoly-

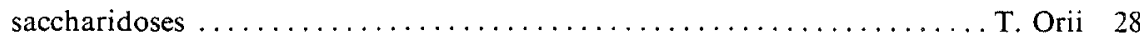

\section{Luncheon Seminars}

LS-1 Apoptosis of Hepatocytes in Genetic Diseases ................ F. Endo 29

LS-2 Molecular Genetics of Essential Hypertension.................. In Inoue 29

LS-3 Ethical, Legal and Social Issues in Human Genetics................ Takebe 30

LS-4 Intra-body Evolution of Pathogenic Viruses with Special References to HIV and

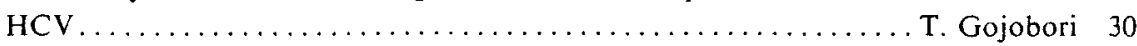

LS-5 Developmental and Morphological Plans of Mammalian Viscerocranium $\ldots \ldots \ldots \ldots \ldots \ldots \ldots \ldots \ldots \ldots \ldots \ldots \ldots$ S. Kuratani, I. Matsuo and S. Aizawa 31

LS-6 A New Technology for Cancer Diagnosis-Telomerase-

K. Ohyashiki, J.H. Ohyashiki and M. Oshimura

\section{Symposium}

S-1-1 Fluorescence In Situ Hybridization: Application on Genome Mapping and the Cytomolecular Genetics of Cancer ................... Inazawa 32

S-I-2 Genomic Imprinting and Its Relevance to Genetic Diseases......... N. Niikawa 32

S-I-3 Behavior of the Human XIST Gene in Mouse Cells... I. Yoshida and N. Takagi 33

S-I-4 Cellular Senescence and Telomerase.................... Oshimura 33

S-II-1 Genetic Alterations and Diagnosis in Human Breast Cancer ............................. Emi, Y. Miki and Y. Nakamura 34

S-II-2 Hyperlipidemia and Coronary Heart Disease

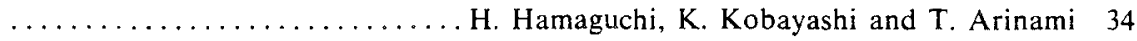

S-II-3 Genetic Studies of Alcoholism............ T. Muramatsu and S. Higuchi 35

S-II-4 A Prospect of Early Prevention of Pregnancy-induced Hypertension Using Genetic and Environmental Risk Factors 
Plenary Lectures

PL-2

DNA REPAIR DEFECTS IN MUTAGENESIS AND CARCINOGENESIS. Mutsuo SEKIGUCHI (Dept. Biol., Fukuoka Dental College, Fukuoka)

There is a special class of mutations that increases the frequency of spontaneous mutation. These are collectively termed mutators and are useful tools for elucidating cellular mechanisms related to the high fidelity of DNA replication. Once a mutant with a mutator phenotype is isolated, it can be used to clone the gene responsible and the gene product can be identified. This in turn paves the way for determination of the biochemical nature of the gene product and further elucidation of its role in the entire process of replication. These proteins may be responsible for genomic stability and defects in the genes would cause an increased frequercy of occurrence of cancers.

PL-3

HUMAN GENETICS--- PAST, PRESENT, AND FUTURE

Toshiyuki YANASE (Prof. Emeritus, Univ. Kyushu, Fukuoka)

This is a special lecture commemorating the 40th anniversary of the founding of the Japan Society of Human Genetics. The following items are covered: Human genetics in the earlier days and four pioneering studies in Japan/ Establishment of the Japan Society of Human Genetics (1956)/ Monumentary studies at the dawn of a new age- those in human population genetics, cytogenetics, and biochemical genetics/ Genetic epidemiology and statistical genetics particularly involving analysis of family data and genetic linkage/ Inborn errors of metabolism discovered in Japan/ Studies on biological effects of inbreeding and genetic load (1960-1970)/ Some indications of new current-discoveries of major histocompatibility antigens (HLA), Philadelphia chromosome, somatic cell fusion, two hit theory in carcinogenesis, etc. (1955-1970)/ Introduction of technologies of gene manipulation into medical biology/ New knowledges of interactions between allelic or non-allelic genes/ Heterogeneity at the DNA level of mutation and molecular pathology of single gene disorders/ Classification of single gene disorders based upon new genetic concepts/ Genomic rearrangement-programmed and unprogrammed rearrangement/ Approaches to the analysis of molecular basis of common polygenic diseases/A mile stone of gene mapping- assignment of genetic locus responsible for Huntington's disease by RFLP linkage/ Human genome project- present and future directions/Gene diagnosis and therapy/ Estimation of genetic risks and informed consent in the recombinant DNA era/ Ecogenetic and xenogenetic problems in the recent past, present, and future, with special reference to genomic chanqes in microbes and man. 
PL-4

Molecular pathogenesis of nonketotic hyperglycinemia. Shigeo Kure (Dept. Biochem. Genet., Tohoku Univ. School of Medicine, Sendai)

Nonketotic hyperglycinemia (NKH) is a metabolic disorder with autosomal recessive inheritance, causing severe neurological symptoms. The metabolic lesion of $\mathrm{NKH}$ resides in the glycine cleavage system (GCS), a complex enzyme system with four components; $\mathrm{P}-\mathrm{T}-, \mathrm{H}-$, and $\mathrm{L}$-protein. The enzymatic analysis revealed that more than $80 \%$ of the patients with NKH are deficient of P-protein activity. We cloned the $\mathrm{P}$-protein cDNA and its genomic counterparts. $\mathrm{p}$-protein gene spanned more than $130 \mathrm{kbp}$ and had 25 exons. Several mutations were identified: One missence mutation accounts for $70 \%$ of the mutant alleles in Finland, where the incidence of $\mathrm{NKH}$ is unusually high. To elucidate the neuropathogenesis of $\mathrm{NKH}$ we examined structure and expression of the GCS in rat brain and primary cultured neurons and astrocytes. Those studies supports the hypothesis that the neurological disturbance in NKH is caused by excitoneurotoxicity through the NMDA receptor, which is allosterically activated by high concentration of glycine.

\section{PL-5}

MOLECULAR BASIS OF ZELLWEGER SYNDROME, $\beta$-KETOTHIOLASE DEFICIENCY AND MUCOPOLYSACCHARIDOSES. Tadao ORII (Chubu Women's College, Seki)

Zellweger syndrome is a fatal autosomal recessive disease, with clinical evidence of severe neurologic abnormalities, dysmorphic features, hepatomegaly, and multiple renal cysts. We isolated three different types of peroxisome-deficient mutant Chinesehamster-ovary cells - Z24, Z65, and ZP92-as models for human groups E, F, and C, respectively, and clarified that mutation in PAF-1 is the primary defect in the group $F$ patient. We recently cloned human PAF-2 cDNA that restores peroxisomes of group $C$ Zellweger fibroblasts and identified two pathogenic mutations in the PAF-2 gene in two patients with group $\mathrm{C}$ Zellweger syndrome. $\beta$-Ketothiolase deficiency is a deficiency in mitochondrial acetoacetyl-CoA thiolase (T2). Seventeen mutations were identified in 13 T2-deficient patients. We have identified the first different exonic mutations causing $\beta$-glucuronidase deficiency in three unrelated Japanese familiies with mucopolysaccharidosis VII, and the first two kinds of exonic mutations causing GalNAc6S sulfatase deficiency : one is the two base pair deletion which causes a frame shift (1342delCA) found in a classical Morquio patient and the other is a point mutation (N204K) which destroys one of the two asparagine-linked glycosylation sites, as detected in two mildly affected siblings with mucopolysaccharidosis IVA. 


\title{
Luncheon Seminars
}

\section{LS-1}

\author{
APOPTOSIS OF HEPATOCYTES IN GENETIC DISEASES \\ Fumio Endo (Deparrtment of Pediatrics Kumamoto University School of \\ Medicine, Honjo 1-1-1 860 Japan)
}

Many genetic disorders involve inpairment of metabolic activities in hepatocytes. Some of these cause hepatocytes injury, typically seen in diseases such as galactosemia, furctose intolerance, Wilson disease, a-1 anti-trypsin deficiency. The hepaticytes in the patients with these diseases seem to undergo premature death due to chemical sustances formed in the hepatocyets. However precise mechanisms of hepatocyte death under such conditions have not been elucidated. Among these, hereditary tyrosinemia 1(HT1) is characterized by progressive liver damage from infancy and by a high risk for hepatocellular carcinomas. HT1 is caused by the mutations in the fumarylacetoacetate hydrolase gene $F A H$, encoding the last enzyme in the tyrosine catabolic pathway. To investigate the hepatocytes injury in HT1 we developed a mouse model which carried inactivating mutations in both FAH gene and HPD gene, in which the later mutation rescues the perinatal death due to FAH defect. The double mutant $F A H$ /- HPD-/- mice appeared normal, at least until age 18 months and with no evidence of liver disease. The hepatocytes of $F A H /-$ - undergo rapid apoptosis by retrieval of $H P D$ function and acute death follows. Apoptosis of hepetocyes in HI1 has implications in treatment and mechanism for liver pathology of genetic liver diseases.

\section{LS-2}

\section{MOLECULAR GENETICS OF ESSENTIAL HYPERTENSION. Ituro INOUE (Human Genetics, University of Utah)}

\footnotetext{
Human hypertension is a very common, heterogeneous disorder. In the recent study, angiotensinogen (AGT) gene has been implicated in human essential hypertension ( $\mathrm{EH}$ ) through both genetic linkage and allelic association. In particular, the substitution of a threonine for a methionine at amino acid residue 235 , denoted $235 \mathrm{~T}$, was found to be associated with $\mathrm{EH}$ both in Caucasian and Japanese. Furthermore 235T is associated with elevated plasma AGT. In the course of a systematic mutation search in the AGT gene, we have identified a variant in the proximal promoter in tight linkage disequilibrium with T235, adenine instead of guanine, six residues upstream from the transcription start site, denoted -6A. Consequently all association described between $235 \mathrm{~T}$ and $\mathrm{EH}$ or plasma AGT extends directly to this promoter variant. Since biochemical analysis such as a kinetic study or a pulse-chase experiment shows a negative impact on $235 \mathrm{~T}$, our functional test of AGT was targeted to a transcriptional activity due to the variation in the promoter. Two segments of AGT promoter were fused to luciferase gene, and activity of this enzyme after transfection in HepG2 served as a reporter of promoter activity. Detailed statistical analysis of the data revealed a highly significant difference in the promoter activity, although difference was small. Also presence of a specific DNA binding protein in the region that behaves as a negative regulator was confirmed. These results reveal that the nucleotide substitution at position -6 affects the transcriptional activity of AGT, which could lead to the developement of EH.
} 
LS-3

ETHICAL, LEGAL AND SOCIAL ISSUES IN HUMAN GENETICS. Hiraku TAKEBE (Dept. Radiat. Genet., Fac. Med., Kyoto Univ., Kyoto)

Recent rapid progress in human genetics and human gene studies appears to be changing the concept of medicine. Gene diagnosis can predict certain diseases far before the development of the symptoms. Gene therapy may be able to treat some diseases which have been regarded intractable. From the biological view, however, the diversity of genes, or the genome diversity, is the basic characteristics of all living organisms, and human beings are no exception. Every person should have at least several recessive genes which might seriously affect one's health in the homozygous state. Mutations can take place at certain probability in all genes. Human beings must live with the existing human genome, and to abolish genetic diseases should not be the goal of human genetics. To discuss ethical, legal and social issues (ELSI) in human genetics, "all human beings are born free and equal in dignity and rights", as stated in the United Nations Declaration of Human Rights (1948) must be the starting point. The Human Genome Organization (HUGO) established ELSI Committee in 1992 and statement on the Pricipled Conduct of Genetic Research, emphasizing 10 "C"s, communication, consent, confidentiality, etc. was published in 1996.

\section{LS -4}

\section{INTRA-BODY EVOLUTION OF PATHOGENIC VIRUSES WITH SPECIAL REFERENCES TO HIV AND HCV}

\section{Takashi GOJOBORI (National Institute of Genetics, Mishima)}

It is now known that the rate of nucleotide substitution for the genes of HIV (Human Immunodeficiency Virus) and HCV (Hepatitis C Virus), is a million times higher than that for human genes. This characteristic feature of pathogenic viruses gives us a unique opportunity to observe the generating mechanism of genetic variability, even withing a single host. Indeed, it is rather common practice to obtain a viral isolate from a single patient or carrier at several time points after infection. The isolated viral clones have been sequenced and the nucleotide sequences compared with each other to estimate the numbers of nucleotide substitutions. By using the substitution numbers, we successfully constructed a phylogenetic tree for the clones isolated from a single host. The phylogentic tree obtained showed that the homogeneous populations of viral clones present at the initial stage, gradually accumulated genetic variability within the human body. We also found that there was a particular period of time when amino acid substitutions were significantly favored. This implies that some sort of positive selection is taking place during this time, in order for viruses to escape from the immune system of the host. These results will be useful in analyzing the evolutionary interaction between the viruses and their hosts. 
LS-5

DEVELOPMENTAL AND MORPHOLOGICAL PLANS OF MAMMALIAN VISCEROCRANIUM. ShigerU KURATANI, Isao MATSUO, and Shinichi AlZAWA (Dept. Morphogenesis, IMEG, Kumamoto Univ. School of Medicine, Kumamoto)

The vertebrate skull is composed of the neurocranium and the viscerocranium. The latter is derived from the cephalic neural crest and so is the prechordal part of the neurocranium. A view we favor considers the prechordal cranium as the premandibular viscerocranium, and the whole skull to consist of the neural crest-derived viscerocranium and the mesodermal neurocranium. Of the mammalian viscerocranium, the mandibular arch skeleton undergoes a striking modification through development as seen in middle ear ossicles. The Hox code which is known to function in specification of the viscerocranium does not extend rostrally into the mandibular and premandibular segments. By genetic manipulation of rostrally expressed nonHox homeobox genes, the patterning mechanism of the head is demonstrated to be more complicated than isomorphic registration of the Hox code to pharyngeal arches. The phenotype of Otx2 haplo-insufficiency implies the premandibular (prechordal) cranium shares a common specification mechanism with the mandibular arch. Our interpretation of the metamerical plan of the viscerocranium offers a new scheme of molecular codes associated with the vertebrate head evolution.

\section{LS-6}

A NEW TECHNOLOGY FOR CANCER DIAGNOSIS - TELOMERASE-. Kazuma OHYASHIKI ${ }^{1}$ Junko H. OHYASHIKI ${ }^{1}$ and Mitsuo OSHIMURA ${ }^{2}$. ( ${ }^{1}$ First Dept. Internal Med., Tokyo Med. Coll., Tokyo, ${ }^{2}$ Dept. of Mol. \& Cell Genet., Sch. of Life Scis., Fac. Med., Tottori Univ., Tottori)

Telomeres are very important structures that protect chromosomal ends from recombination, but the structure itself induces inreversible reduction without the presence of telomerase activity. Researchers are now collecting evidence of telomere dynamics in clinical samples, but we are still far from being able to discuss telomere dynamics and chromosome changes in clinical samples. Although there is a growing body of evidence that telomerase might be a very important key enzyme to obtain immortality, and possibly oncogenesis, other pathways for immortal characteristics are currently being reported. Thus, telomerase is considered to be a new marker of neoplasias. We present the conventional TRAP (telomeric repeat amplification protocol) and a new technique, including fluorescent TRAP that makes it possible to detect telomerase activity semi-quantatively and in situ TRAP assay that allows us to determine the exact telomerase-positive cells. Our current techniques would provide further informations in clinical oncology. 


\section{Symposium \\ S-I-1 \\ FLUORESCENCE IN SITU HYBRIDIZATION: APPLICATION ON GENOME MAPPING AND THE CYTOMOLECULAR GENETICS OF CANCER Johii INAZAWA (Dept. of Hyg. Kyoto Pref. Univ. of Med.)}

For establishment of a high-resolution ordering system elongated prophase chromosomes were prepared and applied them to multi-color FISH. This prophase FISH ordering system gives information about orientation as well as order of adjacent DNA loci that are as little as about $100 \mathrm{~kb}$ apart. This technique can bridge the gap between the genomic distances analyzed by pulsed-field gel electrophoresis (PFGE) or YAC technologies. FISH to interphase nuclei with chromosome-specific probes is being used frequently to analyze chromosome aberrations in neoplastic tumors. Losses of loci on chromosome $1 \mathrm{p}$ were examined in brain tumors using double-target FISH. The $1 \mathrm{p}$ loss was found in all of the samples from oligodendrogliomas examined, whereas our series of astrocytic tumors showed a low incidence of deletions of this region. These results strongly suggest that at least one tumor suppressor gene responsible oligodendroglial tumors lies on the short arm of chromosome 1. For the clinical point of view, we investigated FISH as a tool for diagnosis of several types of solid tumors. Of them we examined numerical aberrations of chromosomes 1,11 , and 17 by multicolor FISH of selected probes to cell nuclei derived from fine-needle biopsies of 106 breast tumors. None of the benign tumors and phyllodes tumors showed evidence of aneusomy for each chromosome. However, 71 of the 74 breast cancers $(95.9 \%)$ for which sufficient material was available showed aneusomic for at least one of the three chromosomes tested. These results suggest that FSH analysis of fine-needle aspiration biopsies can be a practical and useful method for diagnosis of carcinoma in breast tumors.

\section{S-1-2}

GENOMIC IMPRINTING AND ITS RELEVANCE TO GENETIC DISEASES. Norio NIIKAWA (Dept. Hum. Genet., Nagasaki Univ. Sch. Med., Nagasaki)

Genomic imprinting is a biological phenomenon determined by an underlying system that may control harmonious development and growth in mammals. It is also relevant to some genetic disorders in man. Since 2 regions, $15 q 11-q 13$ and $11 \mathrm{p} 15.5$, have well been analyzed among 16 UPD chromosomes, where Prader.Willi syndrome (PWS)/Angelman syndrome (AS) and Beckwith-Wiedemann syndrome (BWS) regions are located, I reviewed recent cytogenetic/molecular genetic findings on these syndromes, especially focusing on imprinting centers. There have been a few PWS/AS patients with imprinting mutations. Similar findings were obtained in a few BWS patients. From the findings in these exceptional cases, an imprinting center (IC) hypothesis was proposed: normally, IC may suppressively control the disease locus or a putative imprinting switch initiation site (SIS), and a mutation in IC may result in a failure of the control, thus leading to the diseases. The IC for PWS/AS may exist at around the SNRPN-exon 1 and that for BWS may be the $\mathrm{p} 57^{\mathrm{KIP2}}$ gene itself. As for the IC at $15 \mathrm{q} 11-\mathrm{q} 13$, in the normal female germline, the paternal IC suppresses SIS function, and therefore the paternal imprint would switch to the maternal imprint, whereas in the normal male germline, since $I C$ on the maternally-derived chromosome is inactive, SIS would mark the chromosome with the paternal imprint. This model was successful to explain complex genetic findings on PWS/AS patients. Regarding the $I C$ at $11 p 15$, we recently identified a nonsense mutation in the p57 KIP2 gene in 4 of 15 familial or sporadic BWS cases. Furthermore, in one family, the phenotypically normal mother had the same mutation as the patient, the findings being consistent with the maternal transmission of mutation in familial BWS cases and with the characteristic of the $I C$. Further studies on how this gene interacts with $I G F 2$ are required. 


\section{S-I-3}

BEHAVIOR OF THE HUMAN XIST GENE IN MOUSE CELIS. Ikuya YOSHIDA and Nobuo TAKAGI (Res. Ctr. Mol. Genet. and Grad. Sch. Envir. Earth Sci., Hokkaido Univ.)

CF150, a mouse-human somatic hybrid cell line, retains one or more inactive human $X$ chromosome(s) as the only human element. This $X$ chromosome was judged to be inactive because it replicates late in $S$ phase, and the XIST gene is expressed while several $X-1$ inked genes, which are usually subject to inactivation, are not expressed. We, however, could not find in this hybrid cell line any perinuclear-localized sex chromatin body (SCB) at interphase, and chromosome(s) markedly understained with an anti-acetylated histone $\mathrm{H} 4$ antibody at metaphase, two of important traits characterizing the inactive $X$ chromosome in mammals. Apparently, the $X$ chromosome remains inactive without SCB formation and hypoacetylation of histone $\mathrm{H} 4$, and certain species-specific factors are involved in the manifestation of these characters. In agreement with this view, the $X$ chromosome transferred to Hela cells was hypoacetylated and formed SCB. We introduced the human inactive $X$ chromosome into mouse embryonal carcinoma cells by microcell fusion to further explore interspecific difference. The human $X$ chromosome was reactivated in monochromosome hybrids, while the XIST gene continued to express actively. The methylation status of $5^{\prime}$ region of the $X I S T$ gene varied considerably in different hybrid clones. Thus, it is evident that the $X$ chromosome inactivation is a multi-step phenomenon diverged, to a certain extent, among different mamalian species. It is also envisaged that the inactivation is maintained predominantly by a single condition such as heterochromatinization or replication asynchrony, or collectively by a multitude of attributes so that the breakdown of only a few of them may not entail activation.

\section{S-I -4}

\section{CELLULAR SENESCENCE AND TELOMERASE. Mitsuo OSHIMURA (Dept. Mol. Cell Genet., Sch. Life Scis., Fac. Med., Tottori Univ., Tottori)}

Hybrids between immortal cells and normal cells senesce, indicating that immortal cells have lost, mutated or inactivated genes that are required for the program of senescence in normal cells. Genes involved in the senescent program have been mapped to 10 different loci by introduction of human chromosomes via microcell fusion. Multiple pathways of cellular senescence have also been demonstrated by chromosome transfer, indicating that the functions of the senescence genes mapped to different chromosomes are probably variable. One possibility is that one or more of the senescence genes defined by chromosome transfer may suppress telomerase activity in tumor cells, resulting in telomere shortening and cellular senescence. To test this hypothesis, we examined telomerase activity and the length of terminal restriction fragments (TRFs) in microcell hybrids by introducing single human chromosomes into various tumor cell lines. Reintroduction of a normal chromosome 3 into some renal cell and lung carcinoma cell lines with loss of the short arm of chromosome 3 restored the program of cellular senescence with or without the loss of telomerase activity and shortening of telomeres. Thus, chromosome 3 carries functionally distinct senescence genes, one of which is invoved in the telomerase pathways. Radiation hybrid experiments with transfer of fragmented chromosomes showed the region to be a $3 \mathrm{p} 14$ 21. 
S-II-1

GENETIC ALTERATIONS AND DIAGNOSIS IN HUMAN BREAST CANCER. Mitsuru EMI, Yoshio MIRI, Yusuke NAKAMURA ( Inst. Geront. Nippon Med. Sch., Kawasaki, Cancer Inst.,Tokyo, Inst. Med. Sci., Univ.of Tokyo, Tokyo )

predisposing mutationg in a BRCAl gene have been recently identified in germ-line of 17q-linked breast and ovarian cancer families. To understand the frequency, distribution and nature of BRCA1 mutations in Japanese breast cancer patients, we screened 1,000 unselected primary cancers for mutations in exon 11, which accounts for $61 \%$ of the entire BRCA1 coding sequence. Using a method based on multiplex single-strand conformational polymorphism (SSCP) analysis of multiple restriction fragments generated by restriction-enzyme digestion of amplified DNA, we identified eight mutations including four that we had previously found in a subset of these cases. All eight were germline mutations; four of them were non-sense mutations or small deletions resulting in premature stop codons, and the other four were missense mutations. The Japanese carriers of these mutant BRCA1 alleles had developed breast cancers at ages ranging from 45 to 62, five of them bilaterally. Taking into account the effect of various factors such as life-time risk of breast cancer, screening efficiency, and the region examined, we roughly estimate that $2-3$ of breast cancer in Japan is attributable to BRCAl mutation and that 1 in 1,500-2,000 Japanese women carry a germline mutation in the BRCA1 gene.

\section{S-II-2}

HYPERLIPIDEMIA AND CORONARY HEART DISEASE.

Hideo HAMAGUCHI, Kimiko KOBAYASHI, and Tadao ARINAMI

(Dept. Med.Genet., Inst. Basic Med. Sci., Univ. Tsukuba, Tsukuba)

The genetic etiology of coronary heart disease (CHD) is complex and heterogeneous. We are searching for the polymorphic loci responsible for multifactorial hypercholesterolemia. We are also evaluating relative risks for CHD in Japanese subjects with the polymorphic genes which have been reported to be associated with CHD in Caucasians. Analysis by QTL and affected sib-pair methods using 101 Japanese families with child sib-pairs collected through a hypercholesterolemic child suggested the presence of the locus responsible for the variation of serum cholesterol levels and hypercholesterolemia in the apoAI/CIII/AIV gene cluster region $(\mathrm{p}=0.00007$ and $\mathrm{p}=0.02$, respectively). On the other hand, odds ratio for the risk of $\mathrm{CHD}$ calculated based on case-control studies was 1.58 (95\% CI, 1.0-2.4) in subjects with the apoE4 allele, $2.5(1.6-4.1)$ in subjects with the apo(a) alleles of kringle 4 repeats less than 24, and 2.3 (1.5-3.7) in subjects with the methylenetetrahydrofolate reductase (MTHFR) TT genotype. The presence of a synergistic effect of the apoEA allele and the MTHFR TT genotype on the risk of CHD was suggested. For the predictive genetic diagnosis of CHD, further extensive studies are required, except for familial hypercholesterolemia. 
S-II-3

GENETIC STUDIES OF ALCOHOLISM. Ta TO MURAMATSU and SUSUmU HIGUCHI. Department of Psychiatry, Kurihama National Hospital, Kanagawa, Japan.

Twin and adoption studies consistently show the involvement of genetic factors in alcohol ism. Prevention of this common disease is, at least theoretically, simple: Drink sensibly or abstinence. Accordingly, search for genes related to alcohol ism will be of great help in the future preventive activities. 1. Alcohol metabolizing enzymes: Ethanol is el iminated from the body by oxidation to acetaldehyde and then to acetate, reactions catalyzed by alcohol dehydrogenase (ADH2) and aldehyde dehydrogenase (ALDH2), respectively. The latter gene has a common mutation which leads to inactivation of the enzyme activity. Individuals who have this mutant allele, ALDH2*2, are prevented from becoming alcoholics because of acetaldehydemia and associated unpleasant symptoms after drinking. In Japan, approximately $10 \%$ of alcoholics have this allele, compared with approximately $50 \%$ of controls.

2. Dopamine system: Because its involvement in reward-seeking behavior, dysfunction of dopamine system could be the biological factor of alcohol ism. Thus polymorphic genes of this system have been targets of association studies of alcoholism, with conflicting results, due mostly to the heterogeneity of the disease. One strategy to obtain a homogeneous group is to focus on alcoholics with ALDH $2 * 2$ allele, because these patients should have some strong factor(s) to overcome the negative risk factor. In fact. allele distributions of dopamine 04 receptor and dopamine transporter differed between this group and control.

\section{S-II-4}

A PROSPECT OF EARLY PREVENTION OF PREGNANCY-INDUCED HYPERTENSION USING GENETIC AND ENVIRONMENTAL RISK FACTORS. Gen KOBASHI (Dept. Public Health, Hokkaido Univ. School of Med., Sapporo)

Pregnancy-induced hypertension (PIH) occurs via an interaction of genetic and nongenetic factors. To elucidate synergism of predisposing genes and non-genetic factors in $\mathrm{PIH}, 62$ cases and 93 controls were studied. A variant of angiotensinogen (AGT) gene $\left(\mathrm{Met}^{235} \rightarrow \mathrm{Thr}\right)$ in the exon 2 , and that of angiotensin type 1 receptor $(\mathrm{AlR})$ gene $\left(\mathrm{A}^{1166} \rightarrow\right.$ C) in 3'-untranslated region were analyzed by PCR and hybridization. Lifestyles were mail-questionnaired, 1-6 months after delivery. Fourteen factors out of 100 items were selected $(\mathrm{p}<0.1)$ by univariate analysis. After a stepwise regression analysis, 5 factors; TT genotype of AGT gene', 'AC+CC genotype of A IR gene', 'BMI $\geq 24$ before pregnancy', 'low comsumption of milk during pregnancy' and 'mentally hard during pregnancy', were screened. Compared with a reference group with none of the risks, those with the 5 major risk factors were 735.1 times more liable to $\mathrm{PIH}$ in a multiple logistic model. It may give a clue to establish an effective individualized prediction and prevention of PIH, by eliminating manageable risk factors in lifestyles, particularly among the inherited high-risk individuals. Social and ethical issues on notification, informed consent, framework for intervention, evaluation of the effectiveness are problems to be evaluated in order to establish a prevention program for PIH. 
General Contributions

\section{A-1}

THE POSSIBLE RELATIONSHIP BETWEEN CONSTITUTIONAL CHROMOSOME ANOMALIES AND DEVELOPMENT OF ACQUIRED CYSTIC DISEASE OF THE KIDNEY (ACDK) AND PAPILLARY RENAL CELL CARCINOMA IN LONG-TERM HEMODIALYSIS PATIENTS. Mitsuaki A. YOSHIDA ${ }^{2}$, Yukio KAGEYAMA ${ }^{2}$, Hideyuki OGASAWARA ${ }^{3}$, Akihiro SHISHIKURA ${ }^{4}$, Hiroyuki OSHIMA ${ }^{2}$ and Tatsuro IKEUCHI ${ }^{1}$ ( ${ }^{1}$ Dept. Cytogenet., Med. Res. Inst., ${ }^{2}$ Dept.Urol. , Sch. Med., Tokyo Med. \& Dent. Univ., Tokyo, ${ }^{3}$ Dept. , Urol., Sch. Med., Kumamoto Univ., Kumamoto, ${ }^{4}$ Blood Transf. Ser., Jikei Univ. Sch. Med., Tokyo)

Acquired cystic disease of the kidney (ACDK) develops in long-term haemodialysis patients, and renal cell carcinoma (RCC), particularly, of papillary type, is frequently observed in ACDK patients. To understand the possible genetic mechanism involved in the pathological states, we performed chromosome analysis in ACOK and papillary RCC from hemodialysis patients. During the course of this study, chromosomes of blood lymphocyte cultures from these patients have also been studied, and 4 cases among 55 patients analyzed showed constitutional chromosome abnormalities; They include one case each of del(15q) in Prader-Willi syndrome, XYY male, and two reciprocal translocations, 7q;19q and $X p ; 10 q$. The incidence of such constitutional chromosome abnormalities in hemodialysis patients was extremely higher than that in the general population. Papillary RCCs from 5 hemodialysis patients have been chromosomally analyzed, and 2 of them showed various types of acquired chromosome abnormalities, such as 7- and 16-trisomies, partial trisomy of 10, inv $(Y)$ and unbalanced translocation of $1 q$ and $10 p$ : there have been no structural anomalies possibly related to the above constituional chromosome translocations. Further chromosome studies are needed in an incresed number of hemodialysis patients.

\section{A-2}

\section{EPIDEMIOLOGY OF GENITO-URINARY MALFORMATIONS ASSOCIATED}

WITH CHILDHOOD MALIGNANCIES IN JAPAN. JUn ABE, Masako TANIMURA, Ichiro MATSUI (Dept. Child Ecology, National Children's Med. Res. Ctr., Tokyo) and Noboru KOBAY ASHI (National Children's Hospital, Tokyo)

Between 1962 and 1992, 29,685 children with malignant tumors were registered at the JCCR (Japan Children's Cancer Registry) at Tokyo. They consist of leukemia (40.4\%), malignant lymphoma (8.2), brain tumor (8.8), neuroblastoma (12.0), retinoblastoma (7.7), germ cell tumor (7.1), Wilms tumor (3.9), hepatoblastoma (2.3), and the other tumors $(9.7)$.

Among these tumors, Wilms tumor and germ cell tumor had the higher incidence of the congenital genito-urinary malformations compared with the other tumors. In Wilms tumor, hypospadias and cryptorchidism were seen in $3.0 \%$ and $4.9 \%$ of male patients, respectively $(p<0.01)$, and in germ cell tumor, cryptorchidism was seen in $1.4 \%$ of male patients $(p<0.01)$. The earlier age at the diagnosis of Wilms tumor was seen in patients with hypospadias $(p<0.01)$ and with cryptorchidism $(p<0.05)$ as reported in patients with AGR and Drash syndromes in which WTI gene mutation has been found.

Wilms tumor was also associated with the higher incidence of renal-ureteral dysplasia such as fused kidney $(0.4 \%)$ and duplicated kidney $(0.2 \%)$. Besides Wilms tumor, neuroblastoma had an elevated incidence of hemi-hypoplastic kidney $(0.1 \%)$ and duplicated kidney $(0.1 \%)(\mathrm{p}<0.01)$. The association of renal-ureteral dysplasia with these two solid tumors and the absence of the relationship with early onset in these patients may suggest the other possible genes than WT1 gene that work in both carcinogenesis and organogenesis. 
A-3

FAMILY HISTORY OF NEUROBLASTOMA

Masako TANIMURA, Ichiro MATSUI (Dept. Child Ecology, Natl. Children's Medical Research Center) and Noboru KOBAYASHI (Nat1. Children's Hospital)

We reviewed family histories of 3808 neuroblastoma (NB) cases, diagnosed between 1969 and 1992 , from among those entered in the Japan Children's Cancer Registry. Three sib1 ings of $N B$ probands in 3 families and 2 cousins in 2 families died of NB. In these families NB patients were diagnosed at $0-6$ years old, suggesting that the NB mass screening for 6-month infants is somewhat effective for early detection of malignant-type NB.

The rate of probands with a history of an aunt's uterine cancer in NB probands $(0.45 \%)$ was significantly higher than in other childhood cancer probands $(0.21 \%)$. out of 22 families of NB probands having a history of aunt's uterine cancer, other type of cancer occurred in aunt's sibs in 3 families and abortions or still births occurred in proband's sibs in 3 families. The uterine cancer incidence in grandmothers of NB probands was also significantly higher than in those of other childhood cancer probands. These facts imply that there is a genetic factor associated both with NB in childhood and uterus cancer in adults.

\section{A-4}

CORRELATION OF LOSS OF HETEROZYGOSITY WITH CLINICOPATHO. LOGICAL PARAMETERS IN PRIMARY BREAST CANCER. 1,2Satoshi

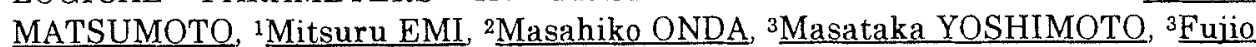
KASUMI, "Yusuke NAKAMURA ( IDept. Mol. Biol., Inst. Gerontol., Nippon Med. Sch., Kawasaki., ${ }^{2} 1$ st. Dept. Surg., Nippon Med. Sch., Tokyo., 3Dept. Surg., Cancer Inst. Hosp., Tokyo., ${ }^{4}$ Labo. Mol. Med., Inst. Med. Sci., Univ. Tokyo, Tokyo )

In order to investigate the role of loss of heterozygosity ( $\mathrm{LOH}$ ) during tumor development and/or progression, we looked for correlations between various clinicopathological parameters of breast cancer and $\mathrm{LOH}$ at chromosomal regions, $1 p, 3 p, 8 p, 9 q, 11 p, 16 q, 17 p, 17 q$ and $22 q$, where we have been detected frequent losses in primary tumors. In the present study, we examined 152 primary breast cancers for $\mathrm{LOH}$ at 18 regions on the 9 different chromosomal arms using 24 highly informative microsatellite markers. Our results suggest the following below. 1) LOH at $16 q 22-24$ and $17 q 21$ might be early events in breast carcinogenesis. 2) LOH at $3 \mathrm{p} 14-21,11 \mathrm{p} 15.5,13 \mathrm{q} 12-14$ and $17 \mathrm{q} 21$ could be associated with the loss of hormone dependency in progression of primary breast cancer. 3) LOH at 1p22-31 and $17 \mathrm{p} 13.3$ could have a significant role during the regional lymphnode metastasis. 
HUMAN NEDD-4 AS A FAMILY MEMBER OF UBIQUTTIN LIGASES :

Tadashi ANAN ${ }^{1,2}$, Yoichi NAGATA ${ }^{1}$, Yoshiomi HONDA ${ }^{1}$, Yoriyoshi KIMURA ${ }^{1}$, Akira KUWANO $^{3}$, Nobuo NOMURA ${ }^{4}$. Ichiro MATSUDA ${ }^{2}$, Hideyuki SAYA ${ }^{1}$, Mitsuyoshi NAKAO $^{1}{ }^{1}$ Dept.Tumor Genet.Biol., ${ }^{2}$ Dept.Pediatr.Kumamoto Univ.Kumamoto., ${ }^{3}$ Dept.Hygiene. Ehime Univ. Matsuyama., ${ }^{4}$ Kazusa DNA Research Institute.Kisarazu)

Ubiquitin-proteasome proteolytic pathway is involved in a number of cellular physiology. In this system, a ubiquitin ligase, or E3 enzyme, is a major component which recognizes a specific substrate protein for targeted degradation. E6-associated protein (E6-AP) has been recently found to be a member of the E3 enzyme family that is characterized by a conserved carboxy-terminal sequence, termed hect-domain. Using human EST data bases, we identified five uncharacterized genes of this family. By FISH and radiation hybrid panel,these genes were mapped to subchromosomal locations as follows; E6-AP (15q12-13), NEDD-4 (15q22; D15S209), D28476 (2q35-36; D2S396), D13635 (7q36; FB16B4), and D25215 (4q21-22; WI-6336). NEDD-4 gene was mapped close to the translocation breakpoint of acute promyelocytic leukemia. Interestingly, NEDD-4 was highly conserved among species from yeast to human, suggesting its significant function on basic biomodulation. Northern blot analysis showed that NEDD-4 mRNA was much higher expressed in lung carcinoma A549 and chronic myelogenous leukemia K562 than in other cancer cell lines tested. The rest of the members, except D25215, were ubiquitously expressed in all cells. In immunoblot analysis, human NEDD-4 protein was down-regulated during neural differentiation in BDNFtreated neuroblastoma cells. Collectively, our data suggest that NEDD-4 protein may function as a ubiquitin ligase closely related to development, differentiation and tumorigenesis.

\section{A-6}

FUNCTIONAL ANALYSIS OF TUMOR SUPPRESSOR P53 PROTEIN REGULATED BY UBIQUITIN-PROTEASOME SYSTEM. Yoichi NAGATA Tadashi ANAN, Yoshiomi HONDA, Reiji KIMURA, Hideyuki SAYA, Mitsuyoshi NAKAO (Dept.of Tumor Genet. and Biol., Kumamoto Univ, Kumamoto)Motomi NAKATA, Naoki SHINBARA(Sumitomo Electorical Industry, Yokohama)Keiji TANAKA'(The Tokyo Metropolitan Inst. of Med. Sci.,Tokyo) Satoshi OMURA(Kitazato Inst., Tokyo)

The tumor suppressor 553 protein is most important for cell regulation such as cell cycle and apoptosis. In HPV-infected cells including HeLa cells, a viral oncoprotein E6 and a cellular E6-associated protein (E6AP) function together as a ubiquitin ligase targetting for $\mathrm{p} 53$. The complex plays a major role in the tumorigenesis by rapid turnover of $\mathrm{p} 53$. However, the mechanism of $\mathrm{p} 53$ degradation in normal cells remains unclear. 1) Using proteasome inhibitors, 553 protein was significantily accumulated in primary fibroblasts as well as HeLa cells in vivo. 2) Recombinant p53 proteins destined for wild- or mutant(273His)-type were analysed in an appropriate buffer and rabbit reticulocyte lysates in vitro. Much slower degradation of mutant-p 53 was found compared with the case of wild-p 53 . Interestingly, both-types of p53 were multiubiquitinated in a similar manner. 3) In fibroblasts infected with p53-expressing adenovirus, wild-p 53 protein was co-immunoprecipitated with anti-E6AP antibody. In summary, E6AP may also work in the p53 ubiquitination in normal cells adding to E6-dependent case. Ubiquitinated mutant-p 53 becomes resistant to degradation, suggesting that mutant-p 53 is hardly recognized and/or degraded by proteasome due to unknown mechanism. 


\begin{abstract}
A-7
DETECTION OF p53 MUTATION IN HUMAN AND RAT TUMOR CELLS BY YEAST FUNCTIONAL ASSAY. Daichi NAKATA ${ }^{1}$, Hidefumi TONOKI ${ }^{1}$, Haruhiko KASHIWAZAKI ${ }^{1}, Y i$ $\mathrm{BA}^{1}$. Jun-ichi HAMADA ${ }^{1}$, Masuo HOSOKAWA ${ }^{2}$, Mitsuhiro TADA ${ }^{3}$ and Tetsuya MORIUCHI ${ }^{1}$ ( ${ }^{2}$ Lab.Cell Biol., ${ }^{2}$ Lab. Pathol. Cancer Inst. and ${ }^{3}$ Dept. Neurosurgery Hokkaido Univ. School of Med., Sapporo)
\end{abstract}

Yeast functional assay is a simple and sensitive screening method for detection of p53 mutaion in human tumor tissue. The RT-PCR products are directly assayed according to its DNA binding capacity in yeast. Relative population of cells carrying mutant p53 allele is ascertained by counting red colonies. We analyzed the sensitivity and the clinical application of this method. Mutant p53 alleles are detectable from samples containing at least $6 \%$ of mutant $\mathrm{p} 53 \mathrm{cDNA}$. It is disclosed that more than $20 \%$ of red colonies suggests the existence of clonal expansion of cells carrying mutant p53 allele. We reconstructed this method to establish a yeast assay for rat p53 gene. By this method, several p53 mutations were newly identified in rat tumor cell lines. Hepatocellular carcinoma and cholangiofibrosis tissues in LEC rat liver were then assayed with this method. Ratios of red colony were significantly elevated in these tissues, but were not large enough to suggest the existence of clonal p53 mutation. This result suggests that p53 mutaion is not a primary event for the development of hepatocellular carcinoma in LEC rat and that increased red colonies may indicate a possible genomic instability in LEC rat liver. In conclusion, the yeast functional assay is sensitive and useful method for the detection of clinical mutation. This assay for rat $\mathrm{p} 53$ gene provides a new monitor system of $\mathrm{p} 53$ status in various experiment.

\title{
A-8
}

Isolation and Chracterization of chromosome specific gene, that contains a variable number of tandem repeats (VNTR) site. Kumiko KOYAMA, Mieko MATUSHIMA and Yusuke NAKAMURA(Lab. Molecular Medicine, Ins. Med. Sci., Univ. Tokyo)

Variable number of tandem repeat (VNTR) markers, which tend to be highly polymorphic, have contributed to many studies in positional cloning and fornsic medicine. In addition to their usefulness as genetic markers to distinguish between alleles, VNTR loci may have a biological role, have recently indicated that the number of repeats within the VNTR that lies in the 5 reaion of the insulin gene is likly to be associated with susceptibility to insulin-dependent diabetes mellitus.

Nou we have isolated and chracterized a numbr of novel human genes, that contains VNTR sequences. Furthermore, we tried functional assay to these genes. 


\begin{abstract}
A-9
SELECTION OF CHROMOSOME 12 SPECIFIC ALPHA SATELLTTE DNA USING NYLON MEMBRANE. Takazumi KOZAKI Yasunobu YOKOYAMA Tadashi KAJll (Genetic Research Division, Center for Molecular Biology and Cytogenetics, SRL, Inc.)

We have isolated $1.4 \mathrm{~kb} \alpha$-satellite DNA of chromosome 12 using a combination of microdissection, PCR amplification, hybridization of the amplified products with larger DNA fragments, and selection of the hybridized segments with nylon membrane (Satish Parimoo et al.,1995).

The centromeric region of chromosome 12 was microdissected, a $171 \mathrm{bp}$ segment of microdissection products was amplified using $\alpha$-satellite consensus primers, and the amplified DNAs were cloned. Southern blot analysis of Hind III-digested human genomic DNAs revealed a $1.4 \mathrm{~kb}$ band with the $171 \mathrm{bp}$ cloned DNAs as a probe (Looijenga L.H.J.et al.,1991). DNAs were extracted from the band, PCR amplified with $M 13$ primers, and selected with hybridization to the $171 \mathrm{bp}$ DNAs immobilized onto a nylon membrane. The selection process was repeated twice. The selected products were checked with chromosomal FISH for their specificity, and cloned in pBluescript $\mathrm{ll}$. Cloning efficiency was one in 27 clones with the membrane selection process, while it was 0 in 192 clones without the process.
\end{abstract}

\author{
A-10 \\ MICRODISSECTION-MEDIATED ISOLATION OF CHROMOSOMAL REGION-SPECIFIC CDNAS. \\ Yasunobu YOKOYAMA. Takazumi KOZAKI (Center for Molecular Biology and \\ Cytogenetics, SRL, Inc., Tokyo) and Keiko OHSUGL, Norio SAKURAGAWA (National \\ Institute of Neuroscience, NCNP., Tokyo)
}

K562 is a cell line with two acrocentric marker chromosomes each with abnomally banded regions ( $A B R s$ ), derived from Ph-positive CML. Using reverse and forward chromosome painting FISH analysis, we found that $9 q 34,13 q 31$, and $22 q 11$ regions co-amplified in the ABRs. Utilizing the ABRs as target DNA of CDNA selection, we established a simple procedure for the isolation of chromosomal region-specific CDNAs.

First strand CDNAs were synthesized from fetal brain mRNA with an oligo-(dT) 17 primer. With the 1 st strand cDNAs as templates, short-fragment cDNAs (sf-cDNAs) were synthesized using modified Degenerate Oligonucleotide Primed Shuttle Polymerase Chain Reaction (DOP-Shuttle-PCR) (Cytogenet Cell Genet 71:32-36, 1995). The sfCDNAs were hybridized onto RNase A-treated metaphases from K562, and their ABRs were microdissected and reamplified with DOP-Shuttle-PCR primer II. Ladder amplification products, ranging from 150 to $400 \mathrm{bp}$ were observed by gel electrophoresis. The reamplified sf-cDNAs were cloned into a pBluescript vector. Randomly chosen 20 clones were sequenced and classified into 8 groups. Three out of the 8 clones had been mapped at 22q11, whereas the other 5 were novel cDNAs. Quantitative Southern blot analysis indicated that 7 out the 8 clones (87.5\%) to be derived from the co-amplified regions. 
$\mathbf{A - 1 1}$

A NOVEL 4.7-kb TANDEM REPETITIVE SEQUENCE "RS447": HIGHLY POLYMORPHIC IN JAPANESE POPULATION. Yoichi GONDO $^{1,2}, \underline{\text { Takeya OKADA }}^{1}$, Shinji HADANO ${ }^{1,2}$ Jun GOTO $^{3}, \underline{\text { Ichiro }}^{3}$ KANAZAWA ${ }^{3}$ and Joh-E IKEDA ${ }^{1,2}$ (1 Inst. Med. Sci., Tokai Univ.; 2JST/Canada Int'l Res. Exchange Program "Neurogenes"; 3Univ. of Tokyo Sch. Med.)

While positional-cloning of the Huntington's disease (HD) gene at the Human $4 p$ region, a novel tandem repetitive sequence RS447, a unit size of which was 4746 bp was identified (Kogi et al., in preparation). Pulsedfield gel electrophoresis revealed that the copy number of the RS447 tandem repeats was highly polymorphic ranging between 12 and 90 in Japanese population. Each allele has been found to be transmitted to offspring based upon the Menderian's genetics. There was an open reading frame of $1629 \mathrm{bp}$ within which the consensus donor as well as acceptor exon-intron boundary sequences existed. RS447 was a novel sequence by database search but conserved in mammals. RS447, therefore, might be expressed with a biological function(s). We call the RS447 tandem repetitive sequence "megasatellite".

A-12

STRUCTURAL ORGANIZATION AND CANDIDATE GENE ANALYSIS OF X ARRESTIN. Hitoshi SAKUMA, Toshihiro YAJIMA, (Dept. of Ophth., Juntendo Univ., Tokyo) Tomomi HIGASHIDE, (Dept. of Ophth., Kanazawa Univ., Kanazawa) Akira MURAKAMI, (Dept. of Ophth., Nat. Defense Medical College, Tokorozawa) Margaret McLAREN and George INANA (Bascom Palmer Eye Institute, Univ. of Miami School of Medicine, Florida, U.S.A.)

$\mathrm{X}$ - arrestin is a newly isolated human retinal arrestin mapping to $\mathrm{X}$ chromosome. $\mathrm{X}$ - arrestin is enriched in retina and its sequence is homologous to Arrestin $(\mathrm{S}-\mathrm{Ag})$ and $\beta$-arrestin. The role of $\mathrm{S}-\mathrm{Ag}$ is thought to quench the activated phototransduction cascade by binding to phosphorylated rhodopsin. Recently, 1 - bp deletion of the arrestin gene was found in some patients with Oguchi disease. Otherwise, our immunohistochemical study by using anti-peptide antibody to human $\mathrm{X}$ - arrestin showed that $\mathrm{X}$ - arrestin is expressed intensely in cone photoreceptors in human retina. Although the precise function of $\mathrm{X}$-arrestin is unknown, these results suggest that $\mathrm{X}$-arrestin might be a cause of retinal dysfunction and it may be useful as a candidate gene for $X$ - linked retinal diseases. To obtain information of gene structure, $\mathrm{X}$ - arrestin genes were isolated by screening human genome libraries using cDNA as a probe and analyzed by sequencing. The $\mathrm{X}$ - arrestin gene has 17 exons and is approx. $20 \mathrm{kbp}$ long. Its structure has similarity to $\mathrm{S}-\mathrm{Ag}$ already reported. $96 \mathrm{X}$ - linked retinal disease patients were screened for mutation by PCR - DGGE analysis. Some types of mobility shift were observed, but no exon mutation was found except silent mutation at exon 3 and polymorphism at exon 12. Further analysis of $\mathrm{X}$-arrestin gene will contribute for better understanding of cone photoreceptor visual transduction system. 


\begin{abstract}
A-13
A MUTATION OF CHM GENE IN A JAPANESE CHOROIDEREMIA PATIENT AND HIS MOTHER. Takuro FUJIMAKI, Yoshihiro HOTTA, Keiko FUJIKI, Mutsuko HAYAKAWA, Rie DOI, Nao KOHNO, Misako TAKEDA, Atsushi KANAI (Dept. Ophthalmol., Juntendo Univ., School of Med., Tokyo)
\end{abstract}

Choroideremia is a $\mathrm{X}$ - linked chorioretinal dystrophy in which clinical feature is similar to typical retinitis pigmentosa. Choroideremia (CHM) gene was recently isolated and characterized. Although CHM gene defects were reported in patients with choroideremia in Europe, no report was recognized in the other countries. We analyzed the CHM gene in Japanese patients with choroideremia and found a family with a mutation in CHM gene. DNAs were isolated from peripheral blood in 4 patients from 4 Japanese families with choroideremia. Exons 11,12,13 and 14 were amplified by PCR using primers (van den Hurk et al, Am J Hum Genet,1992) encompassing these exons. The PCR products were screened by SSCP (single strand conformation polymorphism) and directly sequenced. Mutation from $\mathrm{A}$ to $\mathrm{CC}$ in the nucleotide position 1608 of CHM gene was detected in a patient. His mother was heterozygote of wild and mutant type of CHM gene. Other 3 patients from 3 Japanese families have no mutation in exons $11,12,13$ and 14 .

\title{
A-14
}

ANALYSES OF PERIPHERIN/RDS GENE IN SEVERAL RETINAL DEGENERATIONS. Keiko FUJIKI, Yoshihiro HOTTA, Mutsuko HAYAKAWA, Rie DOI, Nao KOHNO, Misako TAKEDA, Atsushi KANAI (Dept. Ophthalmol., Juntendo Univ., School of Med., Tokyo) Yasushi ISASHIKI', Norio OHBA ('Center for Chronic Viral Diseases and Dept. Ophthalmol., Fac. of Med., Kagoshima Univ., Kagoshima)

To detect a peripherin/RDS gene defect in patients with several retinal degenerations, genomic DNAs were extracted from peripheral blood of 77 patients with autosomal dominant retinitis pigmentosa (40), cone rod dystrophy (11), vitelliform macular degeneration (4), macular degeneration (3), rod cone dystrophy (2), cone dystrophy (2), fundus albipunctatus (2), fundus flavimaculatus (2) and retinitis pigmentosa with macular degeneration (11). Three exons of the peripherin $\angle R D S$ gene were amplified to DNA fragments of approximately 200 base pairs by polymerase chain reaction (PCR) method and analyzed by single strand conformation polymorphism (SSCP). The DNA fragments suspected of any variation were directly sequenced.

Seven point mutations were detected. Among them Glu304Gln and Gly338Asp mutations have substituted amino acid. Nevertheless nobody was co-segregated with the disease, and also these mutations were found in normal controls with high frequencies in which the rate of the variation was $0.195 \pm 0.028$ in codon 304 and $0.194 \pm 0.038$ in codon 338. Further studies for another candidate genes are required. 
A-15

MISSENSE MUTATION IN THE C-TERMINAL PART OF THE PAX6 PAIRED DOMAIN IN A FAMILY WITH ISOLATED FOVEAL HYPOPLASIA. Noriyuki AZUMA', Sachiko NISHINA', Hiroko YANAGISAWA ${ }^{2}$, Torayuki OKUYAMA ${ }^{2}$ \& Masao YAMADA ${ }^{2}$. ( ${ }^{1}$ Dept. of Ophthalmology, National Children's Hospital, ${ }^{2}$ National Children's Med. Res. Ctr., 3-35-31, Taishido, Setagaya, Tokyo 154).

The fovea is an excavated area of the retina at the posterior end of the visual axis that facilitates visual acuity. Whereas foveal hypoplasia with decreased visual acuity and congenital nystagmus is a common feature of recognized ocular disorders such as albinism and aniridia, isolated foveal hypoplasia which is not associated with other known ocular abnormalities is rare and sporadic. Although a single family with autosomal dominant isolated foveal hypoplasia has been previously reported (MIM 136520), the molecular defect segregating in this kindred has not been identified. We have now ascertained a second family with isolated foveal hypoplasia and detected a missense mutation in the PAX6 gene. The mutation occurred in the C-terminal part of the paired domain, which is the first mutation identified in this region in any member of the PAX gene family (Azuma et al. Nature Genet., 13, 13,141-142, 1996). Although PAX6 is well known to be involved in eye morphogenesis as demonstrated in aniridia and Peter's anomaly, the phenotype-genotype correlation in this family raises an interesting hypothesis regarding the function of Pax proteins.

\section{A-16}

MULTIPLE ALLELES RESPONSIBLE FOR A2 AND A2B PHENOTYPES Kenichi OGASAWARA ${ }^{1}$, Rvuichi YABE ${ }^{1}$, Kenichi NAKATA ${ }^{1}$, Michiko TAKENAKA ${ }^{1}$, Yuii TAKAHASHI', Makoto UCHIKAWA ${ }^{2}$ and Katsushi TOKUNAGA ${ }^{23}$ (1. Japanese Red Cross Tokyo Metropolitan Blood Center, 2. Japanese Red Cross Central Blood Center, 3. Department of Human Genetics, Graduate School of International Health, University of Tokyo).

In some populations, including Japanese, the frequency of $\mathrm{A}_{2} \mathrm{~B}$ phenotype is significantly higher than that expected based on the $A_{2}$ phenotype frequency. To explain the high $A_{2} B$ phenotype frequency, we have examined relative frequencies of the presence of $A B O$ alleles in selected individuals with $A_{1}$, $\mathrm{A}_{1} \mathrm{~B}, \mathrm{~A}_{2}$ and $\mathrm{A}_{2} \mathrm{~B}$ phenotypes. Using PCR-SSCP and nucleotide sequence analyses, we identified five different alleles, ${ }^{*} A 105,{ }^{*} A 106, *^{*} A 107,{ }^{*} A 111$ and ${ }^{*} R 101$, in $\mathrm{A}_{2}-$ and $\mathrm{A}$ BB-positive samples. In $\mathrm{Az}_{2}$ positive samples, ${ }^{*} A 106$ and ${ }^{*} A 107$ were common with frequencies of $48 \%$ and $41 \%$, respectively. In $\mathrm{A}_{2} \mathrm{~B}$-positive samples, both alleles were uncommon and ${ }^{*} R 101$ was predominant (41\%). When $401 \mathrm{~A}_{\mathrm{l}}$ samples were examined, $1 \%$ of them were found to possess ${ }^{*} R 101$, but neither ${ }^{*} A 106$ nor ${ }^{*} A 107$ was detected. These results indicate that $\star^{*} A 106$ and $\star_{A 107}$ encode a catalytically weak transferase. ${ }^{\star} R 101$ is presumably expressed as $A_{1}$ in ${ }^{\star} R 101^{*} O$ individuals, but as $A_{2}$ in ${ }^{*} R 101^{*} B$ individuals, thus giving rise to high $\mathrm{A}_{2} \mathrm{~B}$ phenotype frequency. 
A-17

DE NOVO RECOMBINATION CASE AT THE ABO IOCUS AND OCCURRENCE OF RECOMBINANTS IN A RANDOM POPULATION. HirokO TSUJI, Misa IWATA, Kiyoshi MATSUI, Akiyoshi TAMURA, Tokiko MIYAZAKI, Koichi SUzUKI, (Dept. Legal Medicine, Osaka Medical College, Takatsuki)

In a paternity case where parentage between the father and child was excluded only at the ABO locus (mother: B, child: A, father: O), a hybrid allele was found to involved in the discrepancy. Sequencing of PCR products spanning exon 6 to 7 of the ABO gene for the three showed that one allele of the child had a hybrid nature, consisting of the $B$ and 01 sequences in exon 6 and 7 , respectively (abbreviated as b-ol). Survey of a Japanese random population for such hybrid alleles by using SSCP analysis demonstrated relatively frequent occurrence of them in a Japanese population. Sequencing showed that these were b-b/olv, ol-olv, olv-al (or -ol) with their sequences changing within exon 7 , intron $V I$, and intron VI-exon 7 boundary, respectively. This result suggested that there are recombination hotspots in the gene region.

\section{A-18}

THE GENE ANALYSIS OF A JAPANESE PROPOSITUS WITH D-PHENOTYPE. Hiroshi OKUDA, Masaki KAWANO, Eiji KAJII (Dept. Legal medicine and Human genetics., Jichi Medical School, Tochigi) and Tomoko ISHIDA, Shosaku NOMURA, Shiro FUKUHARA(Dept.Transfusion Service.,Kansai Medical College,Osaka)

Recent study on $\mathrm{Rh}$ blood group system is extremely progressed. The two genes theory ( $R H C E$ gene, $R H D$ gene), which was previously suggested, is acceptable by recent molecular studies. We analysed a Japanese D-- propositus and parents with molecular genetics methods based on new knowledges. The gene analyses of D-- propositus showed a gross deletion of RHCE gene and a new rearrangement of $R H C E ; C E-D-C E$ hybrid gene. It was demonstrated that the hybrid gene was composed of exon 1 from the $R H C E$ gene, followed by exons 3 to 7 from the $R H D$ gene and exons 8 to 10 from the $R H C E$ gene. It was undetectable which exon 2 of the RHD or RHCE gene is contained in the CE-D$C E$ gene. The $\mathrm{D}$ - gene complex from paternal side comprised the $R H D$ and $C E-D-C E$ gene. On the other hand, that complex from the maternal side seemed to be only the RHD gene. The Rh phenotype of mother was CcDEe. There are two hypotheses for explaining this discrepant event in mother. The other gene complex may be composed of two or three genes; two RHCE and/or one RHD genes. Otherwise, the $D$-- gene complex might be produced at the stage of gametogenesis. The futher study - the analysis of intron which is the hybrid site - shall be carried out. 


\begin{abstract}
A-19
ANALYSIS OF RH RELATED cDNAS IN A PROPOSITUS OF REGULATOR TYPE RHnull SYNDROME. Sadahiko IWAMOTO, Masaki KAWANO, Hiroshi OKUDA, Eiji KAJII (Dept. Legal Med. and Human Genet., Jichi Medical School, Tochigi)

The erythrocytes of Rhnull phenotype lack all Rh blood group antigens. Rhnull may anse from two genetic backgrounds; Rhnull regulator type, occurs by an autosomal suppressor gene that unlink to RH gene, Rhnull amorph type, occurs by homozygosity of a silent allele of RH locuses. Rhnull cells lack not only Rh antigens, but $L W$ antigen and Rh50 glycoprotein. Severe reduction of CD47 glycoprotein and glycophorin B have also been reported. Among them, the Rh50 glycoprotein was proposed as a most plausible candidate for a suppressor gene of regulator type Rhnull. We analyzed the Rh50 cDNA of a propositus with Rhnull phenotype. RT-PCR analysis from reticulocytes RNA revealed that the Rh50 cDNA deleted $122 \mathrm{bp}$ fragment from nt. 902 to 1052 , despite any mutations were not observed in RhD and CE cDNAs. The 122bp deletion also gave rise to frame-shift and resulted in short and abnormal $\mathrm{Rh} 50$ glycoprotein. Then, the $\mathrm{Rh} 50$ glycoprotein was regarded as a most essential factor for the expression of Rh antigen complexes.
\end{abstract}

A-20

A NEW DETECTION METHOD OF POINT MUTATION BASED ON PCR-PRIMER INTRODUCED RESTRICTION ANALYSIS(PCR-PIRA)

Kazuo HIDAKA ${ }^{1}$, Toshiko YAMASAKI ${ }^{1}$, Masafumi TOMITA ${ }^{2}$, Iwao IUCH| ${ }^{1}$ (Dept. Biochem. ${ }^{1}$, Legal Med. ${ }^{2}$, Kawasaki Med. School)

A new detection method of PCR-PIRA using a specific mismatched primer was introduced to detect carriers in family members of the patient with silent type BChE variant simply and rapidly. The specimens from two families with different BChE variant was used. At the first case(BChEY128C), a new Tsp45 I restriction enzym site was introdued into the PCR product from the aberrant allele and at the second case (BChEA199), a new Pst I site was created into the PCR product from the normal allele. The digest obtained from the family members by treatment of two enzymes,Tsp45 I and Pst I, were separated by capillary gel electrophoresis(CGE). In a total of 14 members containing the propositus in two families, four members were homozygote and seven were heterozygote. These results demonsirate that the PCR-PIRA method is a recommendable procedure to family analysis. 
$\mathbf{A - 2 1}$

MOLECULAR ANALYSIS OF FAMILIAL HYPOTRANSFERRINEMIA

Midori Asada SENJU, Toyoki MAEDA, Yoshinao WADA*, Akira HAYASHI* and

Tomokazu SUZUKI (Dept. Clin. Genet., Med. Inst, of Bioregulation, Kyushu

Univ., Beppuand *Osaka Medical Center and Research Institute for Maternal

and Child Health)

We previously reported a clinical course of a patient with familial hypotransferrinemia for 20 years from seven years of age, who was suffered from severe anemia and growth retardation deduced from the trace level of serum TF (transferrin). The isoelectric focusing study revealed that his father's serum TF had an abnormal isoclectric point. Nucleotide sequence analysis of the TF gene revealed that the propositas was a compound heterozygote of a maternal null allele concomitant with a synonymous mutation, a $\mathrm{C}$ to $\mathrm{T}$ transition at the position 760 , and a paternal mutant allele with a $\mathrm{G}$ to $\mathrm{A}$ transition at the position 1210 changing glutamic acid to lysine at the amino acid residue 404. The paternal mutation was not thought to be a polymorphism, because this mutation was not found among 100 people analyzed with PCR-RFLP. Further study is necessary to delineate the maternal unknown null mutation.

MOLECULAR ANALYSIS OF HEREDITARY METHEMOGLOBINEMIA. Jun-ichi MANABE ${ }^{1,2}$ Roopen ARYA $^{3}$, Hideki SUMMMOTO ${ }^{4}$, Masataka MIYAZAKI ${ }^{5}$, Toshitsugu YUBISUI ${ }^{6}$, D. Mark LAYTON ${ }^{3}$, Yasuyuki FUKUMAKI ${ }^{1}$ ('Inst. Genet. Inf., Kyushu Univ., Fukuoka, ${ }^{2}$ Central Lab., CRC, Inc., Fukuoka, ${ }^{3}$ Dept. Haematol. Med., King's College School of Medicine and Dentistry, London, UK., ${ }^{4}$ Dept. Biochem, Kyushu Univ., Fukuoka, ${ }^{5}$ Gunma Children's Medical Center, Gunma, ${ }^{6}$ Dept. Biol., Kochi Univ., Kochi)

Hereditary methemoglobinemia is an autosomal recessive disorder characterized by $\mathrm{NADH}$-cytochrome $\mathrm{b} 5$ reductase ( $\mathrm{B} 5 \mathrm{R})$ deficiency. This disorder is classified into two types: an erythrocyte (type I) and a generalized (type In types. We analyzed the b5R genes of a patient with type II from a white U. K. family using PCR-related techniques, and found that the patient was a compound heterozygote for two novel mutations, a nonsense mutation at codon 42 (TAC-TAA) and a missense mutation at codon 95 (CCC: Pro-CAC; His). From the allele with the nonsense mutation, the product without the catalytic portion of the enzyme is generated. To characterize the effect of the missense mutation on the enzyme function. we compared GST-fused b5R with the GST-fused mutant enzyme expressed in Escherichia coli. The mutant enzyme exhibited less catalytic activity, less thermostability and more susceptibility to trypsin than did the normal counterpart. The absorption spectrum of the mutant enzyme in the visual region differed from that of the wild type. These results suggested that this amino acid substitution within the FAD-binding domain of the enzyme influences both a secondary structure and a catalytic activity of the enzyme. One Japanese case of type II was also investigated. A novel nonesense mutation (GAG;Glu-TAG;Stop) was detected in the codon 255 of one allele, however no mutation is observed in another allele. A Greek-Cyprus case with typeII, in which no obvious mutation is associated with the b5R gene, was presented. Possible molecular basis of such cases was discussed. 
A-23

MOLECULAR ANALYSIS OF $\beta$-THALASSEMIA IN MALDIVES AND JAPAN. Takahito INOUE'1, Naila FIRDOUS ${ }^{2}$, Hiroyasu FURUUMI' ${ }^{\prime}$, Rie SEMURA ${ }^{\prime}{ }^{3}$, Hideo OHTA' ${ }^{\prime}$, Suthat FUCHAROEN ${ }^{4}$, Yasuyuki FUKUMAKI' ('Ins.Gen.Info., Kyushu Univ., Fukuoka, ${ }^{2}$ Soc. Health.Edu., Republic of Maldives, ${ }^{3}$ C.R.C., Fukuoka, ${ }^{4}$ Mahidol Univ., Sch. Med., Thailand )

$\beta$-thalassemia is a group of disorders characterized by impaired expression of the $\beta$-globin gene. It has a worldwide distribution with particularly high frequencies in the Mediterranean, Indian and Southeast Asian. In malaria endemic regions, the malaria hypothesis is a plausible explanation for the high prevalence of this disorder. To compare the molecular basis of the $\beta$-thalassemia in between malaria endemic and non-endemic regions and to trace the origin and spread of mutations in Asian populations, we analyzed $\beta$-thalassemia mutations and determined the haplotypes and frameworks in 45 Japanese $\beta$-thalassemia patients and 50 Maldivian patients using PCR-related techniques. The following results were obtained. 1) In the Maldivian population, five different mutations were detected. These are IVS1\#5(G-C), Codon $30(\mathrm{G}-\mathrm{C})$, IVS1\#1(G-A), $\beta^{E}$ and Codon41/42(-4bp). In the Japanese population, 13 different mutations were detected. These are IVS2\#654(C-T), Codon90(G-T), IVS2\#1(G-A), -31ATA(A-G), Codon41 142(-4bp), Codon15(-T), Codon54(+G), Codon110(T-C), Codon123(-A), Codon127/128(-AGG), Codon 121(G-T), IVS2\#848(C-G) and Initiation codon(A-G). 2) Analysis of $\beta$-globin gene haplotypes and frameworks suggested that most common mutation, IVS1\#5(G-C) in Maldivian $\beta$-thalassemia genes was derived from the Indian population, and Codon41/42(-4bp) mutation shown by both populations has different origin. 3) In the Japanese population, four dominant mutations were detected. The presence of such mutations in the Japanese population may be explained by a fact that Japan is not malaria endemic and there is a loss of heterozygous advantages against malaria infection in such mutations.

\section{A-24}

HEMIZY GOUS HAPTOGLOBIN GENE DELETION IS A CAUSE OF FAMILIAL ANHAPTOGLOBINEMIA. Yoshiro KODA, Mikike SOEJIMA, Hiroshi KIMURA (Dept. Legal Med., Kurume Univ. School of Med., Fukuoka)

We have found haptoglobin ( $\mathrm{Hp}$ ) gene deletion ( $\mathrm{H} \mathrm{p}^{\mathrm{del}}$ ) during the study of two families of anhaptoglobinemia. Southern blot and DNA sequence analyses have indicated that the gene deletion have been included in the promoter region of the $\mathrm{Hp}$ gene, the $\alpha$ - and $\beta$-chain of Hp gene and the $\alpha$-chain of haptoglobin-related (Hpr) gene but not the $\beta$-chain of $\mathrm{Hpr}$ gene. All 6 individuals tested for $H p^{2} / H p^{d e l}$ genotype showed extremely low serum level of $\mathrm{Hp}(0.006-0.12 \mathrm{mg} / \mathrm{ml})$ as compared with the average value $(1.69 \mathrm{mg} / \mathrm{ml})$ obtained from 95 healthy individuals. While we have found only one hemizygous individuals for $\mathrm{Hp}^{l} / \mathrm{Hp} \mathrm{p}^{\mathrm{del}}$ genotype, the plasma $\mathrm{Hp}$ in this individual is about half level of that in healthy individuals $(0.5 \mathrm{mg} / \mathrm{ml})$. The results suggested that the $H p^{2}$ but not the $H p^{1}$ appeared to be gene dosage-sensitive when the $H p^{2}$ was associated with the $H p^{d e l}$, and that the hemizygote for $H p^{2} / H p^{d e l}$ was the probable cause for the anhaptoglobinemia. 


\begin{abstract}
A-25
GENETIC POLYMORPHISMS OF CYP2C19 AND CYP2C9 GENES IN JAPANESE AND CAUCASIAN POPULATIONS. Kiyoshi INOUE1, Hiroshi YAMAZAKI $^{1}$, Johji INAZAWA ${ }^{2}$, Tatsuo ABE ${ }^{2}$ and Tsutomu SHIMADA $^{1}$ (1Osaka Pref. Inst. Public Health, Osaka, 2Dept. Hygiene, Kyoto Pref. Univ. Med., Kyoto)
\end{abstract}

We investigated genetic polymorphisms in the CYP2C19 and 2C9 genes in Japanese and Caucasian populations. Two defects in the CYP2C19 gene, a single-base pair mutation in exon $5\left(\mathrm{CYP} 2 \mathrm{C} 19_{\mathrm{m} 1}\right)$ and in exon $4\left(\mathrm{CYP} 2 \mathrm{C} 19_{\mathrm{m} 2}\right)$, have been reported in poor metabolizer phenotypes. Of 39 Japanese subjects tested, four were homozygous for the CYP2C19 ${ }_{\mathrm{m} 1}$ mutation, one homozygous for the CYP2C19 ${ }_{\mathrm{m} 2}$ mutation, and two heterozygous for $\mathrm{CYP} 2 \mathrm{C} 19_{\mathrm{m} 1} / \mathrm{CYP} 2 \mathrm{C} 19_{\mathrm{m} 2}$ mutation. In contrast, only one subject was found to be homozygous for the CYP2C19 $9_{\mathrm{m} 1}$ mutation in 45 Caucasian tested. Four variants in the CYP2C9 gene have been represented at $\mathrm{Arg}_{144} / \mathrm{Cys}, \mathrm{Tyr}_{358} / \mathrm{Cys}$, $\mathrm{Ile}_{35} / \mathrm{Leu}$, and $\mathrm{Gly}_{417} / \mathrm{Asp}$. Allele frequencies for Japanese subjects were determined to be 0.04 for Leu $_{359}$. Caucasian subjects showed frequencies for the Cys ${ }_{144}$ and the $L^{2} u_{359}$ alleles of 0.11 and 0.03 , respectively. Our results indicate that the principle CYP2C9 allele is $\mathrm{Arg}_{144} \mathrm{Tyr}_{358} \mathrm{Ile}_{359} \mathrm{Gly}_{417}$ (frequencies of 0.96 and 0.86 in Japanese and Caucasian, respectively). We also found that there are marked interracial differences in the frequencies of polymorphisms in the CYP2C19 and $2 \mathrm{C} 9$.

\begin{abstract}
A-26
ANALYSIS OF HIGHLY HOMOLOGOUS GENOMIC CLONES TO NITRIC OXIDE SYNTHASE II. Akira HATA ${ }^{1}$, Akira KUWANO ${ }^{2}$, Ituro INOUE ${ }^{3}$, Kiyotaro KONDO ${ }^{1}$, and Jean-Marc LALOUEL ${ }^{3}$ ('Dept. of Public Health, Hokkaido University School of Medicine, Sapporo, ${ }^{2}$ Dept. of Hygiene, Ehime University School of Medicine, Ehime, ${ }^{3}$ Howard Hughes Medical Institute, University of Utah, Salt Lake City, USA)

Nitric Oxide synthase (NOS) are a family of enzymes responsible for the synthesis of nitric oxide from $\mathrm{L}$-arginine and molecular oxygen. So far, three NOS enzymes (I, II, III) and their genes have been identified and cloned. Expression of NOS II, unlike I and III, is induced by signals such as cytokines, and is independent of elevated $\mathrm{Ca}^{2+}$. For the purpose of isolating and characterizing genetic markers of human NOS II, we screened P1 library using PCR product from exon 25 to 26. Eleven clones were isolated, of these, two were NOS II, remaining four and five clones were revealed NOS2B and NOS2C reported by Bloch et al. (1995). In this study, we localized the loci of NOS2B and NOS2C to $17 \mathrm{p} 11.2$ and $17 \mathrm{q} 11.2$ by FISH method. Sequencing analysis of NOS2B (exon 21- 25) and NOS2C (exon 23-25) revealed that both genes were about $91 \%$ homologous to NOS II cDNA. If these genes are expressed, they must have important roles.
\end{abstract}




\begin{abstract}
A-27
GENETIC SCREENING OF HYPERLIPIDEMIA TYPE IIa: IDENTIFICATION OF GENETIC MUTATIONS OF THE LDL RECEPTOR GENE IN 14 CASES. Tsunenori HIRAYAMA, Mitsuru EMI Emi YAMAKI (Dept. Molecular Biology, Institute of Gerontology, Nippon Medical School, Kawasaki), Masahiro TSUII (Internal Medicine, Hokkaido Social Security Central Hospital, Sapporo), and Akira HATA (Dept. Public Health, Hokkaido Univ., Sapporo)

Mutation of the low density lipoprotein (LDL) receptor gene cause familial hypercholesterolemia (FH), a genetic entity that manifests type Ia hyperlipidemia. We examined 55 cases of type IIa hyperlipidemia patients for mutation of the LDL receptor gene by PCR-SSCP and direct sequencing analysis. We identified 9 genetic mutations in 14 cases.: the $-84 \mathrm{G} \rightarrow \mathrm{A}$ mutation in exon 1 , a nonsense mutation in exon 3 (the $\mathrm{C} 74 \mathrm{X}$ mutation), a missense mutation in exon 8 (the C337Y mutation), a splice site mutation in intron 11 (the $1705+1 \mathrm{G} \rightarrow \mathrm{T}$ mutation), a missense mutation in exon 12 (the W556C mutation), a 1-bp deletion of nucleotide position 1963 in exon 13, a nonsense mutation in exon 17 (the $\mathrm{K} 790 \mathrm{X}$ mutation), and a missense mutation in exon 18 (the $\mathrm{A} 829 \mathrm{~V}$ mutation). The 3 cases with the C74X mutation were sisters, and the 2 cases with the W556C mutation were mother and son. Other mutations were found in unrelated individuals. Though one of the 9 mutations (K790X) was described previously, other 8 belong to new kind of mutations of the LDL receptor gene.
\end{abstract}

\title{
A-28 \\ MUTATIONS OF THE LDL RECEPTOR GENE IN THREE FAMILIAL HYPERCHOLESTEROLEMIA FAMILIES AND FOUR POLYMORPHISMS. Emi YAMAKI, Mitsuru EMI, Tsunenori HIRAYAMA (Inst. Gerontol., Nippon Med. Sch., Kawasaki), Yachio OHTA (Tenshi Hosp), Masahiro TSUII (Int. Med., Hokkaido Social Security Cent. Hosp., Sapporo) and Akira HATA ( Hokkaido Univ. Sch. Med., Sapporo)
}

Familial hypercholesterolemia $(\mathrm{FH})$ is a common autosomal dominant disorder that is caused by a mutation in the gene for the low density lipoprotein (LDL) receptor. We have identified mutations of the LDL receptor gene in three FH families by PCR-SSCP analysis, direct DNA sequencing, and Southern hybridization of all 18 exons. In the first heterozygous $\mathrm{FH}$ family, three sisters had a nonsense mutation at codon 95 in exon 3 . In the second heterozygous FH family, mother and son had a missense mutation (pro-ser, C-to-T transition) at codon 608 in exon 12. The founder of the last family was a male at 22-year-old with the plasma cholesterol level of $684 \mathrm{mg} / \mathrm{dl}$ and the cutaneous xanthomas. One mutant allele having $2.5-\mathrm{kb}$ insertion around exon 11 was detected by Southern hybridization. Another allele is to be examined. We also report four polymorphisms in the exons of the LDL receptor gene ; (1) AGG-AGA at codon 471 , (2) GTC-GIT at codon 653, (3) CGG-CGA at 744, (4) G-A at +52 in 3'UTR region. 


\begin{abstract}
A-29
MUTATIONS AT 8993 OF MITOCHONDRIAL DNA IN LEIGH'S SYNDROME Michiko MAKINO. Ikuya NONAKA, Yu-ichi GOTO

( Dept.Ultrastructural Res., Natl.Inst.Neuroscience., NCNP, Tokyo )

We studied point mutations at 8993 of mitochondrial DNA in 60 Japanese patients with Leigh's syndrome. We detected the mutations in 8 of 60 patients in heteroplasmic fashion. Seven of them showed a $T>G$ mutation and one patient revealed a $T>C$ mutation at 8993. We examined all the muscle biopsies from 8 patients histologically, histochemically and biochemically. In one patient cytochrome c oxidase activity was decreased on both histochemistry and biochemistry. One patient had a combined biochemical defectwith complex I and cytochrome c oxidase (complex IV) deficiency. These results indicate that the 8993 mutations are relatively common in Leigh's syndrome and also that muscle histochemistry and mitochondrial enzyme activities revealed essentially normal.
\end{abstract}

$\mathbf{A}-\mathbf{3 0}$

MITOCHONDRIAL DNA VARIANTS OBSERVED IN SPORADIC ALZHEIMER DISEASE PATIENTS. Kyoko TATEISHI, Kouzin KAMINO, Aoi YOSHIIWA, Yumiko NISHIWAKI, Tetsuro MIKI, Toshio OGIHARA (Dept. Geriat. Med., Osaka Univ. Med. Sch., Osaka) and Hideki YAMAMOTO, Toshiko KOBAYASHI (Osaka Municipal Kohsaiin Hospital, Osaka)

To elucidate the relationship between mitochondrial variants and Alzheimer disease, patients with senile dementia of Alzheimer's type and non-demented controls in Japanese population were screened for the variants by PCR-RFLP. Among mitochondrial variants identified in Caucasian patients with Alzheimer and/or Parkinson disease described by Wallace and his colleages, ND24732 and ND25460 were found, while $12 S$ rRNA $956-965$ ins, $12 S$ rRNA ${ }^{721}$, 16S rRNA3196, ND1 3397 , tRNAGln4336 and ND5 variants were not. Novel variants were also identifed; $12 S$ rRNA ${ }^{856}$, $12 S$ rRNA1005 and ND25465. Although our results did not support the hypothesis that the variants of mitochondrial genes encoding NADH dehydrogenase and $t R N A G l n$ are related with Alzheimer disease, we proposed that novel mitochondrial variants of $12 S$ rRNA $^{856}$ and $12 S$ rRNA ${ }^{1005}$ are possible risk factors for SDAT. 
A-31

Tissue specificity in the processing of the mitochondrial polycistronic RNA at the tRNA ${ }^{\text {Leu(UUR) }}$ gene boundary. Yasutoshi. KOGA and Hirohisa KATO.

(Dept. Pediat. Kurume Univ. Fukuoka)

We described the novel unprocessed RNA species (RNA19), corresponding to the genes of $16 \mathrm{~S}$ rRNA + tRNA ${ }^{\text {Leu(UUR) }}+\mathrm{ND} 1$ genes. In this study, we have analyzed the steady state levels of unprocessed RNA intermediates at tRNA ${ }^{\text {Leu(UUR) }}$ gene boundary, to know the biological meanings of this novel mitochondrial transcripts. Total RNA was isolated, electrophoresed, transferred, and hybridized with 16R rRNA, or tRNA ${ }^{\text {Leu(UUR) }}$, or ND 1 probes. The RNA 19 is recognized in all human tissues including muscle, heart, brain, kidney, liver, spleen and uterus, ranging $3.5 \%, 11.6 \%, 13.6 \%, 8.4 \%, 4.2 \%, 1.7 \%$, and $6.5 \%$ of their total ND 1 signal, respectively. Using tRNA ${ }^{\text {Leu(UUR) }}$ as a probe, transcript corresponding to tRNA ${ }^{\text {Leu(UUR) }}+$ ND 1 is a dominant molecules in heart, muscle and liver, kidney, however, transcripts corresponding to $16 \mathrm{~S}$ rRNA + tRNA Leu(UUR) is dominant in cultured skin fibroblasts. Our date suggest that mitochondrial processing system at $t R N A^{\text {Leu(UUR) }}$ boundary may be influenced by tissue specific manner. Since their steady state levels varied, it may contribute the oxygen capacity of the tissues, which may play an important role of the mitochondrial respiratory capacity in the tissues.

\section{A-32}

Mitochondrial DNA polymorphism in East Asian populations with special reference to the peopling of Japan. Satoshi HORAI (National Institute of Genetics), Goonnapa FUCHAROEN (Khon Kaen Univ.), Shinji HARIHARA (Univ. of Tokyo), Kyung Sook PARK (Sung-Shin Women's Univ.), Keiichi OMOTO (International Center for Japanese Studies) and I-Hung PAN(National Taiwan Univ.)

Nucleotide sequences of the D-loop region of human mitochondrial DNA from five East Asian populations including mainland Japanese, Ainu, Ryukyuans, Koreans and Chinese were analyzed. Based on a comparison of 482 base pair sequences in 293 East Asians, 207 different sequence types were observed. Of these, 189 were unique to their respective populations, whereas 18 were shared between two or three populations. Among the shared types, eight were found in common between the mainland Japanese and Koreans, which is the largest number in the comparison. Phylogenetic analysis revealed that East Asian lineages were classified into at least 18 monophyletic clusters, though lineages from the five populations were completely intermingled in the phylogenetic tree. However, we assigned 14 out of the 18 clusters for their specificity based on the population from which the maximum number of individuals in each cluster was derived. Of note is the finding that $50 \%$ of the mainland Japanese had continental specificity in which Chinese or Koreans were dominant, while less than $20 \%$ of either Ryukyuans or Ainu possessed continental specificity. Phylogenetic analysis of the entire human population revealed the closest genetic affinity between the mainland Japanese and Koreans. Thus, the results of this study are compatible with the hybridization model on the origin of modern Japanese. It is suggested that about $65 \%$ of the gene pool in mainland Japanese was derived from the continental gene flow after the Yayoi Age. 
A-33

THE APPLICATION OF GENETIC BACKGROUND ANALYSIS USING MITOCHONDRIAL DNA AND SKEWED PREVALENCE OF COMMON MUTATIONS IN MPS VIA Zenichiro KATO, Seiji FUKUDA, Shunji TOMATSU, AtsushiYAMAGISHI, Naoto YAMADA, Kazuko SUKEGAWA, Tadao ORII, Naomi KONDO. (Department of Pediatrics, Gifu University School of Medicine, Gifu)

We analysed the genetic background of MPS IV A using mtDNA lineages in association with common mutations of the disease-causing gene. We compared the nucleotide sequence of the major non-coding region of patients' mtDNA with reported lineages. Colombian and Mexican patients lineages fall into distinct clusters observed in native-Americans with some variation. Caucasian (British, Irish and Australian) and Japanese patients had similar lineages to the reported lineages in the respective populations. We have identified a novel common mutation, G301C, in 68 $\%$ of unrelated mutant alleles of Colombia, but not in the other populations. The haplotype analysis suggested the founder effects of the common mutation. The skewed prevalence of $\mathrm{G} 301 \mathrm{C}$ mutation can be explained as a founder effect during the Mongoloid migrations that contributed to the colonization of Colombia. The mtDNA lineage analysis can pave the way to obtain a quantitative information about genetic background of the patients. Moreover, it can be applied for the other many inherited diseases even if they don't have informative intragenic polymorphisms.

\section{A-34}

POLYMORPHISM OF THE A LDOSE REDUCTASE GENE IS ASSOCIA TED WITH ALDOSE REDUCTA SE PROTEN LEVELS A ND DLABETIC MICROANGIOPA THY Makiko OGATA ${ }^{\prime}$, Naoko IWASAKI', Masao KANAMORI', Sachiyo KARIBE!', Yoshiatsu TAKAHSASHI $^{1}$, Hisako OHGAWARA ${ }^{3}$, Yasue OMORI ${ }^{1}$ Diabetes Center ${ }^{1}$ and Medical Research Institute ${ }^{3}$,Tokyo Women's Medical College, Department of Hygiene, Toho University $^{2}$

Glycation thought to affect the development of diabetic complications such as retinopathy, nephropathy and neuropathy. Here we have measured erythrocyte aldose reductase (AR) protein levels and genotyped AR gene in 140 NIDDM patients, without overt renal dysfunction or the history of AR inhibitors. Erythrocyte AR protein levels were measured by two-site ELISA using recombinant human AR. The microsatellite polymorphism in the 5'-flanking region of the AR gene has been typed using PCR. Average protein levels of AR in NIDDM group was $9.7 \pm 3.2$ (mean $\pm \mathrm{SD}$ ) $\mathrm{ng} / \mathrm{mgHb}$, which is nearly equal to the reported data for the normal controls. Tandem C-A repeats of the AR gene were highly polymorphilic, 9 alleles were observed in NIDDM group and 10 alleles in 74 normal control subjects. Patients who have allele 5 and 10 , the latter one is not observed in Chinese population showed higher AR levels than others, respectively. The frequency of preproliferative or proliferative retinopathy (PDR) was 4.85 folds higher in patients whose AR levels were over $12.0 \mathrm{ng} / \mathrm{mgHb}$ compared to those whose levels were lower than $7.4 \mathrm{ng} / \mathrm{mgHb}$, significantly. The size of allele 5 is 136 base pairs which was correspond to the size previously reported to associate with retinopathy in Chinese. We have observed that the number of patients with allele 10 were frequent among the group who have PDR. Nephropathy was also frequent among the patients who have allele 10. These results show that the AR protein levels are regulated by genetic factors and associate to retinopathy and nephropathy in NIDDM. 
$\mathbf{A}-35$

GENETIC STUDY ON SUSCEPTIBILITY TO PARKINSON'S DISEASE. Yuji MORIMOTO, Ikuko KONDO, Fumie TAKAKUBO, Kazuhiro SHIGEMOTO(Dept. of Hygiene, Ehime Univ., Ehime), and Mitsutoshi YAMAMOTO(Dept. of Neurol. Kagawa Pref. Cen. Hosp., Kagawa)

Parkinson's disease is a multifactorial neurodegenerative disorder. A negative association between PD and cigarette smoking has been reported epidemiological studies of risk factors for PD. In addition, nicotine stimulates dopamine release. Cytochrome P450IAl plays an important role in the activation of mutagens such as benzo[a] pyrene and aromatic hydrocarbons found in cigarette smoke. DNA mutations in 3' flanking region(MspI polymorphism) and exon 7 of CYPIAl gene (genotypes of Ile and Val) are associated with inducible phenotype of CYPIAl enzyme. Then, We studied on the association between CYPIAl genotypes and susceptibility to PD. The frequency of MspI polymorphic allele, a variant of CYPIAl (m2), was significantly higher in patients with $\mathrm{PD}(0.444)$ than in controls(0.349). The risk of $P D$ in homozygotes for 2 was 2.34 fold greater than homozygotes for the wild type,m 1. The relative risk for PD in homozygotes for CYPIA1Val was 6.54-fold higher than in homozygotes for the wild type(CYPIA1Le) $(p<0.001)$. These results strongly suggest that the CYPIAl might be one of the susceptibility genes for PD.

A-36

NO ASSOCIATION BETWEEN A POLYMORPHISM OF THE ENDOTHELIAL CONSTITUTIVE NITRIC OXIDE SYNTHASE GENE AND ISCHEMIC STROKE IN A JAPANESE POPULATION. Yoshitsugu YAHASHI (Div. Genet., ICMR, Kobe Univ. Med., Hyogo), Kazuomi KARIO (Dept. Cardiol., Jichi Med. Sch., Tochigi), Masafumi MATSUO (Div. Genet., ICMR, Kobe Univ. Med., Hyogo)

Endothelial-derived nitric oxide (NO) formed by endothelial constitutive nitric oxide synthase (ecNOS) mediates vasodilation and antithrombotic action. A close association between a polymorphism of ecNOS gene (27-bp repeats in intron 4) and onset of coronary artery disease in Caucasian was reported and a close association between onset of angiopathy and this polymorphism was suggested. We analyzed this polymorphism in 127 ischemic stroke patients (18 atherothrombotic, 58 lacunar, 51 silent lacunar) and 91 healthy subjects. We identified 2 alleles (denoted as "allele a" for 4-repeats and "allele b" for 5-repeats), and grouped the subjects into 3 genotypes (a/a, b/a, b/b). There was no significant difference in the genotype distribution and allele frequencies between the stroke and control groups. There was also no significant difference in the genotype distribution and allele frequencies between the stroke types. From these findings, we could not find the evidence that this ecNOS gene polymorphism may be a genetic factor for the onset of cerebrovascular disease. 
A-37

THE POLYMORPHISM OF ARYLAMINE N-ACETYLTRANSFERASE AND $0^{\circ}$. METHYLGUANINE-DNA METHYLTRANSFERASE IN ALZHEIMER DISEASE

Masanobu OGAWA, Ryo INOUE, Masako ABE, Toshihiro YOSHIZAWA* and Tomokazu SUZUKI (Dept. Clin. Genet., Med. Inst. of Bioregulation, Kyushu Univ., Beppu and *Dept. Neurol., Univ. Tsukuba, Tsukuba)

$\mathrm{N}$-acetylation polymorphism is a representative of pharmacogenetic traits determined by polymorphic arylamine $\mathrm{N}$-acetyltransferase (NAT2) activity. $\mathrm{O}^{6}$-methylguanine-DNA methyltransferase (MGMT), which repairs the DNA damages caused by alkylating agents, has also polymorphism in the MGMT gene. There are still some genetic loci that need to be identified in Alzheimer disease (AD). We have investigated the possible association between the polymorphisms of the two xenobiotic enzymes and $A D$. Using the genomic DNA extracted from leukocytes in 81 patients with $A D$ and 645 normal subjects, the acetylator genotype was determined by a PCR-RFLP method and the polymorphism in the MGMT gene was detected by a PCR-SSCP method, as we descrived before. The distribution of presumed acetylator phenotype in patients with $A D$ was not significantly different from that in normal subjects. There was also no significant difference in the prevalence of mutated MGMT allele between $\mathrm{AD}$ patients and normal subjects. In conclusion, ncither polymorphism of NAT2 nor MGMT might be ecogenetically involved in AD.

\section{A-38}

A GENOME-WIDE SCREEN FOR NIDDM-SUSCEPTIBILITY GENES IN JAPANESE. Naoko IWASAKI, Makiko OGATA, Yumiko SAKISAKA, Yasue OMORI (Diabetes Center, Tokyo Womens Medical College) Hisako OHGAWARA (Medical Research Institute, Tokyo Womens Medical College) Nancy J. COX, Graeme I. BELL(Howard Hughes Medical Institute, The University of Chicago)

Genetic factors contribute to the development of NIDDM. We have begun a genome-wide screen to localize the genes that contribute to the development of this form of diabetes mellitus in Japanese. The study population consisted of 264 affected sib pairs (142 sibships with 2 affected, 22 with 3 affected, 6 with 4 affected and 2 with 5). A diagnosis of NIDDM was made using the criteria of WHO. The age at diagnosis was $44.3 \pm 11.7$ years, duration of diabetes was 13.5 \pm 9.2 years, BMI at the time of study was $23.2 \pm 3.3$, and current treatment of diabetes was $31 \%$ diet, $38 \%$ oral hypoglycemic agent, $31 \%$ insulin. Subjects have been genotyped with polymerase chain reaction based microsatellite markers. Evidence for linkage has been evaluated using two different two-point linkage statistics, a maximum likelihood of odds score (MLOD) computed using the estimated identical-by-descent (IBD) probabilities and a chisquare statistic comparing the observed and expected distribution of alleles identical-by-state (IBS). A multipoint analysis has been used to maximize the information from each chromosome and provide a bias for exclusion. Of 150 markers typed to date, markers D2S2366, D2S1391, D15S112, D21S1270, D21S1440, D21S266 and D22S420 showed nominal evidence for linkage $(\mathrm{P}<0.05)$. Suggestive and significant evidence for linkage require $\mathrm{P}<7 \times 10^{-4}$ and $\mathrm{P}<2 \times 10^{-5}$, respectively). Candidate genes have been tested have not shown any evidence for linkage. The genome-wide screen is continuing in order to localize all the NIDDM susceptibility loci segregating in this population. 


\begin{abstract}
A-39
An Association between the Angiotensin Converting Enzyme Gene Polymorphism and Parameters of Circulation System. Yingning ZHANG ${ }^{1}$. Zentaro YAMAGATA ${ }^{2}$, Sumio IIJMMA ${ }^{1}$, and Akio ASAKA ${ }^{1}$

('Dept. of Health Sciences, Yamanashi Medical University, and ${ }^{2}$ Health Care Center, Yamanshi University)

We studied an association between angiotensin converting enzyme (ACE) gene polymorphism and parameters of circulation system on 384 healthy unrelated Japanese aged from 21 to 89 years (mean=58.5 \pm 14.2 ). Insertion (I) and deletion (D) allele in ACE gene was determined by PCR method and parameters of circulation system such as total cholesterol, HDL-cholesterol, and blood pressure were determined in the group. The gene frequency was 0.624 for allele $\mathrm{I}$ and 0.376 for allele $\mathrm{D}$. This population was in Hardy-Weinberg equilibrium. Values of total cholesterol were $196.1 \mathrm{mg} / \mathrm{dl}, 194.9 \mathrm{mg} / \mathrm{dl}$, and $191.9 \mathrm{mg} / \mathrm{dl}$ in the subjects who have genotype II, ID, and DD, respectively. HDL-cholesterol was $52.7 \mathrm{mg} / \mathrm{dl}, 52.4 \mathrm{mg} / \mathrm{dl}$, and $54.2 \mathrm{mg} / \mathrm{dl}$ in genotype II, ID, and DD subjects, respectively. Furthermore, we demonstrated that subjects who carried allele I had more platelet numbers than allele $D$ gene. But this variety is not significant difference. Finally, our result showed that there was no association between ACE genotype and blood pressure.
\end{abstract}

\footnotetext{
A-40

POLYMORPHISM OF THE ANGIOTENSINOGEN AND ANGIOTENSIN II TYPE 1 RECEPTER GENES IN JAPANESE PATIENTS WITH PREGNANCY INDUCED HYPERTENSION. Naoki YAMADA, Satoshi SOHDA, Hiromi HAMADA. Takeshi KUBO (Dept.Obstet. Gynecol.,Inst.Clinical Med.,Univ.Tsukuba), Tadao ARINAMI, Trista Y OU, Kimiko KOBAYASHI. Hideo HAMAGUCHI (Dept.Med.Genet.Inst.Basic Med. Sci., Univ. Tsukuba)

The purpose of the present study was to assess the association of pregnancy induced hypertension (PIH) with the M235T polymorphism of the angiotensinogen gene(AGT),T174M polymorphism of the AGT, and A1166C polymorphism of the angiotensin II type 1 receoter gene $(A T 1)$. The subjects were $67 \mathrm{PIH}$ patients, 56 normotensive pregnant subjects, and 380 control subjects. No significant differences in the frequency of $\mathrm{C} 1166$ allele of the $A T 1$ gene $(0.04$ vs $0.04, \mathrm{p}=0.79)$ and $\mathrm{T} 235$ allele of the $A G T$ gene ( 0.77 vs $0.85, \mathrm{p}=0.11)$ were observed between PIH and pregnant controls. The M174 variant allele has significantly increased in the patients group compared with controls $(0.16$ vs $0.07, \mathrm{p}=0.006)$. The $\mathrm{M} 174$ variants also tended to increase in the patients compared with the nomotensive pregnant controls. This results suggest the contribution of the M174 variant of the angiotensinogen gene to the occurence of PIH.
} 
A-41

METHYLENETETRAHYDROFOLATE REDUCTASE POLYMORPHISM AND PREECLAMPSIA. Satoshi SOHDA, Hiromi HAMADA, Takeshi KUBO (Dept. Obstet. Gynecol., Univ. of Tsukuba, Ibaraki), Trista OU, Kimiko YAMAKAWAKOBAYASHI, Tadao ARINAMI, Hideo HAMAGUCHI (Dept. Med. Genet., Univ. of Tsukuba, Ibaraki)

A common missense mutation in the MTHFR gene, a C-to-T substitution at nucleotide 677 , is responsible for reduced MTHFR activities and associated with modestly increased plasma homocysteine concentrations. Since underlying matemal vascular disease increases the risk of preeclampsia, we had the working hypothesis that preeclampsia patients would have an increased $\mathrm{T} 677$ allele frequency compared with controls. The MTHFR genotypes were determined in 67 preeclampsia patients, 98 normal pregnant women and 260 healthy adults by the PCR/RFLP methods. The T677 allele and the genotype homozygous for the T677 allele were significantly increased in the preeclamptic group compared with the total controls ( $p<0.02$ and $p<0.004$, respectively, ).

The data indicate that the T677 variant of the MTHFR gene is one of the genetic risk factors for preeclampsia.

$\mathbf{A}-\mathbf{4 2}$

SYNERGISTIC EFFECTS OF METHYLENETETRAHYDROFOLATE REDUCTASE AND APOLIPOPROTEIN E GENE POLYMORPHISMS ON RISK OF CORONARY HEART DISEASE. Trista Y. OU, Naoki YAMADA,

Kimiko KOBAYASHI, Tadao ARINAMI, Hideo HAMAGUCHI (Dept. Med. Gent., Inst. Basic Med. Sci. Univ. Tsukuba, Tsukuba)

It has been reported that increased plasma homocysteine levels are associated with coronary heart disease(CHD). A missense polymorophism, C677T(Ala $\rightarrow$ Val), of the methylenetetrahydrofolate reductase(MTHFR) gene is responsible for thermolabile MTHFR variant which causes increased levels of plasma homocysteine. To examine whether the MTHFR polymorphism is associated with CHD in Japanese populations. We analyzed it in 187 CHD patients and 362 control subjects. Our data showed the TT genotype was significantly increased in the CHD patients compared with the control subjects (odds ratio=2.3 $p<0.001$ ). The allele frequency of apoE4 which is associated with increased levels of LDL cholesterol tended to increases in the CHD patients than in the controls (odds ratio $=1.5 \mathrm{p}=0.05$ ).

In addition, the effect of the MTHFR TT genotype on risk of CHD increased in subjects with the apoE4 allele compared with those without the allele. Thus, synergistic effects of the MTHFR TT genotype and apoE4 allele on risk of CHD was suggested (odds ratio $=6.2 \mathrm{p}=0.001$ ). 


\begin{abstract}
A-43
GENE POLYMORPHISMS OF RENIN ANGIOTENSIN SYSTEM IN HEMODLALYSIS PATIENTS WITH GLOMERULAR DISEASE. Makiko FUNAMIZU' ${ }^{1}$ Akira HATA", Takamichi NAKAMURA ${ }^{2}$, Munemasa TAJIRI ${ }^{3}$, Haruo YAMASHITA ${ }^{4}$, Kensuke TAKADA ${ }^{5}$, Yoshihei HIRASAWA ${ }^{6}$, Koichi SHIDO ${ }^{1}$, and Kiyotaro KONDO ${ }^{1}$ (DDept. Public Health, Hokkaido Univ. School of Med., Sapporo, ${ }^{2}$ Div. Blood Transfusion, Yamanashi Med. University, ${ }^{3}$ Kurokami Clinic, Kumamoto, ${ }^{4}$ Yamanashi Chuo Hosp., ${ }^{5}$ Fujiyoshida City Hosp., ${ }^{6}$ Shinrakuen Hosp., Niigata)

Renin angiotensin system (RAS) has been considered to play an important role in renal disease progression. To investigate the influence of the components of RAS in the progression, we genotyped polymorphisms of angiotensinogen (AGT: M235T), angiotensin converting enzyme (ACE: I/D), and type I angiotensin II receptor (AIIR: A1166C) genes in 212 hemodialysis patients (age $46.7 \pm 13.0$ ) and 189 sex-and age-matched healthy controls (age $47.8 \pm 12.5$ ). The native kidney disease that led to end stage renal failure was of glomerular origin, including 158 patients with chronic glomerulonephritic syundrome (CGNS) and 54 patients with diabetic nephropathy $(\mathrm{DN})$. The frequencies of $\mathrm{DD}$ genotype of $\mathrm{ACE}$ gene and TT genotype of AGT gene in CGNS, DN, and controls were $0.09,0.07,0.08$ and $0.63,0.58$, 0.66 , respectively. Those of $\mathrm{AC}+\mathrm{CC}$ genotypes of AIIR were $0.16,0.17$, and 0.13 . None of the differences was significant, which may indicate that these three components of RAS are not a major risk factor for renal disease pregression.
\end{abstract}

\title{
$\mathbf{A}-\mathbf{4 4}$
}

RELATION OF VITAMIN D AND VITAMIN D RECEPTOR GENE POLYMORPHISMS ON POSTMENOPAUSAL BONE LOSS. Makoto OWADA, Kumiko SUZUKI, Satoshi ONOGI, Hidekazu YAMADA, Susumu Tsukikawa, Kazuhiko HOSHI and Akira SATO (Dept. Obstet. Gynecol., Fukushima Medical College, Fukushima)

In order to assess the effect of vitamin D receptor(VDR) gene polymorphisms on vitamin D3 therapy for postmenopausal bone loss. 34 japanease postmenopausal women, administerd vitamin D3 (Alfarol $1.0 \mu \mathrm{g} /$ day) and $\mathrm{Ca}(2.0 \mathrm{~g} /$ day) for 18 months, were analyzed by RFLP method. Bone mineral density(BMD) at the lumber spine (L2-4) and Oscalcis were measured every 6 months by dual energy $X$-ray absorptiometry (DXA) and single energy $X$-ray absorptiometry (SXA). VDR-gene allelic polymorphisms were assessed by Bsm 1 endonuclease restriction after specific PCR amplification. Genotypic polymorphism was defined as $\mathrm{BB}, \mathrm{bb}$ and $\mathrm{Bb}$. The genotypes were $\mathrm{BB}$ in $1(3.1 \%), \mathrm{Bb}$ in $13(40.6 \%)$, and $\mathrm{bb}$ in $18(56.3 \%)$. The women with these two major VDR genotype groups ( $\mathrm{Bb}$ and $\mathrm{bb}$ ) were similar in their backgrounds (terms of age, menopausal age, body mass index, and BMD in premedication). However, VDR genotype was associated with the percent of change of BMD after treatment. In Group-Bb, the mean percent increase in L2-4 BMD were $3.2 \%$, $4.9 \%$ and $4.1 \%$ at each 6,12 and 18 months. In contrast, in Group-bb were $0.8 \%, 1.8 \%$ and $1.2 \%$ at the same points. Analysis of VDR alleles may prove useful in selection of vitamin $\mathrm{D}$ therapy for osteopenia before treatment. 


\begin{abstract}
$A-45$
VITAMIN-D-RECEPTOR-GENE POLYMORPHISMS ARE ASSOCIATED WITH OSTEOPOROSIS IN JAPANESE WOMEN . Hisako YANAGI ${ }^{2}$ Hitoshi AMAGAI $^{2}$, Shigeo TOMURA ${ }^{2}$, Kimika KAWANAMI ${ }^{1}$, MiWa HOSOKAWA ${ }^{2}$, Mari TANAKA ${ }^{1}$, Kei KOBAYASHI ${ }^{2}$ Koichiro HAYASHI ${ }^{2}$, Hideo HAMAGUCHI $^{3}$ and Shigeru TSUCHIYA ${ }^{2}$ ('Institute of Community Medicine, ${ }^{2}$ Institute of Clinical Medicine, ${ }^{3}$ Institute of Basic Medical Sciences, University of Tsukuba, Tsukuba)

Polymorphisms of the vitamin-D-receptor (VDR) gene have been shown to be associated with bone mineral density (BMD). We analyzed the VDR alleles in 68 Japanese female patients with osteoporosis and 66 age-matched volunteer women. VDRgene allelic polymorphisms were assessed by BSmI endonuclease restriction after specific PCR amplification. sixteen out of 68 patients had the BB (absence of restriction site on both alleles) genotype, while only two out of 66 controls had the BB genotype. The difference was significant $(p<0.001)$. Odds ratios for osteoporosis of $b b$, $\mathrm{Bb}$ and $\mathrm{BB}$ were $1.0,3.0$ and 12.0 , respectively. These data suggest that BB homozygosity of the VDR gene is a strong genetic risk factor for osteoporosis in Japanese women.
\end{abstract}

A-46

AN ASSOCIATION BETWEEN ESTROGEN RECEPTOR GENE POLYMORPHISMS AND BONE MINERAL DENSITY. Zentaro YAMAGATA (Health Care Center, Yamanashi University), Yingning ZHANG, Toshihiro MIYAMURA, Sumio IIJIMA, Akio ASAKA (Dept. of Health Sciences, Yamanashi Medical University)

To examine a possible influence of estrogen receptor (ESR) gene polymorphisms on bone mineral density (BMD) we analyzed two gene polymorphisms within ESR gene in 107 healthy Japanese women. Two polymorphisms were that of PVuII and XbaI restriction enzymes by PCR in intron 1. BMD were measured dual energy $X$-ray absorptiometry. They were 15.08 PP homozygotes, $52.3 \%$ Pp heterozygotes and 32.78 pp homozygotes for the pvuII polymorphism, and the frequency of genotype for $x b a$ polymorphism were 2.88 for $\mathrm{XX}, 39.38$ for $\mathrm{Xx}$ and $57.9 \%$ for $\mathrm{xx}$. BMD adjusted by age, menopause status, weight and VDR genotypes increased in the order $\mathrm{pp}, \mathrm{Pp}$ and $\mathrm{PP}(\mathrm{F}=3.59, \mathrm{p}=0.032)$, and increased in the order $\mathrm{xx}$, $\mathrm{XX}$ and $\mathrm{XX}(\mathrm{F}=13.12, \mathrm{p}=0.0001)$. BMD adjusted by age, menopause status, weight and VDR genotypes in haplotype XXPP was significantly higher than one in the other genotypes. This study indicated that ESR gene polymorphisms had an influence on BMD in Japanese women. 
A-47

AN ASSOCIATION STUDY ON ESTROGEN RECEPTOR GENE POLYMORPHISM WITH BREAST CANCER Masao KANAMORI*, Zentaro YAMAGATA**, Takashi FUKUTOMI ${ }^{* * *}$, Akio ASAKA****, Yingning ZHANG****, Minatu KOBAYASHI*, and Minoru SUGITA*, (*Dept. Environ. Health, Toho Univ. School of Med., Tokyo, **Health Care Center, Yamanashi University, Yamanashi, ***Dept. Surgery, National Cancer Center Hospital, Tokyo, ${ }^{* * * *}$ Dept. Health Sciencies, Yamanashi Medical University, Yamanashi)

The common hereditary forms of breast cancer(BC) have been largely attributed to the mutations in BRCA1 or BRCA2. We have studied on an influence of estrogen receptor(ESR) gene polymorphisms on breast cancer. 43 cases (who visited National Cancer Center Hospital on September, 1996, it is a spot value, no selection bias) and 173 healthy controls are surveyed. PvulI and Xbal restriction enzymes in intron 1 are examined by PCR. The results were as follows: 1) a significant association between Pvull and XbaI polymorphisms in healthy controls. 2) not significant differencies between frequencies of Pvull and XbaI genotypes in $\mathrm{BC}$ patients and in controls. 3) Assuming PvuII and XbaI polymorpisms as independent variables, the relative risk (odds ratio) of pair of homozygotes with haplotypes $\mathrm{p}$ and $\mathrm{x}$ to other pairs have been elevated.

\begin{abstract}
A-48
ASSOCIATION STUDY ON OSTEOPOROSIS WITH THE MICROSATELLITE MARKER POLYMORPHISMS FLANKING THE CANDIDATE GENES. Kazuhiro TSUKAMOTO, Ken HARUTA, Mitsuru EMI (Dept. Mol. Biol., Inst. Gerontol., Nippon Med. Sch., Kawasaki), Takayuki HOSOI (Dept. Geroat., Univ. Tokyo, Tokyo) and Hajime ORIMO (Minist. Finance, Tokyo Hosp., Tokyo)
\end{abstract}

The etiology of osteoporosis involves a complex interplay of exogenous and endogenous factors, including genetic factors. The identification of candidate genes has helped to refine the characterization of osteoporosis. We carried out an association study between bone mineral density (BMD) as well as biochemical parameters for bone metabolism and the microsatellite (CA repeat) marker polymorphisms which we newly isolated flanking candidate genes, calcitonin, parathyroid hormone (PTH), PTH receptor, interleukin 6 (IL6), IL6 receptor, interleukin 1 alpha, beta, and estrogen receptor (ER). We detected P1-derived artificial chromosome (PAC) clones including the sequence of the candidate gene by PCR-based 3D screening of human PAC DNA library. These PAC clones were subcloned into the plasmid vectors after endonuclease digestion and the DNA fragments including the CA repeat sequence were detected by $(\mathrm{GT})_{20}$ oligonucleotide hybridization. After sequencing, the primer pair flanking the CA repeat was newly designed for PCR. Correlation was sought between ER genotype $\mathrm{C}$ (the number of CA repeat was 16) and BMD as well as biochemical parameter. 
A-49

DETECTION OF $t(11 ; 14)(q 13 ; q 32.33)$ IN INTERPHASE NUCLEI OF MANTLE CELL LYMPHOMA BY IN SITU HYBRIDIZATION. Teruyuki TAKASHIMA', Yutaka UEDA1, Shigeo HORIIKE1, Kazuhiro NISHIDA1, Shinichi MISAWA1, Tatsuo ABE2 2 Masao SETO $^{3}$, and Masafumi TANIWAKI' (1Dept. Internal Medicine and 2Dept. Hygiene, Kyoto Prefectural University of Medicine, Kyoto, and 3Dept. Chemotherapy, Aichi Cancer Center Research Institute, Nagoya)

To assess the incidence and pathogenetic implication of $t(11 ; 14)(q 13 ; q 32.33)$ in mantle cell lymphoma (MCL), we performed fluorescence in situ hybridization (FISH) with PRAD1/CCND1 and IgH gene probes. Twenty-eight patients were studied; 6 with leukemic phase of MCL, 18 patients with chronic lymphocytic leukemia (CLL), 2 with CLL of mixed cell types (CLL/PL), 2 with prolymphocytic leukemia (PLL). Double-color FISH was performed with 2 cosmid clones, CPP4 and CPP29 containing PRAD1 gene, in combination with $\mathrm{Cr}$ or $\mathrm{V}_{\mathrm{H}}$ gene probes. Five patients with $\mathrm{MCL}, 1$ with CLL/PL, and 1 with PLL showed $t(11 ; 14)$. In a patient with PLL, the breakpoint was in $5^{\prime}$ flanking region of PRAD1 gene. Interphase FISH facilitates to correlate molecular characteristics of $\mathfrak{t}(11 ; 14)$ with clinical features of $B$-cell leukemia/lymphomas.

\footnotetext{
A-50

ANALYSIS OF CHROMOSOMAL ABERRATIONS IN THYROID TUMORS BY FISH. Takashi SHINOMIYA ${ }^{1,2}$, Satosi TAKAMI ${ }^{5}$, Toshiki MORI ${ }^{1}$, Kousei DATE $^{1}$, Kazuma KOIDE ${ }^{1}$, Shinsuke ISHINO ${ }^{1}$, Youhei HOSOKAWA ${ }^{4}$, Norio YASUDA $^{3}$, Yasushi MURAKAMI ${ }^{2}$, Johii INAZAWA', Tatsuo ABE' (Dept.Hygiene' and Otorhinolaryngol. ${ }^{2}$, Kyoto,Pref. Univ. of Med.,Dept.Otorhinolaryngol. ${ }^{3}$,and Pathol. ${ }^{4}$, Kyoto 1 st Red Cross Hosp., Ohtsuka Assay Inst. ${ }^{5}$.)

Fluorescence in situ hybridization(FISH)with probes specific for (peri)centromeric regions of chromosomes $1,2,7,8,10,11,17,18$ was performed to detect numerical chromosomal aberrations in 24 thyroid tumors and tumor-like lesions.In addition,double target FISH with probes specific for $1 \mathrm{p} 36$ and 1q12 was used for the detection of loss on 1p.The nuclear specimens were obtained by fine-needle aspiration of the fresh surgical tissue. Numerical aberrations were found in 3 of 14 papillary carcinomas (PC), 2 of 3 follicular carcinomas (FC), 3 of 4 benign follicular lesions. We added LOH study on 2p21 (D2S 123) ,3p14.3-21.1 (D3S1067),17p13.1(TP53)in a case with polysomy of chromosome 1,7,10, diagnosed as adenomatous goiter at first. LOH was found on $3 p$ but not $2 p$ and $17 p$.This case was reexamined pathologically, and finally diagnosed FC,minimally invasive. FISH analysis of fine-needle aspiration may provide useful information for the preoperative diagnosis of thyroid tumors.
} 


\begin{abstract}
A-51
FREQUENT MULTIPLICATIONS OF THE LONG ARM OF CHROMOSOME 1 IN HUMAN BREAST CANCERS

Kosei DATE $^{1}$, Daisuke ICHIKAWA ${ }^{1}$, Takashi SHINOMIYA ${ }^{1}$, Toshiki MORI ${ }^{1}$, Kazuma KOIDE ${ }^{1}$, Hitoshi TSUDA ${ }^{2}$, Setsuo HIROHASHI ${ }^{2}$, JOhji INAZAWA ${ }^{1}$, Tatsuo ABE $^{1}$

(1Dept. of Hygiene, Kyoto Pref. Univ. of Med., 2pathol. Div., Natl. Cancer Ctr.Res.Inst.)

We performed FISH to investigate the copy number of chromosomes $1,8,11,17$ as well as deletions of chromosome $1 \mathrm{p}$ in human breast cancers. These data were analyzed with respect to the histological grade in each tumor. Gains of copy number of chromosome 1 were the most frequent events among three different grades, whereas numerical aberrations of chromosomes $8,11,17$ were closely related to the up-grading. Furthermore PCR-IOH analyses throughout chromosome 1 revealed that allelic imbalance was detected on the long arm of chrmosome 1, but not on the short arm in all low-grade breast cancers examined. These results suggest that the gain of $1 \mathrm{q}$ on one allele may be an even earlier event among the several types of specific chromosomal aberrations in breast cancers previously reported.
\end{abstract}

\title{
$\mathbf{A}-52$
}

CHROMOSOME ANALYSIS OF MALIGNANT ASTROCYTOMA CELL LINE (U251MG) BY COMPARATIVE GENOMIC HYBRIDIZATION. Toshiki MORI ${ }^{1.2}$, Chohei SAKAKURA', Youii ARIYAMA', Takashi SHINOMIYA', Kazuma KOIDE' ${ }^{\prime}$ Kousei DATE', Satoshi UEDA $^{2}$, Johji INAZAWA', Tatsuo $\mathrm{ABE}^{1}$ ('Depts. of Hygiene and 'Neurosurgery, Kyoto Pref. Univ. of Med.)

Chromosomal aberrations of two neuroectodermal tumor cell lines were analyzed by comparative genomic hybridization (CGH). The materials were a malignant astrocytoma cell line (U251-MG) and a neuroblastoma cell line (RTR). Sample DNAs extracted from the cell lines and normal DNA from normal lymphocytes were labeled with two different fluorochromes of Spectrum green and Spectrum red by nick-translation, respectively, and then the both were cohybridized to metaphase chromosomes. Imaging and analyses of chromosomal losses, gains and amplifications for them were carried out by using MacProbe and MacKaryotype (PSI). In U251-MG, copy number gains were observed on chromosomes 1p13.1-13.2, 1q21.1-21.2, 3q27-29, 4q-12, 6, 7, 17q, 19q, X and copy number losses on 11q, 18q, 20p, 21 and Y. RTR showed copy number gains on 2p24, $5 p, 17 q, 20 q, 21 q, 22 q$ and copy number losses on 1p, 18 and Y. Amplifications were clearly detected, however, deletions were detected only in the metaphase hybridized properly. $\mathrm{CGH}$ was proved to be useful for chromosomal analysis. 
A-53

ANALYSIS OF CHROMOSOMAL ABERRATION IN HUMAN GASTRIC CANCERS Chouhei SAKAKURA ${ }^{1.2}$, Toshiki MORI ${ }^{2}$, Yohji ARIYAMA ${ }^{2}$, Yoshiteru ARAKAWA ${ }^{2}$, Kazuma KOIDE ${ }^{1,2}$, Takashi SHINOMIYA ${ }^{2}$, Yukio DATE ${ }^{2}$, Akeo HAGIWARA', Toshiharu YAMAGUCHI', Toshio TAKAHASHI ${ }^{1}$, Tatsuo $\mathrm{ABE}^{2}$ and Johje INAZAWA' ${ }^{2}$ (Kyoto Prefectural University of Medicine, 'Department of Hygiene, ${ }^{2}$ First Deptartment of Surgery)

In order to screen for DNA sequence copy number changes in gastric cancer, CGH analysis was performed in 42 gastric cancers. In the present study $\mathrm{CGH}$ analysis indicated DNA sequence copy number changes in $95 \%$ of primary gastric cancers. Losses were often involved in $1 \mathrm{p}, 5 \mathrm{q}, 17 \mathrm{p}, 18$. Gains were often involved in 1q, 7p, $11 \mathrm{p}$, and $\mathrm{X}$. Novel gene amplification was identifed on $8 \mathrm{p} 23.1$ in about $10 \%$ of advanced gastric cancers (Borrman 3 and 4), suggesting that this region may contain dominant gene related to the progression of gastric cancer. CGH is powerful tool for direct orsualization of chromosomal loss and gain among all chromosomes.

\begin{abstract}
A-54
EVALUATION ON ABILITY OF ABNORMALITY DETECTION BY CGH METHOD IN TUMOR CHROMOSOMES AND ITS METHODOLOGICAL IMPROVEMENT

Kiyomi YAMADA (Dept Genetics. Res Institute, Nat Inter Med Cent Japan), Fumihiro ASANO, Hiroshi YAMAZAKI (Koutoubiken Central Laboratory, Tsukuba), Eiii ISHIZUKA and Youichi KISHI (Dept Urology, Hospital, Nat Inter Med Cent Japan, Tokyo)

Comparative genomic hybridization $(\mathrm{CGH})$ is said to be useful for screening losses and gains of chromosomal regions along all chromosomes of tumor cells. We have investigated on accuracy and reproducibility of this method using two tumor cell-lines mostly; lung cancer cells with a sharp mode of 67 chrmosomes and brain tumr cells with 54 chromosomes. In both cell-lines, all chromosome abnormalities were completely identified by G-banding and FISH painting and none of cells with normal karyotype was present. Each of $10 \mathrm{ul}$ of probe solution containing either $200 \mathrm{ng}$ of digoxigenin-labeled normal DNA or $200 \mathrm{ng}$ of biotin-labeled tumor DNA in addition to $10 \mathrm{ug}$ of salmon sperm DNA and $20 \mathrm{ug}$ of cot-1 DNA, was mixed in volume ratio of $1: 1$ or 1:1.5. $\mathrm{CGH}$ analysis was done using Cytovision and $\mathrm{CGH}$ analysis software (AI inc.). Results: 1) Detection of gene amplification in fluorescence intensity ratio profiles was most powerfully sensitive. 2) Sensitivity to detect trisomic chromosomal regions was relatively low and insufficient. 3 3) By the increase of tumor DNA amount according to the cellular DNA content, detection for trisomic chromosomal regions became remarkably effective. 4) However, in this experiment supression hybridization must be enhanced especially for telomeric chromosomal regions by adding more 20-40 ug of cot-1 DNA.
\end{abstract}




\begin{abstract}
A-55
Interstitial Deletion On the Long Arm Chromosome 4, del(4)(q21.22-23). Kiyotaka Suwa,Toshihiro Kuramatu, and Mariko Momoi(Dept.Pediat.Jichi Medical School,Tochigi)

We report the first case of an interstitial deletion of chromosome 4, $\operatorname{del}(4)(q 21.22-3)$. The patient was a boy presenting clinical features associated with $4 \mathrm{q}$ - syndrome, such as low birth weight at term, micrognathia, cardiac malformations, delayed psychomotor development,clinodactyly of the 5th finger, hypoplasia of external genitalia, hypospadias, and a liver tumor. The association of liver tumor with $4 \mathrm{q}$ - syndrome has not been reported previously. Although pathological studies of the tumor were not performed, hepatoblastoma was most likely because of the elevated serum level of afetoprotein, rapid growth, and findings of Ultrasonography and CT scans. Recent molecular studies on primary hepatocellular carcinoma (PHC) have suggested the presence of tumor suppressor gene on chromosome 4, and the $\mathrm{LOH}$ in hepatocellular carcinoma has been observed at 4q13-26. It has been of interests that this region overlaps with the locus of human smg GDS gene, $4 q 21-25$, that has possible relation with the molecular events of malignant transformation. The occurrence of liver tumor in the patient with interstitial deletion at $4 q 21.22-23$ suggested that this deletion locus included the locus of tumor suppressor gene for PHC on 4q.
\end{abstract}

\title{
$A-56$
}

ORDERING OF FIVE GENES IDENTIFIED WITHIN AN AMPLIFIED DNA UNIT (17q12) IN BREAST AND STOMACH CANCER CELLS BY MEANS OF FIBERFISH ANALYSIS. Aiko HAYASHI ${ }^{1,2}$, Tomoki ISHIZUKA ${ }^{3}$, Hiroki SASAKI ${ }^{3}$, Fumiko SAITO-OHARA ${ }^{1}$, Sei-ichi KOHNO ${ }^{2}$, Masaaki TERADA ${ }^{3}$, and Tatsuro IKEUCHI ${ }^{1}$ ('Div. Genet., Med. Res. Inst., Tokyo Med. Dent. Univ., 2Dept. Biol., Fac. Sci., Toho Univ., ${ }^{3}$ Genet. Div., Natl. Cancer Center Res. Inst.)

FISH signals on extended chromatin fibers (ECF) released form interphase nuclei are shown to be linear, and the resolution attainable should be comparable to analysis of a straight DNA molecule itself: $1 \mu \mathrm{m}$ in size of the linear FISH signal under the microscope corresponds to a DNA length of $3-10 \mathrm{~kb}$. We have applied this fiber-FISH method to the structural analysis of amplified DNA regions including c-ERBB2 at the chromosome $17 \mathrm{q} 12$ region in breast and stomach cancer cells. A total of $12 \lambda$ EMBL 3 clones (20-30 kb) were isolated from the amplified DNA unit ( $\sim 450 \mathrm{~kb})$, each contain- ing sequences of 5 different genes that were identified within this amplified chromosome region. ECF preparations were made by the $\mathrm{NaOH}$ treatment method (Fidlerova et al., 1994) with slight modifications. After repeating of 2- or 3-colored FISH experiments with various combinations of the probes, the 12 clones could be set in array where 3 regions were found to be duplicated each other and 2 clones be localized contiguously. As a result, the order of the genes within the amplified unit was determined as follows: A39 - CAB1- C51 - c-ERBB2 - GRB7. The detailed physical map would enable to further determine the commonly amplified DNA regions in different cancer specimens. 
ALTERED EXPRESSION OF p21(WAF1/CIP1) DURING CELL DIFFERENTIATION. Tomoko HASHIMOTO ${ }^{1}$, HidenaoYAMAMOTO ${ }^{2}$ ), Koubou SASAK[ (3), ShuTAMURA ${ }^{4}$, Jiro FUJIMOTO 2), EizoOKAMOTO2), Hisao TACHIBANA3), Minoru SUGITA3), Eizo KAKISHTA ${ }^{4}$ ), and Jun-ichi FURUYAMA1). (1) Dept.Genetics, 2) 1st Dept.Surg, 3) 5th, and 4) 2nd Dept.Int.Med., Hyogo Coll. Med., Nishinomiya)

p21 is one of the factors that inhibit cell cycle. The expression of p21 is induced during cell differentiation and also up-regulated by wild type $\mathrm{p} 53$, but not by mutant $\mathrm{p} 53$. We examined the expression levels of p 21 during differentiation of human hepatoma cell lines, in which mutation of $\mathrm{p} 53$ has been frequently found. In hepatocellular carcinoma (HCC) cell lines in a log phase, lower levels of p21 mRNA were found in cells with mutant $\mathrm{p} 53$ than those with wild-type p53. In hepatoblastoma (HB) cell lines with wild-type p53, p21 expression was higher than all HCC cell lines. After induction of differentiation with sodium butyrate, marked induction of $\mathrm{p} 21 \mathrm{mRNA}$ was observed in all HCC cell lines. In HB cell lines, however, no change in the $\mathrm{p} 21$ level was found. We then examined mouse P19 embryonal carcinoma cells. The level of p21 was high in a log phase and slightly decreased after neuronal differentiation with retinoic acid. These results suggest that (1) the basal levels of expression of p21 is high in immature cells and low in mature cells, (2) induction of p21 during differentiation may be independent of types of p53, and vary with the developmental stage of cells.

A-58

CHROMOSOMAL SEGMENT TRANSLOCATION IN LEUKEMIAS AND LYMPHOMAS WITH COMPLEX KARYOTYPE. Kimio TANAKA, Mariko EGUCHI, Mansyur ARIF and Nanao KAMADA (Dept.Cancer Cytogent., Res.Inst. for Radiat. Biol. \& Med., Hiroshima Univ., Hiroshima)

One hundred and fifty leukemia and lymphoma patients were studied in detail by FISH to identify the associated oncogene with malignant transformation. Specific chromosome regions were translocated onto structurally abnormal chromosomes, resulting in partial tri-,tetra- or penta-somy of these regions. We called this type of translocation "segmental jumping translocation (SJT)". SJT were found in several chromosomal regions of $8 \mathrm{q} 24,9 \mathrm{q} 34,11 \mathrm{ql} 3,1 \mathrm{lq} 32,2 \mathrm{lq} 22$ and $22 \mathrm{q} 11$. SJT at $9 \mathrm{q} 34$, which involved $A B L$ oncogene was found in three of eight secondary leukemia patients, who were treated with anticancer drugs and radiation. Non-Hodgkin's lymphoma patients and acute myeloid leukemia (AML) patients had 3-12 copies of SJT at $11 \mathrm{q} 13$ and 11q23, respectively. Those at $14 \mathrm{q} 32$ and $21 \mathrm{q} 22$ were also predominantly detected in acute type of adult T-cell leukemia ( 8 of 27 patients) and in AML (3 of 12 patients), respectively. Further FISH analysis using many cosmid and YAC probes revealed that size of SJT regions were variable among the patients. Overlapping region within the SJT could involve commonly associating oncogene(s) with the transformation to advanced stage in leukemias and lymphomas. The SJT suggests an evidence of new mechanism for gene amplification and formation of unidentified marker chromosomes in advanced stage. 


\begin{abstract}
A-59
CYTOGENETICAL AND MOLECULAR BIOLOGICAL DIFFERENCE IN CHILD AND ADULT HEMATOLOGICAL MALIGNANCIES WTTH 11 q23 CHROMOSOMAL ABNORMALITY. Mariko EGUCHI, Kimio TANAKA, Mansyur ARIF, Nanao KAMADA (Dept. Cancer Cytogenet, Res. Inst. for Radiat. Biol and Med, Hiroshima Univ., Hiroshima) and Masao SETO (Lab. Chemotherapy, Aichi Cancer Res. Ins., Nagoya)
\end{abstract}

Reciprocal translocations involving chromosome 11, band q23 are frequently observed in human acute leukemia and lymphoma with more than 20 different cytogenetic loci as the partner. These leukemia are clinically distinct in that they are common in infants under one year of age, may be of either myeloid or lymphoid lineage or sometimes biphenotypic, and have a poor prognosis. Several groups have recently characterized a gene called MLL or ALL-1 that is structurally interrupted by $11 q 23$ translocations. The $\mathrm{CDNA}$ probe from this region detect MLL, rearrangements on conventional Southern blots.

We analyzed molecular and cytogenetical differences between child and adult 11q23 abnormal cases in 30 hematological patients. All the 13 child patients under age of 15 had a common clinical, molecular biological and cytogenetical characteristics including MLL gene rearrangements. On the other hand 17 adult leukemia and lymphoma patients were distinct from child patients in that they had more complex karyotype and less involvement of MLLgene.

FISH method was applied to identify a novel breakpoint cluster region in the 11q23 area in these MLL rearrangement negative adult hematological patients. Thirteen of the 16 patients analyzed had their breakpoint between probe 433 and 526 which is located on 11q23.1, suggesting some genetic locus in this area may be involved in 11q23 abnormal hematological disorders.

A-60

MICROSATELLITE INSTABILITY IN MYELODYSPLASTIC SYNDROME.

Shinichi MISAWA, Shigeo HORIIKE, Hiroto KANEKO, Shouhei YOKOTA, Masafumi TANIWAKI, and Kei KASHIMA (Third Dept. Med., Kyoto Prefectural University of Medicine, Kyoto)

We examined microsatellite instability(MSI) at 10 loci of dinucleotide repeats using the polymerase chain reaction( $P C R)$ in patients with myelodysplastic syndrome(MDS). Bone marrow samples were obtained from 45 patients repeatedly during the disease course and fibroblast DNA was also collected from 19 patients as a normal control. Three patients showed an alteration of MSI at 3 or more loci when the allele length was compared between the fibroblast DNA and the initial marrow DNA. On the other hand, none of the 45 patients showed an alteration between the initial marrow samples and the latest ones. The 3 patients with MSI did not show any of a disease progression, complex karyotype, karyotypic evolution, or mutation of N-RAS of TP53 gene. Moreover, a frameshift mutation of the transforming growth factor beta type II receptor gene at 10 repeating adenines, which may be critical target of MSI, was not found in any of the 45 patients. These findings suggest that MSI is an early but infrequent genetic event and is independent of other critical genetic aberrations in the development of MDS. 
A-61

CHROMOSOME ABERRATION IN PATIENTS WITH MULTIPLE ENDOCRINE NEOPLASIA TYPE 1 (MEN1). Miyuki KATAI, Akihiro SAKURAI, Yasunori ITAKURA, Kiyoshi HASHIZUME (Dept. Geriat,, Endocrinol., Metab., Shinshu Univ. Sch. Med., Matsumoto) and Yoshimitsu FUKUSHIMA (Dept. Hygiene, Med. Genet., Shinshu Univ. Sch. Med., Matsumoto)

Chromosomal instability is known to be associated with certain cancer-prone disorders such as Fanconi's anemia. These disorders, designated DNA repair syndromes, have common characteristics such as autosomal recessive inheritance mode, short stature and mental retardation. MEN1 is an autosomal dominant disorder characterized by development of tumors or hyperplasia in two or more endocrine organs, and chromosomal instability in patients with MEN1 has been described. The clinical features of MEN1 are, however, distinct from other DNA repair syndromes except predisposition to tumors. Therefore, we reevaluated chromosomal instability in familial and sporadic MEN1 patients and their relatives including an asymptomatic carriex confirmed by linkage study. Phytohemagglutinin stimulated lymphocytes were cultured with and without diepoxybutane (DEB), and chromosome aberrations were analyzed in Giemsa stained preparations. An increase in the frequency of spontaneous chromosomal aberrations in some patients with MEN1 was observed. With DEB, we found a significant increase in chromosomal abberations in MENI patients and an asymptomatic carrier, but not in control subjects. We conclude that chromosomal instability exists in patients with MENl and an asymptomatic carrier of it. Molecular mechanisms of this phenomenon and relationship to tumorigenesis in endocrine organs should be elucidated.

\section{A-62}

ANALYSIS OF THE DNA SPOTS SPECIFIC FOR A LUNG TUMOR IDENTIFIED BY TWO-DIMENTIONAL ELECTROPHORESIS OF DNA. Mieko KODAIRA ${ }^{\prime}$, Keiko HIYAMA $^{1,2}$, Masaaki IMANAKA ${ }^{1}$, Satomichi KANEOKA ${ }^{1}$, Takahiro TSUJI ${ }^{1}$, Chiyoko SATOH $^{1}$, Michio YAMAKIDO ${ }^{2}$, Jun-ichi ASAKAWA ${ }^{1}$ 'Dept. Genet. Radiation Effects Research Foundation, Hiroshima, ${ }^{2}$ 2nd Dept. Internal Medicine, Hiroshima University School of Medicine, Hiroshima)

We have developed a vertical two-dimentional electrophoresis (2-DE) in which an agarose disc gel made in teflon-tubing was used. Alterations in a lung tumor was examined by this technique. Genomic DNAs were digested with Notl and EcoRV and labeled at the NotI sites before the first dimentional electrophoresis. The separated DNA in the disc gel was further digested with HinfI prior to the second-dimension electrophoresis. When intensities of spots on the 2-DE pattern are quantitated, copy numbers of corresponding DNA fragments can be estimated. The use of Not $\mathrm{I}$, a methylation sensitive enzyme, allows studies of genomic DNA methylation. Comparison of the 2-DE patterns of the primary tumor and its surrounding normal tissue from a lung tumor patient revealed DNA spots with increased copy numbers in the tumor. We cloned Not $\mathrm{V} / \mathrm{HinfI}$ DNA fragments which were directly recovered from the 2-DE gel spots and characterized them. One of intensified spots derived from DNA fragments amplified in this tumor. Each of another 4 intensified DNA spots was revealed to be a part of a repeating unit containing a Not I recognition sequence. The Not $\mathrm{I}$ site in each repeating unit was methylated and resistant to be cleaved with $N o t I$ in the normal cells, but the intensified signals in the tumor were caused due to demethylation in these recognition sequence of NorI. 
A-63

ANALYSIS OF A CANDIDATE TUMOR SUPPRESSOR GENE FOR OVARIAN CANCER ISOLATED FROM CHROMOSOME 6q27. Syuya SHIRAHAMA, SUSUmu SAITO (SRL, Inc., Tokyo) and Yusuke NAKAMURA (Lab. Mol. Med., Inst. Med. Sci., Univ. Tokyo, Tokyo)

The frequent losses of heterozygosity ( $\mathrm{LOH}$ ) observed on chromosome $6 q$ in ovarian carcinomas suggest the presence of one or more putative tumor suppressor genes on this chromosomal arm. We previously observed frequent allelic losses in ovarian tumors between loci at 6q26 and 6q27 and defined a commonly-deleted region between loci defined by $\mathrm{Cl} 6-111$ (D6S193) and Cl6-24 (D6S149). From this region we isolated YAC clones and constructed a cosmid contig map. To isolate expressed sequences from this region, we performed exon trapping experiments and we found that the human AF-6 gene, which is disrupted in acute myeloid leukemia cells that carry a $(6 ; 11)$ (q27;q23) translocation, is located within the commonly-deleted region. Subsequent screening of the AF-6 gene in ovarian carcinomas revealed no mutations. Cosmid contig map and expressed sequences will contribute important data for isolating other candidate genes and should facilitate eventual identification of the putative ovarian tumor suppressor(s) on chromosome 6q.

A-64

DETECTION OF GERM-LINE MUTATIONS OF THE ADENOMATOUS POLYPOSIS COLI GENE BY NON-RADIOACTIVE PCR-SSCP. Yochinori NIMURA', Chizumi FURUWATARI ${ }^{2}$, Minoru FUIMORI', Wataru ADACH', Yoshifumi OGISO'2, Ken-ichi

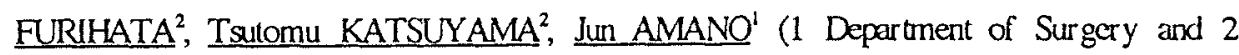
Department of Clinical laboratory, Shinshu University schoot of medicine, Matsumoto)

Germline mutations of the adenomatous polyposis coli $(A P C)$ gene have been reported in patients with familial adenomatous polyposis and belived to be an early events in colorectal carcinoma. We report the results of screening for the germ. line mutations of the APC gene in 3 cases of 2 kindreds using PCR-SSCP (Polymerase chain reaction-single strand conformation polymorphisms) analysis and DNA sequencing.

The mutation in kindred 1 was 4 bp deletion at codon 849 in exon 15, resulting in a frameshift leading to truncation of the $A P C$ gene product at $30 \mathrm{bpdownstream}$. In kindred 2, a transition of $\mathrm{C}$ to $G$ at codon 2038 was observed, resulting in an amino acid change from levcine to valine. In this case, it is possible to screen presymptomatic diagnosis easily and quickly with digestion by restriction enzyme EcoNI. 
A-65

ANALYSIS OF THE WERNER SYNDROME GENE MUTATIONS. Atsuyuki MORISHIMA, IUn NAKURA, Lin YE, Tetsuro MIKI Toshio OGIHARA (Dept. Geriat. Med., Osaka Univ. Med. Sch., Osaka), Junko OSHIMA, GM MARTIN(Dept. Pathology, Univ. of Washington, Seattle), and Chang-En YU GD SCHELLENBERG, (Dept. Neurology, Univ. of Washington, Seattle)

Werner syndrome (WRN) is a rare autosomal recessive disorder, one of the progeroid syndromes. This syndrome is a model of aging, and characterized by features of premature aging : cataracta, hypogonadism, osteoporosis, and hyperkeratosis. The mean age-at-death is about 50 years old, and main cause of death are neoplasias, myocardial infarcts, and cerebral vascular disease.

The gene for WRN, located on chromosome $8 \mathrm{p} 12$, was recently isolated by positional cloning methods. The WRN gene encodes a 1432 amino acid protein, which shows homology to the DExH box DNA and RNA helicases.

Four mutations has been detected in this gene. We have studied these mutations by SSCP method on Japanese population . In the result, one particular mutation holds about $70 \%$ of the WRN gene mutations in Japanese.

A-66

A GENETIC, PHYSICAL, AND EST MAP AROUND THE WERNER'S SYNDROME REGION (8p12-21). Lin YE, Jun NAKURA, Atuyuki MORISHIMA, Noriaki MITSUDA, Tetsuro MIKI and Toshio OGIHARA (Dept. Geriatr. Medicine, Osaka University, Osaka)

Wemer syndrome (WS) is an autosomal recessive dosorder characterized by the premature ocurrence of many age-related features. To identify the gene for WS (WRN), previously assigned to the 8 p 12-21 region, we used the positional cloning strategy. First, we constructed a genetic map. The map comprises 34 dinucleotide repeat polymorphic markers and spans about $43 \mathrm{cM}$ across the 8 p12-21 region. Second, we analyzed 58 patiens for the 34 markers by homozygosity analysis to refine the WRN locus, resulting in narrowing the position of the WRN locus to $1.6 \mathrm{cM}$. Third, we tested linkage disequilibrium between the WRN locus and 16 dinucleotide repeat polymorphic marker loci positioned within the WRN candidate region. This resulted in detection of linkage disequilibrium between WRN and D8S1223 ( $p<0.05)$, D8S1055 ( $<<0.01)$, D8S1445 $(p<0.001)$, D8S339 ( $p<0.001)$, GSR1 $(p<0.001)$, GSR2 $(p<0.001)$, and D8S1444 $(p<0.05)$. Fourth, to construct a physical map containing all of these 7 markers, we assembled 16 YAC clones and 44 Pl clones into a single contig covering a minimum of $1.5 \mathrm{Mb}$ physically and $2.8 \mathrm{cM}$ genetically with 12 polymorphic and 28 nonpolymorphic STSs within the 8p12-21 region. These YAC and $\mathrm{P} 1$ clones were used to isolated several candidate genes. Fifth, we also construct a EST map on this cloned region and integrated the EST map into a genetic and physical map. This resulting map should help to promote our understanding of this region. 


\begin{abstract}
A-67
THE MUTATIONS OF THE RET PROTO-ONCOGENE WITH MULTIPLE ENDOCRINE NEOPLASIA TYPE 2 (MEN 2). Kenji OGURA, Shuya SHIRAHAMA, Kazumasa HIKIJI (SRL, Inc., Tokyo) Hiroshi TAKAMI (1 st Dept. Surg., Teikyo Univ. Sch. Med., Tokyo) Tohichi TOHSEN (Tohsen Clinic, Shizuopka) Kunihiko ITOH (Ito Hospital, Tokyo) and Yusuke NAKAMURA (Lab. Mol. Med., Inst. Med. Sci., Univ. Tokyo, Tokyo)
\end{abstract}

Multiple endocrine neoplasia types 2A and 2B (MEN 2A and 2B) and familial medullary thyroid carcinoma (FMTC) are autosomal, dominantly inherited syndromes involving endocrine tumors. Responsible genes of these diseases have been elucidated to be RET proto-oncogene located on chromosome 10q11.2, and it has been shown that, mutations in MEN 2A and FMTC occur at codons $609,611,618,620,630$ and 634 on exons 10 and 11 which encode cystein and in MEN 2B occur at codon 918 on exon 16. We have further studied genetic analysis of RET gene, and found the high frequencis of mutations such as $97 \%(28 / 29), 100 \%(4 / 4)$ and $100 \%(3 / 3)$ in 29 cases of MEN $2 A, 4$ cases of MEN $2 B$ and 3 cases of FMTC, respectively. Furthermore, we identified the mutation of GAG (Glu) to GAC (Asp) at codon 768 on exon 13 in 2 patients of MTC. It was suggested that this genetic analysis of RET protooncogene is useful for the screening of carriers having mutations relating to MEN 2A, 2B and FMTC.

A-68

UVB-induced skin carcinogenesis in XPA-deficient mice. Kiyoji Tanaka (Institute for Molecular and Cellular Biology, Osaka University, Osaka)

Nucleotide excision repair (NER) is a versatile repair system capable of rectifying a broad spectrum of DNA damage. Xeroderma pigmentosum (XP), a human inherited disease which is characterized by a high incidence of skin cancer in sun-exposed areas and several neurological complications, has a defect in early steps of NER processes. There are seven different complementation groups ( $A$ through $G$ ) in XP. We have been interested in the functions of the XPA gene in NER processes. The XPA gene encodes a protein of 273 amino acids with $C 4$ type zinc finger motif, and it preferentially bound to DNA damaged by UV, cisplatin or osmium tetroxide, indicating that the XPA protein is involved in the damage recognition step of NER processes. Besides this DNA binding domain, the XPA protein has the regions involved in the protein-protein interactions to coordinate the NER processes. We found that RPA (replication protein A), ERCC1 protein and several new other proteins bound to the XPA protein. To elucidate the molecular basis of group A XP, we established XPA-deficient mice by gene targeting. The XPA-deficient mice were defective in NER process and highly susceptible to UV-induced skin tumorigenesis. The XPA-deficient mice provide a good in vivo model to study UV-induced skin carcinogenesis in group A XP patients. 


\author{
A-69 \\ Characterisation of germline mutations in the neurofibromatosis 1 \\ (NF1) gene in Japan. \\ Nobuaki HATTA, Yuzuru KOBAYASHI, Shigeru FUJITA (The First Dept. \\ Int. Med., Ehime Univ., Ehime) \\ Takahiko HORIUCHI (The First Dept. Int. Med., Kyushu Univ., Fukuoka) \\ Neurofibromatosis 1 (NF1) is an autosomal dominant disease \\ characterized by abnormalities in multiple tissues derived \\ from the neural crest. The gene responsible for NF 1 was \\ estimated recently. We analysed 95 unrelated Japanese patients \\ for NF1 gene mutation by PCR/SSCP analysis for all exons. \\ Here we demonstrated eleven deletions, three insertions, \\ three missense mutations, three nonsense mutations and three \\ splicing mutations. And also, we employed cDNA analysis such \\ as RT-PCR and RT-PCR/SSCP, and detected four splicing mutations \\ with exon skippings in addition to the above mutations. Most \\ of the detected mutations generated frameshifts or stop codons \\ resulting in truncation of NF1 product (neurofibromin). \\ Those results suggested that our strategies such as PCR/SSCP \\ and RT-PCR/SSCP were useful tools for the investigation of NF1 \\ mutations.
}

\title{
A-70
}

MUTATIONS IN THE BRCA2 GENE IN PRIMARY BREAST CANCERS AND OTHER CANCERS. Toyomasa KATAGIRI Maiko MINAMI YUmi NAKAJIMA. Hiroko BANDO Yoshio MIKI (Dept. Hum. Genome Anal., Cancer Chemother. Ctr., Jpn. Fdn. Cancer Res., Tokyo) and Yusuke NAKAMURA (Dept. Hum. Genome Anal., Cancer Chemother. Ctr., Jpn. Fdn. Cancer Res. and Lab. Mol. Med., Inst. Med. Sci., Univ. Tokyo, Tokyo)

To define the role of BRCA2 in sporadic breast cancer and other cancers, we screened the entire coding region of this gene for mutations in 100 primary breast cancers, 60 hepatocellular carcinomas (HCCs), and 36 pancreatic cancers (PCs) from Japanese patients. We found three mutations including two germline and one somatic mutations in primary breast cancers. One of the germline mutations was insertion of Alu element into exon 22, and the other showed 4-bp deletion in exon 9. Somatic mutation was a missense mutation of unknown significanct. No alteration was found in any of PCs examined. Three mutations were identified in HCCs; one was a somatic 6-bp deletion within intron 6 . The other two mutations were missense mutations in the germline. Furthermore, we found that BRCA2 expressed in adult liver tissue. These results indicate that somatic mutations in $B R C A 2$ is very rare, like somatic mutations in $B R C A 1$, in primary breast cancer, and inactivation of $B R C A 2$ may play some role in development or progression of $\mathrm{HCC}$. 
A-71

ANALYSIS OF p16 AND p15 GENE ALTERATION IN ORAL SQUAMOUS CELL CARCINOMA CELL LINES, Narikazu UZAWA ${ }^{1,2}$, Daisuke AKANUMA ${ }^{1.2}$, Mitsuaki A. YOSHIDA' ${ }^{\prime}$, Teruo AMAGASA ${ }^{2}$, Masao S. SASAKI ${ }^{3}$ and Tatsuro IKEUCHI ${ }^{1}$. ( ${ }^{1}$ Dept. Cytogenet., Med. Res. Inst., ${ }^{2}$ 1st Dept. Oral \& Maxillofac. Surg., Fac. Dent., Tokyo Med. \& Dent. Univ., Tokyo., ' Radiation Biology Center, Kyoto Univ., Kyoto)

Allelic loss at $9 \mathrm{p} 21$ occurs frequently as an early event in head and neck squamous cell carcinoma(SCC) including oral cancer. The pl6/MTSI/CDKN2A and p15/MTS2/CDKN2B genes, which code cell cycle regulator proteins, have been mapped to the $9 \mathrm{p} 21$ region. Highly frequent alterations of these genes have been reported in human cancers. However, whether $p / 6$ and/or $p / 5$ inactivations are the target of this early loss event in oral SCC has remained unsolved. We examined the genomic status and mRNA expressions of these genes in 11 oral SCC cell lines by using methods based on PCR. Homozygous deletion of both $p 15$ and p16 was detected in only one cell line. RT-PCR analysis revealed that two and five cell lines did not express p 16 mRNA and 15 mRNA, respectively. We are now investigating these gene alterations including deletion, abnormal methylation and mutation, in primary samples of oral SCC.

\section{A-72 \\ ISOLATION OF CDNA CLONES FROM A BREAKPOINT OF INV(21) IN A PATIENT WITH TRANSIENT ABNORMAL MYELOPOIESIS (TAM)}

Motoi NAKANO, Tohru OHTA, Norio NIIKAWA (Dept. Hum. Genet., Nagasaki Univ. Sch. Med., Nagasaki)

TAM is a transient leukemia occurring occasionally in Down syndrome newborn infants. We presumed the TAM locus at 21q11.1, based on the results of our cytogenetic and molecular studies. We previously encountered a TAM patient with inv(21)(q11.1q22.13). We confirmed that the proximal breakpoint of the $\operatorname{inv}(21)$ of the patient is located between two STS markers at 21q11.1, and isolated a cosmid clone (Q62E11) corresponding to the breakpoint.

In the present study, we have isolated several cDNA clones from the cosmid, Q62E11. In order to know that the sequence in this clone was conserved in other animals, zoo-blotting was first performed. A $15-\mathrm{kb} E c o$ RI subclone detected hybridization signals in cow, pig and other mammals. As a CPG island was found in this fragment, we screened an adult bone-marrow cDNA library and isolated 13 cDNA clones. We are characterizing these cDNA clones. 
A-73

GENE THERAPY FOR PHENYLKETONURIA USING RERLICATION-DEEECTIVE RECOMBINANT ADENOVIRUS. Yutaka NAGASAKI, Yoichi MATSUBARA, Kunihiro EUJII, Jun AKANUMA, Hideaki TAKANO, Shigeo KURE, Kazutosi TAKAHASHI, Kuniaki NARISAWA (Dept.Biochem.Genet., Tohoku Univ.Sch.Med., Sendai) and Yumi KANEGAE, Izumu SAITO (Lab.Mol.Genet., Med.Sci.Inst., Tokyo Univ., Tokyo)

Phenylketonuria (PKU) is due to deficiency of phenylalanine hydroxylase (PAH). It causes severe mental retardation, hypopigmentation and hyperphenylalanemia. Toward the gene therapy of $\mathrm{PKU}$, we constructed a replication-defective recombinant adenovirus using a cosmid-cassette method. The adenovirus was administrated into tail veins of PKU model mice. Serum phenylalanine level decreased to less than 10\% $(2.2 \mathrm{mg} / \mathrm{dl})$ of the pre-treatment value $(30.9 \mathrm{mg} / \mathrm{dl})$ within 24 hrs and lasted for 10 days. Daily subcutaneous injection of immunosuppresant FK506 after adenovirus injection prolonged the period to more than 35 days and allowed succesful

repeated gene delivery. PAHcDNA was mainly detected in liver .PAH activity was present exclusively in liver. In these experiments, hypopigmented PKU mice showed pigmentation of hair, from grayish color to black. The study demonstrated the correction of physical phenotype as well as biochemical phenotype by gene transfer and efficacy of immunosuppresant for adenovirus-mediated gene therapy.

\section{A-74}

EXPRESSION OF MULTIPOTENTIAL NEURAL STEM CELL MARKERS IN AMNIOTIC EPITHELIAL CELLS FROM HUMAN, MONKEY AND RAT. Norio SAKURAGAWA, Ramasamy THANGAVEL (Dep. Inher. Met. Dis., Nat. Inst. Neurosci., NCNP, Tokyo), Osamu OKUDA, Ikuko OGINO (Dep. Neurosug. Juntendo Univ. Sch. Med., Tokyo), Fumiko ONO, Yasuhiro YOSHIKAWA (NIH: Tsukuba Primates Center, Ibaragi)

Human amniotic epithelial cells (AEC) are formed from amnioblasts, separated from the epiblasts at about the 8 th day after fertilization. Recently we found the expression of markers for both neuronal and glial cells in human amniotic epithelial cells. In this study we report the comparative study using AEC from human, monkey and rat. AEC were immunocytochemically stained as described previously. Appropriate FITC or rhodamin-labeled antibodies were used for double staining. AEC from human, monkey and rat displayed positive immunoreactivity to neural stem cell markers as well as neural and glial cell markers. Double staining for neuron and glial cells showed coexpression of these markers in the majority of cells. In addition, oligodendrocyte cell lineage was present in the same field as well as cortical glial cell lineage, indicating heterogeneous coexpressions. These results showed that expression of neural stem cell markers is present in the different species, indicating possible use of animal models of transplantation of these cells into brain for treatment of neurodegenerative or metabolic diseases. 


\begin{abstract}
A-75
THE RECOMBINANT ADENO-ASSOCIATED VIRUS FOR HEPATIC GENE THERAPY. Torayuki OKUYAMA, and Masao YAMADA. ( Dept. Genet., Nationl Children's Medical Research Center, Tokyo)
\end{abstract}

We synthesized recombinant adeno-associated virus vector for hepatic gene therapy. The construct pTRNAET was made to clone a $1.7 \mathrm{~kb} \mathrm{Neo}^{\mathrm{R}}$ cassette ( PGK promoter$\mathrm{Neo}^{\mathrm{R}}$ gene-rabbit $\beta$-globin polyA) and a $3.5 \mathrm{~kb}$ liver specific expression cassette for hAAT ( ApoE enhancer -hAAT promoter-hAATcDNA-SV40polyA) into an AAV vector plasmid, pTR(+). We established the stable clone HeLa-TRNAET which carries the DNA of pTRNAET in HeLa cells. The plasmid pIM45 (packaging plasmid for AAV) and Ad5 was transinfected into HeLa-TRNAET to synthesize the rAAV vector AAV-TRNAET. The Neo ${ }^{R}$ titer of AAV-TRNAET is approximately $1.0 \times 10^{5} \mathrm{cfu} /$ pl00 in the examined four cell lines ( HeLa, HepG2, NIH3T3, and Hepa1A). We detected the expression of hAAT in gene-transduced HepalA cells, and the level of expression corresponded $25 \%$ of endogenous level of hAAT in HepG 2 cells. However, no expression was seen in the HeLa cells transduced by the rAAV. Based on these observations, we conclude that the AAV-TRNAET can transduce the cell lines derived from hepatocytes efficiently and keeps the tissue specificity in expression.

B-1

AN ASSOCIATION OF DRB $1 * 1501$ WITH WESTEERN TYPE MULTIPLE SCLEROSIS IN JAPANEASE. Yasuharu NISHIMURA ${ }^{1}$, Takayuki KANAI ${ }^{1}$, Jun-ichi $\mathrm{KIRA}^{2}$ and Takuro KOBAYASHI ${ }^{2}$ ('Div. Immunogenet., Kumamoto Univ. Grad. Sch. Med. Sci., Kumamoto, '2Dept. of Neurol., Neurol. Inst., Faculty Med., Kyushu Univ., Fukuoka)

In caucasians, the statistically strong association between HLA-DRB1*1501 and multiple sclerosis(MS) was well established. Whereas it is controversial in Japanese patients with MS. In this study the polymorphism of HLA-DRB1, -DRB3 and -DRB5 genes as well as magnetic resonance imaging(MRI) of the brain and spinal cord were studied in 57 Japanese patients with MS. According to the clinical findings, 23 patients who showed a relapsing-remitting course and a selective involvement of the optic nerve and spinal cord with minimal brainstem signs were classified as Asian type MS. The other 34 patients demonstrating an involvement of multiple sites in the central nervous system were classified as Western type MS. Asian type MS showed a significantly lower number of brain lesions on MRI than did Western type, while Asian type MS showed a significantly higher frequency of gadolinium-enhanced lesions on the spinal cord MRI than did Western type ( $47 \%$ vs. $17 \%$ ). Among the DRb chain genes examined, only the frequency of the DR2-associated DRB $1 * 1501$ allele and DRB $5 * 0101$ allele were found to be significantly higher in Western type (41.2\%) than in either Asian type $(0 \%)$ or healthy controls $(14.2 \%)$. Heterogeneity in the immunogenetic background and in the MRI features between the two subtypes of MS thus suggests the presence of two etiologically distinct MS in Asians. 
B-2

IDENTIFICATION OF AN AUTOIMMUNE T CELL EPITOPE PRESENTED BY THE DISEASE SUSCEPTIBLE HLA CLASS II IN INFANT-ONSET MYASTHENIA GRAVIS. Takayuki KANAI ${ }^{1}$, Yoshiko NOMURA ${ }^{2}$, Masaya SEGAWA ${ }^{2}$, Sho MATSUSHITA ${ }^{1}$ and Yasuharu NISHIMURA ${ }^{1}{ }^{1}$ Div. Immunogenet., Kumamoto Univ. Grad. Sch. Med. Sci., Kumamoto, ${ }^{2}$ Segawa Neurological Clinic for Children, Tokyo)

Infant-onset $(<3 y)$ myasthenia gravis $(\mathrm{MG})$ is an Orientals-specific autoimmune disease that affects predominantly neuromuscular junctions in ocular muscles. It was reported that the frequency of Orientals-specific HLA class II alleles, HLA-DR9-DQ9, DR13DQ6 and HLA-DR9/DR13 heterozygote were significantly increased in the patients. We synthesized overlapping peptides covering acetylcholine receptor $a$-subunit (AChRa), regarded as an autoantigen in $\mathrm{MG}$. By stimulating peripheral blood mononuclear cell(PBMC) from a patient heterozygous for HLA-DR9-DQ9 and DR13-DQ6 with a mixture of those overlapping peptides, we established an AChRa peptide (p71-91) specific autoreactive $\mathrm{CD} 4^{+} \alpha \beta$ T cell clone. The $\mathrm{T}$ cell clone recognized the $\mathrm{AChR} \alpha$ peptide in the context of HLA-DQ6 molecule. A core epitope of the autoantigenic peptide is encorded for by an alternatively spliced exon P3A of AChR $\alpha$ gene. The T cell clone produced a large amount of IFN- $\gamma$, whereas produced little IL-4, suggesting Th1 like phenotype. The result seems to be a proof that the level of anti-AChR autoantibodies in serum with infant-onset MG patients is lower than adult-onset MG in which Th2 like AChR autoreactive $T$ cells dominate to produce a large amount of anti-AChR autoantibody.Thus, an orientals-specific HLA class II allele directly controls susceptibility to infant-onset MG, specific to Orientals.

B-3

FUNCTIONAL EXPRESSION OF HUMAN INTERLEUKIN-4 RECEPTOR $\alpha$ GENE ON A MOUSE MACROPHAGE CELL LINE. Takeshi OTSUKA, Yoshiaki NEMOTO, Kunihiro YAMAOKA, Hitoshi NAKASHIMA, Hiroaki NIIRO, Yosuke TANAKA, Eiichi OHGAMI, Yojiro ARINOBU, Yoshiyuki NIHO (Dept. Int. Med., Kyushu University, Fukuoka) and IZUHARA Kenji (Dept. Hum. Genetics, National Institute of Genetics, Mishima)

By using B cells of X-linked severe combined immunodeficiency (XSCID) patients, we indicated that mutation of the IL-2 receptor $\gamma$ chain $(\gamma c)$ caused abnormal signal transduction not only of IL-2 but also of IL-4. In this study, we evaluated a functional significance of $\gamma \mathrm{c}$ in IL-4 receptor system of monocytes/macrophages. Mouse monocytic cells never responded to human IL-4. We introduced human IL-4 receptor $\alpha$ chain (IL-4R $\alpha$ ) gene into a mouse monocytic cell line and established cell lines stably expressing human IL-4R $\alpha$. Human IL-4, as well as mouse IL-4, reduced productions of TNF- $\alpha$, prostaglandins and nitric oxide inducibly produced by such transformed cell lines stimulated with lipopolysaccharide. Neutralizing antibody against $\gamma c$ hardly blocked these functions of human IL-4, indicating that $\gamma c$ may be less important in transducing signals carried out by human IL-4. Further studies are still needed to explain significance of IL-4R $\alpha$ and $\gamma c$ of functional IL-4 receptor. 
B-4

The Human Gene Encoding The Heavy Chain of The Major

Histocompatibility Complex Class I-Like Fc Receptor (FCGRT) Maps to

$19 q 13.3$

Masayuki EGASHIRA, Osamu MIYOSHI, Norio NIIKAWA (Dept. Hum. Genet., Nagasaki Univ. Sch. Med., Nagasaki),

Eman KANDIL, Teruo ISHIBASHI, Masanori KASAHARA (Dept. Biochem. Hokkaido Univ. Sch. Med., Sapporo)

$F c R n$ is an $F c$ receptor that structurally resembles the major histocompatibility complex class I molecule. It has been reported that $\mathrm{FCRn}$ in the intestinal epithelium of neonatal mice and rats mediates the selective uptake of $\operatorname{IgG}$, and helps to acquire passive immunity. In this study, we isolated the human gene encoding the heavy chain of $\mathrm{FcRn}$ (FCGRT), and using two FCGRT lambda clones H6-1-1 and H9- I-I (insert sizes of 18 and $16 \mathrm{~kb}$ ) we mapped it by fluorescence in situ hybridization to human chromosome, 19q13.3. Thus, like its mouse counterpart, the human FCGRT gene is located outside the major histocompatibility complex.

B-5

HLA SUSCEPTIBILITY GENES IN JUVENILE RHEUMATOID ARTHRITIS. Kiyoshi ZAMA ${ }^{1,2}$, Katsushi TOKUNAGA ${ }^{2,3}$, Satoshi MORIYAMA ${ }^{2}, \underline{\text { Hiroshi }}$ MITSUI $^{4}$ and Takeo JUII ${ }^{2}$ (Dept. Orthop., Med., Univ. Tokyo, Tokyo, ${ }^{2} \mathrm{Jpn}$. Red Cross Ctrl. Bld. Ctr., Tokyo, ${ }^{3}$ Dept. Hum. Genet., Univ. Tokyo, Tokyo, ${ }^{4}$ Mitsui Memorial Hosp., Tokyo)

HLA class I and class II genes in 66 Japanese patients with juvenile rheumatoid arthritis (JRA) were studied by means of both serological and DNA typing. The typing results revealed positive associations of polyarticular JRA with HLA-A*2402, -B59, -Cw7, and -DRB1*0405-DQB1*0401, pauciarticular JRA with HLA-A*2603 and -B39, and systemic JRA with HLA-A31, -Cw9, -DRB1*1501-DQB1*0602 and -DPB $1 * 0301$. These HLA alleles/loci were considered to show independent associations except for the B59-DRB1*0405-DQB1*0401 and DRB1*1501-DQB1*0602 haplotypes. Polyarticular and systemic JRA showed negative associations with DQA1*0501 and the DRB $1 * 0901$ $D Q B 1 * 0303$ haplotype, respectively. In particular, the common Japanese haplotype A33-B44-DRB1*1302-DQB 1*0604-DPB1*0401 was not detected in any of the JRA patients. These results suggest that 1) the pathogenetic bases of these three JRA subtypes differ and 2) the gene(s) carried by the A33-B44-DRB1*1302 haplotype are protective for all the JRA subtypes. 
INCIDENCE OF HLA-DPB1 AND -DRB1 ALLELES IN PATIENTS WITH

KAWASAKI SYNDROME. Michiko ONIMARU, Jun ABE, Takao KOHSAKA (National Children's Med. Res. Ctr., Tokyo), Yoshihisa WATANABE, Satoshi MORIYAMA (JRC Central Blood Center, Tokyo) and Katsushi TOKUNAGA (Dept. Human Genetics, Tokyo Univ.)

Kawasaki syndrome (KS) is an acute vasculitis primarily affecting infants and young children. Although the etiology of the illness is unknown, epidemiological studies indicate that the incidence of KS is especially high in Japan. In this study, we examined the incidence of HLA-DPB1 and -DRB1 alleles among 64 patients with KS using PCRPHFA (preferential homoduplex formation assay) and PCR-MPH (micro titer hybridization) method, respectively. The results were analyzed by the $x^{2}$ test using the data from Akaza T. et al (Kon-nichi No Ishoku 7, 1994) as a control.

Among the 14 DPB 1 alleles studied, no allele had significant difference in the incidence between the patients and controls. On the other hand, the incidence of DR8 was significantly increased in KS. By high resolution typing, 16 out of 64 patients (25\%) were positive for $\mathrm{DRB} 1 * 0803(\mathrm{p}<0.05)$ and $23(36 \%)$ were positive for either $* 0802$ or $* 0803(p<0.02)$. Between the $* 0803$ positive and negative patients, no significant difference was observed in the patients' age, sex, severity of clinical symptoms, and the laboratory data such as WBC, CRP and IL-6. The incidence of coronary aneurysm was $30.0 \%$ and $26.3 \%$ in the $* 0803$ positive and negative patients, respectively.

The frequency of DR8 in Japan (13.3\%) is the highest compared with the other countries (The 11th International Histocompatibility Workshop, 1991). It might be of interest to determine whether DR8 is also increased in patients from other countries.

\section{B-7}

HLA CLASS II DNA TYPING IN BUERGER'S DISEASE. Wulin AERBAJNAI, Terumasa TSUCHIYA, Yukio YASUKOCHI ( Dept. Molecul. Genet., M.R.I., Tokyo Med.\& Den. Univ., Tokyo.) and Fujio NUMANO (Dept. Int. Med., Tokyo Med.\& Den. Univ., Tokyo.)

To analyze the genetic factors involved in the pathogenesis of Buerger's disease, the polymorphisms of HLA class II genes (HLA-DP, DQ and DRB) were investigated in 36 patients using polymerase chain reaction-restriction fragment length polymorphism (PCR-RFLP) method. HLA class I (B54 and B52) and HLA class II (DQ alleles) genes were also typed by polymerase chain reaction-sequence-specific oligonucleotide probe (PCR-SSOP) method to confirm alleles. PCR-RFLP typing revealed that the frequencies of HLA class II genes, DRB 1*0405, DQB $1 * 0401$, DQA $1 * 03$ and DPB $1 * 0501$, were significantly increased in the patients with Buerger's disease compared with the healthy controls. Further, DNA typing confirmed that HLA-B54 was associated with Buerger's disease. These results suggested that the haplotype of HLA-B54-DRB1*0405-DQB1*0401-DQA 1*03-DPB $1 * 0501$ was associated with Buerger's disease in Japanese population. 
SEQUENCE-LEVEL POLYMORPHISM OF HLA CLASS I GENES (A, B, and C) IN JAPANESE. Katsushi TOKUNAGA ${ }^{12}$, Yoshihide ISHIKAWA ${ }^{2}$, Atsuko OGAWA ${ }^{2}$, Huiru WANG ${ }^{2}$, Makoto BANNAI ${ }^{3}$, Kenji TADOKORO ${ }^{2}$, and Takeo JUJI ${ }^{2}$ ('Dept. Human Genetics, University of Tokyo, Tokyo, ${ }^{2}$ Japanese Red Cross Central Blood Center, Tokyo, ${ }^{3}$ Tokyo Metropolitan Blood Center, Tokyo)

Nucleotide sequences of HLA class I alleles have been determined in Japanese. Up to now, 23,42 , and 16 different alleles, in which 8,12 , and 3 were new, have been identified at HLA-A, $-\mathrm{B}$, and $-\mathrm{C}$ loci, respectively. Thus the HLA diversity at the sequence level is much larger than that detected by conventional serological typing. Moreover, we have performed high resolution DNA typing for these class I genes in a Japanese population sample. Numbers of alleles observed at gene frequencies of more than $3 \%$ were 8,13 , and 9 at HLA-A, -B, and -C loci, respectively. Putting class I and II data together, a number of significant associations were detected among different $\mathrm{HLA}$ loci, and several common multi-locus haplotypes could be deduced, such as $A^{*} 3303-\mathrm{CW}^{*} 1403-\mathrm{B}^{*} 4403$ DRB1*1302-DQB1*0604 and A*2402-Cw*1202-B*5201-DRB1*1502-DQB1*0601. These findings should become useful for studies on disease susceptibility genes, matching for bone marrow transplantation, and ethnic diversity.

\section{B-9}

Chromosomal localization of the human natural killer cell inhibitory receptor family genes and the natural killer gene complex (NKC) by fluorescence in situ hybridization. Yumiko SUTO 1, Katsumi MAENAKA1, Toshio YABE1, Momoki HIRAI2, Katsushi TOKUNAGA 1. 3, Kenji TADOKOROI and Takeo JUJI I. (1 JRC Ctrl Bld Ctr, 2 Dept Biol Sci, Univ Tokyo, 3 Dept Hum Genet, Univ Tokyo, Tokyo)

Recently cDNAs of at least ten human natural killer (NK) cell inhibitory receptor (KIR) family genes have been described. These genes encode transmembrane proteins with two or three immunoglobulin-superfamily extracellular domains. While, in the mouse, a supergene family of type II integral membrane protein with a C-type lectin domain is identified as NK cell receptors and mapped on mouse chromosome 6 region named the NK gene complex (NKC). In this study, the KIR genes (NKAT1, 2) and the human NK-related lectin genes (NKG2A-D, CD69, etc.) were assigned on human chromosomes by modified fluorescence in situ hybridization (FISH). Biotin-labeled PCR products under $1 \mathrm{~kb}$ were used as probes. Hybridization signals were amplified using rabbit antibiotin IgG, FITC-goat antirabbit IgG, and as the third layer, Cy2-donkey antigoat IgG. The KIR genes were localized on human chromosome 19q13.4. Detected signals were disproportionately large for the size of the probes, suggesting a tandem arrangement of many genes of this gene family. All the lectin genes examined were localized on human chromosome 12p13, suggesting the presence of the human NKC in this region. 
B-10

\section{COMPLEMENTATION STUDY AND GENETIC MAPPING OF NIJMEGEN BREAKAGE SYNDROME}

Shinya MATSUURA, Hideki TAKAMI, Noriko KONDO, Hiroshi TAUCHI, Satoru ENDO, Kenshi KOMATSU (Dept. of Rad. Biol., Res. Inst. Rad. Biol. \& Med., Hiroshima Univ., Hiroshima), Mitsuo OSHIMURA (Tottori Univ,, Yonago), and $\underline{C}$. WEEMAES (Nijmegen Univ., The Netherlands)

Nijmegen breakage syndrome (NBS) is an autosomal recessive disease characterized by immunodeficiency, a high incidence of cancer, and hypersensitivity to ionizing radiation. Two complementation groups, V1 and V2, have been reported in NBS, based on restoration of RDS. We have newly established V1 cell lines using SV40 transformation. To localize the NBS gene, we have performed functional complementation assays using somatic cell fusion between NBS-V1 and NBS-V2, and then carried out a genome-wide search for NBS locus using microcell-mediated chromosome transfer, followed by complementation assays based on radiosensitivity. We found that radiation resistance was not restored in fused cells between NBS-V1 and NBS-V2. Only human chromosome 8 complements the sensitivity to ionizing radiation in NBS cell lines. Merely the long arm of chromosome 8 was sufficient for restoring the defect. Our results suggested that NBS is a homogeneous disorder, and that the gene for NBS is located at $8 \mathrm{q}$.

\section{B-11}

WISKOTT-ALDRICH SYNDROME IN THO SISTERS. Tatsuro KONDOH, Tadashi MATSUMOTO, Yoshiro TSUJI (Dept.Pediatrics, Nagasaki University School of Medicine, Nagasaki )

We report two sisters in a family representing manifestations of hiskottAldrich syndrome (WAS). The younger sister had suffered from recurrent infections, small thrombocytopenic petechiae, purpura, and eczema, and died of intracranial bleeding at age 2 years. The elder sister had the same manifestations as the younger sister's. She took Takayasu disease from 8 years old, and died of the rupture of the aorta at age 10 years. All the laboratory data of them were compatible with WAS. RT-PCR study against WASP mRNA in the elder sister's peripheral leukocytes could not be shown the abnormal sized fragment. Studies on the motherdaughter transmission of $X$ chromosome suggested that each sister had inherited a different $X$ chromosome from the mother. Sialophorin analysis revealed that in the elder sister a $115-\mathrm{KD}$ band that should be specific for sialophorin was reduced in quantity, and instead an additional $135-\mathrm{KD}$ fragment was present as a main band. PCR and SSCP analysis of the sialophorin gene demonstrated that there were no detectable size-change nor electrophoretic mobility change. Including mother-daughter transmission tests of chromosome 16, the results indicated that their sialophorin gene: structure should be normal.

Recently, it is reported that WAS protein is a novel effector for the GTPase CDC42Hs. At least two explanations are plausile for the occurrence of the WAS in our cases : our patients have an autosomal gene mutation which break the CDC42HsWASP pathway, or, altenatively, the condition in this family is an autosomal recessive disorder separated etiologically from the X-1inked WAS. 
B-12

BONE MARROW TRANSPLANTATION IN DI GEORGE SYNDROME. Masahiko NAKAYAMA, Tatsuro KONDOH, Toshimitsu TAKAYANAGI, Tadashi MATSUMOTO, Yoshiro TSUJI (Dept.Pediatrics,' Nagasaki University School of Medicine, Nagasaki )

Di George syndrome is a congenital immunodeficiency associated with defective development of the first through sixth branchial pouches, manifested clinically by peculiar facies, hypoparathroidism and hypocalcenia, congenital heart disease, and increased susceptibility to infections due to the deficiency of $T$ cell function by a/hypo-plasia of the thymus. As one of treatments, there are two reports that bone marrow transplantation (BMT) is effective to Di George syndrome patient. We report a severe type of Di Geroge syndrome patient who was treated by BMT. The patient was the $3275 \mathrm{~g}$ full-term, appropriate for gestational age male, born to unrelated parents. At birth the infant had cyanosis, and diagnosed as the severe type of Tetralogy of Fallot by cardioechogram and cardiac catheterization. Te tried chromosomal analyses twice to him, but his lymphocytes did not respond to PHA stimulation. He has clinical features consistent with $\mathrm{Di}$ George syndrome including peculiar face, hypocalcemia due to hypoparathyroidism, and reduction of the percentage of CD3,CD4 and CD8 in his peripheral 1 ymphocytes. FISH study with the chromoprobe located on CATCH 22 region showed the only one signal suggested the deletion in this region on one allele. The tendency of susceptibility to infections and his general conditions become worse. So we had to choose BMT therapy to him, bacause thymic transplantation method could not be available actually. As a conditioning and a prevension for GVHD, ATG and CyA/MIX were used, respectively. We checked whether BMT to him was succeeded or not by DNA analysis, but the result was a rejection. So, we proceed to re-BMT now.

B-13

LARGE-SCALE CHROMOSOMAL MAPPING OF HUMAN CDNA BY FISH. Masami NAGATA, Mikio SUZUKI, Ako TAKAICHI, Hiroichi SHINOMIYA, Takeshi WATANABE, Tsutomu FUJIWARA, Ei-ichi TAKAHASHI, (Otsuka GEN Res. Inst., Otsuka Pharmaceutical Co. Ltd., Tokushima) and Yusuke NAKAMURA (Lab. of Molecular Medicine, Inst. of Medical Science, The Univ. of Tokyo, Tokyo)

We have performed a single pass sequencing from fetal brain, aorta and placenta cDNA libraries to isolate novel genes responsible for genetic diseases and cancers. Chromosomal mapping is an essential step for positional candidate approach from these random cDNA sequences.

We have constructed an arrayed human genomic cosmid and BAC library, and prepared high density replica filters for colony-hybridization and DNA pools for PCR screening. Using this system, a total of 481 clones corresponding to cDNAs have been isolated and mapped by direct R-banding FISH. Among these clones, about $90 \%$ were preferentially sublocalized to $R$-positive bands, with the half of these to $T$-band regions. These results indicate that human genes are unequally distributed on chromosomal bands. 


\section{ASSIGNMENT OF THE HUMAN GLI2 GENE, GLI2, TO 21q14 BY FLUORESCENCE IN SITU HYBRIDIZATION Osamu MIYOSHI, Naomichi MATSUMOTO, Masahiro FUJIMOTO, Rumiko KATO, Norio NIIKAWA (Dept. Hum. Genet., Nagasaki Univ. Sch. Med., Nagasaki)}

GLI2 belongs to a gene family including the human oncogene, $G L I$, and its related gene, GLI3. Dusruption of GLI3 in Greig cephalopolysyndactyly syndrome (GCPS) patients suggested that this gene plays a role in limb/craniofacial development in mammals. GLI2 was localized to chromosome 2 by a human-rodent hybrid panel analysis. The present study deals with subregional mapping of $G L I 2$ by FISH. A bacterial artificial chromosome (BAC) clone, 28F13, containing GLI2, was isolated from a human BAC library by means of PCR. A set of primers for PCR was designed from the genomic GLI2 sequences. The BAC-DNA was used as a FISH probe on human R-banded metaphase chromosomes. The signals were clustered on chromosome band $2 q 14$, and no specific double-signals were observed on any other chromosomal regions, thus allowing the precise localization of GLI2 to $2 q 14$. The predicted amino acid sequences of the zinc finger regions show $89 \%$ similarity between $G L I 2$ and $G L I$, and $92 \%$ between $G L I 2$ and $G L I 3$. The GLI-family probably encodes DNA- or RNA-binding proteins which may regulate transcription and involves an important biological process. Since a GLI3 disruption results in GCPS, it is plausible that GLI2 also plays a role in the development in humans. Although no disease loci reminiscent of developmental defects have been assigned to 2 q14, once mapped to this region, patients with such a disorder may represent a GLI2 mutation.

B-15

ASSIGNMENT OF THE HUMAN CONNEXIN43 GENE, GJAI, TO 6q22.3 Rumiko KATO, Naomichi MATSUMOTO, Norio NIIKAWA (Dept. Hum. Genet., Nagasaki Univ. Sch. Med., Nagasaki)

Connexin 43 is one of connexin proteins which make up the intercellular gap junctions, and are abundantly expressed in the mammalian heart. Targeted null mutation of the mouse connexin 43 gene has been reported to be neonatally lethal due to right ventricular outlet stenosis. Moreover, single-base mutations of the human homolog (GJAI) were identified in patients with laterality defects of the chest and abdominal organs, suggesting that connexin 43 is participating in embryogenesis, cellular differentiation, and development of heart. The locus of an expressed human connexin 43 gene (GJAI) has been sublocalized to band $6 \mathrm{q} 21-\mathrm{q} 23.2$ by a study with somatic cell hybrid panel. We isolated a bacterial artificial chromosome (BAC) clone that covered almost the entire GJA1. Then, fluorescence in situ hybridization (FISH) using the $\mathrm{BAC}$ clone as a probe, and sequential G-banding on the same metaphases revealed that GJAl was assigned to chromosome $6 \mathrm{q} 22.3$. 
B-16

GENOME ANALYSIS OF HUMAN CHROMOSOME 14Q32 REGION FOR SEARCHING DISEASE RELATED GENES. Masaharu ISOBE, Jun SUGIMOTO, Hiroshi KATO, Toyomasa HATAKEYAMA (Molecular and Cellular Biology Lab., Faculty of Engineering, Toyama University, Toyama)

Band 32 region on the long arm of human chromosome 14 (14q32) contains about 10 $\mathrm{Mb}$ of genomic DNA. The region represented by this cytogenetic band is known to contain several genes of biological and medical interest such as the putative oncogene for $\mathrm{T}$-cell leukemia and the tumor suppressor gene(s) for colon and bladder cancer as well as the gene for Usher syndrome type IA. As a first step to identify those disease related genes, we have generated a physical map of the human chromosome 14 at band $\mathrm{q} 32$ by using yeast artificial chromosome (YAC) clones. The contig spanning about $8 \mathrm{Mb}$ between D14S81 and D14S250 has been assembled by STS and probe content mapping for 40 loci with average spacing of about $200 \mathrm{~kb}$. A subset of YAC clones has been used for searching transcripts from $14 \mathrm{q} 32$ region. We have isolated 18 independent cDNA clones by screening cDNA libraries using evolutionally conserved DNA fragments found in those YAC clones as probes. The several fold coverage of $14 \mathrm{q} 32$ region and isolated cDNA clones will provide a reliable resource for the searching disease related genes.

\section{B-17}

\section{LOCALIZATION OF THE HUMAN CYTOSOLIC ACETOACETYL- COENZIME A THIOLASE (ACAT2) GENE TO CHROMOSOME} 6q25.3-q26. Mitsuo MASUNO ${ }^{1}$, TOShiyuki FUKAO ${ }^{2}$, Xiang-Qian SONG ${ }^{2}$, Seili YAMAGUCHI ${ }^{3}$, Tadao ORII ${ }^{2}$, NaOmi KONDO ${ }^{2}$, Takuma ISHII ${ }^{1}$, Kiyoshi IMAIZUMI $^{1}$, and Yoshikazu KUROKI ${ }^{1}\left({ }^{1}\right.$ Div. of Med. Genet., Kanagawa Children's Med. Ctr., Yokohama; ${ }^{2}$ Dept. of Pediatr., Gifu Univ. School of Med., Gifu; and ${ }^{3}$ Dept. of Pediatr., Shimane Med. Univ., Izumo)

Previously, we have cloned the human cytosolic acetoacetylCOA thiolase (ACAT2; EC.2.3.1.9) CDNA and have found that the $3^{\prime}$ portion $(330 \mathrm{bp})$ of the sense strand sequence of the ACAT2 CDNA complementarily overlapped with the $3^{\prime}$ region of the human t-complex polypeptide-1 (TCP1) gene. As the human TCP1 gene has been assigned to chromosome 6q25-q27, the ACAT2 gene is considered to be localized to the same chromosome region. To confirm this speculation and determine the location of the ACAT2 gene more precisely, we performed FISH experiments using a CDNA probe(849-bp ECORI fragment) of the human ACAT2.

Among 117 R-banded (pro)metaphase spreads examined, 40 (34\%) exhibited 148 hybridization signals. Twenty-four signals on 17 (pro)metaphase spreads localized to 6q25.3-q26. As the majority of the signals were located on or near the distal end of 6q25.3, with some signals extending into 6q26, the most likely location of the ACAT2 gene is in $6 \mathrm{q} 25.3$. 
B-18

Precise chromosomal mapping of 280 unidentified human genes by FISH and use of radiation hybrid panels.

Naohiko SEKI, Takahiro NAGASE, Ken-ichi ISHIKAWA and Nobuo NOMURA (Gene Strucrute I, Kazusa DNA Research Institute, Chiba)

We have isolated a total of 280 unidentified full-length cDNA clones with relatively long sizes from human immature myeloid cell line KG-1 and human brain, and analyzed their sequence feature as well as expression profiles in various human tissues. The chromosomal assignment of these clones has also been made by scoring segregation patterns of PCR products in human-rodent somatic cell-hybrid DNA. We now determined more precise chromosomal location of $\mathbf{2 8 0}$ genes by fluorescence in situ hybridization (FISH) or by the use of radiation hybrid panels. The mapping data will provide valuable resources for gene hunting in the human gemonic regions where disease-related linkages are suggested or being pursued.

\section{B-19}

FINE REGIONAL MAPPING OF HUMAN CHROMOSOME 2q12-q14 WITH 36 COSMID MARKERS BY FISH. Momoki HIRAI, Fumio KASAI,(Dept. Biol. Sci., Tokyo Univ., Tokyo), Yumiko SUTO (Japan Red Cross Blood Ctr.), Kumiko KOYAMA, Yusuke NAKAMURA (Inst. Med. Sci., Tokyo Univ., Tokyo) and Ei-ichi TAKAHASHI (Ohtsuka Gen Inst., Tokushima)

The order of 36 cosmid markers derived from human chromosome 2q12-q14 was exactly determined by high-resolution fluorescence in situ hybridization (FISH). This. region includes the telomere-to-telomere fusion point of two ancestral ape-type chromosomes. These clones were hybridized to R-banded chimpanzee chromosomes. Seventeen centromeric clones were located to chimpanzee chromosome $12 \mathrm{p}$, while 19 telomeric clones were located to chimpanzee chromosome 13p. The order of clones in each chimpanzee chromosome was identical to that in human chromosome 2. This highresolution mapping, therefore, contributes not only to genetic mapping but also to the dating of chromosomal reorganization that might have occurred in primate evolution. 
B-20

PARTIAL GENOMIC STRUCTURE OF THE HUMAN DNA-PKCS GENE THAT COMPLEMENTS HYPER-RADIOSENSITIVITY OF THE SCID MUTATION. Masahiro FUJIMOTO, Naomichi MATSUMOTO, Norio NIIKAWA (Dept. Hum. Genet., Nagasaki Univ. Sch. Med., Nagasaki) and Kenshi KOMATSU (Dept. Radiat. Biol., Res. Inst. Radiat. Biol. Med.. Hiroshima Univ., Hiroshima)

Murine severe combined immunodeficiency (scid) is an autosomal recessive disorder characterized by a lack of functional $\mathrm{B}$ and T lymphocytes due to a failure of $V(D) J$ recombination activity and hyper-radiosensitivity due to a failure of DNA double-strand break repair. We previously mapped the putative human gene for hyper-radiosensitivity that is complementary to the murine scid to human chromosome $8 \mathrm{q} 11.1$ by fluoresence in situ hybridization (FISH) using human-scid mouse radiation cell hybrids. The human DNA-dependent protein kinase catalytic subunit gene (DNA-PKCS) is a strong candidate which complements the scid mutation and its huge cDNA $(13.4 \mathrm{~kb})$ has been cloned. In our previous study we isolated by a CEPH-YAC library screening 3 yeast artificial chromosome (YAC) clones covering DNA-PKCS. We subcloned the YACs to cosmid clones cotaining $5^{\prime}-D N A-P K C S$. From the cosmid clone sequences, we identified the first 10 intron-exon boundaries of $D N A-P K C S$ with a primer walking strategy. The length of the 10 exons is from $3 \mathrm{lbp}$ to $206 \mathrm{bp}$ and an average length $103 \mathrm{bp}$. The sequen -ces of the 10 exons matched exactly those of the corresponding cDNA. Predicted intron-exon boundaries fit well with the GT-AG rule for splice site selection.

\section{B-21}

MOLECULAR ANALYSIS OF THE ENDPOINT OF THE COMMON LARGE DELETION IN CATCH22. Hiroki KURAHASHI ${ }^{1,2}$, Takahiro NAKAYAMA ${ }^{1}$, Shintaro OKADA ${ }^{2}$, and Isamu NISHISHOl. ('Dept. Med. Genet., 2Dept. Pediatr., Osaka Univ. Med. School., Osaka)

CATCH22 patients are known to show marked phenotipic variability, although the extents of $22 \mathrm{q} 11$ deletion are uniform. It is suggested that at both ends of the deletion there lies region specific repetitive sequence prone to deletion. We firstly analyzed YAC y 966 A 8 which should contain the proximal end, resulting that critical region is revealed to be deleted in the YAC. Then, y849E9 which should contain the distal end was subcloned into cosmids and analyzed by FISH and Southern hybridization. Approximately half of the cosmids were single copy and located out of the common large deletion. The other half were found to contain $22 q 11$ specific multicopy sequences. FISH analysis on various translocated chromosomes showed that their homologous regions are located near the proximal end. It is suggested that these $22 q 11$ specific repetitive sequences are related to development of the common large deletion. However, no cosmids showed apparent rearranged bands in patients with deletion. In this region, we identified a VNTR whose homologous region is also located near the proximal end. Detailed analysis of the vicinity of the VNTR revealed that some of patients have rearrangement in the VNTR. It is strongly suggested that this VNTR should be related to development of some types of CATCH22 deletion. 
B-22

CONSTRUCTION OF BAC/COSMID CONTIGS FOR THE CAT EYE SYNDROME CHROMOSOME REGION (22q11) Shinsei MINOSHIMA, Shuichi ASAKAWA, Kazuhiko KAWASAKI, Yimin WANG, Jun KUDOH and Nobuyoshi SHIMIZU (Department of Molecular Biology, Keio University School of Medicine, Tokyo)

Cat eye syndrome (CES) is caused by partial tetrasomy of the $22 q 11$. The morphological anomalies in CES include coloboma of the eye and characteristic heart malformation (totally anomalous pulmonary venous return). Most (>90\%) of the CES patient has a supernumerary bisatellited marker chromosome [22pter-q11::22q11-pter] consisting of two copies of the 22 pter-q11 region. We have constructed BAC/cosmid contigs of the CES chromosomal region to facilitate isolation of the disease-causing genes.

As DNA resources, we used a CES region-specific cosmid library from the flowsorted marker chromosomes of a CES cell line (Minoshima et al., this meeting last year) and a BAC library from human total DNA (Asakawa et al., in this meeting). A number of STS's were established from cosmid clones and used to screen CEPH YAC library. Twenty YAC clones were identified and arrayed into a YAC contig. Thus, these YAC clones were used as probes to screen the CES cosmid library and BAC library, and 1,740 cosmids and 98 BAC clones were isolated. To construct $\mathrm{BAC} /$ cosmid contigs, the vectorette PCR method and finger printing have been applied. To date, 9 contigs consisting of $25 \mathrm{BAC}$ clones and 24 cosmid clones have been constructed covering over $1.3 \mathrm{Mb}$. Genomic sequencing of one cosmid clone $(36,226 \mathrm{bp})$ has been completed and other clones are in progress. The genomic sequence information is being used to identify the CES-causing genes.

B-23

A TRANSCRIPT MAP OF THE CANDIDATE GENES IN THE DOWN SYNDROME CRITICAL REGION OF HUMAN CHROMOSOME 21 . Nobuyoshi SHIMIZU', ${ }^{\text {Nobuaki SHINDOH }}{ }^{1}$, Hideto MAEDA ${ }^{1}$, Akiko YAMAKI ${ }^{2}$, Kazuhiko KAWASAKI ${ }^{\prime}$,

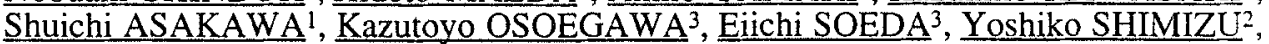
Shinsei MINOSHIMA', and Jun KUDOH'. 'Dept. Mol. Biol., Keio Univ. Sch. Med., Tokyo, ${ }^{2}$ Dept. Clin. Genet., Sch. Health Sci., Kyorin Univ., Tokyo, and ${ }^{3}$ RIKEN. Tsukuba Life Sci. Ctr., Tsukuba.

To isolate genes potentially involved in the pathogenesis of Down syndrome, we have performed exon trapping for the "Down syndrome critical region". We have isolated over 100 exons including those from known human genes and homologs of Drosophila singleminded (sim) and minibrain ( $m n b)$ genes. These genes locate in the order of cen-SIM2HCS-TPRD-MNB-KCNJ6-ERG-tel. Drosophila sim and $m n b$ genes are required for development of central nervous system. The structural characteristics of human and mouse SIM2 proteins that contain bHLH and PAS domains and expression in the diencephalon during mouse embryogenesis strongly suggest that SIM proteins function as a transcriptional regulator in the development of the central nervous system. Human MNB CDNA encodes a protein kinase with a nuclear targeting signal and a catalytic domain highly homologous to Drosophila mnb protein kinase and strikingly resembles the rat Dyrk protein kinase with a dual specificity. The MNB mRNA is expressed in various tissues including fetal and adult brains. These results implicate that human MNB protein may play a significant role in a signaling pathway regulating nuclear functions of neuronal cell proliferation, contributing to certain features of Down syndrome. 
B-24

HUMAN BAC LIBRARY: ITS APPLICATION TO MAPPING OF 21q22.3 AND ISOLATION OF DISEASE GENES. Shuichi ASAKAWA, Izumi ABE, Yoshiki KUDOH, Kentaro NAGAMINE, Yimin WANG, Kazuhiko KAWASAKI, Jun KUDOH, Shinsei MINOSHIMA, and Nobuyoshi SHIMIZU (Department of Molecular Biology, KeioUniversity School of Medicine, Tokyo)

We have constructed a human genomic BAC library using a human pre-pro-B cell line. This BAC library consists of 96,000 clones with an average DNA insert size of $110 \mathrm{~kb}$, covering the human genome approximately 3 times. We have established three different screening systems: 1) Probe hybridization to 31 high density replica (HDR) filters: each filter contains 3,072 BAC clones which were gridded in a $6 \times 6$ pattern, 2) Probe hybridization to 2 Southern blot filters each containing 31 Hind III digests of the pooled 3,072 BAC clones. This identifies a particular HDR filter for further probe hybridization, and 3) Two step-polymerase chain reaction (PCR): First PCR is applied to 10 DNA samples from superpools of 9,600 BAC clones to identify a particular superpool and the second PCR applies to 40 DNA samples from 4 dimensionally assigned $B A C$ clones. The two step PCR screening is particularly powerful since it allows us to isolate a desired BAC clone(s) within a day or so. The BAC clones are very useful to construct long range contigs and to utilize starting as a material of sequencing analysis. As a typical example of BAC application, the analysis of 21 q22.3 has been presented.

B-25

CHROMOSOMAL LOCALIZATION OF A PSEUDOAUTOSOMAL GROWTH GENE(S). Tsutomu OGATA $(1,2)$, Koji MUROYA $(1,2)$, Yoshimitsu FUKUSHIMA (3), Maki FUKAMI (2,4), Gudrun RAPPOLD (4), Nobutake MATSUO (2)

(1, Department of Pediatrics, Tokyo Electric Power Hospital; 2, Department of Pediatrics, Keio University School of Medicine; 3, Department of Hygiene and Medical Genetics, Shinshu University School of Medicine: 4, Department of Human Gnetics, Heidelberg University)

The XP/Yp pseudoautosomal region (PAR) carries a pseudoautosomal growth gene(s) ( $P$-growth gene). To localize the P-growth gene(s), we correlated stature with pseudoautosomal genotype in eight Japanese and eight Caucasian non-mosaic patients with partial monosomy of the PAR. The stature was assessed by the comparisons with the race-specific population standards and with the parental heights. The pseudoautosomal genotype was determined for a total of 15 loci by Southern blotting and FISH analysis. Eight patient missing a region between DXYS60-DXYS15 in the distal part of the PAR had definite short stature, whereas four patients preserving the region were normal in height (the remaining four patients were borderline in height and, therefore, excluded from the genotype-phenotype correlations). The results suggest that the P-growth gene(s) is localized to the approximately $350 \mathrm{~kb}$ region defined by DXYS60 and by DXYS15. At present, the positional cloning approach is under progress for the P-growth gene(s). 
B-26

CHROMOSOMAL LOCALIZATION OF A GENE FOR NON-SPECIFIC X-LINKED MENTAL RETARDATION AT Xp22.3. Maki FUKAMI $(1,2)$, Koji MUROYA (1,3), Nobutake MATSUO (1), Hirofumi OHASHI (4), Yoshimitsu FUKUSHIMA (5), Toshiro NAGAI (6), Gudrun RAPPOLD (2), Tsutomu QGATA (1,3) (1, Department of Pediatrics, Keio University School of Medicine; 2, Department of Human Gnetics, Heidelberg University; 3, Department of Pediatrics, Tokyo Electric Power Hospital; 4, Division of Medical Genetics, Saitama Children's Medical Center; 5, Department of Hygiene and Medical Genetics, Shinshu University School of Medicine; 6, Department of Neurology and Medical Genetics, Tokyo Metropolitan Kiypse Children's Hospital)

A gene for non-specific X-linked metal retardation (MRX) has been assigned to the Xp22.3 region. To localize the MRX gene(s), we carried out genotype-phenotype correlations in 13 male patients with partial nullisomy of the X-differential region at Xp22.3. The mental status was assessed by IQ, DQ, and daily life performance. The genotype was determined for a total of 26 loci by PCR and FISH analysis. Three patients missing a region between DXS996 and DXS6834 had obvious mental retardation, whereas the remaining ten patients preserving the regionwere normal in intelligence. The results suggest that the MRX gene is localized to the approximately $500 \mathrm{~kb}$ region between DXS996 and DXS6834. At present, the positional cloning approach is under progress for theMRX gene.

\section{B-27}

TURNER SOMATIC STIGMATA: PATHOGENIC ANALYSIS AND CHROMOSOMAL LOCALIZATION OF THE RELEVANT LYMPHOGENIC GENE(S). KojiMUROYA $(1,2)$, TsutomuOGATA $(1,2)$, TomonobuHASEGAWA (2), Nobutake MATSUO (2) (1, Department of Pediatrics, Tokyo Electric Power Hospital; 2, Department of Pediatrics, Keio University School of Medicine)

Turner syndrome is associated with characteristic surface and visceral somatic anomalies. Here, we propose that the characteristic Turner stigmata are caused by lymphatic hypoplasia, and attempt to localize the relevant lymphogenic gene(s).

[Lymphatic hypoplasia and Turner somatic stigmata] Turner syndrome is accompanied by lymphatic hypoplasia. Lymphatic hypoplasia causes lymph fluid stasis and resultant distended lymphatics and lymphedema, exerting a mechanical force on the adjacent tissues and organs. Thus, it is hypothesized that Turner somatic stigmata are deformations explained as a malformation sequence initiated by lymphatic hypoplasia. Indeed, Turner somatic anomalies are found in the regions susceptible to the mechanical force initiated by lymphatic hypoplasia.

[Chromosomal localization of the lymphogenic gene(s)]

It has been usggested that the lymphogenic gene(s) for Turner stigmata is shared by Xp and $Y p$, and haploinsufficiency of the gene(s) results in the development of Turner stigmata. To localize the lymphogenic gene(s) on $Y p$, wesummarized geneotype-phenotype correlations in 18 patients with a partial Yp deletion. The results suggest that the lymphogenic gene(s) for Turner somatic stigmata is present in the ZFY-DYS255 region (about $4 \mathrm{Mb}$ in size) in the distal part of Yp. 


\title{
B-28
}

\author{
GENE EXPRESSION OF A NOVEL LOCUS ON THE X CHROMOSOME WHICH \\ ESCAPES METHYLATION INACTIVATION IDENTIFIED BY TWO- \\ DIMENSIONAL ELECTROPHORESIS OF HUMAN DNA. IUn-ichi ASAKAWA, \\ Mieko KODAIRA Masaaki IMANAKA, Satomichi KANEOKA, Takahiro TSUJI, \\ Eiko NISHIKORI, Chiyoko SATOH (Dept. Genet. Radiation Effects Research \\ Foundation, Hiroshima)
}

We have implemented a computer based approach for the analysis of two-dimensional patterns of genomic restriction fragments derived from six mother/father/child trios. We have also undertaken studies of genetic variation which distinguish quantitatively between one- and two-copy fragments. The use of a methylation sensitive cutter for the first dimension separation allows studies of genomic DNA methylation and the identification of novel loci on the $\mathrm{X}$ chromosome which escape methylation inactivation. A separate fragment, termed spot 369 , was observed as a one-copy spot in male samples, while always as a two-copy spot in female samples. We believe that the NotI site of spot 369 on the X chromosome is not methylated on either $\mathrm{X}$ in females and thus escapes methylation inactivation. We have cloned a $3.5-\mathrm{kb} N o t / E c o R V$ fragment corresponding to this spot. The cloned DNA fragment was mapped to Xp11.4 by FISH analysis. We also cloned and sequenced the $6.5-\mathrm{kb} E c o$ RV DNA fragment which contained the NotI sites. There was no identical sequence in the DNA data base. Only a few loci have been described on the X chromosome that escape inactivation and have no homologues on the $Y$ chromosome. We have studied the gene expression of this novel locus. We will present preliminary results of a Northern blotting and a cDNA library screening.

\section{B-29}

NOVEL POLYMORPHIC MARKER DXYS241 ON THE X-Y HOMOLOGOUS PORTION OF THE HUMAN Y CHROMOSOME AND APPLICATIONS OF ITS POLYMORPHISM. Svetlana E. KOTLIAROVA (Dept. Hum. Genet., Univ. of Tokyo and MEDIGEN Laboratory, Novosibirsk, Russia), Tatsushi TODA, Ikumi MATSUSHITA, Katsushi TOKUNAGA, Yasuo NAKAGOME, Yutaka NAKAHORI (Dept. Hum. Genet., School of Int.Health, Univ. of Tokyo)

$Y$ chromosome is unique because it represents the patrilineal contribution to the male genome. $X-Y$ homologous non-recombining portion of $Y$ chromosome is especially interesting in respect that it can provide information both on the male-specific gene flow and on the sex chromosome evolution studies. However, the number of polymorphic markers developed on this portion of $Y$ chromosome is still scarce. Hereby we present a new polymorphic (CA)n microsatellite marker DXYS241 developed on the nonrecombining portion of $X-Y$ homologous region of $Y p 11$. The alleles at this locus are found to be associated with sex chromosomes. Three differences were detected between $\mathrm{Y}$ and $\mathrm{X}$ chromosome-specific alleles, allowing sex-chromsome-specific allele amplification. The marker was polymorphic in three examined ethnic groups: Japanese, US Caucasians and US Negroids. A total of 13 different alleles and 27 genotypes are detected in the studied 136 individuals. Among the Y-chromosome specific alleles population-associated alleles are revealed. DXYS241 can be applied for a variety of purposes: for tracing male-specific background; for haplotype construction on the human Y chromosome and for sex determination. It is potentially useful informative marker for forensics and for other genetic studies. 
B-30

ANALYSIS OF THE $X-Y$ HOMOLOGOUS REGION SURROUNDING THE AMELOGENIN GENE. Ayuchi TSUBOI, Bunkichi TSUNEKAWA, Akiko HIDA, Ikumi MATSUSHITA, Tatsushi TODA, Katsushi TOKUNAGA and Yutaka NAKAHORI (Dept. Hum. Genet., Univ. of Tokyo, Tokyo)

It has been proposed that the human sex chromosomes evolved from a pair of homologous autosomes which eventually became different in structure from each other. However, there are a number of regions on these sex chromosomes that retain homology, and genes that were conserved on the $Y$ chromosome may exist in these $\mathrm{X}-\mathrm{Y}$ homologous regions.

The amelogenin gene is located in one of the X-Y homologous regions; Xp22.2 and $Y p 11.2$. Since several disease genes are located in the $X p 22.2-22.3$ region, we are aiming to clone novel genes from the region surrounding the amelogenin gene.

The 540kb Y-derived YAC (CEPH 235F3) that contains the amelogenin gene has $2 \mathrm{CpG}$ islands, and by utilizing them as markers for screening the cDNA library, several clones were obtained. Sequence analysis of these clones showed that a clone from one of the $\mathrm{CpG}$ islands is highly homologous to the endogenous retrovirus, and the clone from the other $\mathrm{CpG}$ island contained a $1 \mathrm{~kb}$ open reading frame. The latter clone may be a novel gene, and further analysis, including the existence of a homologue on the $\mathrm{X}$ chromosome, is under way.

\section{B-31}

A POLYMORPHISM IN THE EXON OF THE SRY GENE AND HAPLOTYPING OF THE Y CHROMOSOME IN JAPANESE. Keiko TOMITA, Tatsushi TODA, Aoi JO, Katsushi TOKUNAGA, Yasuo NAKAGOME, Yutaka NAKAHORI (Dept. Hum.Genet.,Univ. of Tokyo, Tokyo) and Toshikatsu SHINKA (Dept.Pediat., Tohoku Univ.,Sendai)

We described a new substitution polymorphism in the coding sequence of the testis determining gene SRY. The frequency of the new allele in Japanese was 30\%, which was almost the same as in Korean, whereas it was not observed among Caucasians and Negroes. The combination analysis with the other two polymorphic loci on the $\mathrm{Y}$ chromosome indicated that the base substitution occurred before the rise of $\mathrm{Y} 2$ allele of DXYS5Y and after the branching of the YAP(+) and YAP(-) alleles of DYS287. Since the Y2 allele is geographically restricted to the narrow regions of east Asia, the SRY polymorphism may contribute to the exploration of the origin of Japanese. 
B-32

ANALYSIS OF DELETED REGION ON Y CHROMOSOME LONG ARM IN AZOOSPERMIC PATIENTS. Yoko KUROKI, Rie KOMAKI, Kazuhiro KOBAYASHI, Jing ZHANG, Tatsushi TODA, Yasuo NAKAGOME, Katsushi TOKUNAGA, Yutaka NAKAHORI (Dept. Hum. Genet., Univ. of Tokyo, Tokyo) Mikio NAMIKI (Dept. Urol., Kanazawa Univ., Ishikawa) Teruaki IWAMOTO (Dept. Urol., St. Marianna Univ., Kanagawa)

We have previously reported the results of patient analysis with either azoospermia or oligozoospermia whose Y chromosomes were cytogenetically normal. The results by Southern hybridization and PCR showed a common interstitial microdeletion involving DYS7C and DYS 1 loci on the long arm of the Y (Yq) in almost one tenth of the patients. Recently, two candidate genes for azoospermia have been cloned from the azoospermic factor $(\mathrm{AZF})$ region on $\mathrm{Yq}$, but a point mutation of these genes has not been detected in patients. Interestingly, although these patients seem to possess common micro-deletion in the same region, they exhibit different phenotypes. Therefore we assume that the region around the breakpoint is critically important for spermatogenesis. We made the restriction map of a YAC clone (yOX21) spanning the proximal breakpoint, and as a result, we recognized the distance between DYS7C and the breakpoint to be not more than $260 \mathrm{~Kb}$. Using the cosmid library prepared from the YAC, we are currently constructing the cosmid contig covering the proximal breakpoint.

B-33

DETECTION OF SEX SPECIFICALLY EXPRESSED GENES USING DIFFERENTIAL DISPLAY. Sumiyo MORITA, Tatsushi TODA, Katsushi TOKUNAGA, and Yutaka NAKAHORI (Dept Hum. Genet, Univ. of Tokyo, Tokyo) and Taku IIDA (Dept. Obstet. and Gynecol, Univ. of Tokyo, Tokyo)

In human, development into males is determined by the presence of the $Y$ chromosome. The testis determining factor SRY was cloned in 1990. After that, several genes have been proposed as factors for sex determination or sex differentiation, although the function and the relationship between each factor are yet unknown. Recently it has been supposed that the different species have their own mechanism of sex determination, and even in mammals the scheme may not be completely the same. The sex determination of human is thought to occur at the 7 weeks of gestation. To elucidate the sex determining path in human, we used the Differential Display technique to detect the differential transcripts between male and female in the crucial period. Currently, several mRNAs are supposed to be differently expressed and the clones are investigated. 


\section{B-34}

Developmental genetic analysis of mouse neurological mutant, quaking; Identification of responsible gene, $q k I$.

${ }^{1}$ Kuniya Abe, ${ }^{1}$ Tatsuya Kondo, ${ }^{1}$ Tadashi Kaname, ${ }^{2}$ Tom Ebersole, ${ }^{2}$ Karen Artzt, ${ }^{1}$ Ken-ichi Yamamura ${ }^{1}$ Inst. of Molecular Embryology \& Genetics, Kumamoto Univ. School of Medicine, Kumamoto 862, Japan; ${ }^{2}$ Dept. of Zoology, Univ. of Texas at Austin, Tx78712, USA.

Mouse quaking ( $q k$ ) mutation is a pleiotropic locus required for myelination, embryogenesis, and spermiogenesis. After detailed structural characterization of the $q k$ genomic region, a strong candidate gene for $q k$ mutation has been found adjacent to the deletion break point in the $q k^{p}$ mutant genome, and designated as $q k I$. This gene encodes a putative RNA binding protein, and show predominant expression in myelinating brain and in embryos. However, $q k I$ gene itself is not structurally altered in the mutant genome, and also the level of expression is not changed from normal mice. In order to formally prove that $q k I$ is the responsible gene for $q k$ mutation, we have produced $q k I$ gene knockout mice. It was found that double heterozygote mice for $q k^{v}$ and this qKI-KO allele indeed developed tremor, unambiguously demonstrating 'hat the association of the $q k I$ gene with the quaking neurological phenotype.

\section{B-35}

FUNCTIONAL ANALYSIS OF MOUSE NEUROLOGICAL MUTANT, quaking.

${ }^{1}$ Tadashi KANAME, ${ }^{1}$ Tatsuya KONDO, ${ }^{2}$ Tom EBERSOLE, ${ }^{1}$ Mako MORIYAMA 2 Karen ARTZT ${ }^{1}$ Ken-ichi YAMAMURA and ${ }^{1}$ Kuniya ABE. ('Inst. of Molecular Embryology \& Genetics, Kumamoto Univ. School of Medicine, Kumamoto 862, Japan; ${ }^{2}$ Dept. of Zoology, Univ. of Texas at Austin, Tx78712, USA.)

Mouse quaking ( $q k$ ) mutation is a pleiotropic locus required for myelination, embryogenesis, and spermiogenesis. The mouse quaking is thought as a model of one type of dysmyelinating disorder. Recently, a strong candidate gene for $q k$ mutation has been found adjacent to the deletion break point, and designated as qkI (Ebersole et al. Nature Genetics 12, 260-265, 1996).

This qkI gene is expressed three types of mRNA caused by alternative splicing. The gene encodes a putative RNA binding protein with homology to human Srcassociated protein Sam 68 . To know function of its product, we have produced qkI gene knockout mice by inserting IRES-ßgeo into a highly conserved domain of the gene. It was found that compound heterozygote mice for $q k^{v}$ and this qKI-KO allele indeed developed tremor, directly demonstrating the association of the qkI gene with the quaking phenotype. Besides, the gene was expressed neural tissues and heart during embryogenensis from 8.5 day of pregnancy and in adult. qkI gene was also expressed during myelin formation in the brain. myelination.

Thus, we concluded that the $\mathrm{qkI}$ gene product plays an important role during 
B-36

LINKAGE MAPPING OF CHARCOT-MARIE-TOOTH DISEASE TYPE 2A (CMT2A)TO CHROMOSOME 1p. Masaaki. SAITO1, Yasuko. HAYASHI', Takashi. SUZUKI2, Haiime. TANAKA' and Shoji. TSUJI1. (1; Dept. Neurol. Brain Research Inst., Niigata Univ., Niigata. 2; Dept. Neurol., Toyama Central Hospital, Toyama.)

Charcot-Marie-Tooth disease type2 (CMT2) is a genetically heterogeneous disorder with at least two loci identified; 4 families with CMT2A (1p35-36) and 1 family with CMT2B (3q13-22). By the linkage analysis of 2 Japanese CMT2 families (family 693 and family 694), the highest multipoint lod scores of 2.01 at D1S244 and 1.93 at D1S228 were obtained for family 694 and family 693, respectively, and the highest cumulative multipoint lod score of 3.69 was obtained at D1S244. Obligate recombination events at D1S160 and D1S228 as well as the multipoint linkage analysis indicate that the gene for CMT2A is likely to be localized within a $14.7 \mathrm{cM}$ region as a $95 \%$ confidence interval. Clinical characteristics of the two CMT2A families include the following; 1) the posterior tibial muscles are often as severely involved as the anterior tibial muscles, 2) generalized areflexia is infrequent, 3) peripheral nerves are not clinically thickened and 4) sensory loss is infrequent.

\section{B $\sim 37$}

MUTATIONS IN THE TRKA /HIGH AFFINITY NGF RECEPTOR GENE IN PATIENTS WITH CONGENITAL INSENSITIVITY TO PAIN WITH ANHIDROSIS. Yasuhiro INDO, Motoko TSURUTA, Yumi HAYASHIDA, Md Azharul KARIM, Kohji OHTA, Tomoyasu KAWANO, Hiroshi MITSUBUCHI, Ichiro MATSUDA (Dept. Pediat., Kumamoto Univ., Kumamoto), Hidefumi TONOKI (Dept. Pediat., Hokkaido Univ., Sapporo), and Yutaka AWAYA (Dept. Pediat., Seibo Hospital, Tokyo)

Congenital insensitivity to pain with anhidrosis (CIPA) is an autosomal-recessive disorder characterized by recurrent episodes of unexplained fever, anhidrosis (absence of sweating) and absence of reaction to noxious stimuli, self-mutilating behavior, and mental retardation. The genetic basis for CIPA is unknown. Nerve growth factor (NGF) induces neurite outgrowth and promotes survival of embryonic sensory and sympathetic neurons. Mice lacking the gene for TrkA, a receptor tyrosine kinase for NGF, share dramatic phenotypic features of CIPA, including loss of responses to painful stimuli, although anhidrosis is not apparent in these animals. We therefore consider the human TRKA homologue as a candidate for the CIPA gene. The mRNA and genomic DNA encoding for TRKA were analyzed in three unrelated CIPA patients who had consanguineous parents. We detected a deletion-, splice-, and a missense-mutation in the tyrosine kinase domain in these three patients. Our findings strongly suggest that defects in TRKA cause CIPA and that the NGF-TrkA system has a crucial role in the development and function of the nociceptive reception as well as establishment of thermoregulation via sweating in humans. These results also implicate genes encoding other TRK and neurotrophin family members as candidates for developmental defect(s) of nervous system. 
B- -38

A de novo insertional mutation of the $\mathrm{P} 0$ gene in a patient with congenital hypornyelination neuropathy.Naoki KOSUKA,Nobutada Tachi(Sch.of Health Sci.,Sapporo Med.Univ.,Sapporo), Kazuhiro OHYA,Shunzo CHIBA(Dept.of Pediatr., Sapporo Med. Univ.,Sapporo), and Sumimasa YAMASHITA(Kanagawa Children's Med.Center of Yokohama,Kanagaea)

We present a patient that corresponds to a diagnostic criteria of congenital hypomyelination neuropayhy(CMT type 3)and disclosed a de novo insertional mutation of the $\mathrm{PO}$ gene.This case was 8-year-old-boy.He had been normal pregnancy and delivery.His motor function and milestones were retarded by muscle hypotonia. At 4 year, he could walk with support.Physical examination revealed the patient to be well nourished and in a normal mental state,but he had mild hypotonia with predominantly distal muscle weakness.He showed Gower's sign.There were no signs of celebellar dysfunction.In gene analysis, the patient showed no CMT1A duplication within the chromosome 17p11.2-12 by Southern blot hybridization of Mspl digested genomic DNA with probe pVAW409R3. By heteroduplex analysis of exon 4 in P0 gene, a heteroduplex band was detected in the patient but not in his parents.

Direct nucleotide sequence determination was identified a GGCA insertion at position between nucleotide 560 and 561.This mutation was not identified in his parents. This is a first case of congenital hypomyelination neuropathy who had a de novo insertional mutation of the $\mathrm{PO}$ gene.

B-39

CLINICAL AND MOLECULAR GENETIC STUDY OF JUVENILE MYOCLONIC EPILEPSY. Miyako OGUNI,Hirokazu OGUNI,Kayoko SAITO,Makiko OSAWA (Dept. Pediatr,Tokyo Women's Medical College,Tokyo),Naoyuki KAMATANI (Dept. Rheumatology), Yukio FUKUYAMA(Pediartric neurological institute), Tetsuro MIKI, Koujin KAMINO(Dept. Internal Med, Osaka university, Osaka)

Juvenile myoclonic epilepsy(JME) is the most well established syndrome among the idiopatheic epilepsies. JME aggregates in families, but the exact mode of inheritance remains unknown. Segregation analysis has been undertaken since Greenberg et al. first reported an evidence favoring linkage of a locus predisposing to JME to the HLA region of chromosome 6p. Subsequently, Liu et al. showed that an epilepsy locus existed on chromosome 6p21.2-p11. We conducted pairwise linkage analysis of JME families as a means of assessing autosomal recessive inheritance.

The diagnosis was confirmed by the clinical and EEG findings in 8 families. Family members were typed for 11 polymorphic loci on chromosome 6p. The maximum lod score in this region was 3.3. Further investigation with a larger number of families is planed to confirm whether chromosome 6p21.2-p11 is a genetic locus of JME. 


\title{
B-40
}

\author{
Induction of NAIP mRNA in the brain produced by middle cerebral artery occlusion in \\ rat. \\ Hitoshi OSUGA, Harumi SAKAI(JRDC/Canada Int'l Research Exchange Program), Yukito \\ SHINOHARA(Department of Neurology Tokai University School of Medicine), Joh-E IKEDA(The \\ institute of Medical science Tokai University School of Medicine)
}

\begin{abstract}
$<$ Introduction $>$ Neuronal apoptosis inhibitory protein (NAIP) presumed to have a strong relations to neuronal cell death in various conditions. The purpose of our study is to evaluate the expression of NAIP mRNA in rat focal brain ischemia model (middle cerebral artery model, MCA occlusion), topologically and chronologically. $<$ Materials and Methods $>$ Eight SD rats were anesthetized by $2 \%$ halothane and MCA occlusion was made by Tamura's method. The brain was removed $0,1,3$ and 24 hours after occlusion and frozen at $-40^{\circ} \mathrm{C}$. Brains were stored at $-80^{\circ} \mathrm{C}$. Ten $\mu \mathrm{m}$ thick coronal brain sections were cut by cryo-microtome through the MCA territory. Digoxigenin(DIG)-labeled RNA probe was designed by targeting NAIP mRNA sequences including BIR domain conserved in other IAP(inhibitor of apoptosis) families. Hybrid RNA probe was detected by using DIG-label in-situ hybridization method. NAIP was also stained by immunohistochemical method. $\langle$ Results $>$ Fine signals were observed symmetrically in cortex and striatum in normal brain. Clear signals were seen 1 hour after occlusion in infarct and penumbra-area (adjacent to the infarct area). Three hours later occlusion, the intensity of signals were increased and extended in injured hemisphere. Although signals were disappeared in the core of infarction, The signal was apparently demonstrated in penumbra-area and a part of contralateral hemisphere. The development of NAIP was not clearly correlate with that of NAIP mRNA. <Conclusion> NAIP mRNA was induced by ischemic stress in rat brain. NAIP presumed to be necessary for insulted neuronal cells to survive, because the expression of NAIP mRNA was prominent in penumbra.
\end{abstract}

B-41

DIFFERENT ORIGINS OF EXPANDED CAG REPEATS IN DENTATORUBRAL AND PALLIDOLUYSIAN ATROPHY AND HAW RIVER SYNDROME. HirokO YANAGISA WA $^{1,2}$, Shigeo NAGAFUCHI', Yutaka NAKAHORI ${ }^{2}$ \& Masao YAMADA'. ('Natl. Children's Med. Res. Ctr., 3-35-31, Taishido, Setagaya, Tokyo $154,{ }^{2}$ Dept. of Human Genetics, Univ. of Tokyo)

Dentatorubral and pallidoluysian atrophy (DRPLA) is an autosomal dominant neurodegenerative disorder, and has been shown to be due to an expanded trinucleotide repeats in a coding region of the DRPLA gene located on 12p13.31. The prevalence of DRPLA is quite low in Europeans compared to the Japanese population. Outside Japan, however, 8 DRPLA kindreds were so far detected by molecular analysis. Haw River Syndrome (HRS) which occurs in a large AfricanAmerican family residing in rural areas of North Carolina has also shown to be caused by expansion of the same repeat as DRPLA. Although the two disorders show similar clinical observations, some differences are noted including the absence of genetic anticipation in HRS and the presence of extensive subcortical white matter demyelination, basal ganglia calcifications and neuroaxonal dystrophy in HRS. We have been analyzing haplotypes around the DRPLA gene and repeats number in a various of DNA samples. All the expanded repeats of DRPLA patients in Japan and of two Caucasian DRPLA kindreds were exclusively associated with the A1-B1 haplotype, suggesting a unique origin for expanded DRPLA repeats (Yanagisawa et al. Hum. Mol. Genet. 5, 373-379, 1996). We have now analyzed three additional Caucasian DRPLA kindreds, which confirms the previous observation. In contrast, the HRS patients have expanded repeats on chromosomes with a different haplotype (A1-B2). This indicates a second predisposing haplotype in Africans as in the case of myotonic distrophy. 
$B-42$

MOLECULAR GENETIC DIAGNOSIS OF SPINAL MUSCULAR ATROPHY. Yumi SHIRAIWA, Kayoke SAITO, Haruko SUZUKI, Keiko SHISHIKURA, Makiko OSAWA, Xukie EUKUYAMA (Dept. Pediatri. ,Tokyo Women's Medical College,Tokyo), lo-EIKEDA (Institute of Molecular Science, Tokai University, Kanagawa), Hiroyosdi KOIDE (Dept.Pediatri., Saitama Medical College,Saitama), Toshiyzki KUMAGAI (Dept. Pediatri. , Aichi Prefectural Colony Central Hospital, Aichi).

Spinal muscular atrophy (SMA) is an autosomal resessive disorder characterized by primary degeneration of the anterior horn cells of spinal cord. We examined two candidate genes, NAIP (neuronal apoptosis inhibitory protein) gene snd SMN (survival motor neuron) gene. The subjects included < group $A>38$ SMA patients (12 cases of type I, 19 of typell and 7 of typeII), $<$ group $B>53$ normal individuals from families with SMA patients and $<$ group $C>$ 26 normal controls. Exon 7 and 8 of the SMN gene and exon 4,5 and 6 of the NAIP gene were amplified by PCR. Thirty-three SMA cases (including 10 of type I, 17 of type II and 3 of type III) showed deletions of SMN telomeric copies of both exon 7 and 8 (0/groupB, 0/groupC). One case of each types showed the deletion of only SMN exon 7. In another 5 cases (i.e., 1 case of type I, 1 of type II and 3 of type III), no deletion was found of either exon 7 or 8. Two cases of SMA type I also showed the deletion of exon 5 of the NAIP gene (0/groupB, 0/groupC) as well as exons 7 and 8 of the SMN gene. In the other $36 \mathrm{SMA}$ patients, no deletion was detected in exon 5 of the NAIP gene.

B-43

CLONING OF THE TWO GENES RESPONSIBLE FOR AN AUTOSOMAL RECESSIVE MUSCULAR DYSTROPHY, SCARMD. Mikihan YOSHIDA, Satoru NOGUCHI, Yuji MIZUNO, Yasuko HAGIWARA, Ikuya Nonaka and Eijiro OZAWA (National Institute of Neuroscience, NCNP, Tokyo)

SCARMD is a Duchenne-like but an autosomal recessive muscular dystrophy. As a protein responsible for SCARMD, adhalin, one of dystrophin-associated proteins (DAPs), was focused in 1992. Soon, however, SCARMD was shown to be genetically heterogeneous diseases. In 1994 on the basis of our results, we proposed a hypothesis that SCARMD is the disease deficient in the sarcoglycan (SG) complex rather than adhalin. The complex, which we biochemically found, is composed of three DAPs called $\alpha-, \beta$ - and $\gamma$-SGs and adhalin corresponds to $\alpha-S G$. The heterogeneity of SCARMD can be explained on the assumption that, if any one of the SG genes is defective, the SG complex would not be formed on the sarcolemma and function any more.

In this study, we have cloned the cDNAs of $\beta$ - and $\gamma$-SGs and determined their gene loci on the human chromosomes. We have identified the SCARMD patients with defect in either of the SG genes and found in each case that not only the corresponding SG but also the other SGs whose genes are normal were lost in the skeletal muscle. These findings strongly support our hypothesis. We propose the name sarcoglycanopathy for SCARMD. We assume that the SG complex, whose function is yet unknown, must play an important role to keep muscles from degeneration. 
B-44

\author{
MOLECULAR GENETIC EVIDENCE OF CLINICAL HETEROGENEITY IN \\ FUKUYAMA TYPE CONGENTTAL MUSCULAR DYSTROPHY Eri KONDO-IIDA, \\ Kayoko SATTO, Makiko OSAWA (Dept. Pediat., Tokyo Women's Medical College, Tokyo), \\ Hajime TANAKA , Shoji TSUJI (Dept. Neurol., Brain Reserach Institute, Univ., Niigata, \\ Niigata), Tadayuki ISHIHARA (Div.Internal Med., National Higashisaitama \\ Hosp.,Saitama) and Tatsushi Toda (Dept. Human Genet., Univ. Tokyo, Tokyo)
}

A small fraction of Fukuyama type congenital muscular dystrophy (FCMD) patients acquire the capacity to walk. Whether such ambulant cases belong to the classical FCMD spectrum or a different entity has been a topic of considerable debate. We performed linkage analysis for 10 families with ambulant cases, using DNA markers flanking the FCMD locus. The mfd220 locus yielded a significant lod score of 3.09 for ambulant FCMD. We also found evidence for linkage disequilibrium between ambulant FCMD and mfd220. We also conducted haplotype analysis in two FCMD siblings with different phenotypes, one of whom was ambulant while the other was not. The results indicate that the two sets of FCMD siblings share exactly the same haplotype surrounding the FCMD locus. On the basis of these results, we conclude that, generically, ambulat cases are, in fact, part of the FCMD spectrum.

\title{
B-45
}

PRENATAL DIAGNOSIS OF FUKUYAMA TYPE CONGENITAL MUSCULAR DYSTROPHY USING POLYMORPHISM ANALYSIS. Kayoko SAITO, Eri KONDO, Kiyoko IKEYA, Yumi SHIRAIWA, Makiko OSAWA, Yukio FUKUYAMA (Dept. Pediatr., Tokyo Women's Medical College. Tokyo), Tatsushi TODA (Div. Hum. Genet., Tokyo University, Tokyo) and Tomoko YAMAMOTO, Makio KOBAYASHI (Dept. Pathol, Tokyo Women's Medical College, Tokyo)

We reported the first successful prenatal diagnosis in two Fukuyama type congenital muscular dystrophy (FCMD) families. We expanded this topic in 6 additional families. Three affected fetuses were examined neuropathologically. Ethical issues were carefully considered in each case. DNA was extracted from chorionic villi or amniocytes sampled at 10 to 17 gestational weeks (GW). The haplotypes of the family members and fetuses were analysed with polymorphic microsatellite markers flanking the 9q31-33 locus. The parents were informed of the results at 12 to 19 GW. The fetuses in families $1,4,6,7$ and 8 were diagnosed as being unaffected. The babies in families 1 and 4 are healthy. In families 6,7 and 8 , babies are due in November, January and February, respectively. The fetuses in families 2,3 and 5 were revealed to be affected, and the parents opted for abortion. The family 2 fetal brain(20GW) macroscopically showed small multiple granular protrusions over the cerebral surface composed of aberrant neuroglial clusters, as judged on microscopy, which migrated out through the discontinuous pial-glial barrier into the extra-cortical glial layer. The family 3 and 5 fetal brains ( 18 and $17 \mathrm{GW}$, respectively) showed the same findings, as the initial stage of cortical dysplasia, though milder. 


\section{HAPLOTYPE MAPPING OF THE FUKUYAMA-TYPE CONGENITAL MUSCULAR DYSTROPHY (FCMD) GENE. \\ Kazuhiro KOBAYASHI, Masashi MIYAKE, Katsushi TOKUNAGA, Yutaka NAKAHORI and Tatsushi TODA. (Dept. Hum. Genet., Univ. Tokyo, Tokyo.)}

Fukuyama-type congenital muscular dystrophy (FCMD) is an autosomal recessive severe muscular dystrophy associated with brain malformation. After our initial mapping of the FCMD locus to 9q31-33, we have found linkage disequilibrium between FCMD and D9S306 on 9q31, performed linkage-disequilibrium mapping using new microsatellites near D9S306, and presumed that the FCMD gene lies within a region of $<100 \mathrm{~kb}$ containing D9S2107. In the present study, we developed two new microsatellites (E6 and J7) between D9S2105 and D9S2107, determined their location, and examined haplotypes of FCMD chromosomes using the four markers (cen-D9S2105-E6-J7-D9S2107-tel). Eighty \% of FCMD chromosomes shared the founder haplotype (138-6-8-8) and 95\% of FCMD patients carried either two founder haplotypes homozygously or one founder haplotype and one putative newly mutated chromosome heterozygously. This haplotype has not been observed in normal chromosomes yet. These findings verify our hypothesis of a single disease founder in the Japanese population. Only several kinds of haplotype different from the founder's one were observed in FCMD chromosomes, indicateing that mutation events in the FCMD gene have happened so far at most several times except the founder mutation event. Moreover, we found several historical recombinations disrupting the founder haplotype at D9S2105 or E6, suggesting that the FCMD gene is likely to be located between D9S2105 and E6. Taken together with our previous study, the FCMD gene lies just proximal to the marker E6.

\section{B-47}

POINT MUTATION OF THE CARDIAC B-MYOSIN HEAVY CHAIN GENE WITHOUT AMINO ACID EXCHANGE IN FAMILIAL HYPERTROPHIC CARDIOMYOPATHY. Kiyomi NIKI, Michiko FURUTANI, Shouichi ARAI, Shin-ichiro IMAMURA, Kazuo MOMMA, Saichi HOSODA and Rumike MATSUOKA. (The Heart Institute of Japan, Tokyo Women's Medical College)

Point mutation of the cardiac $\beta$-myosin heavy chain ( $\beta$-MHC) gene without amino acid exchange (silent mutation) has been detected in familial hypertrophic cardiomyopathy patients (FHC). We investigated the relation between this silent mutation and the clinical signs of hypertrophic cardiomyopathy (HCM) in a FHC. One family of FHC (5 HCM patients and 11 unaffected family members), and 50 normal subjects were examined for the point mutation of $\beta \cdot M H C$ gene. Point mutation of $\beta$-MHC without amino acid exchange in exon 3 was found in all HCM patients (Thr $63 \mathrm{Thr}$ ). The same mutation was detected in normal subjects but at a much lower rate than $\mathrm{HCM}$ patients $(20 \%$ vs $100 \%$ ). This mutation was also detected in 5 of 11 unaffected family members (45\%); 4 of the 5 are under 30 years old and require further follow up. The high rate of the same silent mutation found in familial hypertrophic cardiomyopathy patients suggests that silent mutation may be associated with hypertrophic cardiomyopathy. 
B-48

STRUCTURAL ANALYSIS OF Ampd3 GENE ENCODING HEART-TYPE AMP DEAMINASE. Takayuki MORISAKI, Kannika SERMSUVITAYAWONG. Xudong WANG. Keiko TOYAMA. Hiroko MORISAKI Tsunehiro MUKAI (Dept.Bioscience, Natl.Cardiovasc.Ctr.Res.Inst., Osaka), lkuo MINEO (Otemae Hosp., Osaka) and Nobuaki OGASAWARA (Aichi Pref.Colony, Aichi)

Myoadenylate deaminase (muscle AMPD) deficiency is one of the most common inherited enzyme defect. Although a point mutation ( $34 \mathrm{C}$ to $\mathrm{T}$ ) in AMPD1 gene is thought to be responsible for all muscle AMPD deficiency examined thus far, many individuals with this mutation show no clinical symptom. This could be explained by gene regulatory mechanisms including alternative splicing and expression of other AMPD genes. To investigate these mechanisms in animal models, we isolated mouse Ampd3 gene encoding the heart-type AMPD, which is also expressed in skeletal muscles. Prokaryotic expression of the isolated gene confirmed that Ampd3 encodes the heart-type isozyme. Mouse Ampd3 gene was found to be more than $40 \mathrm{~kb}$ in length, located on mouse chromosome 7 and consist of 15 exons. Although mouse Ampd3 was found to be quite homologous to human AMPD3, the expression pattern and the structure of the $5^{\prime}$ region of mouse Ampd3 were distinct from those of human AMPD3. These observation will give us a clue to understand the function of Ampd gene family in animal models.

\section{B-49}

MUTATION IN AT LEAST 7 DEFFERENT CONTRACTILE ELEMENTS CAUSES HYPERTROPHIC CARDIOMYOPATHY. Akinori KIMURA, Haruhito HARADA, Shitoshi HIROI, Shu-Reng DUAN, Manatsu SATO, Megumi TAKAHASHI, Taishi SASAOKA, Takeyuki NAKAMURA, and Nobuhisa OHBUCHI (Dept. Tissue Phisiol., Div. Adult Dis., Med. Res. Inst., Tokyo Med. Dent. Univ., Tokyo)

Hypertrophic cardiomyopathy (HCM) is an autosomal dominant disease characterized by cardiac hypertrophy accompanied by myofiblillar disarrays. Genetic linkage studies have revealed at least 4 disease genes; cardiac $\beta$ myosin heavy chain (c $\beta M H C, C M H 1$ locus, 14q2), cardiac tropoin T (cTnT, $C M H 2$ locus, $1 \mathrm{q} 3$ ), $\alpha$ tropomyosin ( $\alpha \mathrm{TM}, C M H 3$ locus, 15q1), and cardiac myosin binding protein C (cMBPC, CMH4 locus, 11p1) genes. To dicipher the molecular basis of HCM in Japan, we have searched for mutations in these HCM genes in a large

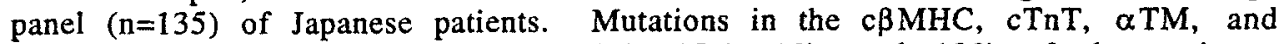
cMBPC genes were identified in $23 \%, 15 \%, 1 \%$, and $10 \%$ of the patients, respectively, i.e. about $49 \%$ of Japanese $\mathrm{HCM}$ was attributable to mutations in the known HCM genes. Because these known HCM genes encode for major contractile elements in the cardiac muscles, we have searched for mutations in the other contractile element genes. By this candidate gene approach, we found mutations in ventricular myosin essential light chain, ventricular myosin regulatory light chain, and cardiac troponin $I$ genes in a few patients. These studies have shown that there are at least 7 different HCM genes accounting for about $53 \%$ of $\mathrm{HCM}$ in Japan. 
B-50

MORTALITY OF WILSON DISEASE IN JAPAN, 1969-1994.

Yoko Imaizumi (Institute of Population Problems, Ministry of Health and Welfare, Tokyol

The death rate of Wilson disease (WD) was analyzed using Japanese vital statistics for the period 1969-1994. Data consisting of 503 (289 males and 214 females) deaths from WD were obtained during that period. The age-adjusted death rates of WD per million population were 0.57 for males and 0.36 for females in 1969 and decreased significantly year by year. The death rate was significantly higher in rural (0.20) than in urban (0.16) areas during that period. There were remarkable differences in the WD death rates among the four marital categories. The lowest age-adjusted death rate was seen in the married group for males (0.08) and females (0.07), whereas the highest rate was seen in the widowed group for males (1.02) and in the single group for females (0.45). The mean age at death from WD was 38 years for both sexes in 1969-1972 and decreased with the year, where the overall mean age at death was about 33 years for both sexes.

B-51

MOLECULAR CHARACTERIZATION OF GALACTOSEMIA MUTATIONS (TYPE 1) IN JAPANESE. Hidetetsu HIROKAWA, Yosiyuki OKANO, Takuji IMAMURA, Gen ISSHIKI (Dept. Pediatr. Osaka City University Medical School) and Itsujin SUYAMA (Osaka Municipal Rehabilitation Center for the Disabled)

Galactosemia (type 1) is an autosomal recessive genetic disorder due to galactose-1phosphate uridyltransferase (GALT) deficiency. Recently we characterized 7 novel mutations of GALT gene in 11 patients from 9 families. All patiens' GALT activities in the erythrocytes were reduced. The 7 novel mutations were 5 missense mutations (M142V, G179D, W249R, P325L, R333Q), a nonsense mutation (W249X), and a deletion (977C-del). These 7 mutations have not been found in Caucasians yet. Therefore, we suggest the mutation due to galactosemia occured after racial divergence between Caucasians and Asians. We recreated these mutant GALT cDNA by site-directed mutagenesis. The mutant constructs have been transfected into COS cells. We analyzed GALT activities in COS cells. The results showed all mutants' GALT activities were reduced and these missense mutations were the cause of GALT deficiency. The values siginificantly related to the GALT activities in the erythrocytes of the patients. 
B-52

cDNA ANALYSIS OF A MALE CASE WITH GALACTOKINASE DEFICIENCY. Akemi HAZEYAMA, Hiroshi NAKANO, Hitoshi ISHIZAKA, Hiroko HARASHIMA, Akira OHTAKE, Nozomu SASAKI (Dept. Pediatr., Saitama Medical School, Moroyama, Saitama), Akie FUJIMOTO (Osaka City Environment and Public Health Association, Osaka) and Yoshiyuki OKANO (Dept. Pediatr., Osaka City Univ. Medical School, Osaka)

We describe here a cDNA analysis of a Japanese male case with galactokinase deficiency. He was the first child of healthy and nonconsanguineous parents. The blood galactose concentration was detected to be high on newborn screening. The galactokinase activity of the proband using red blood cells was $6.6 \%$ of controls and those of parents are $20 \%$ and $47 \%$, respectively. Dietary treatment was started immediately. Since then he does not have cataracts and is developing normally at the age of 1 year and 8 months. We used the reverse transcriptionpolymerase chain reaction to obtain cDNAs encoding galactokinase from lymphoblastoid cell lines. G1045A(Gly349Ser), was identified homozygously in the proband and heterozygously in his mother. Gly349 takes part in the formation of ATP-binding motif and conserves among all the galactokinases.

B-53

ACCUMULATION OF GM2 GANGLIOSIDE IN NIEMANN-PICK DISEASE TYPE C. Tamami YANO, Miyako TANIGUCHI, Kousaku OHNO (Dept. Neurobiology, School of Life Science, Tottori Univ.), Marie T. VANIER (Dept. Biochemistory, INSERUM-CNRS, Lyon-Sud School of Medicine, Oullins Cedex, France), and Goro TAKADA (Dept. Pediatrics, School of Medicine, Akita Univ.)

We have found that Niemann-Pick disease type C (NP-C) fibroblasts have an increased level of bound sialic acid. To characterize the bound sialic acid, we have studied intracellular ganglioside. GM2 ganglioside (GM2) was accumulated in most of NP-C cells. The incorporations of $[3 \mathrm{H}]$ mannosamine into GM2 and GM3 ganglioside fractions were also increased. Cells cultured in lipoprotein-depleted medium diminished the accumulation of cholesterol but not of GM2. It is unlikely that the GM2 accumulation arises from a secondary lysosomal function caused by the storage of excess cholesterol. It is suggested that the accumulation of GM2 together with cholesterol is a unique abnormality in NP-C cells and the defect in NP-C may be involved in intracellular transport of both cholesterol and GM2. 
B-54

PRENATAL EXCLUSION OF CARBAMYLPHCSPHATE SYNTHETASE-I DEFICIENCY BY FETAL LIVER BIOPSY.

Makoto YOSHINO, Atsushi NISHIYORI, Yasutoshi KOGA, Hirohisa KATO (Dept. Pediatr. \& Child Health), Shigeki IZUM, Tetsuro HATASE, Michiaki YAKUSHIJI (Dept. Obst. Gynecol., Kurume Univ. Sch. Med.)

A prenatal enzymatic examination for carbamylphosphate synthetase-I (CPS-I) deficiency was carried out in a pregnant woman at risk for the disease at 21 weeks of gestation. Fetal liver tissue was obtained by aspiration needle biopsy. The activity of CPS-I in the fetus at risk was $4.9 \%$ of mean values of fetal tissue at 18 to 21 weeks of gestation. The activity of ornithine transcarbamylase (OTC) was also low at $8.9 \%$ of the control mean value. We interpreted these apparent low values were due to contaminating blood clotting, and decided that the fetus was unaffected because (1) the fetal CPS-I activity was within detectability, in contrast to the complete absence of CPS-I in the propositus' liver tissue, and because (2) the activity ratio of CPS-I to OTC was $55 \%$ of the control mean value. The pregnancy was continued and the baby was delivered at 40 weeks of gestation and confirmed to be unaffected. Comparison with the propositus' CPS-I activity and the activity ratio may be useful to differentiate whether or not the fetus is affected when a low activity is elicited.

B-55

MOLECULAR CHARACTERIZATION OF PERSISTENT

HYPERMETHIONINEMIA WITH DOMINANT INHERITANCE.

Masayoshi NAGAO (Dept. Pediat, National Otaru hospital, Otaru) and

Kazuhiko OYANAGI (O-dori Children's Clinic, Sapporo)

We describe a type of mild hypermethioninemia due to a point mutation in the hepatic MAT gene, which was inherited in a dominant fashion in a family. Three patients coming from a same family pedigree were ascertained by the presence of isolated hypermethioninemia on mass-screening program. The measurement of MAT activity in a patient's liver indicated a mild partial deficiency of the high $\mathrm{Km}$ form of hepatic MAT. SSCP analysis and direct sequencing of patient's genomic DNAs revealed a $G$ to $A$ mutation at nucleotide 791 that converts Arg-264 to His (R264H) in one allele of MATA1 gene. Gene tracking in the family revealed that the hypermethioninemia is associated with heterozygosity for the R264H mutation in the MATA1 gene. (R264H mutation; J.Y.Chou et al. 1996) 
IDENTIFICATION OF MISSENSE MUTATIONS AND HAPLOTYPING OF CARNITINE PALMITOYLTRANSFERASE II GENE. Jun AKANUMA, Kaon WATAYA, Yoichi MATSUBARA, Shigeo KURE, Kuniaki NARISAWA (Dept. Biochem. Genet., Tohoku Univ. Sch. Med., Sendai), Franco TARONI (Istituto Nazionale Neurol. Milan, Italy), Ichiro YOSHIDA, Makoto YOSHINO (Dept. Pediatr., Kurume Univ. Sch. Med., Kurume), Junichi KIRA (Dept. Neurol., Neurol. Insti., Fac. Med., Kyushu Univ., Fukuoka) and Jun AKANUMA, Teiji YAMAMOTO (Dept. Neurol., Fukushima Med. Col., Fukushima)

Carnitine palmitoyltransferase II (CPTII) deficiency manifests as various clinical phenotypes: a relatively mild form with muscular symptoms and a severe phenotype presenting with hepatocardiomuscular manifestations. We have investigated three Japanese patients with CPT II deficiency. Molecular analysis revealed two novel missense mutations, a glutamate (174)-to-lyine substitution (E174K) and a phenylalanine (383)-to-tyrosine substitution (F383Y) in the CPTII cDNA. Transfection experiments demonstrated that the two mutations reduced CPTII catalytic activity. Case 1 (muscular form) was homozygous for the E174K mutation, whereas case 2 (hepatic form) was homozygous for the F383Y mutation. Interestingly, case 3, who was a compound heterozygote for E174K and F383Y, exhibited hepatic symptoms. We also identified a polymorphism in the CPTII gene, a phenylalanine (352)-to-cysteine substitution (F352C). According to an expression analysis, this mutation did not alter CPTII activity. It was present in 21 out of 100 normal alleles in the Japanese population, but was not observed among Caucasians. Genotyping with this polymorphism and the previously reported polymorphisms V368I and M647V allowed normal alleles to be classified into five haplotypes. In all three families, the E174K mutation resided only on F1V1Ml allele, while the F383Y mutation was observed on F2V2M1 allele, suggesting a single origin of each mutation.

\section{B-57}

MOLECULAR ANALYSIS OF LESCH-NYHAN SYNDROME: A JAPANESE FAMILY WITH TWO POINT MUTATIONS AT INTRON 1 OF HPRT GENE. Yasukazu YAMADA, Haruko GOTO, Nobuaki OGASAWARA (Dept. Genet., Inst. Developmental Res., Aichi Human Service Center, Aichi), Nobuaki IWASAKI (Dept. Pediatr., Inst. Clin. Med., Univ. Tsukuba, Ibaraki)

A virtually complete deficiency of hypoxanthine guanine phosphoribosyltransferase (HPRT) causes Lesch-Nyhan syndrome. A novel mutation of HPRT gene in a Japanese family has been identified by analysis of the HPRT gene of the patient. Two nucleotide substitutions of $G$ to $T$ at the first nucleotide (M1) and $G$ to $T$ at the eighth nucleotide (M8) from the 5'-end of intron 1 were detected by direct sequencing of PCR products from the patient's genomic DNA. In the patient, an altered mRNA including 49-bp of the $5 '$-end of intron 1 was expressed. The altered mRNA resulted in small polypeptide consisting of 8 amino acids encoded in HPRT exon 1 and 17 different amino acids. By the expression studies in human HPRT ${ }^{-}$cells utilizing a mammarian expression vector, respective substitutions ( $\mathrm{M} 1, \mathrm{M} 8$ and $\mathrm{M1}+\mathrm{M} 8$ ) introduced $\mathrm{pCI}$, it was clarified that the nucleotide substitution at the first nucleotide of 5'-end of intron 1 (M1) caused the splicing error changing the splice donor concensus sequence GT to TT. 
MOLECULAR ANALYSIS OF DAX-1 GENE IN X-LINKED ADRENAL HYPOPLASIA CONGENITA. Kenji FUJIEDA, Jun NAKAE, Toshihiro TAJIMA, Nozomi SHINOHARA, Mari MURASHITA, and Shuji ABE (Dept. Pediatrics, Hokkaido University School of Medicine, Sapporo)

The DAX-1[DSS(dosage-sensitive sex)-AHC critical region in the $\mathrm{X}$, gene 1] gene has been reported to be responsible for X-linked adrenal hypoplasia congenita (AHC) and hypogonadotropic hypogonadism. However, the function and structure of the DAX-1 protein have not been characterized. In this study, molecular analysis of the DAX-1 gene from 6 patients with $A H C$, including 2 siblings, identified 5 novel mutations with 3 nonsense mutations and 2 frameshift mutations. Case 1 had a nonsense mutation at position 395 (Q395X). Cases 2 and 3, who were siblings, had a nonsense mutation at position 91 (Y91X). Case 4 had a 2-base deletion (AT) at nucleotide 1610 and 1611 and a 1-base insertion $(G)$ resulting in a premature stop codon at position 462 (1610-1611 del AT ins G). Case 5 had a nonsense mutation at position 271 (Y271X). Case 6 had a 1-base deletion (C) at nucleotide 1169, which induced a frame shift and a premature stop codon at position 371 (1169 del C). All mutated DAX-1 proteins had trucated C-terminal domains. These results suggest that these 5 novel mutations are responsible for $\mathrm{X}$-linked $\mathrm{AHC}$ and that the $\mathrm{C}$ terminus of the DAX-1 protein, especially 11 amino acids, is necessary for normal adrenal cortical embryogenesis.

\section{B-59}

ANALYSIS OF DAX-1 GENE IN A PATIENT WITH X-LINKED CONGENITAL ADRENAL HYPOPLASIA AND HYPOGONADOTROPIC HYPOGONADISM. Kazuyuki HAMAGUCHI, Masaya ARIKAWA, Seigo YASUNAGA, Tetsuya KAKUMA, Koii FUKAGAWA Toshiie SAKATA (Dept. Int. Med. I, Oita Med. Univ., Oita), Toshihiko YANASE, Hajime NAWATA (Third Dept. Med., Kyushu Univ., Fukuoka).

$\mathrm{X}$-linked congenital adrenal hypoplasia (AHC) is a rare disorder manifesting as primary adrenal insufficiency and hypogonadotropic hypogonadism (HHG). DAX-1 gene has been reported to be a responsible gene. The present case (MK), $20 \mathrm{yr}$ old, is a Japanese male patient . Within a week after birth, MK frequently developed nausea and vomiting. He was diagnosed as adrenal insufficiency, and replacement of hydrocortisone was started. He had no secondary sex characteristics even at age of $18 \mathrm{yr}$. On admission, he showed generalized hyperpigmentation of the skin. He had no axillary hair and scanty pubic hair. His bilateral testes were atrophic. Bone age was 13 yr $6 \mathrm{mo}$. Neither adrenal gland was detected by abdominal CT. Endocrinological data were compatible with AHC and HHG. Sequence analysis of MK's DAX-1 gene revealed a 1-bp $(G)$ deletion at amino acid position 49 in exon 1 . This mutation yields frame-shift, such that the mutant protein has a completely different amino acid sequence from codon 49 to the premature stop codon at codon 84 . His mother was a heterozygote of this mutation. His father and the two younger brothers had normal allele. Pulsatile administration of synthetic LHRH resulted in insufficient secretion of FSH and LH. Therefore, HCG/FSH injection has been started, and the patient is under carefull follow up in our hospital. 
B-60

GENE ANALYSIS OF 7 JAPANESE FAMILIES WITH HYPOPHOSPHATASIA. Hideo ORIMO ${ }^{1}$, Masae GOSEKI-SONE ${ }^{2}$, Tadahiro IIMURA ${ }^{2}$, Yuzo TAKAGI ${ }^{3}$, Hisashi WATANABE ${ }^{4}$, Kazuhisa TAKETA ${ }^{5}$, Seiji SATO $^{6}$, Hideaki MAYANAGI ${ }^{7}$, Akira OHTAKE $^{8}$, Shinichiro OIDA ${ }^{2}$ and Takashi SHIMADA' ('Dept. Biochem. Molec. Biol., Nippon Med. Sch., Tokyo, ${ }^{2}$ Dept. Biochem., ${ }^{3}$ Dept. Pedodontics, ${ }^{4}$ Dept. Periodontology, Faculty of Dentistry, Tokyo Med. Dent. Univ., Tokyo, ${ }^{5}$ Dept. Public Health, Okayama Univ., Okayama, ${ }^{6}$ Dept. Pediatrics, Keio Univ., Tokyo, ${ }^{7}$ Dept. Pedodontics, Tohoku Univ., Sendai, ${ }^{8}$ Dept. Pediatrics, Saitama Med. Sch., Moro)

Hypophosphatasia (HOPS) is an autosomal recessive disease with skeretal hypomineralization due to deficiency of tissue-nonspecific alkaline phosphatase (TNSALP). We screened the TNSALP gene in 7 Japanese families with HOPS using PCR-SSCP-direct sequencing method and found 9 novel mutations. E281K, $\triangle \mathrm{F} 310$, and frameshifts downstream from $\mathrm{S} 328$ and from L503 were found in 3 cases of perinatal/infantile type. F310L and V365I, A160T and F310L were found in a childhood type and an adult type, respectively. A94T, E174G and frameshift from L503 were found in 2 cases of odontohypophosphatasia. Partial intronic sequences of the TNSALP gene were determined to design the PCR primers that amplify whole coding exons. The mutations found in Japanese HOPS were completely different from those in North America and there were no clear relations between the mutation sites and phenotypes.

\section{B-61}

PRENATAL DIAGNOSIS OF HYPOPHOSPHATASIA BY PCR-RFIP. Kenji IDA ${ }^{1}$, Emiko ABE ${ }^{1}$, Shigeo YRRA', Takafumi NONOGAKI ${ }^{2}$, Hiroshi OZASA', Norio MIYAMOTO" ${ }^{2}$, Kenji NAKAMURA $^{2}$, Tsuyoshi TANIMURA ${ }^{2}$, Kerva NISHIOKA ${ }^{2}$, Tomomi NISHIMRA ${ }^{3}$, Hisako ONO ${ }^{3}$, $\overline{\text { Okiyoshi SAIGA }}{ }^{3}$. ( Dept. OBGYN ${ }^{2}$, Dept.Pediatrics ${ }^{2}$, Dept.Pathology ${ }^{3}$, OTSU RED CROSS HOSPITAL) Nobuouki YAMAGISHI, Hiraku TAKEBE. (Dept. Padiation Genetics, KYOTO UNIVERSITY SCHOOL OF MEDICINE, KYOTO)

Prenatal Genetic Diagnosis was attempted to a pregnant woman whose previous infant was diagnosed as perinatal hypophosphatasia. DNA was purified from anniotic cell collected by amiocenthesis at 17th meek of gestation and from lymphocyte of the parents and the affected baby. Restriction fragment length polymorphism(PFIP) using PCR product of intron 9 of tissue nonspecic alkal ine phosphatase gene (TNSAIP) digested with Bcl-1 revealed the fetus to be the carrier or affected. The intact development of the bones shown by the fetal sonogram and X-ray study implied the fetus to be the carrier. The pregnancy was continued and the heal thy male infant of birthmeigt $3950 \mathrm{~g}$ was born with the normal serum-AlP level. 
B-62

USE OF BUCCAL SMEARS FOR RAPID DETECTION OF PEROXISOMES. Yasuyuki SUZUKI, Zhongyi ZHANG, Nobuyuki SHIMOZAWA, Naomi KONDO (Dept. Pediatr., Gifu Univ.) Tadao ORII (Chubu Women's College) and Takashi HASHIMOTO (Dept. Biochem., Shinshu Univ.)

Diagnosis of peroxisome biogenesis disorders such as Zellweger syndrome and neonatal adrenoleukodystrophy has been based on demonstrating the defect of peroxisomes in hepatocytes or fibroblasts. These methods are invasive or time-consuming. We investigated on the possible use of buccal smears for the screening of the Zellweger syndrome. Buccal smears were washed once with saline and spread on the fluorescencefree cover slips. The cells were stained by indirect immunofluorescence staining using antibodies against catalase or acyl-CoA oxidase, and FTC-conjugated goat $F\left(a b^{\prime}\right) 2$ antirabbit IgG. Peroxisomes in the control buccal smear cells were visualized with anticatalase and acyl-CoA oxidase. Peroxisomes were detectable in more than $70 \%$ of the smear cells from the control subjects. In two patients with Zellweger syndrome, peroxisomes were not detected using either anti-catalase or anti-acyl-CoA oxidase. Buccal smears are potential materials for rapid and non-invasive diagnosis of peroxisome biogenesis disorders. This method will also be applicable to the diagnosis of other inborn errors of metabolism.

\section{B-63}

STRUCTURAL ORGANIZATION AND EXPRESSION OF MANB GENE ENCODING THE HUMAN a-DMANNOSIDASE. Nobuaki MAKAMATSU. Yasuo GOTODA. Hisaomi KAWAI (First Dept. of Internal Medicine, School of Medicine. The Univ. of Tokushima, Tokushima). Vicki L. Nebes(Allegheny-singer Research Institute, Pittsburgh. PA)

a -D-mannosidase (E. C. 3.2.1.24) is a lysosomal hydrolase that catalyzes the hydrolysis of terminal a -D-mannoside residues from $\mathrm{N}$-linked carbohydrates of glycoproteins. To analyze the gene function of this enzyme, we screened human super $\operatorname{COS}$ cosmid libraries and isolated four overlapping clones containing a-D-mannosidase (MANB) gene. MANB gene spans approximately $23 \mathrm{~kb}$ and consists of 24 exons. The first 160 bp of $5^{-}$flanking sequence shows a high $\mathrm{G}+\mathrm{C}$ content ( $76 \%$ ) wi th two candidate $\mathrm{GC}$ boxes and three Ap- 2 binding sites. Promoter analysis using CAT reporter system demonstrated that 150 bp of $5^{-}$sequence had activity to promote this gene. Thus, like other lysosomal hydrolases, MANB gene is also controlled by sequences located within $150 \mathrm{bp}$ of $\mathrm{ATG}$ initiation site. 


\section{B-64}

IDENTIFICATION OF MUTATIONS IN THE MANB GENE IN PATIENTS WITH $\alpha$-MANNOSIDOSIS. Yasuo GOTODA, Nobuaki WAKAMATSU, Hisaomi KAWAI, Yoshihiko NISHIDA, and Shiro SAITO (First Dept. of Internal Med., School of Med., Univ. of Tokushima, Tokushima)

$\alpha$-Mannosidosis which is characterized clinically by hearing loss, coarse face and mental retardation, is an autosomal recessive lysosomal storage disease with deficiency of $\alpha-$ D-mannosidase activity. We have analyzed the $\alpha$-D-mannosidase (MANB) gene in 6 unrelated type II patients using SSCP to screen all 24 exons and intron/exon boundaries of the gene, followed by direct sequencing and restriction-enzyme analysis of abnormal DNA fragments obtained by the screening. Three of these patients had a homozygous mutation of A146T (His49Leu), C995G (Pro332Arg) and C2176T (Arg726Trp), respectively, while one patient was a compound heterozygote with C1843T (Gln615Stop) and C2176T(Arg726Trp) mutations. No mutations were detected in other 2 patients by the present method. These results indicate that type II $\alpha$-mannosidosis is mostly due to point mutations of the MANB gene.

\section{B-65}

A CASE OF MILD TYPE WOLMAN DISEASE

Youichi HIGUCHI Ryogo MORI, Akira KAMITAMARI Eiichi KINOSHITA. Tsuneyoshi BABA Tadashi MATSUMOTO Yoshiro TSUJI(Dept. Pediatrics, Nagasaki Univ. School of Medicine, Nagasaki) Norio SAKURAGAWA(Dept. Inherited Metabolic Disease, National Institute of Neuroscience, NCNP, Tokyo)

Wolman disease (WD), characterized by hepatosplenomegaly, steatorrhea, abdominal distention and calcification of adrenal glands, is a rare autosomal recessive disorder and fatal in infancy. WD has been reported to be due to the defect of human lysosomal acid lipase (HLAL). Recently, it is reported that some patients with WD have some mutations of LIPA gene, the responsible gene for HLAL. We report here a 3-years-old girl with mild type WD together with the results of LIPA gene analysis.

Anemia and liver dysfunction were noticed at the age of 1 month. A marked abdominal distention and hepatosplenomegaly appeared at the age of 3 month. Laboratory data showed hyperlipidemia (TG:448mg/dl, TC:158mg/dl). Abdominal CT scan revealed calcifications of the adrenal glands. Histological examination of the liver showed enlarged and vacuolated hepatic cells. HLAL activity measured from peripheral lymphocytes was extremely reduced. She was diagnosed as having WD and has been treated with low fat diet and the HMG-CoA reductase inhibitor.

LIPA gene of the patient was analyzed by using exon specific PCR-SSCP. PCR product amplified with exon 1 specific primers indicated divergent SSCP band. Further analysis with sequencing would elucidate the phenotype-genotype correlation of mild type WD. 
B-66

RELATIVE FREQUENCY OF ANGELMAN SYNDROME IMPRINTING MUTATION PATIENTS. Takahito WADA ${ }^{1}$, Shinii SAITOH ${ }^{1}$, Naomichi MATSUMOTO ${ }^{2}$, Norio NIIKAWA ${ }^{2}$ ('Dept. Pediatr. Hokkaido Univ. Sch. Med., Sapporo; ${ }^{2}$ Dept. Hum. Genet. Nagasaki Univ. Sch. Med., Nagasaki)

Angelman syndrome is a neurobehavioral syndrome characterized by severe mental retardation, epilepsy, characteristic facies, and happy disposition. Incidence is estimated as $1 / 10,000$ to $1 / 20,000$, and it is one of common genetic disorders in severely retarded patients.

Approximately $70 \%$ of AS patients have alarge deletion of maternally inherited $15 q 11-q 13$, which is easily detected by FISH. Less than $2 \%$ of AS patients have patemal uniparental disomy (UPD) of chromosome 15. Rest of patients are designated as non-deletion, non-UPD patients. Recently, a new subset of AS patients are identified, who have DNA methylation abnormality throughout 15q11-q13, and named imprinting mutation (IM) patients.

We previously examined 61 AS patients, and $66 \%$ showed a large deletion, none had UPD, and $34 \%$ were non-deletion, non-UPD patients. To know the frequency of $M$ patients, we performed DNA methylation tests using SNRPN and PW71 as probes in 17 non-deletion, nonUPD patients ( 4 familial and 13 sporadic), whose DNA were available from the previous study. Patemal only DNA methylation pattern (AS pattern) was identified in 2 familial (2/4) and 2 sporadic (2/13) patients. These findings clearly indicate that $M$ is not rare even in sporadic patients. Since most of $M$ patients are known to have inherited small deletions at Imprinting center (IC) region, it is important to identify IM patients for genetic counseling purpose.

B-67

A MOLECULAR STUDY OF ANGELMAN AND PRADER-WILLI IMPRINTING MUTATION PATIENTS. Shinii SAITOH' ${ }^{1}$ Robert D. NICHOLLS ${ }^{2}$ ('Dept. Pediatr. Hokkaido Univ. Sch. Med., Sapporo; ${ }^{2}$ Dept. Genet. Case Western Reserve Univ., Cleveland, USA)

Imprinting mutation is a newly identified subset of patients of Angelman (AS) and PraderWill (PWS) syndromes. it is characterized by abnormal DNA methylation throughout $15 q 11$ q13 despite no evidence of a typical deletion or uniparental disomy (UPD). $\mathbb{t}$ is believed to be associated with a mutation of imprinting process.

We examined six AS and three PWS imprinting mutation families. A typical deletion and UPD were ruled out by FISH and PCR microsattelite analyses. DNA methylation tests at SNRPN, D15S9, and D15S63 loci revealed patemal only methylation pattern in all of AS patients, and maternal only pattern in all of PWS patients examined. Expression study of SNRPN, IPW, and ZNF127 genes showed no expression of any genes in PWS imprinting mutation patients, whereas it showed biallelic expression in AS imprinting mutation patients.

We used a phage contig covering D15S63 through SNRPN and identified small deletions $(6$ to $150 \mathrm{~kb})$ located upstream of the SNRPN gene in these patients. The same deletions were found in their mothers and maternal grand fathers (AS); and in their fathers and paternal grand mothers (PWS). Therefore, this region, we designated imprinting center $(I C)$, should contain a novel cis acting genetic element which plays a role in erasing or resetting of genomic imprinting of 15q11-q13 during gametogenesis. 
B-68

Molecular mechanism of genomic imprinting in the region of human SNRPN gene. Mitsuyeshi NAKAQ(Tumor Genet. and Biol., Kumamoto University, Kumamoto), Ikuko KONDO(Hygiene, Ehime University, Matsuyama), Huq. A.H.M.M. and Arthur L. BEAUDET(Molec. and Hum. Genet., Bayor College of Med., Houston)

The gene encoding for the small nuclear ribonucleoprotein-associated polypeptide N(SNRPN) localizes in the Prader-Willi syndrome(PWS) critical region on chromosome 15, and is expressed only from the paternal allele. A CpG island containing the exon $\alpha$ of SNRPN gene is differentially methylated on the maternal chromosome. Sequence analysis of cosmid 102 containing of exon $\alpha, \beta$ and 1 as well as $20 \mathrm{~kb}$-upstream from exon $\alpha$ revealed there are multiple direct repeat sequences $-0.8 \mathrm{~kb}$-downstream exon $\alpha$ which are thought as character of the imprinted genes. A DNasel-hypersensitive site was also found $\sim 0.7 \mathrm{~kb}$-upstream exon $\alpha$. The promoter of exon $\alpha$ showed a much stronger activity than that of exon 1 , and was completely abolished by in vitro methylation. These findings suggest that the imprinted regulation of SNRPN gene is correlated with short direct repeats, open chromatin structure and DNA methylation. Since recent reports of several imprinting mutations in the PWS patients with smaller deletions have suggest an imprinting center in male germline is close to exon $\alpha$, our data will be very helpful for the identification of such regulatory elements in this region.

\section{B-69}

THE MOUSE L23mrp GENE LOCATED DOWNSTREAM OF THE IMPRINTED Ins2/Igf2/H19 REGION IS BIALLELICALLY EXPRESSED AND NOT INFLUENCED BY THE H19 ENHANCER. Hiroyuki SASAKI and Mohamad ZUBAIR (Institute of Genetic Information, Kyushu University, Fukuoka)

The Ins2 (insulin II), Igf2 (insulin-like growth factor II) and $H 19$ genes are closely linked on mouse chromosome 7 and all are subject to tissuespecific parental imprinting. It was previously shown that the imprinting of these genes involves their parental-origin-specific interactions with the endoderm-specific $H 19$ enhancer. To know the extent and boundaries of this imprinted domain, we have cloned and characterized the mouse homolog of the human $L 23 M R P$ gene, which had been mapped approximately $40 \mathrm{~kb}$ downstream of the human $H 19$ gene. Our findings show that the mouse $L 23 m r p$ gene is expressed biallelically in various developmental stages and tissues. On the basis of the analysis of $H 19$ enhancer deletion mice, we also conclude that the enhancer does not influence $L 23 m r p$ expression. Thus it is likely that this gene demarcates the $3^{\prime}$ end of the imprinted domain. The lack of interactions between the enhancer and the gene may be due to either the promoter specificity of the enhancer or to the presence of a putative chromatin insulator. 
B-70

\section{GENOMIC CLONING AND LOCALIZATION OF THE HUMAN ACHAETE-SCUTE HOMOLOG 2 (ASCL2) TO CHROMOSOME $11 \mathrm{p} 15.5$}

Toshinobu MIYAMOTO, Mutsuo ISHIKAWA (Dept. Obstet. Gynecol., Asahikawa Med. Coll., Asahikawa), Yoshihiro IINNO and Norio NIIKAWA (Dept. Hum. Genet., Nagasaki Univ. Sch. Med., Nagasaki)

The mouse achaete-scute homolog-2 gene (Mash2 or Ascl2), a member of the achaete-scute gene family, encodes a transcription factor that plays an important role in the development of the trophoblast. It has recently been reported that mouse $A s c l 2$ is genomically imprinted and mapped to the distal region of mouse chromosome 7 , where other imprinted genes are located. We isolated a clone carrying the partial human homolog, $A S C L 2$, from a human genomic phage library using a PCR product for the rat $A s c l 2$-cDNA as a probe. Sequence comparisons of the human $A S C L 2$ clone and the rat Ascl2-cDNA showed $86.9 \%$ identity spanning 206 nucleotides. By FISH using a phage clone as a probe, we assigned $A S C L 2$ to human chromosome $11 \mathrm{p} 15.5$, where the human imprinted gene, $\mathrm{p} 57^{\mathrm{KLP} 2}, I G F 2$ and $H 19$ are located. Thus, it is of great interest to know whether $A S C L 2$ is also imprinted.

B-71

IDENTIFICATION ANDSTRUCTURALANALYSIS OF A REGONWTHA PATERNAL SPECIFIC METHYLTIONIMPRINT AT THE HUMANH1 9 LOCUS. Yos hihiro JINNO Norio NIKAWA (Dept . Hum. Genet, Nagas aki Univ, Nagas aki), Tadayuki ISHIMARU(Dept . Obstet. Gynecol, Nagas aki Univ, Nagas aki), Kazuo SENGOKU, Tos hinobu MYAMOTO(Dept . Obst et. Gynecol, As a hikaw a MEd. College, Asahikawa) and Mt suyos hi NAKAO (Dept. Tuomor Genet. Biol, Kumamoto Univ, Kumamoto)

We have ident ified a region with characteristics of a paternal-specific methylat ion imprint at the human $\mathrm{Hl} 9$ locus. This region, ext ending from -2.0 $\mathrm{kb}$ upst ream to the start of transcription, is heavily methylated in sperm and on the paternal allele in somatic cells. This methylation was preserved during pre-implantation. Astructural analys is revealed a feat ure of CpGislands and a striking organization of a large direct repeat with a $400 \mathrm{bp}$ sequence reiterated several times, but no significant sequence homology to the corres ponding region of the mouse $\mathrm{H1} 9$ gene. While these findings present somew hat puzzling as pect as to evolution of the Hl 9 regulat ory region in human and mouse, they may explain the apparent difference in $\mathrm{Hl} 9$ expression in human placent a compared to mouse. 
ISSUES SURROUNDING GENETIC DISEASE DISCRIMINATION. Mitsushiro KIDA (Teikyo Women's Junior College)

One university professor has said, "In today's society, smaller numbers of babies are being born and smaller numbers of people are dying. Genetic mutation is thus somthing that cannot be avoided. If selection is at work, as it was in Japan in the past, genetic abnormalities will not accumulate in society, but they will natually accumulate in today's society.

As a result, by conducing genetic tests, abortions should be performed, otherwise society as we know it will cases to function. "He adovocates the spread of genetic tests before birth and unconditional artificial abortion when a genetic abnormality is detected.After lectureing for a while at a women's college, I asked the students two true/fals question:(1) Both of my parents are healthy and all of my blood relatives are healthy. Thus, I have no bad genes. (2) If all people with a genetic disease decided not to have children, then there would be no-one on earth with a genetic disease. They are both "fals." The ratio of correct answers for question 1 was $254 / 377(67.3 \%$ ); for question $2,314 / 377(83.8 \%)$.

These two examples shine light on the ethical problems that human geneticists of today avoid and will not discuss, such as, who decides the rihght and wrongs of a particular disease? when, and with what authority?; Are all genetic disease bad and must be eradicated? Will it be possible to eradicate all genetic diseases by artifical selection? Should a society force artifificial abortion on people?; Should such question be decided only by specialists and public officials without counseling the general public, including the patients themselves? The idea of eugenics is a concept put by Galton in England in 1885, and was so abused by Hitler. Human genom researchers must not travel the same path.

B-73

CONSENSUS SURVEY ON HEREDITY IN FUKUI, INDIA, BEIJING. Mikio HIRAYAMA, Masaru KURIYAMA(Second Dept. Int. Med., Fukui Medical School, Fukui), Norio FUJIKI(Toyobo Gene Lab. Tsuruga), Shigeaki NAKAZAKI(Kunitaka Hospital, Takefu), I.C. VERMA(Dept. Pediat. All India Inst. Med. Sci., New Delhi) and Wilson H. Y. LO(Inst. Basic Med. Sci. Peking Union Med. Coll, Beijing)

Consensus survey was done in Fukui, India, Beijing. Those with an image of heredity as scientific were $26 \%$ in Fukui, $63 \%$ in India, $80 \%$ in Beijing. $3 \%$ answered correctly the frequency of congenital anomaly in Fukui, $24 \%$ in India, 37\% in Beijing. Knowledge of prenatal diagnosis was $40 \%$ in Fukui, $63 \%$ in India, $75 \%$ in Beijing. $74 \%$ would take the amniocentesis test in case of Down's syndrome in Fukui, $43 \%$ in India, $80 \%$ in Beijing. Those who would abort the child after the result was positive, were $40 \%$ in Fukui, $70 \%$ in India, $87 \%$ in Beijing. In Beijing, most of the respondents were with higher education and one child policy increased the knowledge of genetic diseases. In India, most of the respondents had handicapped children, and this influenced the result. The necessity of education of medical genetics was emphasized. 


\section{B-74}

SHINSHU UNIVERSITY HOSPITAL ESTABLISHED THE DIVISION OF CLINICAL GENETICS AS ONE OF ITS CENTRAL SERVICE DEPARTMENTS. Yoshimitsu FUKUSHIMA, Shuichi IKEDA, Kovo SAKURAI, Kenichi KOIKE Kazuhiko MATSUMOTO Minoru FUJIMORI, Toshio NIKAIDO, Kenichi FURIHATA, Kivoshi MATUO and Jun KOMIYAMA (Div. Clin. Genet., Shinshu University Hospital )

Recent advances in medical genetics enable us to do carrier detection, presymptomatic diagnosis or prenatal diagnosis of many genetic disorders. These techniques are useful for reduction of anxiety of patients or families, and early diagnosis and treatment. To effectively use these techniques, a division of clinical genetics, at which genetic diagnosis and counseling are provided, is necessary. However, the field of clinical genetics is lagging in Japan. Shinshu University Hospital established the division of clinical genetics as one of its central service departments. Several MDs from the departments of internal medicine, geriatrics, pediatrics, surgery, laboratory medicine and hygiene staff this project . All of the staff are certified as members of the Japanese Board of Medical Genetics, Clinical Geneticist or as its trainees, and serve concurrently. This is the first clinical genetics department in the National University Hospitals in Japan. This system of having a clinical genetics division is likely to be available in other university hospitals, while some problems lie in the referring system, confidentiality and financial support.

Attitude OF YOUNG WOMEN STUDYING HEALTH CARE TO PRENATAL MATERNAL SERUM SCREENING. Tomoko HASEGAWA, Chigusa MASUMURA, Kimiko MIYAKAWA, Tomoyuki KATAHIRA(Div. CIin Genet, Shizuoka Children's Hospital, Shizuoka, Niigata, Dept. Gynecol. \& Obstet. National Nagoya Hospital, Nagoya) Prenatal maternal serum (MS) screening for Down syndrome(DS) has recently started in Japan. However many medical scientists do not agree with the spread of this screening, since it is easy to perform in any obstetric clinic, but genetic counselling staff are not available at most of these clinics in Japan. In April 1996 a documentary about MS screening was televised. We asked female students taking a midwifery training course at two nursing schools, and a social welfare course at a college for their opinion about this screening after watching the TV programme. Most of the students were unable to comprehend exactly the concept of MS screening. However, they were concerned that as the results of screening is not certain, it is difficult for the public to understand, therefore women who obtain a positive or false negative result may be psychologically injured. They were also concerned that pregnant women might select easy termination of pregnancy without considering the life and rights of the people with DS. During lectures on congenital disorders, students should be taught that most parents have a great love for their children with DS and feel that the life including people with DS in the family and the community is not only suffering but also pleasing. However, only a few people get this information. We asked 20 students at the nursing school in shizuoka whether they would conduct screening or not, and 15 stated that they would not. Four stated that they would conduct it. Of these, three stated that they would wish to know and think of the life of their future children and themselves, and one stated that she would terminate for fear of child with any anomaly if the result of the screening was positive. 
Mutation View : A NETWORK DATABASE SYSTEM FOR HUMAN DISEASE-ASSOCIATED MUTATIONS. Shinsei MINOSHIMA, Susumu MITSUYAMA and Nobuyoshi SHIMIZU (Department of Molecular Biology, Keio University School of Medicine, Tokyo)

The genes responsible for hereditary disorders and cancers are being investigated as one of the most important aspects of the human genome project. To date, approximately 1,100 diseases have been mapped to particular chromosomal regions and over 500 diseasecausing genes have been identified. We have developed a computer software Mutation View to systematically integrate genetic, molecular biological and clinical findings of each disease and to assist DNA diagnosis and gene therapy. The features of Mutation View are as follows.

(1) Chromosome ideograms are drawn to list diseases in the mapped regions. OMIM documents can be cited for each disease. (2) Primary structure of the gene or its cDNA is shown schematically and various mutations are located on appropriate positions with symbols. The detailed information of each mutation is displayed by clicking of the mutation symbol. Zoom-in is possible in wide ranges until nucleotide sequence can be displayed. Relative frequency or number of cases for each mutation can be shown as a histogram and classification of mutation types or symptoms is available. (3) Input and editing of new mutations are easily manipulated and new data can be shown together with existing data. (4) The exact mutation is shown with reference of normal nucleotide sequence. Change of restriction sites on the mutation position can be automatically analyzed even for newly added data. (5) Since this Mutation View has been designed as a distributed database, any laboratory can take a role as a server site for a particular disease and the users can access to any disease information via internet.

A prototype of Mutation View using a cystic fibrosis database compiled by Dr. LapChee Tsui has been demonstrated using a workstation.

(This work was done in collaboration with Chi Co., Ltd. and NEC Corporation.)

C-1

PRESSURE-INDUCED CELL DEATH AND APOPTOSIS IN HUMAN

LYMPHOBLASTS. Takako TAKANO, Yasuko YAMANOUCHI (Dept. of

Hygiene \& Pub. Health, Teikyo Univ. School of Med., Tokyo), Takaaki SATOU and Kaoru J. TAKANO (Institute of Materials Science, Univ. of Tsukuba, Tsukuba)

The observation of human cells at high pressure is useful to research the cell biology and medical application. We investigated the cell death of EB virus transformed human lymphoblast pressureized for 30 minutes at $37^{\circ} \mathrm{C}$ using a high pressure apparatus. The viability just after releasing high pressure decreased from $100 \%$ to $0 \%$ with increasing pressure from $85 \mathrm{MPa}$ to 200 $\mathrm{MPa}$. In the case of $50 \mathrm{MPa}$, the viability was not damaged during monitered 48 hours after decompression and cell counts increased gradually. In the case of $100 \mathrm{MPa}$, necrosis progressed after decompression for about 12 hours. The apoptotic cells, which were detected by TUNEL method and Hoechst 33258 nuclear stain, began to be observed from 8 hours after decompression. By 24 hours, there was an increase in the percentage of apoptosis. Induction of apoptosis by compression and acceleration of both apoptosis and necrosis in $S$ phase, were confirmed. 
$\mathrm{C}-2$

EVOLUTIONARY CONSIDERATION FOR THE GENEALOGICAL ORIGIN OF HUMAN CHROMOSOME 9 BY FISH ANALYSES IN HIGHER PRIMATES. Hideyuki TANABE, Takafumi ISHIDA ${ }^{2}$, Shintaroh UEDA ${ }^{2}$, Toshio SOFUNI ${ }^{1}$ and Hiroshi MIZUSAWA ${ }^{\prime}$ ('Cell Bank Labo., Div. Genet. and Mutagenesis, Natl. Inst. Health Sci., Tokyo, ${ }^{2}$ Graduate School of Sci., The Univ. of Tokyo, Tokyo)

Evolutionary origin of human chromosome 9 (HSA9) and its homologues of higher primates were genealogically considered through comparative mapping of the immunoglobulin processed pseudogene C 83 (IGHEP2) and three DNA markers on HSA9. IGHEP2 (HSA9p24.2 $\rightarrow$ p24.1) was assigned to PTR1lq34 (common chimpanzee), PPA11q34 (pygmy chimpanzee), GGO13q22 (gorilla), PPY13q16 (orangutan), HLA8qter (white-handed gibbon), HAG8qter (agile gibbon), and MFU14q22 (Japanese macaque) and other DNA markers were assigned to PTR/PPA11p11 (cCI9-37 and 135), PTR/PPA11q22 (cCl9-208), PPY13q22 (cCl9-37 and 135), and PPY13q12 (cCI9-208) by FISH. These results indicate that the pericentric inversions occurred twice during the hominoid evolution generating human and the great ape species. The first pericentric inversion occurred at PPY13p13/13q16 in a human-chimp ancestor after the branching off of the gorilla and the second pericentric inversion took place at PTR11p11/11q22 in the chimp branch. These data provide a hypothesis that supports the results from banding analyses of HSA9 and its homologues.

\section{$\mathrm{C}-3$}

AN IMPROVED SILVER-STAINING METHOD FOR "ACTIVE" CENTROMERES: ANALYSIS USING CONSTITUTIONAL DICENTRIC CHROMOSOMES.

Jia ZHAO, Tomohiro HAYAKAWA, and Tatsuro IKEUCHI (Dept. Cytogenet., Med. Res. Inst., Tokyo Med. Dent. Univ., Tokyo)

The centromere dot (Cd)-staining method by Eiberg (1974) has been well-known to selectively stain the "active" centromere, as revealed with pseudodicentric chromosomes. However, there are some problems in the Cd-staining method for its practical use, including stainablility and reproducibility. We have devised a more simplified and reliable method for $\mathrm{Cd}$-staining by modifying the silver-staining technique that is known to detect the nucleolar organizing regions: The method consists of incubation of chromosome slides in $2 \times \mathrm{SSC}$ at $60^{\circ} \mathrm{C}$ for $15 \mathrm{~min}$, and staining with an $\mathrm{AgNO}_{3}$ solution $(0.5 \mathrm{~g}$ of $\mathrm{AgNO}_{3}$ in $1 \mathrm{ml}$ of $\mathrm{DW}$ ) covered with a nylon cloth at $80^{\circ} \mathrm{C}$ for $40-60 \mathrm{~min}$. This $\mathrm{Ag} / \mathrm{Cd}$-staining method was applied to two different constitutional dicentric chromosomes seen in phenotypically abnormal patients. In psu dic(18) (p11.32) chromosomes in one case, the $\mathrm{Ag}$-stained $\mathrm{Cd}$ was positive only at the primary constriction, and no stain was seen at the second centromeric region, where both the C-band and FISH signals by using an alpha satellite DNA probe were positive with two separate dots on each chromatid. Thus, the present method was confirmed to discriminate between the "active" and "suppressed" centromeres in psu dic chromosomes. The other case had a rob $(21 ; 22)$ (p11;p11) chromosome with two C-bands, in which the two pairs of silver-stained $\mathrm{Cd}$ were detected, indicating that the two centromeres in this case were both "active". 


\section{C-4}

MEIOTIC CROSSING-OVER AND SEGREGATION OF INVERSION CHROMOSOMES. Shin-ichi SONTA, Noriko NOMURA (Department of Genetics, Institute for Developmental Research, Aichi Human Service Center, Kasugai, Aichi)

In the human population, there are a number of inversion carriers. However, the data on the crossing-over and segregation of inversion chromosomes are insufficient. By chromosome analysis of meiotic cells in male and female Chinese hamsters heterozygous for inversion 1,4 and $X$, we examined the segregation, meiotic crossing-over on the interstitial segment and interchromosomal effect of inversions. The chromosome analysis of MII cells revealed that the number of cells with an inversion and ones with a normal homologues was almost equal. The crossing-over on the interstitial segments of inversion chromosomes caused the appearance of a marker chromosome with unequal-length chromatids at MII. The analysis using such marker chromosomes revealed that the frequency of cells with crossing-over on the interstitial segments of inv(1), inv(4) and inv(X) chromosomes in female heterozygotes was $18.2 \%, 5.5 \%$ and $1.2 \%$ which was significantly lower than that on the same segments of normal chromosomes 1, 4 and X. Further analysis of MII chromosomes from single and double heterozygotes for both inversion and reciprocal translocations indicated that the existence of inversion induced no abnormal disjunction of normal chromosomes and also had no influence on the segregation of the quadrivalents. These findings suggest that inversions have no interchromosomal effect.

\section{$\mathbf{C}-5$}

STUDY OF ANEUPLOIDY RATE OF SPERM IN A MAN HETEROZYGOUS FOR A $\mathrm{t}(3 ; 9)(\mathrm{p} 25 ; \mathrm{q} 32)$ RECIPROCAL TRANSLOCATION BY FISH. Hiroshi HONDA, Norio MIHARU, Nao NAKATA, and Koso OHAMA. (Dept. of Obstet.and Gynecol., Hiroshima Univ. School of Medicine, Hiroshima )

[Objectives] In order to quantify the relative proportion of sperm with unbalanced chromosomes resulting from the meiotic segregation, molecular cytogenetic analysis was done with sperm from a man heterozygous for a $t(3 ; 9)(\mathrm{p} 25 ; \mathrm{q} 32)$ reciprocal traslocation carrier using fluorescence in situ hybridization (FISH). [Methods] Semen samples were obtained from the carrier and a normal man. Two color FISH was performed with DNA probes (biotin labeled alpha-satellite D3Z1 probe and digoxigenin labeled beta-satellite D9Z5 probe) . A total of 3319 sperm from the carrier and 3050 sperm from normal man were scored. [Resuls] The frequency of sperm with (3/-), $(3 / 9),(3 / 3 /-),(3 / 3 / 9),(3 / 3 / 9 / 9),(3 / 9 / 9),(-/ 9 / 9),(-/ 9)$ signal was $2.95 \%, 90.3 \%$, $0.271 \%, 1.48 \%, 0.181 \%, 1.17 \%, 0.421 \%, 3.10 \%$, respectively in a carrier, and $0.280 \%, 99.0 \%, 0 \%, 0.280 \%, 0.0628 \%, 0.249 \%, 0 \%, 0.0621 \%$ in a control man. [Conclusion] These data indicate that at least $10 \%$ sperm arc produced by unbalanced segregation. 
C-6

OBSERVATIONS OF DERIVATIVE CHROMOSOMES FROM RECPROCAL TRANSLOCATIONS BY SCANNING ELECTRON MICROSCOPE.

Takenari NINUMA, Shigeki UEHARA, Toshifumi TAKABAYASHI, Kunihiro OKAMURA, Akira YAJMMA. (Dept. Obster. Gyne. Tohoku Univ. Sendai.) Hiroyuki SASAKI (SASAKI Gyne. Sendai)

we observed the fine structure of derivative chromosomes from reciprocal translocations by scanning electron microscope (SEM) and recognized irregularity of the chromosomal structure on the connective points of reciprocal translocations. we studied three cases: $46, X X, t(6 ; 7)(q 25 ; p 15), 46, X X, t(X ; 19)(q 22 ; q 13), 46, X X, t(3 ; 14)(p 21 ; q 32)$ and had white blood cells from them. we cultured them on RPMI 1640 (20\% FCS,3\% PHA added) for 72 hous and added Colcemid and harvested and made them low tensile and fixed dry on slideglasses. we dyed them by Gyemsa metbod for 3 hours and took pbotographs by light microscope and choose adequate chromosomes on metaphase and cut and put them steamed by platinum and observed by SEM. we recognized gap which width is about $0.5 \mu \mathrm{m}$ in correspondence to the points connected by large fragments of reciprocal translocations (der(6), der(19), der(14)) in all three cases and we did not find out the same changes of structure in derivative chromoromes connected by small fragments of reciprocal translocations. this data suggest that there is the irregularity of chromatin fibers in connective points of derivative chromosomes originated from reciprocal translocations and the width is in accordance with middle sized Gband.

\section{C-7}

PCR-BASED DETECTION OF MOSAICISM IN CYTOGENITICALLY 45,X TURNER SYDNROME PATIENTS. Tohru YORIFUJI, Junko MUROI, Masahiko KAWAI (Dept. Pediat., Kyoto University Hospital) Hiroshi SASAKI (Dept. Pediat., Kurashiki Central Hospital), Toru MOMOI (Dept. Pediat., Japanese Red Cross Society Wakayama Medical Center), Masayuki KAJI (Dept. Pediat., Shizuoka Children's Hospital),

To study the possible role of cryptic mosaicism in phenotypical variations of 45,X Turner syndrome, we analyzed low-level mosaicism by PCR-based methods. For detection of $X$ chromosome mosaicism, we employed a novel modified HUMARA assay, which proved to be a sensitive method with a detection limit as low as 1 in 960 cells. Using this assay, we detected low frequency cryptic $X$ chromosome mosaicism in 2 of 18 cytogenetically $45, \mathrm{X}$ patients. 


\section{C-8}

SMALL INTERSTITIAL DELETION OF THE LONG ARM OF CHROMOSOME 2 (2q24.3) DETECT BY ASSISTANCE WTTH OUR ORIGINAL COMPUTERIZED DATABASE, UR-DBMS. Yasutsugu CHINEN, Takaya TOHMA, Yoshinori IZUMIKAWA, Tetsu IHA, Yoshinobu GOYA, Kenji NARITOMI (Dept. Pediat., Ryukyus Univ.Sch. Med.,Okinawa)

To date, 30 patients have been described with deletions of the long arm of chromosome 2. A distinct phenotype-karyotype correlation has been suggested in patients with del(2)(q31q33)(Ramer et al., 1989). We report on an additional patient with a karyotype, 46,XX,del(2)(q24.2q31). The proposita was bom at 38 weeks of gestation and had a birth weight of $1984 \mathrm{~g}$. She had a peculiar facies similar to Treacher-Collins syndrome due to downward slanting of the palpcbral fissures, low-set and posteriorly rotated ears and microretrognathia. Other findings included an occipital encephalocele, hypertelorism, short palpebral fissures, a beaked nose with its bulbous tip, clenched hands and complete atrio-ventricular septal defect. At two months of age, she died of the progressive heart failure. By the use of our original computerized database, UR-DBMS (Naritomi, 1996), chromosomal aberrations were highly suspected. We detected a small interstitial delction involving the band $2 \mathrm{q} 24.3$ in high-resolution GTG-banded. chromosomes. To confirm a phenotype-karyotype correlation among medial $2 q$ monosomies, clinical findings of 10 reponted patients with a deletion involving $2 q 24$ were compared with those of 11 reported patients with a del(2)(q31q33). As a result, the cardinal findings and their frequencies are almost similar between the two. Because the smallest region of overlap is located at a band $2 q 31$, we may define a $2 q$ medial monosomy syndrome associatcd with a delction of $2 q 31$.

\section{C-9}

SEX PHENOTYPE IN 45,X/46,X, dic(Yq) INDIVIDUALS: CYTOGENETIC AND MOLECULAR STUDIES. Michio TERAOKA, Koji NARAHARA, Kiyoko KOYAMA, Yuji YOKOYAMA, Rintaro Mori and Yoshiki SEINO (Dept. Pediatr. Okayama Univ. Med. Sch. Okayama)

The 45,X/46,X, $\operatorname{dic}(\mathrm{Yq})$ mosaicism is associated with various sex phenotypes. To clarify whether the sex phenotype is caused by a dilution effect or abnormality of SRY gene, we conducted cytogenetic and molecular studies in 4 patients with this mosaicism, of whom 2 had normal male phenotype and 2 Turner syndrome. Chromosome analysis showed that the ratio of cells with a $\operatorname{dic}(\mathrm{Yq})$ varied from an individual to an individual (25-100\% in peripheral blood lymphocytes, and 0-50\% in skin fibroblasts) and was not related to the given sex phenotype. PCR of lymphocyte DNAs demonstrated an intact SRY gene in all patients. FISH studies using a SRY gene probe, $\mathrm{pHu} 14$, showed two discrete signals on $\operatorname{dic}(\mathrm{Yq})$ chromosomes from both patients with Turner syndrome and male phenotype. We conclude that the distribution of cells with a $\operatorname{dic}(\mathrm{Yq})$ in primordial gonads may be a major determinant of sex phenotype in $45, X / 46, X, \operatorname{dic}(Y q)$ individuals. 
C-10

A CASE OF 45,X/46,X,idic(Y)(q11.2) WITH SHORT STATURE AND NORMAL MALE EXTERNAL GENITALIA.

Eiko HIDAKA ${ }^{1}$, Keiko WAKUI $^{2}$, Masayo ISHIKAWA ${ }^{1}$, Kyoko ADACHI $^{3}$, Hideo USHIKU $^{3}, \underline{\text { Keiko }}^{2}$ TOMTTA ${ }^{4}$, Yutaka NAKAHORI ${ }^{4}$, Tutomu KATSUYAMA ${ }^{5}$, Yoshimitsu FUKUSHIMA ${ }^{2}$ ('Central Clinical Laboratories, 2 Hygiene and Medical Genetics, 5 Laboratory Medicine,Shinshu University School of Medicine,Matsumoto, ${ }^{3}$ Saku General Hospital, ${ }^{4}$ Tokyo University.)

A 4-month-old male infant was the second child of phenotypically normal parents. He had short stature, normal male external genitalia, and peculiar facies resembling Tumer syndrome. Chromosome analyses by G- and Q-banding and FISH using DYZ3 revealed the following karyotype: $45, X[25] / 46, X, \operatorname{idic}(Y)(q 11.2)$.ish idic(Y)(DYZ3++)[23]/47, $\mathrm{X}, \operatorname{idic}(\mathrm{Y})(\mathrm{q} 11.2) \times 2$ ish idic $(\mathrm{Y})(\mathrm{DYZ} 3++\mathrm{x} 2)[2]$. $\mathrm{PCR}$ analysis with $\mathrm{Y}$-specific sequence tagged sites revealed: PABY(+), SRY(+), AMGL(+), DYZ3(+), DYS139(+), DYS132 $(+)$, DYS1(-), and DYZ1(-). Thus, the breakpoint was delimited between DYS132 and DYS1.

$45, X / 46, X, \operatorname{idic}(Y)(q 11.2)$ has been reported in more than 70 patients. About a half of the patients were phenotypically female, $25 \%$ had ambiguous genitalia and $25 \%$ were phenotypically male. The majority of the phenotypically male patients were affected with abnormal genitalia. An estimation of gonadal function, observation of Turner stigmata, DNA analysis of the deleted region of the $Y$ chromosome and detection of mosaic frequency among different tissues are necessary in this patient.

C-11

A FEMALE CASE OF ALPORT SYNDROME COMPLICATED WITH SHORT STATURE AND HYPOGONADISM SHOWING THE KARYOTYPE OF $46 \mathrm{X}, t(\mathrm{X} ; 1)(\mathrm{q} 22 ; \mathrm{p} 31.1)$. Makoto INOUE, Satomi MIYAMOTO, Seiji YAMAGUCHI (Dept. Pediatr. Shimane Medical University, Shimane) and Kiyoshi KIKUCHI(Dept. Pediatr. Shimane Prefectural Central Hospital, Shimane)

Alport syndrome is characterized by progressive hereditary nephritis and sensorineural deafness, and is inherited in an $\mathrm{X}$-linked fashion in most patientes. It has been attributed to abnormalities in the alpha 5 chain of collagen type IV molecules(COL4A5), whose gene is assigned to chromosome Xq22.

We discribed a female case with Alport syndrome complicated with short stature $(-3 S D)$, obesity $(+69 \%)$, webbed neck and hypogonadism, showing the karyotype of $46 \mathrm{X}, t(X ; 1)$ (q22;p31.1). It was observed by the $R$-band staining that normal $\mathrm{X}$-chromosomes were inactivated. Immunohistochemical study of renal tissue revealed undetectable COL4A5. The break point on the $X$ chpomosome in this patient was coincident with the locus of the Alport gene. Moreover, it is located within the gene region of Xq13-27 that participates in the development of gonads and could be causative of Turner syndrome-like symptoms in this patient. 
C-12

PALATAL RUGA ANOMALIES IN MUTANT MOUSE AND RAT MODELS FOR HUMAN CONGENITAL ANOMALIES. MinEO YASUDA, MizuYO TSUGANE, Ichita MIWA (Dept. Anat. Hiroshima Univ. Sch. Med., Hiroshima), Shinichi MIYABARA (Fetal Genetic Pathology Lab., Saga Med. Sch., Saga) and Michio FUJIWARA (Safety Res. Lab., Yamanouchi Pharm. Co. Ltd., Tokyo)

The oral surface of the palate in mice and rats has eight or nine pairs of transverse ridges, or rugae. In the present study, we examined palatal ruga anomalies in trisomy 16 mice (a mouse model for human trisomy 21), trisomy 14 mice (with high incidence of cardiac anomalies), and Uchida rats (a mutant of which heterozygotes have small eyes resulting from a mutation in the Pax-6 gene). All of the trisomy 16 mouse fetuses had severely altered ruga patterns such as deletion, median division, shortness, and maldirection. Trisomy 14 mouse fetuses showed mild anomalies with supernumerary rugae in the posterior part of the palate. Uchida rat young had rugae with division, peakless, discordance, and supernumerary. These findings indicate that the pattern of palatal rugae is a good phenotypic marker for observation of mutant mice and rats.

\section{C-13}

DERMATOGLYPHICS ON VOLAR SKIN OF TRISOMY 16 MOUSE FETUSES. Mizuyo H. TSUGANE, Mineo YASUDA (Dept. Anat. Hiroshima Univ. Sch. Med., Hiroshima), Shinichi MIYABARA (Fetal Genetic Pathology Lab., Saga Med. Sch., Saga)

It is widely known that Down's syndrome (human trisomy 21) exhibits characteristic dermatoglyphs. We investigated the dermatoglyphs on volar skin of Trisomy 16 (Ts 16) mouse fetuses, the animal model for human trisomy 21 , on gestational day (GD) 18 (plug $=\mathrm{GD} 0$ ) to clarify the relationship between the trisomy and the abnormal dermatoglyphs. Additionally, we compared the dermatoglyphs of Ts 16 fetuses with those of fetuses maternally treated with all trans-retinoic acid (RA) on GD 12.5.

On the volar skin, normal mice have four kinds of pads; 1) digital, 2) interdigital and carpal (tarsal), 3) caterpillar, and 4) cobblestone pads. The pad pattern forms a characteristic dermatoglyph, and is almost constant in every normal mouse. in Ts 16 fetuses, the pad pattern was affected; the cobblestone pads disappeared on all limbs, extra pads often appeared between interdigital pads, and some hindlimbs lacked the fibular tarsal pad. Similar abnormal pad patterns were observed between Ts 16 and RAtreated fetuses. This is the first time that mouse fetuses with chromosomal aberrations are proved to have abnormal dermatoglyphs as human counterparts. These results suggest the possibility to clarify the mechanisms for abnormal dermatoglyphs due to chromosomal aberrations.

(Supported by grant \#08255236 from the Ministry of Education, Science and Culture, Japan.) 
$\mathrm{C}-14$

THE DIFFERENTIATION OF THE UPPER-LIMB MOVEMENT AND

HAND DOMINANCE FOR DOWN SYNDROME. ASAGI YAGINUMA, Hiroshi USHIZIMA (Faculty of Medicine, Department of Maternal and Child Health, Tokyo University, Tokyo) and Makoto HIGURASHI (Tokyo Kasei University, Tokyo)

The purpose of this study was to invastigate the differentiation of the Upper-Limb movement for children with Down Syndrome. The task of the winding thread around a spool was administered to both Down syndrome children and comparison groups. Children with Down Syndrome had the retardation of the differentiation of the Upper-Limb movement, and the level of motor development was nearly the same developmental stage as the normal children (4 years to 6 years). Girls with Down Syndrome winded the thread faster than boys with Down Syndrome significantly. Boys winded faster than the right hand than the left hand.

\section{C-15}

THYROID FUNCTIONS OF DOWN SYNDROME. Byuichi TSUKINO (Dept.Pediat, ,Arida City Hospital, Wakayama), Mitsuyo SASAKI (Dept.Pediat, Wakayama Medical College, Wakayama).

A total of 144 individuals with Down syndrome aged 0 to 29 were observed for medical and social care at genetic department of Wakayama Medical College and Kinan general hospital .

As one of these medical cares, TSH, free T3 and free T4 were examined as screening test for thyroid functions. Under one age, about $1 / 3$ showed abnormally high value of $\mathrm{TSH}(>5 \mu \mathrm{U} / \mathrm{ml})$. And 3 infants were diagnosed as hypothyroidism and suffered supplement therapy. But the remains were observed without therapy about 6 months for a regular check-up. To evaluate this procedure which proper or not, the height as an index of thyroid functions of two groups (TSH $<5 \mu \mathrm{U} / \mathrm{ml}$ and TSH $\geqq 10 \mu \mathrm{U} / \mathrm{ml}$ group)were compared. In one group which was observed from under one year ,individuals of showing of TSH $<5 \mu \mathrm{U} / \mathrm{ml}$ and $\mathrm{TSH} \geqq 10 \mu \mathrm{U} / \mathrm{ml}$ were 16 respectively. The other group was observed through whole follow -up period and the former was 27 and later 25 respectively. The $t$ test showed no significance difference at height between both groups. We conclude that if abnormal clinical findings and any other abnormal thyroid function tests are not found, this our follow-up studies were proper. 
$\mathrm{C}-16$

STUDY ON THE RELATIONSHIP BETHEEN CLINICAL PHENOTYPES AND X CHROMOSOME ABNORMALITIES. Yuko SHINTAKU (Dept. Obstet. Gynecol., Iwate Prefectual Iwai Hospital, Iwate) Shigeki UEHARA, Toshifumi TAKABAYASHI, and Akira YAJIMA (Dept. 0bstet. Gynecol., Tohoku University School of Medicine, Sendai)

We have examined $X$ chromosome abnormalities in patients referred to Tohoku University Hospital because of primary or secondary amenorrhea and habitual abortion. 20 of 68 primary amenorrhea(28\%), 4 of 16 secondary amenorrhea (25\%), and 13 of 266 habitual abortion (5\%) showed $X$ chromosome abnormalities. There was 10 of non-mosaics, and 27 of masaicism. In non-mosaic cases, monosomy $X(45, X)$ was seen in only one case, the other cases had a variety of karyotypes with a structual alteration of the $X$ chromosome : 2 of isochromosome for long arm of $X$, 3 deletions of part of $X p$ or $X q, 1$ ring $X$ chromosome, 2 balanced translocations and 1 unbalanced translocation. Most of the mosaic cases had $45, \mathrm{X}$. In habitual abortion $47, \mathrm{XXX}, 48, \mathrm{XXXX}$ were also seen, but the proportion of abnormal $X$ chromosome was very low. Short stature was observed in deletions of $\mathrm{Xp}$.

C-17

DE NOVO $t(2 ; 15)$ TRANSLOCATION IN A BOY WITH PROBABLE SHPRINTZEN-GOLDBERG SYNDROME. ShINSUKO NINOMIYA RYOZO KASAl (Asahigawa Jidoin Children's Hospital, OKayama), KOi i NARAHARA Yuji YOKOYAMA, and Yoshiki SEINO (Dept. Pediatr. Okayama Medical School, okayama)

Shprintzen-Goldberg syndrome (SGS) represents a clinical syndrome characterized by craniosynostosis and mental retardation in addition to Marfan syndrome findings. Recently, mutation of FBNl were detected in two patients with this syndrome. We reported a $10-$ year-old mentally retarted boy who had characteristic craniofacial dysmorphia, arachnodactyly, retentio testis, and tetralogy of Fallot. His phenotype is consistent with SGS. Chromosomal analysis showed a karyotype of $46, \times Y, t(2 ; 15)$ (q2 4.2; q21.2) or (q31.1; q22. 1) de novo. The localization of the 15 q breakpoint in this pationt at 15 q21 to which FBNi is mapped and the report of mutation suggest that FBN may be a candidate gene of SGS. 
C-18

ANALYSIS ON A RELATIONSHIP BETWEEN THE PHENOTYPE AND
FREQUENCY OF TRISOMIC CELLS IN FIVE MOSAICS FOR TRISOMY 20

K. Abe (Kyushu Med. Sci., Nagasaki), H. Miharu (Dept. Obstet. Gynecol., Hiroshima Univ.), Y. Hisanaga (Hisanaga Clinic), T. Nakaya (Dept. Obstet. Gynecol., Midori City Hosp.), K. Kunimoto (Dept. Obstet. Gynecol., Takizawa Center Hosp.), H. Masuzaki and N. Niikawa (Dept. Obstet. Gynecol. and Dept. Hum. Genet., Nagasaki Univ.)

Approximately $90 \%$ of trisomy-20 mosaics were associated with a grossly normal phenotype, and 20-trisomic cells have not been detected in their blood cultures. It is likely that, in the majority of cases, cells with trisomy 20 were extraembryonic in origin or largely confined to certain fetal organs. Moreover, it is impossible to determine the tissue origin of 20 -trisomic cells in amniocytes. Thus, trisomy-20 mosaicism has a serious dilemma in prenatal diagnosis and genetic counseling. We experienced 5 cases of trisomy 20 mosaicism among 4,782 cases with prenatal chromosomal analysis, and examined whether the phenotype is related to the frequency of trisomic cells in these mosaics. Of 4 cases whose trisomic cell-frequency was less than $60 \%$, two showed a normal phenotype but the other two were uninformative. One case with $94 \%$ of cell frequency showed a slightly abnormal phenotype without renal and heart abnormalities typical for reported trisomy-20 mosaics, indicating that a high mosaic frequency is not always related to severe abnormalities.

\section{C-19}

A 12q PARTIAL MONOSOMY(q11-13.1) BOY WTTH A COMPLEX

TRANSLOCATION INVOLVING CHROMOSOME 12,13, AND 21. Mitsuyo

SASAKI (Dept. Pediat., Wakayama Medical College, Wakayama), Rruichi TSUKNNO

(Dept. Pediat., Arida City Hospital, Wakayama), Kiichi SHIMIZU, and Takahiro

MNNESHITA (Shionogi Biomedical Laboratories, Osaka)

We report on a 4-year-old boy with mild mental retardation and an apparently unbalanced de novo translocation involving chromosomes 12,13, and 21 , and six break points ( 4 points in chromosome 12, one point in 13 and 21 , respectively).

To determine detail break points, whole painting probe and high resolution G-banding was complexed, and he was diagnosed $12 q$ partial monosomy doe to interstitial deletion $12 \mathrm{q}$ from $\mathrm{q} 11$ to $\mathrm{q} 13.1$

The karyotype was $46, X Y,+\operatorname{der}(12) \mathrm{t}(12 ; 13 ; 21)(21 \mathrm{pter} \rightarrow 21 \mathrm{q} 21:: 21 \mathrm{p} 21.2 \rightarrow$ $12 q 11:: 12 q 21.2 \rightarrow 12 q 13.1:: 13 q 32 \rightarrow 13 p t e r),+\operatorname{der}(13) t(12 ; 13)(q 21.2 ; q 32)$, $+\operatorname{der}(21) \mathrm{t}(12 ; 21)(\mathrm{p} 12.2 ; \mathrm{q} 21)$.

In our knowledge ,this type deletion was not found.

The child had a hirsutism, long eyelashes, strabismus, synophrys, flat nasal bridge, bulbous nose, arched mouth, short philtrum, full cheeks, low hair line, simian lines, moderate short stature $(-1.5 \mathrm{SD})$ and mild mental retardation. 
$\mathrm{C}-\mathbf{2 0}$

A Yq- CASE OF SHORT STATURE WITH Q-BANDING NEGATIVE HETEROCHROMATIN REGION. Kvoung Chang KIM Kazunari MATSUSHIMA Tsutomu OHNO, Hirofumi OHASHI (Saitama Children's Med. Ctr, Saitama) and Keiko WAKUI and Yoshimitsu FUKUSHIMA (Shinshu Univ. Sch. Med., Nagano)

The patient, a male, was born at 39 weeks of gestation to healthy and unrelated parents. His birth weight was $1,440 \mathrm{~g}(-4.4 \mathrm{SD})$ and length $40 \mathrm{~cm}(-5.3 \mathrm{SD})$. G-banded chromosome analysis revealed a $46, X,+$ mar karyotype. By FISH with $Y$ specific centromeric repetitive probe (DYZ3), the marker was found to originate from $Y$.We diagnosed that it was Yq-.Q-banding showed no fluorescent heterochromatin region on the $\mathrm{Yq}$, though other cytogenetic and FISH analyses revealed a tiny but obvious heterochromatin segment at its end. At 14 months his length was $71 \mathrm{~cm}(-2.3 \mathrm{SD})$ and his development was normal.His father had a normal $Y$ chromosome.The break of the $\mathrm{Yq}$ in this patient seems to separate the heterochromatin region of $\mathrm{Yq}$ into $\mathrm{Q}$-banding positive and negative segments. Furthermore, this case may suggest that putative growth control genes exist at this Q-banding negative heterochromatin segment of $\mathrm{Yq}$.

C-21

Monozygotic twins with CATCH22 and discordant phenotype

Hiroyuki YAMAGISHI, Chihiro ISHII, Jun MAEDA, Yoshifumi KOJIMA, Nobutake MATSUO (Dept. Pediatr., Keio Univ., Tokyo), Rumiko MATSUOKA, Misa KIMURA, Atsuyoshi TAKAO, Kazuo MOMMA (Tokyo Women's Medical College, Tokyo)

CATCH22 (cardiac defect, anomaly facies, thymic hypoplasia, cleft palate and hypocalcaemia) is due to deletion on chromosome 22q11. Goodship et al. recently described $22 \mathrm{q} 11$ deletion in monozygotic twins having discordant phenotypes (J. Med. Genet. $1995 ; 32: 746-8$ ). We report on male monozygotic twins with CATCH22 in whom phenotypic discordance was more conspicuous. They were delivered at 37 weeks' gestation with twin 1 weighing $1572 \mathrm{~g}$ and twin 2 weighing $2376 \mathrm{~g}$. Twin-twin transfusion syndrome was diagnosed (hemoglobin, twin $1 ; 10.4 \mathrm{~g} / \mathrm{dl}$ vs twin $2 ; 17.4 \mathrm{~g} / \mathrm{dl}$ ). FISH analysis showed microdeletion on chromosome $22 \mathrm{q} 11$ in each and various blood types were identical (probability of monozygosity of 99.95\%). Twin 1 had cardiac defect, characteristic facial appearance, swallowing dysfunction, anal atresia, and mental retardation. Twin 2 had characteristic facial appearance but no other stigmata of CATCH22. Our observation further suggests that phenotypic variability in CATCH22 may be in part due to early intrauterine environmental factors. The role of twin-twin transfusion syndrome appears to be subsidary, since it occurs late in intrauterine life. 
$\mathrm{C}-22$

Evolving clinical spectrum in CATCH22: Observations on 20 patients Jun MAEDA, Hiroyuki YAMAGISHI, Rika KIZU, Yoshifumi KOJIMA, Nobutake MATSUO (Dept. Pediatr., Keio Univ., Tokyo)

Chromosome 22q11 deletion syndrome, CATCH22 (cardiac defect, anomaly facies, thymic hypoplasia, cleft palate and hypocalcemia) is known to present a wide clinical spectrum. We report on subtle features of velo-pharyngeal insufficiency and hypoparathyroidism in 20 patients (14 boys and 6 girls, ages 1 - 15 years) of CATCH22. Abnormalities found in these patients included anomaly facies in 20 , cardiac defects in 16 , recurrent aspiration pneumonia in 9 , velo-pharyngeal insufficiency in 12, and hypocalcemia in 10 . Of the 12 patients with velo-pharyngeal insufficiency, one had overt cleft palate that was diagnosed during neonatal period, and five had occult (submucous) cleft palate that was diagnosed during late infancy when assessment of speech became feasible. Of the 10 patients with hypocalcemia, four had overt hypoparathyroidism manifested by neonatal tetany or convulsion, and six had latent hypoparathyroidism with no clinical sign and symptom. These six patients developed overt hypocalcemia in infancy after prolonged fasting, and two of the six developed overt hypoparathyroidism in puberty. These observations indicate that the clinical definition of CATCH 22 awaits a careful follow-up of similarly affected patients from early infancy to adulthood.

C-23

CORRELATION BETWEEN SMALLER DELETION SIZE AND MENTAL RETARDATION IN del22q11.2 SYNDROME.

Rumiko MATSUOKA', Nobuyoshi SHIMIZU², Misa KIMURA', Shinsei MINOSHIMA ${ }^{2}$, Shin-ichiro IMAMURA', Atsuyoshi TAKAO', Kazuo MOMMA' ('Tokyo Women's Medical College, Dept. of Mol. Biol., Keio Univ. Sch. Med., Tokyo)

DiGeorge anomaly (DGA), conotruncal anomaly face syndrome (CAFS), velo-cardio-facial syndrome and Opitz GBBB syndrome have similar but variable phenotypes, and share the deletion of $22 q 11.2$ as a common feature. One hundred and seventy seven CAFS and 18 DGA patients, who had del22q11.2 detected by fluorescent in situ hybridization (FISH) using a N25 (D22S75) DGCR probe, were examined to compare deletion size and phenotypes. Five out of 177 patients had smaller deletion sizes than $2 \mathrm{Mbp}$ and 3 of them had no mental retardation. CAFS and DGA without CAF patients who did not have del22q11.2 were examined by FISH using a SD10p1 probe. No deletion of $10 p$ region was detected. 
C-24

IDENTICAL TWINS DISCORDANT FOR TURNER SYNDROME: FISH ANALYSIS USING INTERPHASE NUCLEI OF BUCCAL MUCOSA. Keiko WAKUI ${ }^{1}$ Makoto MKAWA $^{2}$ Yoshimitsu FUKUSHIMA ${ }^{1}$ (Dept. of Hygiene and Medical Genetics, Shinshu University School of Medicine, Matsumoto ${ }^{1}$, Kitami Red-Cross Hospital, $\mathrm{Kitami}^{2}$ )

Conventional chromosome analysis using peripheral lymphocytes revealed mos $45, \mathrm{X} / 46, \mathrm{XX}$ in both 16 -month-old identical twins. The frequency of $45, \mathrm{X}$ cell was $5 / 30$ (17\%) in Twin 1 and $8 / 30(27 \%)$ in Twin 2. Twin 2 had typical features of Turner syndrome including short stature, webbed neck and peculiar facies, while Twin 1 was phenotypically normal. Detection of the number of chromosome $X$ was performed on buccal smear preparations from the twins by FISH using DXZ1 probe. 500 nuclei were observed in each case. The frequencies of each number of signals of chromosome $X$ [1:2:3 (signals)] were: [3.4: 95.8: $0.8(\%)$ in Twin 1, [96.7: 3.3: $0(\%)$ ] in Twin 2 and [2.3: 95.4: $2.3(\%)$ ] in normal female control. These findings suggest that loss of an $\mathrm{X}$ chromosome occurred early in embryogenesis with complete separation of $45, \mathrm{X}$ and $46, \mathrm{XX}$ cell lineages at the first cleavage division of the zygote, and the mosaicism in the peripheral blood of the twins is due to twin-to-twin transfusion resulting in a mixture of the two-cell populations in the hematopoietic tissue. Interphase FISH on buccal smear preparations is a rapid, effective and non-invasive method for studies of mosaicism.

\section{C-25}

DETECTION OF ADDITIONAL CRYPTIC CHROMOSOME REARRANGEMENTS BY FISH IN PATIENTS WITH STRUCTURAL CHROMOSOME ABNORMALITIES: REPORT OF TWO CASES. Kazushige MATSUSHIMA, Keiko WAKUI, Takeshi ITO Kyoung Chang KIM(Saitama Children's Medical Center), Shoko TSUNNODA (Umeda Akebono Clinic, Tokyo), Masato TSUKAHARA (Yamaguchi University), Yamaguchi), Y oshimitsu FUKUSHIMA (Shinshu Univ. Sch. Med., Nagano), Hirofumi OHASHI (Saitama Children's Medical Center, Saitama)

We report on two patients with structural chromosomal abnormalities who have additional cryptic chromosome rearrangements unidentifiable on standard chromosome analyses. Case 1: The patient was a 12-year-old girl with features of mental retardation, characteristic facies and short stature. G-banding chromosome analysis showed that she had a direct duplication of $4 \mathrm{q} 31.3->\mathrm{q} 35$. FISH with $4 \mathrm{q}$ distal region painting probe confirmed this duplication, and further revealed additional cryptic translocation between the duplicated $4 \mathrm{q}$ region and chromosome 1 in $83 \%$ cells examined. Case 2: The patient was a 1 10/12-year-old boy with features of developmental delay, infantile spasms and linear skin pigmentation. G-banding analysis showed that he had a marker chromosome in $82 \%$ cells examined. The marker was diagnosed as inv dup(15) by DA/DAPI staining. FISH with D15Z1 (alpha-satellite probe specific for chromosome 15) confirmed this diagnosis, and further detected three D-group chromosomes with a D15Z1 signal. Qbanding $\rightarrow$ FISH with D15Z1 sequential analysis indicated that the extra D-group chromosome was chromosome 14 whose centromeric region was replaced by that of chromosome 15. 
C-26

AN ACCURATE GENDER DETERMINATION ASSAY FROM A SMALL AMOUNT OF DNA SPECIMEN AS AN AID FOR NON-INVASIVE PRENATAL DIAGNOSIS.

Tsuyoshi HASHIBA (Dept OB/GY, Sassa General Hospital, Tokyo), Kou SUEOKA, Noriko KOBAYASHI Masako KUROSHIMA, Toshifumi KOBAYASHI, and Yasunori YOSHIMURA (Dept. OB/GY, Keio University School of Medicine, Tokyo. )

For clinical application of genetic diagnosis from blastomeres, exfoliative fetal cells of the uterine cervix, or circulating fetal cells in the maternal blood, we have developed an accurate multiplex polymerase chain reaction (PCR) assay for gender determination from a small amount of DNA specimen. This assay co-amplifies $X$-and $Y$-specific repetitive sequences (DXZ1/DYZ1), so that 2 bands (DXZ1 and DYZ1 positive) implies male; single band (only DXZ1) means female; no band suggests amplification failure or sampling error. Each band was confirmed to be specific by the direct PCR products sequencing method. To evaluate accuracy and efficiency of this assay in single cell, we sampled a single amniocyte $(n=50)$ with a micromanipulator under an inverted microscope, extracted DNA from it, and analyzed. Sex determination by this PCR method was compared with that by karyotyping. The amplification success rate was $98 \%(49 / 50)$ and misdiagnosis was not observed. This newly developed assay appears efficient and accurate, thus may be applicable to the above mentioned clinical settings.

$\mathrm{C}-27$

APPLICATION FOR PRENATAL DIAGNOSIS OF FLUORESCENCE IN SITU HYBRIDIZA -TION HETHOD - ANALYSIS OF CHROHOSOHAL STRUCTURAL ABNORHALTIES Nobuhiro SUZUYORI, Yitsuyo TANEYURA, Kaoru SUZUYORI(Dept. Obstet. Gynecol. Nagoya City Univ. Hospital, Nagoya), Reiei RII, Hirofumi 0HASHI (Dept - Genetics. Saitama Children's Yedical Centre, I atsuki City. Saitama) and Keiko AKUI, Yoshimitsu FURUSHIM(Dept. Public Health. Shinshu Univ . . Matsunoto)

We studied that, for two pregnant wonen ith chromosomal structural abnornalities, analysis of chorionic villi cells and amiotic fluid cells culture was avarable or not, as prenatal diagnosis. Case 1 ; 34 -year -old-pregnant woman has had three times spontaneos abortions and her chromosone is $46, X X$, ins $(1 ; 2)(q 36 ; q 22 q 24)$. Case $2 ; 31$-year-old-pregnant wonan's chromosome is $46, X X, t(3 ; 12)(p 26.2 ; p 13.1)$ and her first kid had chromosomal abnormaities. Therefore, after informed consent, prenat al diagnosis was occured by fluorescence in situ hybridization(FISH) method. Casel(from chorionic villi);2a-satellite probe, cosmid probe cCI 2-503, Case2(from anniotic fluid);12a-satellite probe, 12 whole pa -inting probe, 3p-distal painting probe, cosaid probe cCI 12-134. After the FISH analysis, Casel; fetal chromosone was same to the mother. Case2; fetal chromosome was $46, \operatorname{der}(3)(3 ; 12)(\mathrm{p} 26.2 ; \mathrm{p} 13.1)$. Me adnitted that FISH method was avarable for prenatal diagnosis of a patient. wo had chromosomal structural abnormalities. 


\section{C-28}

IS THERE ANY PREDICTIVE VALUE IN CHROMOSOME ANALYSIS OF SPONTANEOUS ABORTUSES FOR THE OUTCOME OF SUCCEEDING PREGNANCIES? Kodo SATO, Tomoyuk i MIYAKAWA, Kyoko SHIODA (Dept. Obstet. Gynecol., Toranomon Hospital, Tokyo), Junko IMAMURA and Ryou NAKASONE (Dept. Hematol., Toranomon Hospital, Tokyo)

Predictive value of chromosome analysis of spontaneous abortuses for the outcome of succeeding pregnancies were studied, using 281 spontaneous abortions (1st $A B$ ) where chromosome analys is was carried out and another pregnancies (2nd PREG) were achieved after the 1st $A B$. The maternal age at the 1 st $A B$ and the incidence of spontaneous abortion among the 2nd PREG was revealed to be significantly correlated $(p<0.01)$, and the following formula was calculated. $Y=0.00433 X^{2}-0.267 X+4.156$ ( $Y$ : incidence of abortion among the 2nd PREG, X:maternal age at the lst $A B$ ). Thus, the expected incidence of abortion among the 2nd PREG was calculated. In cases with normal karyotype for the 1st $A B$, the incidence of spontaneous abortion among the 2nd PREG was $7 / 75$, whereas the expected incidence was $9.1 / 75$, thus the ratio of the real incidence against the expected was 0.77 ; in trisomy (121 cases) the ratio was 0.87 ; in triploidy (17 cases) 2.28; in tetraploidy (8 cases) 2.52; in 45, X0 (23 cases) 0.78 ; in mosaicism (27 cases) 0.95 , in structural abnormalities ( 6 cases) 0.00 ; in other abnormalities (4 cases) 4.76. No significant difference was observed for ratio of the real/expected incidence between the different chromosome abnormalities. Thus the chromosome analys is of the spontaneous abortuses was revealed to have of no or little predictive value for the outcome of the following pregnancies.

PRENATAL. DIAGNOSIS OF WILLIAMS SYNDROME BY FISH. Mashio KITATANI, Mamoru OZAKI, Hiroaki TAKAHASHI (Clin. Genet. KanazawaMed. Univ.), Tomoko INOUE (Toyonaka City Hospital), Toshikatu NOBUNAGA (Osaka Med. Center \& Res. Inst. for Maternal \& Child), Fumitaka SAJI, Yuji MURATA (Osaka Univ. Med. Sch.)

The Williams syndrome (WS) is cased by hemizygosity of elastin gene (ELN) on a chromosome region 7q11.23. A monosomy of an elastin locus can not be detected by cytogenetically except for a few cases associated with chromosomal rearrangement. Fluorescent in situ hybridization (FISH), using the Williams syndrome Chromosome Region probe, has been shown to be useful for the diagnosis of WS in lymphoblast. We performed a prenatal diagnosis at the request of the parents whose first child had been a Williams syndrome. Amniotic fluid cells obtained at 15 weeks of gestation, cytogenetical analysis revealed $46, \mathrm{XX}$. Hemizygosity for a region of $7 \mathrm{q} 11.23$, involving the elastin locus, was found in the first child, but was not found in the amniotic fluid cells of the fetus by FISH. The Pregnancy proceeded and resulted in a healthy baby. 
C-30

A CASB OF PARTIAL TRISOHY $11 \mathrm{p}$ DERIVED FROM MATERNAL BALANCED TRANSLOCATION. Tomoyuki MIYAKANA, Kyoko SHIODA, Rodo SATO

(Dept. Obstet. Gynecol., Toranomon Hospital, Tokyo)

Partial trisomy $11 p$ is rare chromosomal abnornalities and was first described by Francke(1972) and Falk et al.(1973), and approximately 20 cases have been reported. Trisomy 11 p was detected by amniocentesis on 24-year-old, gravida 0 woman who was pointed out ol igohydramnios and intrauterine growth retardation(IUGR) by ultrasonography at 27 weeks gestation. The result of amniocentes is was $46, \mathrm{XY}, \mathrm{der}(14) \mathrm{t}(11 ; 14)$. Chromosomal analysis of the parents was performed and thier karyotypes were $46, \mathbb{X}, t(11 ; 14)(\mathrm{p} 15.3 ; q 32.3)$, respectively. At 29 weeks gestation, rupture of the membrane occured and a $572 \mathrm{gm}$ stillborn male fetus was delivered at 33 weeks gestation. The baby had prominent forehead, flat nasal bridge, large nose, hypertelorism, low-set ears, cryptorchidism, and hypospadias. Macroglossia and other major anomalies were not recognized. 0 igohydramnios and severe IUGR are rare abnormality not previously described in partial trisomy 11 .

C-31

PRENATAL DIAGNOSIS OF LOW FREQUENCY MOSAICISM FOR SUPERNUMERARY INV DUP(15)。 Kiyoko KOYAMA, Koji NARAHARA, Yuii YOKOYAMA, MichioTERAOKA, Yoshiki SEINO (Dept. Pediatr. Okayama Univ. Okayama), Katsuhiko TADA and Takafumi KUDO (Dept. Obstet. Gynecol.)

The presence of mosaicism for chromosome imbalance imposes a great challenge to prenatal diagnosis. Although a half of all supenumerary marker chromosomes are derived from a chromosome 15 , inv dup (15)s have rarely been detected in prenatal diagnosis. We report on a case of low frequency mosaicism for supernumerary inv dup (15). A couple underwent prenatal dignosis because of advanced maternal age. The first amniocentesis showed that a small proportion of cells (18/83) had an extra Gsized chromosome. The second aminocentesis and cordocentesis also showed the same abnormality in a minority of cells. The interrupted pregnancy resulted in an apparently normal female fetus with no malformations of internal organs. FISH studies using D15Zl and GABRB3 probes confirmed that the extra chromosome is an inv dup(15). This case illustrates the importance of repeated examinations of different tissues in confirming the low frequency mosaicism as well as the need of molecular tests for predicting the clinical outcome of patients with inv dup(15)s detected prenatally. 
$\mathbf{C}-\mathbf{3 2}$

ORIGIN AND MECHANISM OF MIXOPLOIDY COMPOSED OF $45, \mathrm{X}$ AND $47, X X,+21$ CELL LINES IN A FETUS

Naoki HARADA, Kyohko ABE Tomoko NISHIMURA Masakazu SOUDA Kazuo NODA (Kyushu Med. Sci.,Nagasaki), Kiminori SASAKI, Mutsuo ISHIKAWA (Dept. Obstet. Gynecol., Asahikawa Med Coll., Asahikawa), Tadashi MATSUMOTO and Norio NIIKAWA (Dept. Pediat. \& Dept. Hum. Genet., Nagasaki Univ. Sch. Med., Nagasaki)

Chromosome analysis of amniotic fluid cells from a 17 -week-old fetus suffering from cystic hygroma colli revealed a mixoploid composed of $45, \mathrm{X}$ and $47, \mathrm{XX},+21$ karyotypes. Each cell line was also observed in other tissues including skin, cord blood, amnion and chorionic villus tissues of the fetus, which were collected after termination. We studied the origin and the mechanism of formation of this unique mixoploid using chromosomal heteromorphisms and DNA polymorphisms as genetic markers. All the heteromorphic markers examined showed no discordance in parents-to-child transmission or between the two cell lines. DNAs were extracted from monoclonal cells with each karyotype established from the fetus skin fibroblasts using the limited dilution method. These DNAs and those extracted from peripheral blood leukocytes of the parents were analyzed with 8 polymorphic markers, including one RFLP and 7 VNTRs. Three VNTR markers were informative in this analysis and the two cell lines had identical alleles transmitted from the parents. While the other 4 VNTRs and 1 RFLP markers were uninformative, because both parents were homozygous for these loci. From these findings, we concluded that a zygote had either a $45, \mathrm{X}$ or a $47, \mathrm{XX}+21$ karyotypes, and then subsequent loss of $\mathrm{X}$ chromosome or gain of chromosome 21 due to anaphase lag or somatic nondisjunction, leading to the mosaicism.

C-33

CHARACTERIZATION OF ISOCHROMOSOME $18 \mathrm{q}$ IN PRENATAL DIA GNOSIS BY G-BANDING METHOD AND FLUORESCENCE IN SITU HYBRIDIZATION. Satoshi HAYSHI, Maki HYODO, Masayuki KINUTANI, Hisaya FUJIWARA, Kenjiro DATE, Tomoya MIZUNOE, Y oshinori KISAKA, Takeshi URABE (Dept. Obstet. Gynecol., Hiroshima Prefectural Hospital, Hiroshima) and Norio MIHARU, Koso OHAMA (Dept. Obstet. Gynecol., Hiroshima Univ. Sch. of Medicine, Hiroshima)

The patient was referred for cytogenetic analysis because of polyhydramnios and abnormal findings of the fetus by ultrasonography at a gestation age of 28 weeks. She was a 29-year-old primigravida. Cordcentesis was performed at 29 weeks' gestation. Cytogenetic evaluation from cord blood showed $46, X X,-18,+i(18 q)$ in 20 metaphases by $\mathrm{G}$-banding method. And fluoresence in situ hybridization (FISH) was performed to certify isochromosome $18 \mathrm{q}$ using alphasatellite probe specific for chromosome 18 (Oncor Inc., Gaithersburg, MD). Two strong signals were observed, confirming an isochromosome 18 replacing one normal chromosome18. The baby was stillborn at a gestaton age of 30 weeks. The baby's weight was $1150 \mathrm{~g}$. At pathological examination, there were short neck, low-set ears and small round nose. The cerebral ventricle was dilated. The left diaphragmatic hernia was observed and the left lung was atrophic. The right lung had two lobes and there was pleural effusion. Intracardinally ventricular s eptal defects $(9 \times 10 \mathrm{~mm})$ was found. The umbilical hernia and imperforate anus were found. The characteristic features of this baby were similar to 18 trisomy symdrome but did not present features of 18 pmonosomy syndrome. 


\section{C-34}

MONOZYGOTIC TWINS CONCORDANT OR DISCORDANT FOR MALFORMATIONS

OF MUSCULO-SKEIETAL SYSTEM. YaSUo SUGIURA, Tsuyoshi UEKE

(Kanayama Clinic, Nagoya) and (Chubu Rehabilitation

College, Nagoya)

Since 1954, 6 monozygotic twins have been observed at Nagoya University Hospital, Nagoya City University Hospital and their affiliated hospitals. Diagnosis of monozygosity was decided with various types of gene markers.

Concordant twins were 1 pair for achondroplasia, 1 pair for symphalangism and 2 pairs for postaxial polydacyly of toes. Discordant twins were 1 pair for arthrogryposis multiplex congenita and 1 pair for congenital unilateral short femur.

Concordant twins were considered to be caused from genuine genetic factor, while discordant twins were considered to be caused from interaction between genetical and fetal environmental factor.

C-35

ULTRASOUND SCREENING OF NEWBORN INFANTS FOR KIDNEY AND URINARY TRACT ABNORMALITIES; REPORT OF 14 NEONATES WITH CONGENITAL HYDRONEPHROSIS. Akira MATSUI*, Tsunehisa TAKENAKA** (Dept. Pediat*., and Obstet.Gynecol** Isesaki Municipal Hospital, Gunma) and Masamichi HAYASHI, Hidetoshi YAMANAKA(Dept. Urol., Gunma University School of Medicine,Gunma)

For the purpose of early detection and early treatment of kidney and urinary tract abnomalities, ultrasound screening of newborn infants has been done. A total of 4,610 newbom infants, born at Isesaki Municipal Hospital from October 1988 to October 1996 were examined by ultrasound. Most of them were scanned between 2 to 7 days after birth, using Aloka SSD 650 scanning system equipped with a 5-MHz linear transducer. When abnomal scans were found serial ultrasound studies, urinalyses and uroradiologic examinations were carried out. Out of 4,610 newborn infants 14 revealed congenital hydronephrosis. In this paper, clinical and laboratory findings of these 14 cases(12 males and 2 females) were presented. All these cases showed unilateral hydronephrosis(right kidney in 5 and left in 9). By ultrasound findings at least one side of the renal pelvis was found to be dilated. Grade 2 hydronephrosis was found in 6 cases, grade 3 in 3 and grade 4 in 5. Surgical treatment was applied in 5 cases. Another 5 cases were followed nonoperatively and 4 cases were lost to follow-up.

In conclusion ultrasound may be useful for the screening of congenital hydronephrosis at neonatal period. 
A SECOND CASE OF KABUKI-MAKE-UP SYNDROME WITH LOWER PITS. Yoshio MAKITA, Akie MIYAMOTO, Hiroshi MATSUBARA, Yoshiya ITO, Koichi YANO and Akimasa OKUNO. (Dept. Pediatr. Asahikawa Medical College, Asahikawa, Japan.)

The girl was the first child of a 29-year-old mother and a 33-years old father. She had soft cleft plate and lower lip pits. The diagnosis of Van der woude syndrome(VWS) was made. She was first evaluated by us at the age of 3 years because of her short stature. She had postnatal onset growth retardation, typical facial appearance, typical dermatoglyphic pattern, partial growth hormone deficiency and a low normal limit mentality. She was then also diagnosed as having Kabuki make-up syndrome (KMS).

The girl was the second case, who represented 2 independent dominant syndromes, KMS and VWS. Recently, gene locus of VWS-1 is assigned at 1q32-41, by microsatellite-based mapping[sanger et a1.,1995]. But her high resolution chromosome failed to show any deletion and aberration on this region.

\section{C-38}

FAMILIAL PORO-CYSTIC OSTEODYSPLASIA WITH TARDY PROGRESSIVE PRESENILE DEMENTIA. Isao SUGIURA ( Dept. Orthop. Surg., SL Medical Centr, Nagoya ), Yasuo SUGIURA ( Kanayama Clinic, Nagoya) and Toshiyuki FURUSHO ( Dept. Hum. Genet., Kyohrin Univ., Tokyo )

This disease is characterized by skeletal manifestations with multiple poro-cystic lesions associated with pathologic fractures and by neuropsychiatric dysfunctions with progressive dementia. CT of brain shows marked signs of cortical atrophy and dilatation of the ventricles. The intramedullary lesions are filled with a molted cheese-like adipose tissue which shows histopathologically peculiar characteristic undulating membrano-cystic structures, reacting to PAS, Luxol fast blue and Sudan III. Electron-microscopically, membranocystic lesions are composed of numerous minute tubular structures arranged perpendicullary to the inner surface.

The authors carried out an investigation of 91 Japanese patients of 79 families including their 7 own families with special emphasis on genetical analysis. As regard to consanguinous marriage of the parents, first cousins was found in 34 families, no consanguinity in 22, unknown in 16 and other consanguinity than first cousins in 7. The inheritance of this disease strongly suggests an autosomal recessive, and recessive gene frequency calculated by Dahlberg's formula showed extremely low : $q=0.00038(1972-1977)$ and $q=0.00009(1978-1983)$. 
C-39

A JAPANESE PATIENT OF RESTRICTIVE DERMOPATHY. Mihoko NAKAMURA(Dept. Pediatr., Kagoshima University School of Medicine, Kagoshima), Kiyoshi IMAIZUMI, Takuma ISHII, Mitsuo MASUNO, Yoshikazu KUROKI(Div. of Med. Genet., Kanagawa Children's Med. Ctr., Yokohama), Gen NISHIMURA(Dept. of Radiol., Dokkyo Univ. School of Med., Tochigi)

Restrictive dermopathy is a rare lethal autosomal recessive skin dysplasia with multiple congenital contractures and characteristic facies. We report a girl, the first child of healthy and non-consanguineous Japanese parents. Intrauterine growth retardation of the baby, pulmonary hypoplasia, fixed flexion contractures, and decreased movement with polyhydramnios were revealed on a ultrasound at 31 weeks gestation. High echogenic lesion of each orbit were also observed, which were turned out to be the ectropion of edematous eyelids after birth. She was born at 32 weeks gestation, birth weight was $958 \mathrm{~g}$, OFC $27 \mathrm{~cm}$. Clinical findings included a tight, thin, translucent skin, round face with hypertelorism, edematous and ectropion of eyelids, small pinched nose, low-set ears, small fixed open mouth, protuberant tongue, and micrognathia. Multiple joint contractures and rocker-bottom feet were also observed. She died shortly after birth. Radiographs showed large anterior fontanel, thin and irregular ribs, and hypoplastic clavicles. The ulnar shafts were particularly narrow distally as were the radial shafts proximally. Radiological findings were useful for the diagnosis of Restrictive dermopathy.

$\mathrm{C}-40$

FAMILIAL CASE OF Holt-Oram SYNDROME AND VACTERL ASSOCIATION. Takuma ISHII ${ }^{1}$, Mitsuo MASUNO ${ }^{1}$, Kiyoshi IMAIZUMI ${ }^{1}$, Yoshikazu KUROKI , Hiroshi TAKE ${ }^{2}$, Toshiii NISHI ${ }^{2}$ ('Div. of Medical Genetics, ${ }^{2}$ Dept. of Surgery, Kanagawa Children's Medical Center, Yokohama, Japan)

We report on a first familial case of Holt-0ram syndrome and VACTERL association. Case1 is a 3 -month-old boy with VACTERL association. He is diagnosed by agenesis of sacrum, anal atresia, atrial septal defect, patent ductus arteriosus, cystorectal fistula, hypospadias, bifid scrotum and $\mathrm{limb}$ anomalies (right side is dominant). Case2 is a 21-years-old female with Holt-Oram sundrome. She is a mother of Case1. She is diagnosed by limb anomalies (left side is dominant), ventricular septal defect, patent ductus arteriosus and mitral valve insufficiency. To explain this case, we make three hypotheses. (1)A part (or al1) of VACTERL association is the same disease as Holt-0 ram syndrome. (2)A part (or all) of VACTERL association and isolated type Holt-0ram syndrome are the same single-gene inheritance disease. (3)A part (or al1) of VACTERL association is a contiguous gene syndrome including Holt-0ram syndrome.

To be clear the relation between Holt-0ram syndrome and VACTERL association, description of addtional cases and linkage analysis are necessary. 


\section{C-41}

JAPANESE GIRL WITH NAGER SYNDROME (PREAXIAL ACROFACIAL DYSOSTOSIS) Satoshi ISHIKIRIYAMA, Tamaki NUMAZAWA, Tsuneho NAKAMURA, Fumiyo KUDOH (Chiba Children's Hospital, Chiba) and Michiyo EBARA (Chiba Rehabilitation center, Chiba)

A female baby was born to healthy, non-consanguineous parents after an uneventful pregnancy. At birth, her father was 34 years old, her mother 29 years old, respectively. Both of the parents were Brazilian descended from Japanese. She was an only child of the parents. Her birth weight was $3,276 \mathrm{~g}(+4.4 \mathrm{SD})$, height $48.0 \mathrm{~cm}(-0.47 \mathrm{SD})$, respectively. She had not only downward slanted palpebral fissures, deprssesd nasal bridge, and severe micrognathia but also bilateral hypoplastic thumbs. No other family members had micrognathia and hypoplastic thumbs. She suffered from respiratory distress and failure to thrive during neonatal pariod. She needed nasal tubing during her infancy. Her karyotype was normal female: $46, \mathrm{XX}$.

Nager syndrome is genetically hetrogeneous, partly autosomal dominant and partly autosomal recessive in inheritance, while Treacher-Collins syndrome is completely autosomal dominant. It is important to distinguish Nager syndrome from Treacher-Collins syndrome, so also nescessary to try to detect radial anomalies when one examine a patient with micrognathia.

\section{$\mathrm{C}-42$}

JAPANESE PATIENTS WITH X-LINKED $\alpha$-THALASSEMIA/MENTAL RETARDATION SYNDROME. Kenji KUROSAWA, Akira AKATSUKA, Yukikatsu OCHIAI, Masako ASOH, Jun IKEDA, ('Tokyo Metr. Kita Med. Rehabil. Ctr. for The Handicapped, Tokyol and Kihei MEKAWA (Dep. Pediatr., Jikei Univ. School of Medicine, Tokyo)

$\mathrm{X}$-linked $\alpha$-thalassemia/mental retardation syndrome (ATR-X) is characterized by severe mental retardation, wide range of minor abnormalities, and association with an unusual form of $\alpha$-thalassemia. We report two Japanese patients with ATR-X. In addition to their dysmorphic features including a triangular nose with upturned nares, a broad nasal bridge, nasal alae extending lower than the columella and septum, carp-shaped mouth with full lower lip, and widely spaced teeth, incubation of their blood with $1 \% \mathrm{BCB}$ showed $0.1-0.4 \%$ red cells with $\mathrm{HbH}$ inclusions. Both cases are sporadic ones. In the case of the severely mental retarded, it is important to take this disorder into consideration for differential diagnosis. Other dysmorphic mental retardation, which are linked to the Xq12-q21 region, could be due to mutations in $\mathrm{XH} 2 / \mathrm{XNP}$. 
$\mathrm{C}-43$

POPULATION SCREENING OF FRAXE: CYTOGENETIC AND PCR ANALYSES IN MALES WITH SEVERE MENTAL RETARDATION. Ryozo KASAI', Koji NARAHARA ${ }^{2}$, Shinsuke NINOMIYA', Yuji YOKOYAMA ${ }^{2}$, Kazushiro TSUJI ${ }^{2}$ and Yoshiki SEINO ${ }^{2}$ ('Asahigawa Jidoin Child. Hosp., Okayama and ${ }^{2}$ Dept. Pediatr., Okayama Univ., Okayama)

Expansion of the (CCG)n triplet repeat at the FRAXE is associated with mental impairment in some individuals. To determine the frequency of FRAXE repeat expansion among persons with severe or profound mental retardation, institutionalized 103 males (age of 11 to 66-years-old) were studied by using cytogenetic and molecular method. Cytogenetic studies revealed that 4 out of 103 individuals showed fragile sites at Xq27-28 region between 2 to $6 \%$ of observed cells. It seems likely that four cases with low incidence of fra (X) (q27-28) expression have a common fragile site in this region. On the other hand, FRAXE PCR analyses using primers 598 and 603 (Knight et al., 1993) reveald that all of 103 individuals had PCR products of 300 to $350 \mathrm{bp}$ length which correspond to 4 to 21 (CCG)n normal repeats size. These results suggest that FRAXE (CCG) $n$ repeat expansion is not a cause of severe or profound mental retardation in insititutionalized developmentally delayed males .

\section{$\mathrm{C}-\mathbf{4 4}$}

\section{SMITH-LEMLI-OPITZ SYNDROME IN JAPAN}

Masato TSUKAHARA, Keiko FUJISAWA, Kiyomi YAMAMOTO (School of Allied Health Sciences, Yamaguchi Univ,, Ube)

Smith-Lemli-Opitz (SLO) syndrome is caused by inborn error of cholesterol synthesis. The syndrome is characterized by multiple congenital anomalies/mental retardation, including characteristic facial appearance, microcephaly, growth retardation, anomalies of the limbs, and genitalia. The major biochemical abnormalities in the SLO syndrome consist in reduced serum cholesterol associated with increased 7-dehydrocholesterol concentrations. We sent questionnaire to 554 hospitals to estimate the number of the patients with the SLO syndrome, including University hospitals that were registered by Japan Society of Pediatrics. The response rate was 419/554 (75.6\%). A total of 46 individuals from 24 hospitals were reported to have the SLO syndrome. Of these, one patient was biochemically diagnosis as having the SLO syndrome, 25 were diagnosed on the basis of clinical manifestations, and 20 were suspicious of having the SLO syndrome. The occurrence in monozygotic twins was reported in one family. Eight patients were died, and 38 are still alive. The serum 7-dehydrocholesterol concentrations were determined in 16 patients. All the 16 patients with the suspicion of having the SLO syndrome had nomal levels of the serum 7-dehydrocholesterol. Thus, definite diagnosis was made in one case, and the SLO syndrome was biochemically denied in 16 patients.

The diagnosis of the SLO syndrome seems ambiguous because of its wide spectrum of multiorgan involvement. The serum 7-dehydrocholesterol determination combined with clinical manifestations is necessary to make a definite diagnosis of the SLO syndrome. 


\section{C-45}

A NEW CASE WITH SHPRINTZEN-GOLDBERG SYNDROME WITH BILATERAL ECTOPIA LENTIS. Yoriko WATANABE, Shoji YANO, Yoko SUGAHARA, Yasutoshi KOGA, Makoto YOSHINO, Hirohisa KATO (Dept. Pediat. Kurume University School of Medicine, Kurume)

Shprintzen-Goldberg syndrome (SGS) is a rare disorder with characteristic features including Marfanoid habitus, arachnodactyly, camptodactyly, craniosynostosis, exophthalmos, maxillary and mandibular hypoplasia, palatal shelf soft tissue hypertrophy, infantile hypotonia, and mental retardation. SGS was thought to be a generalized connective tissue dysplasia until Dietz et al. recently reported that SGS is associated with mutations in the same gene that is involved in Marfan syndrome, i.e. fibrillin-1 (FBN-1). We experienced a 9 year-old Japanese boy with clinical phenotype of SGS with bilateral ectopia lentis. He had generalized hypotonia, developmental delay, gingival hypertrophy, and developed dilatation of the aortic root at 3 years of age. He was initially diagnosed with Marfan syndrome because of the mild craniofacial involvement with mild proptosis, strabismus, and facial asymmetry. Ectopia lentis is not a typical finding in SGS although it is known as one of cardinal manifestations in Marfan syndrome. Molecular and functional analysis of FBN-1 gene and its product in this case may help to understand the molecular basis of SGS involving central nervous and craniofacial skeletal system which are not associated with Marfan syndrome.

\section{$\mathrm{C}-46$}

IDENTICAL TWINS DISCORDANT FOR COHEN SYNDROME. Hirofumi

OHASHI Kyoung Chang KIM Shinichiro HAMANO Masato SATO Kibo YOSHIDA (Saitama Children's Medical Center, Saitama), Fumie TAKAKUBO, Ikuko KONDO (Ehime Univ. Sch. Med., Ehime), Yoshimitsu FUKUSHIMA (Shinshu Univ. Sch. Med., Nagano)

Cohen syndrome is a congenital malformation syndrome which follows an autosomal recessive mode of inheritance. The gene locus responsible for Cohen syndrome is assigned around $8 \mathrm{q} 22$. We report on a pair of female identical twins discordant for Cohen syndrome. The twins were born at 36 weeks' gestation to unrelated parents. The patient' twin sister and her elder brother were normal. The features of the patient were mental retardation, hypotonia in infancy, obesity, external strabismus, high nasal bridge, high and narrow palate, prominent incisors, tapering fingers and talipes equinus. The probability of the twins being identical was calculated to be $99.999 \%$, using blood types and DNA polymorphism. The following mechanism was considered to explain the discordance in phenotype between the identical twins: first the twins inherited a defective allele responsible for Cohen syndrome from one carrier parent, and next at the early stage of mitotic cell divisions in the patient a mutation occurred in the other allele which resulted in homozygosity for the defective gene for Cohen syndrome. 
C-47

POLYMORPHISMS AND LOCATION OF THE HUMAN SYNDECAN - 2 GENE FOR COHEN SYNDROME. Yuii MORIMOTO, Fumic TAKAKUBO, Kazuhiru SHIGEMOTO, Ikuko KONDO(Dept. of Hygiene, Ehime Univ, Ehime)

Polymorphisms in the human syndecan-2(SND-2) gene will be useful in the linkage analysis to identify responsible gene(s) for connective tissue

diseases. We identified two single base polymorphisms, a ${ }^{435} \mathrm{C}-\mathrm{T}$ and a ${ }^{463} \mathrm{C}$ Gsubstitutions by sequencing PCR products of the genomic DNA. These polymorphisms are located at 5 uniranslated region of the SND-2 cDNA, and the estimated heterozygosities in Japanese are 0.43 for ${ }^{435} \mathrm{C}-\mathrm{T}$ polymorphism and 0.46 for the ${ }^{463} \mathrm{C}-\mathrm{G}$ polymorphism. The SND-2 gene was assigned in the genetic distance of approximately $2 \mathrm{cM}$ from DNAmarker D8S546(lod score $=4.214, \theta=0.02$ ) centromeric to D8S1762 at the Cohen syndrome(CHS 1) Jocus. Then, we performed linkage analysis of a consanguineous CHS family using these polymorphism. While parents and an unaffected sisterwere heterozygous for the ${ }^{435} \mathrm{~T}^{463} \mathrm{G}$ and the ${ }^{435} \mathrm{C}^{463} \mathrm{Callele,} \mathrm{but} \mathrm{two} \mathrm{sibs} \mathrm{with}$ CHS1 were homozygous for the ${ }^{435} \mathrm{~T}^{463} \mathrm{G}$ allele. There results suggesi that the SND-2 gene can be one of the candidate genes for CHS1.

$\mathrm{C}-48$

ANALYSIS OF CHROMOSOMAL BREAKPOINT IN A PATIENT WITH BLEPHAROPHIMOSIS SYNDROME BEARING $\mathrm{t}(3 ; 4)(\mathrm{q} 23 ; \mathrm{p} 15.2) . \quad$ Yumi NAKAGAWA ${ }^{1,2}$, Johji INAZAWA ${ }^{1}$ Yoshimitu FUKUSHIMA ${ }^{3}$, Yuusuke NAKAMURA $^{4}$, Zenshirou ONOUCHI ${ }^{2}$, Tatuo ABE 1 (Dept. of Hygienel and Division of Pediatrics, Children's Research Hospital2, Kyoto Pref. Univ. of Med., Dept. of Hygiene, Shinshuu Univ. ${ }^{3}$, Dept. of Lab. of Mol. Med., Inst. Med. Sci., Univ. of Tokyo4

Blepharophimosis syndrome(BPES) is an autosomal dominant disorder, and involves blepharophimosis, ptosis and epicanthus inversus. Some recent reports document that BPES maps to $3 q 23$. We analyzed the patient of BPES with translocation between $3 q 23$ and $4 \mathrm{p} 15.2$. We performed two-color FISH on prophase chromosomes to determine the order of cosmid markers localized on 3q23. The order was provided as follows:cen-12811152-1178-937-607-ter. We performed two-color FISH of these markers on the patient's chromosomes. C13-1281 and 1152 are proximal and C13-1178,937,607 are distal to the breakpoint, indicating that the breakpoint lies on the region between $\mathrm{Cl} 3-1152$ and 1178 . We are proceeding with genetic analysis of BPES by using these two cosmid markers. 


\section{C-49}

THE BRAIN FINGER PROTEIN GENE (ZNF179), A MEMBER OF THE RING FINGER FAMILY, MAPS WITHIN THE SMITH-MAGENIS SYNDROME REGION IN 17p11.2. Toshiyuki KIMURA', Yoshiki ARAKAWA', Satoshi INOUE ${ }^{2}$, Yoshimitsu FUKUSHIMA ${ }^{3}$, lkuko KONDO ${ }^{4}$, Kumiko KOYAMA ${ }^{5}$, Masami MURAMATSU' ${ }^{2}$, Yusuke NAKAMURA ${ }^{5}$, Tatsuo ABE', and Johji INAZAWA'.(' Dept. Hygiene, Kyoto Pref. Univ., Kyoto. ${ }^{2}$ Dept. Biochem., Saitama Med. school, Saitama. ${ }^{3}$ Dept. Hygiene, Shinshu Univ., Nagano. ${ }^{4}$ Dept. Hygiene, Ehime Univ., Ehime. ${ }^{5}$ Labo. Mol. Med., Ins Med Sience, Tokyo Univ., Tokyo.)

Smith-Magenis syndrome (SMS) is a congenital chromosome-abnormality associated with visible microdeletions of $17 p 11.2$. The features of SMS include the complex phenotypic aberrations such as developmental and growth delay, facial abnormalities, unusual behavior and sleep problems. The complex phenotype may be due to a haploinsufficiency of several contiguous genes. The human brain finger protein gene (ZNF179), a member of the RING finger protein family, has been isolated and mapped to chromosome 17p11.2. FISH analyses of metaphese or interphase chromosomes of six patients with SMS, revealed that ZNF 179 gene was deleted in one of both homologous chromosomes 17p1 1.2, indicating possible association of the defect of this gene with the pathogenesis of SMS. Futhermore, using a prophase FISH ordering system, we sublocalized ZNF 179 proximally to LLGL1 which lies on the critical region for SMS.

C-50

CA REPEAT ANALYSIS OF DUCHENNE MUSCULAR DYSTROPHY BY THE FLUORESCENCE PCR.

Yoshiko SHIROSHITA, Yukiko NAKANO, Susumu KATAYAMA, Harumi KUBO, Shun HIRAKAWA (1st Dept.Obstet.Gynecol., Toho University School of Medicine, Tokyo)

[Purpose] Dinucleotide repeat polymorphism is useful for linkage analysis because it detects high polymorphisms compared to PCR-RFLP analysis.We examined the efficacy of 8 microsatellite markers within the DMD gene. [ Materials and Methods] Genomic DNA was extracted from blood cells of the 44 normal Japanese females by the standard method. 8 polymorphic regions were amplified by the PCR using primers labeled with fluorescence (three colores).PCR products were electrophoresed on $6 \%$ polyacrylamide sequencing gels using $373 \mathrm{~S}$ auto sequencer(Parkin Elmer) and analyzed by Genescan Soft ware 672. [Result] Number of alleles and observed heterozygosities of 8 regions were:DYS I ; $3 / 29.5 \%$ (no. of X chromosomes $=88$ ), DYS II $10 / 54.5 \%(\mathrm{n}=88$ ), DYSIII ;5/57.6\% ( $\mathrm{n}=80)$, STR 44;10/69.9\%( $\mathrm{n}=88)$, STR 45;15/76.7\%( $\mathrm{n}=86)$,STR49;19/67.4\% $(\mathrm{n}=86)$, STR50;11/59.1\%(n=88),3'CA;4/34.9\%( $\mathrm{n}=86)$. High total P.I.C. was obtained. [Conclusion] CA repeat analysis by the fluorescence PCR is effective in prenatal analysis and carrier diagnosis of DMD because it is safe and convenient in handling and gives high diagnostic applicability. 
ADHALIN GENE MUTATIONS AND THE CLINICAL HETEROGENEITY IN PATIENTS WITH PRIMARY ADHALINOPATHY. Takenori ENDO, Hisaomi KAWAI, Makoto KUNISHIGE, Hideki MINE, Masashi AKAIKE, Takao MITSUI, Yoshihiko NISHIDA, Shiro SAITO(Dept. 1st. Int. Med., Sch. Med., Univ. Tokushima, Tokushima), Katsuhito ADACHI (Dept. of Neurology, National Sanatorium Tokushima Hospital, Tokushima), Yoshihiro YONEDA, Masahito MIYAZAKI, Toshinori HASHIMOTO (Dept. Pediatr., Sch. Med., Univ. Tokushima, Tokushima), Itsuro HIGUCHI, Hidetoshi FUKUNAGA and Mitsuhiro OSAME (Dept. 3rd. Int. Med., Kagoshima University, Kagoshima)

We have studied the clinical heterogeneity among patients with primary adhalinopathy. Twelve personally examined patients from 6 families and 21 patients from 15 families reported by other groups are included. Mutation in the adhalin gene (point mutation, deletion or insertion) was confirmed in each family. The mean age of onset was $7.5 \pm 4.9 \mathrm{yr}$ (range, $1-23 \mathrm{yr}$ ) and loss of ambulation was $13 \pm 4.3 \mathrm{yr}$ (range, $8-21 \mathrm{yr}$ ). There was significant heterogeneity of clinical features even among patients carrying the same mutation, indicating the possible modificication by environmental factors.

\section{C-52}

TRINUCLEOTIDE REPEAT TRANSCRIPTS IN NUCLEI OF LYMPHOID CELL LINES (LCLS) FROM MYOTONIC DYSTROPHY PATIENTS. Fumiko SAITOOHARA $^{1}$, Toru KOJO $^{2}$, Kanako GOTO $^{2}$, Kiichi ARAHATA $^{2}$, and Tatsuro IKEUCHI $^{\mathrm{l}}$ ( ${ }^{\mathrm{l} D e p t .}$ Cytogenet., Med. Res. Inst, Tokyo Med. Dent. Univ., Tokyo, ${ }^{2}$ Dept. Neuromusc. Res., Natl. Inst. Neurosci., NCNP, Tokyo)

In myotonic dystrophy (DM), a trinucleotide (CTG) expansion in the myotonin protein kinase gene (MTPK) results in the pathological phenotype. In the present study, we analyzed the localization of MTPK gene transcripts in nuclei of LCLs established from 8 DM patients and 8 normal individuals by ISH (in situ hybridization) method. The oligonucleotide probes of the sense (CTG-30) and antisense (CAG-30) repeat were labeled with FITC and texas red (TR) respectively, and the nuclei-spreading slides were prepared under the RNase free condition (Taneja et al., 1995). The results showed that TR signals of CAG-30 probe distributed remarkabily in the nuclei of DM LCLs, and no signals in the normal nuclei. FITC signals, however, were absent in both the DM and normal nuclei. In contrast, when DNA in the interphase nuclei was denatured before the hybridization, the FITC signal was observed at the only one site and was co-localized with a TR signal in DM nuclei. These findings showed that the antisense probe hybridized to both the MTPK DNA and its transcript and that MTPK transcripts present as foci of nuclear aggregation in the DM cells may have functional significance in the pathogenesis of myotonic dystrophy. We suggest that the method presented here is applicable to a rather wide range of cultured cells from the patients, and might be of practical use for diagnosis of the affected state. 
ANALYSIS OF MUSCLE DYSTROPHIN MRNA IN DMD/BMD PATIENTS WITH DNA DELETIONS. Juan DU, Kayoko SAITO, Kiyoko IKEYA, Yukiko KAWAKITA, Makiko OSAWA (Dept. Pediatr., Tokyo Women's Medical College, Tokyo)

For the purpose of analyzing the relationship between clinical phenotype and changes at the molecular genetic level, we examined muscle dystrophin mRNA from Duchenne(DMD) and Becker(BMD) patients with internal deletions in the DMD gene.

Muscle mRNA was extracted by the AGPC method. Dystrophin mRNA was amplified in three defferent regions (deletion containing area upstream and downstream) by RT-PCR. The deletion containing area was sequenced with an ALF sequencer.

We found the quantity of muscle mRNA in the DMD cases to be significantly lower than that in the $B M D$ cases $(t=8.33>4.073, n=15$, $\mathrm{p}<0.001)$. The deletions in skeletal muscle mRNA were consistent with those in lymphocyte DNA in 4 BMD and 9 DMD patients, findings compatible with the reading frame theory. As RT-PCR products were not amplified in one DMD case, a transcription failure was assumed. The other DMD case, who had a deletion of exon(E) 48-52 in lymphocyte DNA, died of rhabdomyosarcoma. We detected a deletion of $15 \mathrm{bps}$ in the $3^{\prime}$ region of E48, altermatively spliced to E53.

Thus, we identified one DMD case in whom the deletion of muscle dystrophin mRNA was not consistent with that of lymphocyte DNA.

\section{C-54}

GENE LOCUS FOR AUT OSOMAL RECESSIVE DISTAL MYOPATHY WITH RIMMED VACUOLES MAPS TO CHROMOSOME 9. Takeshi IKEUCHI, Masaaki SAITO, Hajime TANAKA, Sari HIGUCHI, Keiko T ANAKA, Shoji T SUJI (Dept. Neurol., Brain Res. Inst., Niggta Univ., Nïgata), Tomoya ASAKA. Masaharu I AKAMORI (Dept. Neurol., Kan azawa Univ., Kanazawa), Kyoko SAIDA (Dept. Neurol., Utano Hospital), Eiichiro UYAMA (Dept. Neurol., Kumamoto Univ., Kunamoto), Hidenobu MIZUSAWA (Dept. Neurol., Tsukuba Univ., Tsukuba), Nobuyoshi FUKUHARA (Dept. Neurol,, Saigata Hospital, Niigata), Ikuya NONAKA (Dept. Uttrastruct Lal Res., Nat ional Center Hospital for Nervous, Mental and Muscular Disorders, Tokyo)

Distal myopathy with rinmed vacuoles (DMRV) is an autosomal recessive neuromuscular disorder, characterized by clinically by weakness of distal muscles in lower limbs beginning in early adilthood Characteristic features of the histopathological fudings include numerous rimmed vacuoles, amybid deposits, eosinophilic inclusions, and atrophic muscle fibers with the notable absence of inflammation. Hereditary inclusion body myopathy (HIBM) with autosomal recessive trait, which was described in Persian Jews, presents clinical and histopat hological features resembling those of DMRV. The gene for HIBM has recently been mapped to chromosome $9 \mathrm{p}-\mathrm{ql}$.

To test whether DMRV and HIBM map to the same chromosomal region, we performed linkage analy sis on seven Japan ese pedigrees using micro sat ellite markers including D9S319, D9S43, D9S248, D9S165, D9S50, D9S276, D9S15, D9S273, D9S166, and D9S175 on chromosome 9. Significantly high lod scores were obtained at three markers. D9S248 ( $\left.Z_{\max }=5.90, \theta=0\right)$, andD9S43 $\left(Z_{\max }=5.25, \theta=0\right)$, and D9S248 $\left(Z_{\max }=423, \theta=0\right)$. Hap lot ype andmultipoint linkage anaty sesas well as observation of obligate recombinat ion event sindicate that the DMRV gene is most likely to be located in the interval of $23.3 \mathrm{cM}$ between D9S319 and D9S276. Localization of the DMRV and HIBM genes in the same chromosomal region raises the possibilit y that DMRV and HIBM are allelic diseases. 


\section{C-55}

THE PAX 2 MUTATION IN PATIENT IITH OPTIC NERVE COLOBOMA, HYPOPLASTIC KIDNEY AND MILD MENTAL RETARDATION. Kiyoshi IMAIZUMI, Takuma ISHII, Mitsuo MASUNO, Yoshikazu KUROKI (Dept. Med. Genet., Kanagawa Children's Medical Center) and Eihiko TAKAHASHI, Kunihiko AKAGI(Div. Infec. Immuno1, and Rheumatol, Kanagawa Children's Medical Center)

PAX2 is one member of a family of paired box (PAX) gene encoding transcriptional regulaters in involved in fetal development. PAX2 was shown to be mutated in patients with eye and kidney abnormaliteies. Patient is an Japanese 11-year-old boy born to heal thy unrelated parents after uncomplicated pregnancy. He was pointed out poor weight.gain and severe proteinuria at age 1 months. At age 2 yeas, he referred to us because of renal failure and he had continuous ambulatory oeritoneal dialysis. Bilateral optic nerve coloboma, choroid-retinal degeneration were detected. His visual activity was severly disturved. By ultrasound, he had bilateral hypoplastic kidneys. At age 9 he was diagnosed as epilepsy because EEG showed abnormal spike and wave complex during sleep. He had mild mental retardation but MRI and CT examination showed no remarkable change. Each of 12 -exons of PAX2 were amplified by PCR and the products were analysed by single strand coformation polymorphism(SSCP). Abnormal SSCP pattern were observed in exon 2 and a deletion of 22 nucleotides by direct cycle sequencing. PAX 2 mutations were detected in ten patients up to now. Six of the mutations were detected in exon 2 and they suggested common mutational mechanism.

\section{C-56}

LOCALIZATION OF A 10q BREAKPOINT WITHIN THE PAX2 GENE IN A PATIENT WITH A DE NOVO $t(10 ; 13)$ TRANSLOCATION AND OPTIC NERVE COLOBOMA-RENAL DISEASE. Koji NARAHARA, Shigeru ITO, Yuji YOKOYAMA (Dept. Pediatr. Okayama Univ. Okayama), Michael R Eccles (Dept. Biochem. Univ. Otago), Elizabeth BAKER and Grant R SUTHERLAND (Dept. Cytogenet. Mol. Genet. Women's and Children's Hospital, Adelaide)

We describe a 5-year-old boy with a de novo $t(10 ; 13)$ translocation and optic nerve coloboma-renal disease (ONCR). On the basis of GTG-banding analysis of prometaphase chromosomes, the patient's karyotype was interpreted either 46 , $\mathrm{XY}, \mathrm{t}(10 ; 13)(\mathrm{q} 24.3 ; \mathrm{q} 12.3)$ or $\mathrm{t}(10 ; 13)(\mathrm{q} 25.2 ; \mathrm{q} 14.1)$. FISH studies using a YAC clone containing the PAX2 gene and YAC clones adjoining FRA10B at 10q25.2 showed that the $10 \mathrm{q}$ breakpoint had occurred just within the PAX2 gene and was proximal to FRA10B. These FISH results suggest that the translocation causes a disruption of the PAX2 gene and leads to ONCR, in agreement with the recent reports of PAX2 mutations in two unrelated families with ONCR. We refined the regional mapping of the human PAX2 gene to the junction of bands 10q24.3 and 10q25.1. 
C-57

High Resolution Mapping of a Region Spanning a Translocation Breakpoint at $14 \mathrm{q} 13$ in a Patient with Tetramelic Mirror-Image Polydactyly. Naomichi MATSUMOTO, Norio NIIKAWA (Dept. Hum. Genet., Nagasaki Univ. Sch. Med., Nagasaki), Hirohumi OHASHI (Saitama Child. Med. Ctr., Iwatsuki), Yoshimitsu FUKUSHIMA (Dept. Hyg., Shinshu Univ. Sch. Med., Matsumoto)

Mirror-image polydactyly is a rare type polydactyly in which the ulnar side is symmetrically duplicated without the thumb. The cause of the disorder is unknown although many genes involving pattern formations of lims bud have been identified. We reported a male patient with tetramelic mirror-image polydactyly and a karyotype of $46, X Y, t(2 ; 14)(p 23.3 ; q 13)$ de novo. To isolate the putative gene(s) for the disease, we searched for DNA clones containing the translocation breakpoint, $14 \mathrm{q} 13$.

After FISH analysis of $29 \mathrm{CEPH}$ YAC clones at 2p23.3/14q13, a YAC clone, 928b7 spanning the breakpoint at $14 \mathrm{q} 13$ was identified and at least 14 YAC clones showed chimerism (44.8\%). In this YAC, containing a 1.6-Mb human DNA insert, there are 4 STSs: D14S75, AFM200ZH4, D14S306 and D14S728. BAC clones corresponding to these STSs were isolated by PCR screening, and FISH using these BACs revealed the breakpoint exists between AFM200ZH4 and D14S306. We are now constructing BAC contigs between the two STSs and isolated a BAC clone spanning the translocation breakpoint.

C-58

A 4-Mb CRYPTIC DELETION ASSOCIATED WITH inv(8)(q13.1q24.11) IN A TRICHO-RHINO-PHALANGEAL SYNDROME TYPE I PATIENT WITHOUT MENTAL RETARDATION. Tohru SASAKI, Hidenobu SOEJMMA, Norio NIIKAWA (Dept. Hum. Genet., Nagasaki Univ. Sch. Med., Nagasaki) and Hidefumi TONOKI (Dept. Pediatr., Lab. Cell Biol., Cancer Inst., Hokkaido Univ. Sch. Med., Sapporo)

We report on an 11-year-old girl with typical TRPS I features without mental retardation and a de novo paracentric inversion of the long arm of chromosome 8 involving bands q13.1 and q24.11. Molecular analysis using FISH and microsatellite/RFLP markers detected a cytogenetically unidentified cryptic microdeletion that spans about a 4-Mb extent between 2 STS markers (AFMB331YA9 and D8S1200) at a region around the distal inversion breakpoint. Although the deletion extent of the patient is large, mental retardation was not present at all. This is a first case of TRPS I with deletion of which both ends were analyzed at the molecular level. The data obtained are useful for defining the location of the putative gene(s) responsible for mental retardation in TRPS II (Langer-Giedion syndrome) or TRPS I patients. 
FAMILIAL 15p TETRASOMY OF EXTRA SUPERNUMERARY MARKER 15 CHROMOSOME ASSOCIATED WITH ROBERTSONIAN TRANSLOCATION BETWEEN CHROMOSOMES 13 AND 14. Nobuhiko HOSHI, Kazuhiko OKUYAMA, Hideto YAMADA, Tadashi SAGAWA, Satoru MAKINODA and Seiichiro FUJIMOTO (Dept. Obstet. Gynecol., Hokkaido University School of Medicine, Sapporo)

We report on cytogenetic and molecular investigation of a novel familial case of 15p tetrasomy of extra supernumerary marker 15 chromosome associated with der $(13 ; 14)(q 10 ; \mathbf{q} 10)$.

The proband is a 36-year-old married male with severe oligozoospernia and normal intelligence. He and his wife attended to our department to get a genetic amniocentesis because of ICSI pregnancy and advanced maternal age (39-year-old). The chromosome analysis of cultured amniocyte colonies showed a Robertsonian translocation between chromosomes 13 and $14: 45, \mathrm{XX}, \operatorname{der}(13 ; 14)(\mathrm{q} 10 ; \mathrm{q} 10)$. The abnormal cytogenetic result prompted of further cytogenetic examination in the couple to know the origin of the fetus'translocation. The examination revealed that the fetal translocated chromosome is derived from paternal, and extra small bi-satellited metacentric marker chromosome was observed as a new finding in the father (proband). Although FISH with DYZ3, D13/21Z1, D14/22Z1 probes showed no signal in the marker, two strong D15Z1 hybridization signals were seen on either side of the centromeric heterochromatin. Karyotyping of the proband's parents showed that his mother, who has normal intelligence, carried the same translocation and extra supernumerary marker 15 chromosome, that means the cytogenetic abnormalities are familial inherited 15p tetrasomy associated with Robertsonian translocation between chromosome 13 and 14.

In the light of the results with the conventional cytogenetics, in situ hybridization, and case reports published in literature, the marker chromosome was identified as inv dup (15) without loci such as the Prader-Willi/Angelman syndromes critical regions.

C-60

ANALYSIS OF SRY GENE IN CASE OF AN OVARIAN SERTOLILEYDIG CELL TUMOR . Yasuhiko EBINA, Nobuhiko HOSHI, Ritu YAMAMOTO, Takahumi FUJINO, Hitoshi HAREYAMA, Satoru MAKINODA, Seiichirou FUJIMOTO (Dept. Obstet. Gynecol., Hokkaido University, Sapporo)

Sertoli-Leydig cell tumors (SLCT) of the ovary are composed primaly of testicular-type cells, and are associated with virilizing manifestation in approximately $30-40 \%$ of cases.

A 47 year old woman with a history of abdominal distension was admitted and underwent a laparotomy. Histopathological examination showed a moderately differentiated SLCT. She had no evidence of defeminization or masculinizasion and her karyotype was $46, \mathrm{XX}$. Immunostaining for testosterone was negative. SRY gene was not amplified by PCR analysis of the tumor. Further consideration will be needed to know the histogenesis of SLCT. 
C-61

SYNERGISTIC EFFECTS OF ANGIOTENSINOGEN GENE AND ANGIOTENSIN II TYPE 1 RECEPTOR GENE FOR PREGNANCY -INDUCED ÎHYPERTENSION. Gen KOBASHI*, Akira HATA*, Koichi SHIDO*, Seiichiro FUJIMOTO**, and Kiyotaro KONDO* (*Dept. of Public Health, **Dept. of Obstet. and Gynecol., Hokkaido Univ. School of Med., Sapporo, Japan)

To clarify synergism of genetic factors for pregnancy-induced hypertension (PIH), 87 cases and 167 controls were studied. A variant of angiotensinogen (AGT) gene (Met ${ }^{235}$ $\rightarrow \mathrm{Thr}$ ) in the exon 2 , and that of angiotensin type 1 receptor $(A 1 R)$ gene $\left(A^{1166} \rightarrow C\right)$ in 3 '-untranslated region were analyzed by PCR and hybridization. Between PIH and controls, Significant differences were found in frequencies of TT genotype of AGT gene ( $79 \%$ vs. $57 \%, \mathrm{p}<0.001$ ), and in those of $\mathrm{AC}+\mathrm{CC}$ genotype of $\mathrm{A} 1 \mathrm{R}$ gene (18\% vs. $8 \%, \mathrm{p}$ $<0.05$ ). After a stepwise regression analysis, both factors were screened, disclosing that $\mathrm{AGT}$ gene and AlR gene are independant risk factors in PIH. Compared with a reference group with none of the risks, those with those 2 risk factors were 8.2 times more liable to PIH in a multiple logistic model. It may give a clue to elucidate the geneenvironment interaction, and to establish an effective individualized prediction and prevention of $\mathrm{PIH}$, by eliminating manageable risk factors in lifestyles, particularly among the inherited high-risk individuals.

C-62

REGULATION OF THE ERYTHROPOIETIN GENE BY GATA TRANSCRIPTION FACTORS.

Terumasa TSUCHIYA, Mitsuhiro OKADA, Wei ZHANG, and Yukio YASUKOCHI (Department of Molecular Genetics, Medical Research Institute, Tokyo Medical and Dental University, Tokyo)

A molecular basis for hypoxia signaling and erythropoietin (Epo) gene regulation was studied. The GATA consensus motif was identified in the -30 region of the Epo promoter. Syotematic electrophoretic mobility shift assays using competitors and monoclonal antibodies indicated that GATA transcription factors of GATA-2 and GATA-3 bound the motif. Transactivation assays showed that GATA-2 and GATA-3 could not affect Epo gene expression in normoxia. In contrast GATA-2 repressed and GATA-3 activated Epo gene expression in hypoxia, indicating that GATA-3 functioned as a hypoxia-activated transcription factor. 
C-63

HUMAN PYRUVATE KINASE EXPRESSION IN TRANSGENIC MICE: ANALYSIS OF REGULATORY GENE ELEMENTS RESPONSIBLE FOR ERYTHROIDSPECIFIC EXPRESSION.

Hitoshi KANNO, Shiro MIWA (Okinaka Memorial Institute for Medical Research, Tokyo), Hisaichi FUJII (Tokyo Women's Medical College, Tokyo), Tamio NOGUCHI, Tsutomu KOIZUMI (Fukui Medical School, Fukui), Masaru OKABE, Yasuhide YOSHIMURA (Research Institute for Microbial Diseases, Osaka University, Osaka)

Pyruvate kinase (PK) has two structural genes in mammals. We previously showed that a 300-bp R(red blood cell)-type PK promoter was sufficient for transcriptional activity in both K562 cells and murine erythroleukemic (MEL) cells. To investigate regulatory gene sequence(s) responsible for erythroid-specific expression of human R-PK, we prepared a human PK minigene construct and established four lines of transgenic mice. The construct ( $7.5 \mathrm{~kb})$ contained following gene sequences; entire coding sequence of the human R/L(liver-type)-PK, the R- and L-PK promoter, intron 1, 2 and 11 , the 3'-flanking region, and the upstream DNase-I hypersensitive (HSS) region, which have been identified in K562 cells. By RT-PCR assay, human R-PK transcripts were unable to be detected in bone marrow of transgenic mice except a single transgenic line. The R-PK mRNA was also detected in liver but not in muscle of the line, suggesting that the minigene might lack elements responsible for erythroid specificity.

C-65

POSSIBLE ASSOCIATION BETWEEN PRESENILIN1 LOCUS AND

LATE ONSET SPORADIC ALZHEIMER DISEASE. Yumiko NISHIWAKI, Kouzin KAMINO Ani YOSHIIWA, Tetsurn MIKI Tnshin OGIHARA (Dept. Geriat. Med., Osaka Univ. Med. Sch., Osaka) and Hideki YAMAMOTO, Toshiko KOBAYASHI (Osaka Municipal Kohsaiin Hospital, Osaka)

Fifty per cents of the risk for late onset sporadic Alzheimer disease (SPAD) has been attributed to $\varepsilon 4$ alleles at the APOE gene. To evaluate other risk factors of SPAD, we compared allele frequencies of three loci located at 14q24.3; a polymorphism at intron 2 of FOS gene, D14S43 and a polymorphism at intron 9 of presenilin 1 (PS1) gene between SPAD group and normal control group. D14S43, FOS and PS1 loci showed no association with early and late onset SPAD. However, among non-APOE- $\varepsilon 4$ bearers, a significant association was found between the polymorphism of PS1 gene and late onset SPAD $(p=0.016)$. These results indicated that the PS1 gene could be related with pathogenesis of some form of late onset SPAD. 
C-66

APOLIPOPROTEIN E GENOTYPE IN THE HEALTHY POPULATION: FREQUENCY OF GENOTYPE AND A RISK EVALUATION FOR ALZHEIMER DISEASE BY META-ANALYSIS. Masao KANAMORI, Minoru SUGITA, Takashi IZUNO (Dept. Environ. Health, Toho Univ. School of Med., Tokyo), Kimiko KOBAYASHI, Hideo HAMAGUCHI (Dept. Med. Genet., Inst. Basic Med., Univ. Tsukuba, Tsukuba) and Kiyotaro KONDO (Dept. Public Health, Hokkaido Univ. School of Med., Sapporo)

The frequencies of Apolipoprotein $\mathrm{E}(\mathrm{apoE})$ genotype was surveyed from samples representative to the population. The risk for Alzheimer's disease(AD) was evaluated by means of meta-analysis, a set of statistical tools for combining and integrating the results of independent studies of the community-based prevalence surveys of AD in Japan and in Europe. 235 people were selected from age 50 to 75 randomly in Iwate prefecture. The probabilities of developing $\mathrm{AD}$ according to genotype were estimated. The frequencies of $\mathrm{E} 4$ allele were 0.083 for aged 50-64 and 0.104 for aged 65-74. Our results on the allele frequencies were consistent with our Japanese hospital survey . Lower frequency of E4 allele was cleared in Japanese elderly population compared to Caucasian population. The probabilities of developing $\mathrm{AD}$ with or without apoE E4 allele were increased with age., and lower in Japanese than in Caucasians. These results confirm the influence of genetic factors and some environmental factors on the prevalence rate of Alzheimer's disease.

\section{C-67}

CHROMOSOMAL MAPPING OF PRESENILIN 1 AND PRESENILIN 2 GENE BY FLUORESCENCE IN SITU HYBRIDIZATION (FISH).

Yasuko YAMANOUCHI, Takako TAKANO (Dept. Hygiene \& Pub. Health, Teikyo Univ. School of Med., Tokyo), Takuji SHIRASAWA (Dept. Molecular Pathology, Tokyo Metropolitan Institute of Gerontology, Tokyo), Naruhiko SAHARA and Hiroshi MORI (Dept. Molecular Biology, Tokyo Institute of Psychiatry, Tokyo)

The causal genes for early-onset familial Alzheimer's disease(AD) were identified as presenilin 1(PS-1) on chromosome 14 and amyloid precursor protein (APP) on chromosome 21. Presenilin 2 (PS-2) was identified as the third causal gene on chromosome 1. We present its precise physical mapping of PS-1 and PS-2 by fluorescence in situ hybridization (FISH). The genomic DNA (18kb, 17kb insert) encoding PS-1, PS-2 were biotinylated for probes. To suppress the repetitive DNA sequences, $10-50$ times excess amount of human Cot-1 DNA were added to the probe DNA. The PS-1 gene and PS-2 gene were localized to $14 \mathrm{q} 24.3$ and $1 \mathrm{q} 42.1$, respectively. 
AUTOSOMAL DOMINANT EARLY ONSET DEMENTIA IN A JAPANESE FAMILY: CLINICAL AND GENETIC STUDIES

Masanori NAKAGAWA, Yasuhiko UTATSU, Hiroshi TAKASHIMA, Mitsuhiro OSAME

(Third Dept. Internal Med., Kagoshima University, Kagoshima), Kouichi ENDOU, Yoshio MITSUYAMA (Dept. Psychiatry, Miyazaki Medical College, Miyazaki), and Toshiro FUJIMOTO (Fujimoto Hayasuzu Hospital, Miyazaki)

We report the results of clinical and genetic studies of autosomal dominant dementia in a Japanese family. Twenty-two individuals in this family were examined clinically (17 living, 5 deceased) and genetically ( 16 of 17 living members). Ten ( 5 deceased) of 22 individuals had early onset dementia (age of onset: 45.2 112.1 year-old on average) and 4 of them had multiple white matter lesions and brain atrophy on brain MRI without history of brain ischemic attack. Other 4 individuals had abnormal white matter lesions on brain MRI without dementia. Linkage studies for chromosome 1q31-42, $14 \mathrm{q} 24.3$ and 21q21 responsible for Alzheimer's disease, chromosome 19p 13.1-13.2 for cerebral autosomal dominant arteriopathy with subcortical infarcts and leukoencephalopathy. (CADASIL) and chromosome 3 for familial non-specific dementia suggested no specific haplotypes cosegregated with the disease. Apo E genotypes were $\mathrm{E} 2 / 2$ and $\mathrm{E} 2 / 3$ in this family. Clinical, neuroimaging and genetic studies revealed that the disease in this family was distinguished from known familial dementia. This is the first report of a large Japanese family with autosomal dominant early onset dementia and leukoencephalopathy.

\section{C-69}

ANALYSIS OF MICROSATELLITE POLYMORPHISM IN THE HLA DQ REGION ABOUT NARCOLEPSY . Tetsuya Satoh,1), Jun Nakura, 1), Lin Ye,1), Tetsuro Miki, 1), Yutaka Honda, 2), and Toshio Ogihara I) ( (1): Dept. Geriat. Med., Osaka Uniy. Med. Sch., Osaka: 2): Seiwa Hosp.,Neuropsychiatric Research Institure, Tokyo)

Narcolepsy is a kind of sleep disorders, and has four characteristic symptoms; excessive daytime sleepiness, cataplexy, hypnagogic hallucination, and sleep paralysis. Onset of narcolepsy involves in multifactor. Significant association between narcolepsy patients and HLA-DR2 has been already known by analysis of Japanese population. According to past reports, narcoleptics have DQA1*0102-DQB 1*0602 haplotype without exception. In this study, we analyzed two microsatellites (DQCAR,GC) in 103 narcoleptics and 98 controls to narrow down narcolepsy susceptibility region; DQCAR locates between the DQA1 gene and the DQB1 gene. GC locates on the 9th intron of the Vitamin D binding protein gene. We used genomic DNA from peripheral blood for PCR using fluorescent-labeled primers. These PCR products used for fluorescent image detection after electrophoresis. We analyzed the results by chi-squared test. For DQCAR, frequency of a specific allele (allele B) of nine alleles detected was significantly higher in narcoleptics compared to controls; All narcoleptics have one or two of allele B. However, allele frequency of GC showed no significant difference between the two populations. 
C-70

ANTICIPATION IN SCHIZOPHRENIA. Jun KOH, Hiroshi YONEDA, Yasuhiro INAYAMA, Yoshihiro KONO, Kohichi HAYASHI, Jun SAKAI, Yasushi INADA, Akio HIMEI, Akihide HAYASHI and Toshiaki SAKAI

(Dept. Neuropsychiatry Osaka Medical College, Osaka)

Anticipation describes the increase in disease severity or earlier onset in succeeding generations within families. This phenomenon has been rported to be related with expansion of trinucleotide repeat DNA sequences in some genetic illnesses. We examined age of onset among two generations in 19 unilineal schizophrenic families. The age of onset in younger generation was $20.4 \pm 5.1$ years old, in elder generation was $36.0 \pm 9.4$. The difference was significant between two generations by using Wilcoxon $t$ test $(t=3.41$, $\mathrm{df}=18, \mathrm{p}<0.005)$. We conclude that genetic anticipation occurs in these unilineal schizophrenic families. These finding may implicate the expansion of trinucleotide repeat as a genetic etiology of schizophrenia.

C-71

ANALYSIS OF THE $5^{\circ}$-FLANKING REGION OF DOPAMINE D2 RECEPTOR GENE Ming GAO, Tadao ARINAMI, Hideo HAMAGUCHI (Dept. Med. Genet., Inst. Basic Med. Sci., Univ. Tsukuba) and Michio TORU (Dept. Neuropsychiatry, Tokyo Medical and Dental Univ., Sch.Med.)

Motivated by the dopamine hypothesis for schizophrenia, we have searched for functional polymorphisms in the 5'-region of the dopamine D2 receptor gene. Two polymorphisms, A-241G and -141Ins/Del, were detected. Reporter constructs containing the $-141 \mathrm{CDel}$ allele cloned into a luciferase reporter plasmid drove $32 \%$ and $48 \%$ expression compared to those containing the -141Clns allele in Y-79 cells and in 293 cells, respectively. The number of spiperone binding site in the postmortem putamen tended to be decreased in individuals who carried the $141 \mathrm{CDel}$ allele vs. those who did not. In a case-control study, the -141CIns allele frequency was significantly higher in the schizophrenics than in the controls. No significant differences in a luciferase activity expression, in D2 receptor numbers in the postmortem brains, and in the allele frequency between case-control subjects were observed among A-241G genotypes. These results suggest that -141C Ins/Del is a functional polymorphism that affects the expression of dopamine D2 receptor in human. 
C-72

DIFFERENTIAL GENOME ANALYSIS BETWEEN MONOZYGOTIC TWINS DISCORDANT FOR SCHIZOPHRENIA USING THE IGCR PROCEDURE Takahiro TSUJITA, Norio NIIKAWA (Dept. Hum. Genet., Nagasaki Univ. Sch. Med.), Yuji OKAZAKI (Dept. Neuropsychiat., Nagasaki Univ. Sch. Med.), Shin-ichi INOUE (BAN-YU Tsukuba Research Institute), and Michio OHISHI (Institute of Industrial Technology, the Ministry of International Trade and Industry)

The recently developed in-gel competitive reassociation (IGCR) procedure is a method for an efficient cloning of altered anonymous restriction fragments. By means of this method, two pairs and one pair of monozygotic twins (MZT) discordant and concordant for schizophrenia, respectively, and one normal MZT pair were analyzed, whether they have different genomic DNA that may be related to the putative schizophrenia locus. After digestion of genomic DNA by MseI, we executed the IGCR procedure three times, and constructed differential genomic DNA libraries. Clones in the libraries were used as probes for Southern hybridization. As a result, although we analyzed about $40 \%$ of whole genome to date, no difference has been detected in any of the four twin-pairs analyzed. Now, we intend to study these twins in more detail using other restriction enzymes.

\section{C-73}

INFLUENCE OF APOLIPOPROTEIN E GENOTYPES ON PLASMA LIPID AND LIPOPROTEIN CONCENTRATION IN THE HEALTHY POPULATION. Masao KANAMORI, Minoru SUGITA, Takashi ZZUNO (Dept. Environ. Health, Toho Univ. School of Med., Tokyo), Kimiko KOBAYASHI, Hideo HAMAGUCHI (Dept. Med. Genet., Inst. Basic Med., Univ. Tsukuba, Tsukuba) and Kiyotaro KONDO (Dept. Public Health, Hokkaido Univ. School of Med., Sapporo)

Jarvik GP.(1995) reported that the Apolipoprotein E(apoE) locus E4 allele was associated with both late-onset $\mathrm{AD}$ and total cholesterol (TCHO ). The E4 allele is associated with elevations in TCHO levels relative to the E3 allele, while the E2 allele has the opposite effect. The E4 allele is also associated with atherosclerotic disease and myocardial infarction. 235 healthy people were selected from age 50 to 75 randomly in Iwate prefecture. We habe studied on an association between apoE, lipoprotein(a)(Lp(a), TCHO and other plasma lipid . Sex and age-adjusted mean values of plasma lipid lipoprpteins by apoE genotypes were as follows : $\mathrm{Lp}$ (a) $15.6 \mathrm{mg} / \mathrm{dl}$, TCHO $196.7 \mathrm{mg} / \mathrm{dl}$ for E2/E3, Lp(a) 18.5, TCHO 197.8 for E3/E3, Lp(a) 23.8, TCHO 208.4 for E3/E4. Lp(a) were significantly different for apoE genotypes (as determined by a Kruskal-Wallis test). 


\author{
C-74 \\ HIGH DENSITY LIPOPROTEIN REDUCTION AND LIPOPROTEIN LIPASE GENE IN JAPANESE \\ SCHOOL CHILDREN. Kei YAMANA, Hisako YANAGI, Kimiko KOBAYASHI *, Mari TANAKA, \\ Shigeo TOMURA, Shigeru TSUCHIYA, and Hideo HAMAGUCHI * \\ Institute of Community Medicine, * Institute of Basic Medical Science,University of Tsukuba, Japan
}

A reduction of high density lipoprotein cholesterol (HDL-C) is recognized as an important risk factor for coronary artery desease. Lipoprotein lipase (LPL) is an important enzyme for bydrolysis of TG-rich lipoproteins, and its activity is positively correlated with the plasma HDL-C levels. To investigate the association between LPL gene and reduced HDL-C levels in children, we studied the LPL gene polymorphisms in 114 school-age children with reduced HDL-C levels $(<40 \mathrm{mg} / \mathrm{dl}$ ) and in $194 \mathrm{control}$ children with normal HDL-C levels using PCR-restriction fragment length polymorphisms (RFLPs). Subjects with reduced HDL-C divided into two groups:70 subjects with reduced HDL-C and normal trigliceride (TG) levels ( $<100 \mathrm{mg} / \mathrm{dl}$, 90 percentile of Japanese school children) (the low HDL / normal TG group) and 44 subjects with reduced HDL-C and elevated TG levels ( $\geqq 100 \mathrm{mg} / \mathrm{dl}$ ) (the low HDL/ high TG group). Frequency of the $P v u \mathrm{II}+1+$ genotype in the low HDL/ high TG group was significantry higher compared with the low HDL / normal TG group, $\chi^{2}=7.49, p<0.01$, and the control group, $\chi^{2}=7.23, p<0.01$, respectively. In addition, we found one heterozygous for LPLArita (deletion of $G$ at base 916 in exon 5, the common mutation of LPL gene in Japanese), among the low HDL / high TG subjects. These results suggested that genetic variations of the LPL gene may contribute to the reduction of HDL-C associated with elevated TG levels.

\title{
C-75
}

\section{QUANTITATIVE TRAIT LOCUS MAPPING OF HUMAN PLASMA CHOLESTEROL CONCENTRATION. 'Yoshimi IIIMA, 'Kimiko KOBAYASHI, ${ }^{2}$ Hisako YANAGI, ${ }^{3}$ Yae SHIMAKURA, ${ }^{1}$ Tomohiro HAYAKAWA ${ }^{1}$ Tadao ARINAMI, ${ }^{1}$ Hideo HAMAGUCHI ('Dept.Med.Genet.,Inst.Basic med. ${ }^{2}$ and Inst.Comm.Med. ${ }^{3}$ and Inst.Clin.Med., Univ.Tsukuba)}

To map the loci responsible for multifactorial hypercholesterolemia, family studies were done by using genetic markers. We collected samples from 101 Japanese nuclear families ascertained through a child with hypercholesterolemia $(\geq 200 \mathrm{mg} / \mathrm{dl})$. There were 422 individuals and 157 sib-pairs. We tested the linkage between plasma cholesterol concentrations and the candidate genes for LDL-receptor, apoB, apoE/C-I/C-II, apoA-I/C-III/A-IV, apo(a), VLDL-receptor, and LPL, by quantitative trait locus methods (QTL methods). We also tested the linkage between hypercholesterolemia and the candidate genes by affected sib-pair methods. For statistical genetic analyses, the program SIBPAL(S.A.G.E.) and SPLINK were used. The linkage between plasma cholesterol concentrations and the apoA-I/C-III/A-IV gene cluster region were observed $(\mathrm{p}<0.00008)$. In addition, we also observed the linkage between hypercholesterolemia and the apoA-I/C-III/AIV gene cluster region by affected sib-pair methods $(\mathrm{p}<0.02)$. As to other candidate loci, no linkage was observed by QTL methods. Thus, these data suggest that there is a gene responsible for plasma cholesterol concentrations and hypercholesterolemia at or near the apoA-I/C-IIL/A-IVgene cluster region. 
C-76

HYPOALPHALIPOPROTEINEMIA DUE TO MUTATIONS OF APOLIPOPROTEIN A-I GENE. Kimiko KOBAYASHI, Hisako YANAGI, Nao YAMAMOTO, Tadao ARINAMI, Shigeru TSUCHIYA, and Hideo HAMAGUCHI (Dept. Med. Genet., Inst. Basic Med. Sci., and *Inst. Comm. Med., Univ. Tsukuba, Tsukuba)

To investigate the frequency of the hypoalphalipoproteinemia due to the mutant apo A-I gene, we have analyzed the sequence variation of apo A-I gene from 33 pupils with low HDL-cholesterol $(\leq 35 \mathrm{mg} / \mathrm{dl})$ or apo A-I $(\leq 100 \mathrm{mg} / \mathrm{dl})$ levels, who have been screened from 1254 school children in a school survey. We have detected three kinds of frameshift mutations, a splicing mutation, and a missence mutation from them. These five mutations were not observed in 61 other pupils with low HDL-cholesterol levels $(\leq 40 \mathrm{mg} / \mathrm{dl})$. The findings suggest that the hypoalphalipoproteinemia due to the mutant apo A-I gene is a relatively common autosomal dominant inborn error of metabolism that affects about one in 250 300 peoples. In addition, we have examined the relationship between HDLcholesterol and apo A-I levels and a $-76 \mathrm{G} / \mathrm{A}$ polymorphism in the promoter of the apoA-I gene, which was reported to be associated with the apo A-I transcription efficiency in vitro. The frequencies of $A$ allele was higher in pupils with low levels of apo A-I $(\leq 100$ $\mathrm{mg} / \mathrm{dl})$ than the other pupils $(>100 \mathrm{mg} / \mathrm{dl})(0.23$ vs $0.12, \mathrm{p}=0.018)$. There is, however, no association between the polymorphism and HDL-cholesterol levels. These data suggest the $-76 \mathrm{G} / \mathrm{A}$ polymorphism appears to regulate apo A-I production in vivo but its effect on HDL-cholesterol levels is small, if present. 
AUTHOR INDEX

PL: Plenary Lecture, LS: Luncheon Seminar, S: Symposium, Others: General Contribution.

A

B

\begin{tabular}{|c|c|c|c|}
\hline ABE, Izumi & B-24 & $\mathrm{BA}, \mathrm{Yi}$ & $A-7$ \\
\hline ABE, Jun & $A-2, B-6$ & BABA, Tsuneyoshi & $B-65$ \\
\hline ABE, Kuniya & B-34, B-35 & BAKER, E. & $C-56$ \\
\hline ABE, Kyohko & $C-18, C-32$ & BANDO, Hiroko & $A-70$ \\
\hline ABE, Masako & $A-37$ & BANNAI, Makoto & B-8 \\
\hline ABE, Shuji & B-58 & BEAUDET, A.L. & B-68 \\
\hline ABE, Tatsuo & $\begin{array}{l}\text { A-25, A-49, A-50, } \\
\text { A-51, A-52, A-53, } \\
C-48, C-49\end{array}$ & $\begin{array}{r}\text { BELL, Graeme } \\
\text { C }\end{array}$ & A-38 \\
\hline ADACHI, Katsuhito & $C-51$ & CHIBA, Shunzo & B-38 \\
\hline ADACHI, Kyoko & $C-10$ & CHINEN, Yasutsugu & $\mathrm{C}-8$ \\
\hline ADACHI, Wataru & $A-64$ & COX, Nancy & $A-38$ \\
\hline $\begin{array}{l}\text { AERBAJINAI, } \\
\text { Wulin }\end{array}$ & B-7 & 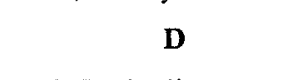 & \\
\hline AIZAWA, Shinichi & LS-5 & DATE, Kenjiro & $C-33$ \\
\hline AKAGI, Kunihiko & $C-55$ & DATE, Kousei & $\mathrm{A}-50, \mathrm{~A}-51, \mathrm{~A}-52$ \\
\hline AKAIKE, Masashi & $C-51$ & DOI, Rie & $A-13, A-14$ \\
\hline $\begin{array}{l}\text { AKANUMA, } \\
\text { Daisuke }\end{array}$ & $A-71$ & $\begin{array}{l}\text { DU, Juan } \\
\text { DUAN, Shu-Reng }\end{array}$ & $\begin{array}{l}C-53 \\
B-49\end{array}$ \\
\hline $\begin{array}{l}\text { AKANUMA, Jun } \\
\text { AKATSUKA, Akira }\end{array}$ & $\begin{array}{l}A-73, B-56 \\
C-42\end{array}$ & (5) & \\
\hline AMAGAI, Hitoshi & $A-45$ & EBARA, Michiyo & $C-41$ \\
\hline AMAGASA, Teruo & $A-71$ & EBERSOLE, Thomas & B $-34, B-35$ \\
\hline AMANO, Jun & $A-64$ & EBINA, Yasuhiko & $C-60$ \\
\hline ANAN, Tadashi & $A-5, A-6$ & ECCLES, M.R. & $\mathrm{C}-56$ \\
\hline ARAHATA, Kiichi & $C-52$ & EGASHIRA, & $B-4$ \\
\hline ARAI, Shouichi & B-47 & Masayuki & \\
\hline $\begin{array}{l}\text { ARAKAWA, } \\
\text { Yoshiki }\end{array}$ & $A-53, C-49$ & $\begin{array}{l}\text { EGUCHI, Mariko } \\
\text { EMI, Mitsuru }\end{array}$ & $\begin{array}{l}\text { A-58, A-59, } \\
\text { S-1I-1, A-4, A-27, }\end{array}$ \\
\hline ARIF, Mansyur & $A-58, A-59$ & & A $-28, A-48$ \\
\hline ARIKAWA, Masaya & B-59 & ENDO, Fumio & LS-1 \\
\hline ARINAMI, Tadao & $\begin{array}{l}\text { S-II- } 2, \text { A- } 40, A-41, \\
\text { A-42, C- } 71, C-75, \\
\text { C- } 76\end{array}$ & $\begin{array}{l}\text { ENDO, Satoru } \\
\text { ENDO, Takenori } \\
\text { ENDOU, Kouichi }\end{array}$ & $\begin{array}{l}B-10 \\
C-51 \\
C-68\end{array}$ \\
\hline ARINOBU, Yojiro & $\mathrm{B}-3$ & F & \\
\hline ARIYAMA, Youji & $A-52, A-53$ & 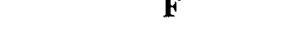 & \\
\hline ARTZT, Karen & $B-34, B-35$ & FIRDOUS, Naila & $A-23$ \\
\hline $\begin{array}{l}\text { ARYA, Roopen } \\
\text { ASAKA, Akio }\end{array}$ & $\begin{array}{l}A-22 \\
A-39, A-46, A-47\end{array}$ & $\begin{array}{l}\text { FUCHAROEN, } \\
\text { Goonnapa }\end{array}$ & A-32 \\
\hline ASAKA, Tomoya & $\mathrm{C}-54$ & FUCHAROEN, & $A-23$ \\
\hline ASAKAWA, Jun-ichi & A-62. B-28 & Suthat & \\
\hline ASAKAWA, Shuichi & B $-22, B-23, B-24$ & FUJIEDA, Kenji & B- 58 \\
\hline ASANO, Fumihiro & $A-54$ & FUJII, Hisaichi & $C-63$ \\
\hline ASOH, Masako & $C-42$ & FUJII, Kunihiro & A-73 \\
\hline AWAYA, Yutaka & $B-37$ & FUJIKI, Keiko & $A-13, A-14$ \\
\hline AZUMA, Noriyuki & $A-15$ & FUJIKI, Norio & $\mathrm{B}-73$ \\
\hline
\end{tabular}




\begin{tabular}{|c|c|}
\hline FUJIMAKI, Takuro & $A-13$ \\
\hline FUJIMORI, Minoru & A-64, B-74 \\
\hline FUJIMOTO, Akie & B-52 \\
\hline FUJIMOTO, Jiro & $A-57$ \\
\hline $\begin{array}{l}\text { FUJIMOTO, } \\
\text { Masahiro }\end{array}$ & B-14, B-20 \\
\hline $\begin{array}{l}\text { FUJIMOTO, } \\
\text { Seiichiro }\end{array}$ & $C-59, C-60, C-61$ \\
\hline FUJIMOTO, Toshiro & $C-68$ \\
\hline FUJINO, Takahumi & $C-60$ \\
\hline FUJISAWA, Keiko & $\mathrm{C}-44$ \\
\hline FUJITA, Shigeru & $A-69$ \\
\hline FUJIWARA, Hisaya & $\mathrm{C}-33$ \\
\hline FUJIWARA, Michio & $\mathrm{C}-12$ \\
\hline $\begin{array}{l}\text { FUJIWARA, } \\
\text { Tsutomu }\end{array}$ & B-13 \\
\hline FUKAGAWA, Koji & B-59 \\
\hline FUKAMI, Maki & B-25, B-26 \\
\hline FUKAO, Toshiyuki & B-17 \\
\hline FUKUDA, Seiji & $A-33$ \\
\hline FUKUHARA, Shiro & $A-18$ \\
\hline $\begin{array}{l}\text { FUKUMAKI, } \\
\text { Yasuyuki }\end{array}$ & $A-22, A-23$ \\
\hline $\begin{array}{l}\text { FUKUNAGA, } \\
\text { Hidetoshi }\end{array}$ & $C-51$ \\
\hline $\begin{array}{l}\text { FUKUSHIMA, } \\
\text { Yoshimitsu }\end{array}$ & $\begin{array}{l}\text { A-61, B-25, B-26, } \\
\text { B- } 74, \text { C-10, C-20, } \\
\text { C-24, C-25, C-27, } \\
\text { C-46, C-48, C-49, } \\
\text { C-57 }\end{array}$ \\
\hline $\begin{array}{l}\text { FUKUTOMI, } \\
\text { Takashi }\end{array}$ & $A-47$ \\
\hline $\begin{array}{l}\text { FUKUYAMA, } \\
\text { Yukio }\end{array}$ & B- $39, \mathrm{~B}-42, \mathrm{~B}-45$ \\
\hline $\begin{array}{l}\text { FUNAMIZU, } \\
\text { Makiko }\end{array}$ & $A-43$ \\
\hline $\begin{array}{l}\text { FURIHATA, } \\
\text { Ken-ichi }\end{array}$ & A- $64, B-74$ \\
\hline $\begin{array}{l}\text { FURUSHO, } \\
\text { Toshiyuki }\end{array}$ & $\mathrm{C}-38$ \\
\hline $\begin{array}{l}\text { FURUTANI, } \\
\text { Michiko }\end{array}$ & B-47 \\
\hline $\begin{array}{l}\text { FURUUMI, } \\
\text { Hiroyasu }\end{array}$ & A -23 \\
\hline $\begin{array}{l}\text { FURUWATARI, } \\
\text { Chizumi }\end{array}$ & $A-64$ \\
\hline $\begin{array}{l}\text { FURUYAMA, } \\
\text { Jun-ichi }\end{array}$ & $A-57$ \\
\hline \multicolumn{2}{|l|}{ G } \\
\hline GAO, Ming & $C-71$ \\
\hline GOJOBORI, Takashi & $\mathrm{LS}-4$ \\
\hline GONDO, Yoichi & $A-11$ \\
\hline
\end{tabular}

$\begin{array}{ll}\begin{array}{l}\text { GOSEKI-SONE, } \\ \text { Masae }\end{array} & \text { B-60 } \\ \text { GOTO, Haruko } & \text { B-57 } \\ \text { GOTO, Jun } & \text { A-11 } \\ \text { GOTO, Kanako } & \text { C-52 } \\ \text { GOTO, Yu-ichi } & \text { A-29 } \\ \text { GOTODA, Yasuo } & \text { B-63, B-64 } \\ \text { GOYA, Yoshinobu } & \text { C-8 }\end{array}$

\section{$\mathbf{H}$}

HADANO, Shinji A-1

HAGIWARA, B-43

Yasuko

HAMADA, Hiromi A-40, A-41

HAMADA, Jun-ichi A-7

HAMAGUCHI, S-II-2, A-40, A-41, Hideo

A-42, A-45, C-66,

C-71, C-73, C-74,

C-75, C-76

HAMAGUCHI, B-59 Kazuyuki

HAMANO, Shinichiro

HARADA, Haruhito

HARADA, Naoki C-32

HARASHIMA, B-52

Hiroko

HAREYAMA, C-60

Hitoshi

HARIHARA, Shinji A-32

HARUTA, Ken A-48

HASEGAWA, B-75

Tomoko

HASEGAWA, B-27

Tomonobu

HASHIBA, Tsuyoshi C-26

HASHIMOTO, B-62

Takashi

HASHIMOTO, A-57

Tomoko

HASHIZUME, A-61

Kiyoshi

HATA, Akira A-26, A-27, A-28,

$A-43, C-61$

B- 16

HATAKEYAMA Toyomasa

HATASE, Tetsuro

HATTA, Nobuaki A-69

HAYAKAWA, A-13, A-14

Mutsuko

HAYAKAWA,

Tomohiro

HAYASHI, Aiko A-56

HAYASHI, Akihide C-70 


\begin{tabular}{|c|c|}
\hline HAYASHI, Akira & $A-21$ \\
\hline HAYASHI, Koichi & $C-70$ \\
\hline HAYASHI, Koichiro & $A-45$ \\
\hline $\begin{array}{l}\text { HAYASHI } \\
\text { Masamichi }\end{array}$ & $C-35$ \\
\hline HAYASHI, Satoshi & $\mathrm{C}-33$ \\
\hline HAYASHI, Yasuko & $B-36$ \\
\hline HAYASHIDA, Yumi & $B-37$ \\
\hline $\begin{array}{l}\text { HAZEYAMA, } \\
\text { Akemi }\end{array}$ & B-52 \\
\hline HIDA, Akiko & $B-30$ \\
\hline HIDAKA, Eiko & $C-10$ \\
\hline HIDAKA, Kazuo & $A-20$ \\
\hline $\begin{array}{l}\text { HIGASHIDE, } \\
\text { Tomomi }\end{array}$ & $A-12$ \\
\hline HIGUCHI, Itsuro & $C-51$ \\
\hline HIGUCHI, Sari & $C-54$ \\
\hline HIGUCHI, Susumu & S-II -3 \\
\hline HIGUCHI, Youichi & $B-65$ \\
\hline $\begin{array}{l}\text { HIGURASHI, } \\
\text { Makoto }\end{array}$ & $C-14$ \\
\hline HIKIJI, Kazumasa & $A-67$ \\
\hline HIMEI, Akio & $C-70$ \\
\hline HIRAI, Momoki & B-9, B-19 \\
\hline HIRAKAWA, Shun & $C-50$ \\
\hline $\begin{array}{l}\text { HIRASAWA } \\
\text { Yoshihei }\end{array}$ & A-43 \\
\hline HIRA Y AMA, Mikio & B-73 \\
\hline $\begin{array}{l}\text { HIRAYAMA, } \\
\text { Tsunenori }\end{array}$ & A-27, A-28 \\
\hline HIROHASHI, Setsuo & $A-5 !$ \\
\hline HIROI, Shitoshi & B- 49 \\
\hline $\begin{array}{l}\text { HIROKAWA, } \\
\text { Hidetetsu }\end{array}$ & $B-51$ \\
\hline HISANAGA, Yukio & $C-18$ \\
\hline HIYAMA, Keiko & $A-62$ \\
\hline HONDA, Hiroshi & $\mathrm{C}-5$ \\
\hline HONDA, Yoshiomi & $A-5, A-6$ \\
\hline HONDA, Yutaka & $C-69$ \\
\hline HORAI, Satoshi & A-32 \\
\hline HORIIKE, Shigeo & $A-49, A-60$ \\
\hline $\begin{array}{l}\text { HORIUCHI, } \\
\text { Takahiko }\end{array}$ & $A-69$ \\
\hline HOSHI, Kazuhiko & $A-44$ \\
\hline HOSHI, Nobuhiko & $C-59, C-60$ \\
\hline HOSODA, Saichi & B-47 \\
\hline HOSOI, Takayuki & $A-48$ \\
\hline $\begin{array}{l}\text { HOSOKAWA } \\
\text { Masuo }\end{array}$ & $A-7$ \\
\hline HOSOKAWA, Miwa & $A-45$ \\
\hline $\begin{array}{l}\text { HOSOKAWA } \\
\text { Youhei }\end{array}$ & $A-50$ \\
\hline HOTTA, Yoshihiro & $A-13, A-14$ \\
\hline HUQ, A.H.M.M. & B-68 \\
\hline
\end{tabular}

\begin{tabular}{|c|c|}
\hline HYODO, Maki & $C-33$ \\
\hline I & \\
\hline $\begin{array}{l}\text { ICHIKAWA, } \\
\text { Daisuke }\end{array}$ & $A-51$ \\
\hline IDA, Kenji & B-61 \\
\hline IHA, Tetsu & $C-8$ \\
\hline IIDA, Taku & $\mathrm{B}-33$ \\
\hline IIJIMA, Sumio & $A-39, A-46$ \\
\hline IIJIMA, Yoshimi & $C-75$ \\
\hline IIMURA, Tadahiro & B- 60 \\
\hline IKEDA, Joh-E & $\mathrm{A}-11, \mathrm{~B}-40, \mathrm{~B}-42$ \\
\hline IKEDA, Jun & $\mathrm{C}-42$ \\
\hline IKEDA, Shuichi & B- 74 \\
\hline IKEUCHI, Takeshi & $C-54$ \\
\hline IKEUCHI, Tatsuro & $\begin{array}{l}A-1, A-56, A-71 \\
C-3, C-52\end{array}$ \\
\hline IKEYA, Kiyoko & $B-45, C-53$ \\
\hline IMAIZUMI, Kiyoshi & $\begin{array}{l}\text { B-17, C- } 39, C-40, \\
\text { C- } 55\end{array}$ \\
\hline IMAIZUMI, Yoko & B -50 \\
\hline IMAMURA, Junko & $\mathrm{C}-28$ \\
\hline $\begin{array}{l}\text { IMAMURA, } \\
\text { Shin-ichiro }\end{array}$ & $B-47, C-23$ \\
\hline IMAMURA, Takuji & $B-51$ \\
\hline IMANAKA, Masaaki & $A-62, B-28$ \\
\hline INADA, Yasushi & $C-70$ \\
\hline INANA, George & $A-12$ \\
\hline $\begin{array}{l}\text { INAYAMA } \\
\text { Yasuhiro }\end{array}$ & $C-70$ \\
\hline INAZAWA, Johji & $\begin{array}{l}\text { S-I-1, A-25, A-50, } \\
\text { A-51, A-52, A-53, } \\
\text { C-48, C-49 }\end{array}$ \\
\hline INDO, Yasuhiro & $\mathrm{B}-37$ \\
\hline INOUE, Eturo & LS-2 \\
\hline INOUE, Ituro & A-26 \\
\hline INOUE, Kiyoshi & A -25 \\
\hline INOUE, Makoto & $C-11$ \\
\hline INOUE, Ryo & A-37 \\
\hline INOUE, Satoshi & $C-49$ \\
\hline INOUE, Shin-ichi & $C-72$ \\
\hline INOUE, Takahito & $A-23$ \\
\hline INOUE, Tomoko & $C-29$ \\
\hline ISASHIKI, Yasushi & $A-14$ \\
\hline ISHIBASHI, Teruo & B-4 \\
\hline ISHIDA, Takafumi & $\mathrm{C}-2$ \\
\hline ISHIDA, Tomoko & $A-18$ \\
\hline $\begin{array}{l}\text { ISHIHARA, } \\
\text { Tadayuki }\end{array}$ & $B-44$ \\
\hline ISHII, Chihiro & $C-21$ \\
\hline ISHII, Takuma & $\begin{array}{l}\mathrm{B}-17, \mathrm{C}-39, \mathrm{C}-40 \\
\mathrm{C}-55\end{array}$ \\
\hline $\begin{array}{l}\text { ISHIKAWA, } \\
\text { Ken-ichi }\end{array}$ & B-18 \\
\hline
\end{tabular}




\begin{tabular}{|c|c|}
\hline ISHIKAWA, Masayo & $C-10$ \\
\hline ISHIKAWA, Mutsuo & $B-70, C-32$ \\
\hline $\begin{array}{l}\text { ISHIKAWA, } \\
\text { Yoshihide }\end{array}$ & B-8 \\
\hline $\begin{array}{l}\text { ISHIKIRIY AMA, } \\
\text { Satoshi }\end{array}$ & $C-41$ \\
\hline $\begin{array}{l}\text { ISHIMARU, } \\
\text { Tadayuki }\end{array}$ & B-71 \\
\hline ISHIZAKA, Hitoshi & B-52 \\
\hline ISHIZUKA, Eiji & A-54 \\
\hline ISHIZUKA, Tomoki & $A-56$ \\
\hline ISOBE, Masaharu & B-16 \\
\hline ISSHIKI, Gen & $B-51$ \\
\hline ITAKURA, Yasunori & $A-61$ \\
\hline ITO, Shigeru & $C-56$ \\
\hline ITO, Takeshi & $\mathrm{C}-25$ \\
\hline ITO, Yoshiya & $C-36$ \\
\hline ITOH, Kunihiko & $A-67$ \\
\hline IUCHI, Iwao & $A-20$ \\
\hline $\begin{array}{l}\text { IWAMOTO } \\
\text { Sadahiko }\end{array}$ & $A-19$ \\
\hline IWAMOTO, Teruaki & $\mathrm{B}-32$ \\
\hline IWASAKI, Naoko & $A-34, A-38$ \\
\hline IWASAKI, Nobuaki & $B-57$ \\
\hline IWATA, Misa & $A-17$ \\
\hline IZUHARA, Kenji & B-3 \\
\hline IZUMI, Shigeki & B-54 \\
\hline $\begin{array}{l}\text { IZUMIKAWA, } \\
\text { Yoshinori }\end{array}$ & $\mathrm{C}-8$ \\
\hline IZUNO, Takashi & $C-66, C-73$ \\
\hline \multicolumn{2}{|l|}{$\mathbf{J}$} \\
\hline JINNO, Yoshihiro & B-70, B-71 \\
\hline $\mathrm{JO}, \mathrm{AOi}$ & $\mathrm{B}-31$ \\
\hline JUJI, Takeo & $\mathrm{B}-5, \mathrm{~B}-8, \mathrm{~B}-9$ \\
\hline \multicolumn{2}{|l|}{$\mathbf{K}$} \\
\hline $\begin{array}{l}\text { KAGEYAMA, } \\
\text { Yukio }\end{array}$ & $A-1$ \\
\hline KAJI, Masayuki & $\mathrm{C}-7$ \\
\hline KAJII, Eiji & $A-18, A-19$ \\
\hline KAJII, Tadashi & $A-9$ \\
\hline KAKISHITA, Eizo & $A-57$ \\
\hline KAKUMA, Tstsuya & B -59 \\
\hline KAMADA, Nanao & $A-58, A-59$ \\
\hline $\begin{array}{l}\text { KAMATANI, } \\
\text { Naoyuki }\end{array}$ & B-39 \\
\hline KAMINO, Kouzin & $A-30, B-39, C-65$ \\
\hline $\begin{array}{l}\text { KAMITAMARI, } \\
\text { Akira }\end{array}$ & B-65 \\
\hline KANAI, Atsushi & $A-13, A-14$ \\
\hline KANAI, Takayuki & $\mathrm{B}-\mathrm{I}, \mathrm{B}-2$ \\
\hline KANAME, Tadashi & B- $-34, B-35$ \\
\hline
\end{tabular}

\begin{tabular}{|c|c|}
\hline KANAMORI, Masao & $\begin{array}{l}A-34, A-47, C-66, \\
C-73\end{array}$ \\
\hline $\begin{array}{l}\text { KANAZAWA, } \\
\text { Ichiro }\end{array}$ & $A-11$ \\
\hline KANDIL, Eman & $B-4$ \\
\hline KANEGAE, Yumi & $A-73$ \\
\hline KANEKO, Hiroto & $A-60$ \\
\hline $\begin{array}{l}\text { KANEOKA } \\
\text { Satomichi }\end{array}$ & $A-62, B-28$ \\
\hline KANNO, Hitoshi & $\mathrm{C}-63$ \\
\hline KARIBE, Sachiyo & A-34 \\
\hline KARIO, Kazuomi & $A-36$ \\
\hline $\begin{array}{l}\text { KASAHARA } \\
\text { Masanori }\end{array}$ & B- 4 \\
\hline KASAI, Fumio & $B-19$ \\
\hline KASAI, Ryozo & $C-17, C-43$ \\
\hline KASHIMA, Kei & A -60 \\
\hline $\begin{array}{l}\text { KASHIWAZAKI, } \\
\text { Haruhiko }\end{array}$ & $A-7$ \\
\hline KASUMI, Fujio & $A-4$ \\
\hline $\begin{array}{l}\text { KATAGIRI. } \\
\text { Toyomasa }\end{array}$ & $A-70$ \\
\hline $\begin{array}{l}\text { KATAHIRA, } \\
\text { Tomoyuki }\end{array}$ & $B-75$ \\
\hline KATAI, Miyuki & $A-6 I$ \\
\hline $\begin{array}{l}\text { KATAYAMA, } \\
\text { Susumu }\end{array}$ & $C-50$ \\
\hline KATO, Hirohisa & $A-31, B-54, C-45$ \\
\hline KATO, Hiroshi & $B-16$ \\
\hline KATO, Rumiko & $B-14, B-15$ \\
\hline KATO, Zenichiro & $A-33$ \\
\hline $\begin{array}{l}\text { KATSUYAMA, } \\
\text { Tsutomu }\end{array}$ & $A-64, C-10$ \\
\hline KAWAI, Hisaomi & B- $63, \mathrm{~B}-64, \mathrm{C}-51$ \\
\hline KAWAI, Masahiko & $C-7$ \\
\hline $\begin{array}{l}\text { KAWAKITA } \\
\text { Yukiko }\end{array}$ & $\mathrm{C}-53$ \\
\hline $\begin{array}{l}\text { KAWANAMI, } \\
\text { Kimika }\end{array}$ & $A-45$ \\
\hline KAWANO, Masaki & $A-18, A-19$ \\
\hline $\begin{array}{l}\text { KAWANO, } \\
\text { Tomoyasu }\end{array}$ & $B-37$ \\
\hline $\begin{array}{l}\text { KAWASAKI, } \\
\text { Kazuhiko }\end{array}$ & B-22. B-23, B-24 \\
\hline KIDA, Mitsushiro & $B-72$ \\
\hline KIKUCHI, Kiyoshi & $\mathrm{C}-11$ \\
\hline KIM, Keiei & $\mathrm{C}-27$ \\
\hline KIM, Kyoung Chang & $C-20, C-25, C-46$ \\
\hline KIMURA, Akinori & B- 49 \\
\hline KIMURA, Hiroshi & $A-24$ \\
\hline KIMURA, Misa & $C-21, C-23$ \\
\hline KIMURA, Reiji & $A-6$ \\
\hline KIMURA, Toshiyuki & $C-49$ \\
\hline KIMURA, Yoriyoshi & $A-5$ \\
\hline
\end{tabular}




\begin{tabular}{|c|c|}
\hline KINOSHITA, Eiichi & B-65 \\
\hline $\begin{array}{l}\text { KINUTANI, } \\
\text { Masayuki }\end{array}$ & $\mathrm{C}-33$ \\
\hline KIRA, Jun-ichi & B- 1, B- 56 \\
\hline KISAKA, Yoshinori & $C-33$ \\
\hline KISHI, Youichi & A-54 \\
\hline KITATANI, Mashio & $\mathrm{C}-29$ \\
\hline KIZU, Rika & $\mathrm{C}-22$ \\
\hline KOBASHI, Gen & $S-I I-4, C-61$ \\
\hline $\begin{array}{l}\text { KOBAYASHI, } \\
\text { Kazuhiro }\end{array}$ & $B-32, B-46$ \\
\hline KOBAYASHI, & S-II $-2, A-40, A-42$ \\
\hline Kimiko & $\begin{array}{l}C-66, C-73, C-74, \\
C-75, C-76\end{array}$ \\
\hline $\begin{array}{l}\text { KOBAYASHI, } \\
\text { Makio }\end{array}$ & $B-45$ \\
\hline $\begin{array}{l}\text { KOBAYASHI, } \\
\text { Minatu }\end{array}$ & $A-47$ \\
\hline $\begin{array}{l}\text { KOBAYASHI, } \\
\text { Noboru }\end{array}$ & $A-2, A-3$ \\
\hline $\begin{array}{l}\text { KOBAYASHI, } \\
\text { Noriko }\end{array}$ & $C-26$ \\
\hline $\begin{array}{l}\text { KOBAYASHI, } \\
\text { Takuro }\end{array}$ & $\mathrm{B}-1$ \\
\hline $\begin{array}{l}\text { KOBAYASHI, } \\
\text { Toshifumi }\end{array}$ & $C-26$ \\
\hline $\begin{array}{l}\text { KOBAYASHI, } \\
\text { Toshiko }\end{array}$ & $A-30, C-65$ \\
\hline $\begin{array}{l}\text { KOBAYASHI, } \\
\text { Yuzuru }\end{array}$ & $A-69$ \\
\hline KODA, Yoshiro & A-24 \\
\hline KODAIRA, Mieko & $A-62, B-28$ \\
\hline KOGA, Yasutoshi & $\mathrm{A}-31, \mathrm{~B}-54, \mathrm{C}-45$ \\
\hline $\mathrm{KOH}$, Jun & $\mathrm{C}-70$ \\
\hline KOHNO, Nao & $A-13, A-14$ \\
\hline KOHNO, Sei-ichi & $A-56$ \\
\hline KOHSAKA, Takao & B-6 \\
\hline KOIDE, Hiroyoshi & $\mathrm{B}-42$ \\
\hline KOIDE, Kazuma & $A-51, A-52, A-53$ \\
\hline KOIKE, Kenichi & $B-74$ \\
\hline KOIZUMI, Tsutomu & $C-63$ \\
\hline KOJIMA, Yoshifumi & $\mathrm{C}-21, \mathrm{C}-22$ \\
\hline KOJO, Toru & $C-52$ \\
\hline KOMAKI, Rie & B-32 \\
\hline KOMATSU, Kenshi & B-10, B-20 \\
\hline KOMIYAMA, Jun & $B-74$ \\
\hline KONDO, Eri & $B-45$ \\
\hline KONDO, Ikuko & $\begin{array}{l}\text { A- } 35, \mathrm{~B}-68, \mathrm{C}-46, \\
\mathrm{C}-47, \mathrm{C}-49\end{array}$ \\
\hline KONDO, Kiyotaro & $\begin{array}{l}\text { A- } 26, A-43, C-61, \\
C-66, C-73\end{array}$ \\
\hline KONDO, Naomi & $A-33, B-17, B-62$ \\
\hline KONDO, Noriko & $B-10$ \\
\hline KONDO, Tatsuya & B- 34, B -35 \\
\hline
\end{tabular}

\begin{tabular}{|c|c|}
\hline KONDO-IIDA, Eri & B-44 \\
\hline KONDOH, Tatsuro & B-11, B-12 \\
\hline KONO, Yoshihiro & $C-70$ \\
\hline $\begin{array}{l}\text { KOTLIAROVA, } \\
\text { Svetlana E. }\end{array}$ & B-29 \\
\hline KOYAMA, Kiyoko & $C-9, C-31$ \\
\hline KOYAMA, Kumiko & $A-8, B-19$ \\
\hline KOZAKI, Takazumi & $A-9, A-10$ \\
\hline KOZUKA, Naoki & B-38 \\
\hline KUBO, Harumi & $C-50$ \\
\hline KUBO, Takeshi & $A-40, A-41$ \\
\hline KUDO, Takafumi & $C-31$ \\
\hline KUDOH, Fumiyo & $C-41$ \\
\hline KUDOH, Jun & $\mathrm{B}-22, \mathrm{~B}-23, \mathrm{~B}-24$ \\
\hline KUDOH, Yoshiki & B-24 \\
\hline $\begin{array}{l}\text { KUMAGAI, } \\
\text { Toshiyuki }\end{array}$ & $B-42$ \\
\hline $\begin{array}{l}\text { KUNIMOTO, } \\
\text { Keikichi }\end{array}$ & $C-18$ \\
\hline $\begin{array}{l}\text { KUNISHIGE, } \\
\text { Makoto }\end{array}$ & $C-51$ \\
\hline $\begin{array}{l}\text { KURAHASHI, } \\
\text { Hiroki }\end{array}$ & B-21 \\
\hline $\begin{array}{l}\text { KURAMATU, } \\
\text { Toshihiro }\end{array}$ & $\mathrm{A}-55$ \\
\hline $\begin{array}{l}\text { KURATANI, } \\
\text { Shigeru }\end{array}$ & LS -5 \\
\hline KURE, Shigeo & PL-4, A-73, B-56 \\
\hline $\begin{array}{l}\text { KURIYAMA, } \\
\text { Masaru }\end{array}$ & $B-73$ \\
\hline KUROKI, Yoko & B-32 \\
\hline KUROKI, Yoshikazu & $\begin{array}{l}\text { B- } 17, C-39, C-40, \\
C-55\end{array}$ \\
\hline KUROSAWA, Kenji & $C-42$ \\
\hline $\begin{array}{l}\text { KUROSHIMA, } \\
\text { Masako }\end{array}$ & $C-26$ \\
\hline KUWANO, Akira & $A-5, A-26$ \\
\hline
\end{tabular}

A- -26

Jean-Marc

LAYTON, D. Mark A-22

LO, Wilson H.Y. B-73

\section{M}

MAEDA, Hideto B-23

MAEDA, Jun C-21, C-22

MAEDA, Toyoki A-21

MAENAKA, B-9

Katsumi

MAKINO, Michiko A-29

MAKINODA, Satoru C-59, C-60

MAKITA, Yoshio C -36

MANABE, Jun-ichi A-22 


\begin{tabular}{|c|c|}
\hline MARTIN, G.M. & $A-65$ \\
\hline $\begin{array}{l}\text { MASUMURA, } \\
\text { Chigusa }\end{array}$ & $B-75$ \\
\hline MASUNO, Mitsuo & $\begin{array}{l}\text { B-17, C-39, C-40, } \\
C-55\end{array}$ \\
\hline $\begin{array}{l}\text { MASUZAKI, } \\
\text { Hideaki }\end{array}$ & $C-18$ \\
\hline $\begin{array}{l}\text { MATSUBARA, } \\
\text { Hiroshi }\end{array}$ & $C-36$ \\
\hline $\begin{array}{l}\text { MATSUBARA, } \\
\text { Yoichi }\end{array}$ & $A-73, B-56$ \\
\hline MATSUDA, Ichiro & A-5, B-37 \\
\hline MATSUl, Akira & $C-35$ \\
\hline MATSUI, Ichiro & $\mathrm{A}-2, \mathrm{~A}-3$ \\
\hline MATSUI, Kiyoshi & $A-17$ \\
\hline $\begin{array}{l}\text { MATSUMOTO, } \\
\text { Kazuhiko }\end{array}$ & B-74 \\
\hline $\begin{array}{l}\text { MATSUMOTO, } \\
\text { Naomichi }\end{array}$ & $\begin{array}{l}\text { B-14, B-15, B-20, } \\
\text { B }-66, C-57\end{array}$ \\
\hline $\begin{array}{l}\text { MATSUMOTO, } \\
\text { Satoshi }\end{array}$ & $A-4$ \\
\hline $\begin{array}{l}\text { MATSUMOTO, } \\
\text { Tadashi }\end{array}$ & $\begin{array}{l}\text { B-11, B-12, B-65, } \\
C-32\end{array}$ \\
\hline MATSUO, Masafumi & A-36 \\
\hline MATSUO, Nobutake & $\begin{array}{l}\text { B-25, B-26, B-27, } \\
\text { C-21, C-22 }\end{array}$ \\
\hline MATSUO, Isao & LS -5 \\
\hline $\begin{array}{l}\text { MATSUOKA, } \\
\text { Rumiko }\end{array}$ & $\mathrm{B}-47, \mathrm{C}-21, \mathrm{C}-23$ \\
\hline $\begin{array}{l}\text { MATSUSHIMA, } \\
\text { Kazushige }\end{array}$ & $C-20, C-25$ \\
\hline $\begin{array}{l}\text { MATSUSHITA, } \\
\text { Ikumi }\end{array}$ & B-29, B-30 \\
\hline MATSUSHITA, Sho & B-2 \\
\hline $\begin{array}{l}\text { MATSUURA, } \\
\text { Shinya }\end{array}$ & $B-10$ \\
\hline $\begin{array}{l}\text { MATUSHIMA, } \\
\text { Mieko }\end{array}$ & $A-8$ \\
\hline McLAREN, Margaret & $A-12$ \\
\hline MEKAWA, Kihei & $\mathrm{C}-42$ \\
\hline MIHARU, Norio & $C-5, C-18, C-33$ \\
\hline MIKAWA, Makoto & $\mathrm{C}-24$ \\
\hline MIKI, Tetsuro & $\begin{array}{l}A-30, A-66, B-39, \\
C-65, C-69\end{array}$ \\
\hline MIKI, Yoshio & $\mathrm{S}-\mathrm{II}-1, \mathrm{~A}-70$ \\
\hline MINAMI, Maiko & A-70 \\
\hline MINEO, Ikuo & B-48 \\
\hline $\begin{array}{l}\text { MINESHITA, } \\
\text { Takahiro }\end{array}$ & $C-19$ \\
\hline $\begin{array}{l}\text { MINOSHIMA, } \\
\text { Shinsei }\end{array}$ & $\begin{array}{l}\text { B-22, B-23, B-24, } \\
\text { B-76, C-23 }\end{array}$ \\
\hline MISAWA, Shinichi & $A-49 . A-60$ \\
\hline $\begin{array}{l}\text { MITSUBUCHI, } \\
\text { Hiroshi }\end{array}$ & B-37 \\
\hline
\end{tabular}

\begin{tabular}{|c|c|}
\hline MITSUDA, Noriaki & A-66 \\
\hline MITSUI, Hiroshi & B-5 \\
\hline $\begin{array}{l}\text { MITSUYAMA, } \\
\text { Susumu }\end{array}$ & $B-76$ \\
\hline $\begin{array}{l}\text { MITSUYAMA, } \\
\text { Yoshio }\end{array}$ & $C-68$ \\
\hline MIWA, Ichita & $\mathrm{C}-12$ \\
\hline MIWA, Shiro & $C-63$ \\
\hline $\begin{array}{l}\text { MIYABARA, } \\
\text { Shinichi }\end{array}$ & $C-12, C-13$ \\
\hline $\begin{array}{l}\text { MIYAKAWA, } \\
\text { Kimiko }\end{array}$ & B-75 \\
\hline $\begin{array}{l}\text { MIYAKAWA, } \\
\text { Tomoyuki }\end{array}$ & $C-28, C-30$ \\
\hline MIYAKE, Masashi & $B-46$ \\
\hline MIY AMOTO, Akie & $C-36$ \\
\hline MIY AMOTO, Norio & $B-61$ \\
\hline MIYAMOTO, Satomi & $C-11$ \\
\hline $\begin{array}{l}\text { MIYAMOTO, } \\
\text { Toshinobu }\end{array}$ & B-70, B-71 \\
\hline $\begin{array}{l}\text { MIYAMURA, } \\
\text { Toshihiro }\end{array}$ & $A-46$ \\
\hline $\begin{array}{l}\text { MIYAZAKI } \\
\text { Masataka }\end{array}$ & $A-22$ \\
\hline MIYAZAKI, Tokiko & $A-17$ \\
\hline MIYOSHI, Osamu & B-4, B-14 \\
\hline MIZUNO, Yuji & $B-43$ \\
\hline MIZUNOE, Tomoya & $\mathrm{C}-33$ \\
\hline $\begin{array}{l}\text { MIZUSAWA } \\
\text { Hiroshi }\end{array}$ & $\mathrm{C}-2$ \\
\hline MOMMA, Kazuo & $\mathrm{B}-47, \mathrm{C}-21, \mathrm{C}-23$ \\
\hline MOMOI, Mariko & $A-55$ \\
\hline MOMOI, Toru & $\mathrm{C}-7$ \\
\hline MORI, Hiroshi & $C-67$ \\
\hline MORI, Rintaro & $\mathrm{C}-9$ \\
\hline MORI, Ryogo & $\mathrm{B}-65$ \\
\hline MORI, Toshiki & $\begin{array}{l}A-50, A-51, A-52 \\
A-53\end{array}$ \\
\hline MORIMOTO, Yuji & $A-35, C-47$ \\
\hline MORISAKI, Hiroko & B-48 \\
\hline $\begin{array}{l}\text { MORISAKI, } \\
\text { Takayuki }\end{array}$ & B- 48 \\
\hline $\begin{array}{l}\text { MORISHIMA, } \\
\text { Atsuyuki }\end{array}$ & A-65, A-66 \\
\hline MORITA, Sumiyo & B-33 \\
\hline MORIUCHI, Tetsuya & $A-7$ \\
\hline MORIYAMA, Mako & B-35 \\
\hline $\begin{array}{l}\text { MORIYAMA, } \\
\text { Satoshi }\end{array}$ & B-5, B-6 \\
\hline MUKAI, Tsunehiro & $B-48$ \\
\hline MUKI, Tetsuro & $A-65$ \\
\hline MURAKAMI, Akira & $A-12$ \\
\hline $\begin{array}{l}\text { MURAKAMI, } \\
\text { Yasushi }\end{array}$ & $A-50$ \\
\hline
\end{tabular}




\begin{tabular}{|c|c|c|c|}
\hline MURAMATSU, & $C-49$ & $\begin{array}{l}\text { NAKATA, Nao } \\
\text { NAKAYA }\end{array}$ & $\begin{array}{l}C-5 \\
C-18\end{array}$ \\
\hline Masami & & NAKAYA, Takayosi & $C-18$ \\
\hline $\begin{array}{l}\text { MURAMATSU, } \\
\text { Taro }\end{array}$ & S-II-3 & $\begin{array}{l}\text { NAKAYAMA, } \\
\text { Masahiko }\end{array}$ & B-12 \\
\hline MURASHITA, Mari & B-58 & NAKAYAMA, & B-21 \\
\hline MURATA, Yuji & $\mathrm{C}-29$ & Takahiro & \\
\hline MUROI, Junko & $\mathrm{C}-7$ & NAKAZAKI, & B-73 \\
\hline MUROYA, Koji & B-25, B-26, B-27 & Shigeaki & \\
\hline $\mathbf{N}$ & & $\begin{array}{l}\text { NAKURA, Jun } \\
\text { NAMIKI, Mikio }\end{array}$ & $\begin{array}{l}\text { A- } 65, \text { A- } 66, C-69 \\
B-32\end{array}$ \\
\hline $\begin{array}{l}\text { NAGAFUCHI, } \\
\text { Shigeo }\end{array}$ & B-41 & NARAHARA, Koji & $\begin{array}{l}C-9, C-17, C-31 \\
C-43, C-56\end{array}$ \\
\hline NAGAI, Toshiro & B-26 & NARISAWA, & A-73, B-56 \\
\hline $\begin{array}{l}\text { NAGAMINE, } \\
\text { Kentaro }\end{array}$ & B-24 & $\begin{array}{l}\text { Kuniaki } \\
\text { NARITOMI, Kenji }\end{array}$ & $C-8$ \\
\hline NAGAO, Masayoshi & $B-55$ & NAWATA, Hajime & B-59 \\
\hline NAGASAKI, Yutaka & $A-73$ & NEBES, Vicki L. & B-63 \\
\hline NAGASE, Takahiro & B-18 & NEMOTO, Yoshiaki & $\mathrm{B}-3$ \\
\hline NAGATA, Masami & B-13 & NICHOLLS, & B-67 \\
\hline NAGATA, Yoichi & $A-5, A-6$ & Robert D. & \\
\hline NAKAE, Jun & B-58 & NIHO, Yoshiyuki & B-3 \\
\hline $\begin{array}{l}\text { NAKAGAWA, } \\
\text { Masanori }\end{array}$ & $C-68$ & NIIKAWA, Norio & $\begin{array}{l}\text { S-I-2, A-72, B-4, } \\
\text { B-14, B-15, B-20, }\end{array}$ \\
\hline $\begin{array}{l}\text { NAKAGAWA, } \\
\text { Yumi }\end{array}$ & $C-48$ & & $\begin{array}{l}\text { B-66, B-70, B-71, } \\
\text { C-18, C-32, C-57, }\end{array}$ \\
\hline $\begin{array}{l}\text { NAKAGOME, } \\
\text { Yasuo }\end{array}$ & B-29, B-31, B-32 & NIINUMA, Takenari & $\begin{array}{l}C-58, C-72 \\
C-6\end{array}$ \\
\hline $\begin{array}{l}\text { NAKAHORI, } \\
\text { Yutaka }\end{array}$ & $\begin{array}{l}\text { B-29, B-30, B-31, } \\
\text { B-32, B-33, B-41, } \\
\text { B- } 46, \text { C- } 10\end{array}$ & $\begin{array}{l}\text { NIIRO, Hiroaki } \\
\text { NIKAIDO, Toshio } \\
\text { NIKI, Kiyomi }\end{array}$ & $\begin{array}{l}\text { B-3 } \\
\text { B-74 } \\
\text { B-47 }\end{array}$ \\
\hline NAKAJIMA, Yumi & $A-70$ & NIMURA, Yoshinori & A -64 \\
\hline NAKAMURA, Kenji & B-6I & NINOMIYA, & $C-17, C-43$ \\
\hline $\begin{array}{l}\text { NAKAMURA, } \\
\text { Mihoko }\end{array}$ & $C-39$ & $\begin{array}{l}\text { Shinsuke } \\
\text { NISHI, Toshiji }\end{array}$ & $C-40$ \\
\hline $\begin{array}{l}\text { NAKAMURA, } \\
\text { Takamichi }\end{array}$ & $A-43$ & $\begin{array}{l}\text { NISHIDA, Kazuhiro } \\
\text { NISHIDA, }\end{array}$ & $\begin{array}{l}A-49 \\
B-64\end{array}$ \\
\hline $\begin{array}{l}\text { NAKAMURA, } \\
\text { Takeyuki }\end{array}$ & B-49 & $\begin{array}{l}\text { Yoshihiko } \\
\text { NISHIKORI, Eiko }\end{array}$ & B-28 \\
\hline $\begin{array}{l}\text { NAKAMURA, } \\
\text { Tsuneho }\end{array}$ & $C-41$ & $\begin{array}{l}\text { NISHIMURA, Gen } \\
\text { NISHIMURA, }\end{array}$ & $\begin{array}{l}C-39 \\
C-32\end{array}$ \\
\hline NAKAMURA, & $S-I I-1, A-4, A-8$ & Tomoko & \\
\hline Yusuke & $\begin{array}{l}\text { A-63, A-67, A-70, } \\
\text { B-13, B-19, C-48, } \\
\text { C-49 }\end{array}$ & $\begin{array}{l}\text { NISHIMURA, } \\
\text { Tomomi } \\
\text { NISHIMURA, }\end{array}$ & $\begin{array}{l}\text { B-61 } \\
\text { B-1, B-2 }\end{array}$ \\
\hline NAKANO, Hiroshi & $B-52$ & Yasuharu & \\
\hline NAKANO, Motoi & $A-72$ & NISHINA, Sachiko & $A-15$ \\
\hline NAKANO, Yukiko & $C-50$ & NISHIOKA, Kenya & B-61 \\
\hline NAKAO, Mitsuyoshi & $A-5, A-6, B-68, B-71$ & NISHISHO, Isamu & B-21 \\
\hline $\begin{array}{l}\text { NAKASHIMA, } \\
\text { Hitoshi }\end{array}$ & $\mathrm{B}-3$ & $\begin{array}{l}\text { NISHIWAKI, } \\
\text { Yumiko }\end{array}$ & $A-30, C-65$ \\
\hline NAKASONE, Ryou & $C-28$ & NISHIYORI, Atsushi & B-54 \\
\hline NAKATA, Daichi & $A-7$ & NOBUNAGA, & $C-29$ \\
\hline NAKATA, Kenichi & $A-16$ & Toshikatu & \\
\hline NAKATA, Motomi & $A-6$ & NODA, Kazuo & $C-32$ \\
\hline
\end{tabular}




\begin{tabular}{|c|c|}
\hline NOGUCHI, Satoru & $B-43$ \\
\hline NOGUCHI, Tamio & $C-63$ \\
\hline NOMURA, Nobuo & $A-5, B-18$ \\
\hline NOMURA, Noriko & $C-4$ \\
\hline NOMURA, Shosaku & A- 18 \\
\hline NOMURA, Yoshiko & B-2 \\
\hline NONAKA, Ikuya & $A-29, B-43, C-54$ \\
\hline NUMANO, Fujio & $\mathrm{B}-7$ \\
\hline $\begin{array}{l}\text { NUMAZAWA, } \\
\text { Tamaki }\end{array}$ & $C-41$ \\
\hline \multicolumn{2}{|l|}{0} \\
\hline OCHIAI, Yukikatsu & $C-42$ \\
\hline $\begin{array}{l}\text { OGASAWARA, } \\
\text { Hideyuki }\end{array}$ & A-1 \\
\hline $\begin{array}{l}\text { OGASAWARA, } \\
\text { Kenichi }\end{array}$ & $A-16$ \\
\hline $\begin{array}{l}\text { OGASAWARA, } \\
\text { Nobuaki }\end{array}$ & B- $48, \mathrm{~B}-57$ \\
\hline OGATA, Makiko & $A-34, A-38$ \\
\hline OGATA, Tsutomu & B- $25, \mathrm{~B}-26, \mathrm{~B}-27$ \\
\hline OGAWA, Atsuko & B-8 \\
\hline OGAWA, Masanobu & $A-37$ \\
\hline OGIHARA, Toshio & $\begin{array}{l}\text { A-30, A-65, A-66, } \\
C-65, C-69\end{array}$ \\
\hline OGINO, Ikuko & $A-74$ \\
\hline OGISO, Yoshifumi & A- 64 \\
\hline OGUNI, Hirokazu & $B-39$ \\
\hline OGUNI, Miyako & $B-39$ \\
\hline OGURA, Kenji & $A-67$ \\
\hline OHAMA, Koso & $C-5, C-33$ \\
\hline OHASHI, Hirofumi & $\begin{array}{l}\mathrm{B}-26, \mathrm{C}-20, \mathrm{C}-25, \\
\mathrm{C}-27, \mathrm{C}-46, \mathrm{C}-57\end{array}$ \\
\hline OHBA, Norio & $A-14$ \\
\hline $\begin{array}{l}\text { OHBUCHI, } \\
\text { Nobuhisa }\end{array}$ & B-49 \\
\hline OHGAMI, Erichi & $B-3$ \\
\hline $\begin{array}{l}\text { OHGAWARA, } \\
\text { Hisako }\end{array}$ & $\mathrm{A}-34, \mathrm{~A}-38$ \\
\hline OHISHI, Michio & $C-72$ \\
\hline OHNO, Kousaku & $B-53$ \\
\hline OHNO, Tsutomu & $\mathrm{C}-20$ \\
\hline OHSUGI, Keiko & $A-10$ \\
\hline OHTA, Hideo & $A-23$ \\
\hline OHTA, Kohji & $B-37$ \\
\hline OHTA, Tohru & $A-72$ \\
\hline OHTA, Yachio & $A-28$ \\
\hline OHTAKE, Akira & $B-52$ \\
\hline OHYA, Kazuhiro & B -38 \\
\hline $\begin{array}{l}\text { OHYASHIKI, } \\
\text { Junko } \mathrm{H} \text {. }\end{array}$ & LS-6 \\
\hline $\begin{array}{l}\text { OHYASHIKI, } \\
\text { Kazuma }\end{array}$ & $\mathrm{LS}-6$ \\
\hline OIDA, Shinichiro & $B-60$ \\
\hline
\end{tabular}

$\begin{array}{ll}\text { OKABE, Masaru } & \text { C-63 } \\ \text { OKADA, Mitsuhiro } & \text { C-62 } \\ \text { OKADA, Shintaro } & \text { B-21 } \\ \text { OKADA, Takeya } & \text { A-11 } \\ \text { OKAMOTO, Eizo } & \text { A-57 } \\ \text { OKAMURA, } & \text { C-6 } \\ \quad \text { Kunihiro } & \\ \text { OKANO, Yoshiyuki } & \text { B-51, B-52 } \\ \text { OKAZAKI, Yuji } & \text { C-72 } \\ \text { OKUDA, Hiroshi } & \text { A-18, A-19 } \\ \text { OKUDA, Osamu } & \text { A-74 } \\ \text { OKUNO, Akimasa } & \text { C-36 } \\ \text { OKUYAMA, } & \mathrm{C}-59 \\ \quad \text { Kazuhiko } & \\ \text { OKUYAMA, } & \text { A-15, A-75 } \\ \quad \text { Torayuki } & \\ \text { OMORI, Yasue } & \text { A-34, A-38 } \\ \text { OMOTO, Keiichi } & \text { A-32 } \\ \text { OMURA, Satoshi } & \text { A-6 } \\ \text { ONDA, Masahiko } & \text { A-4 } \\ \text { ONIMARU, Michiko } & \text { B-6 } \\ \text { ONO, Fumiko } & \text { A-74 } \\ \text { ONOGI, Satoshi } & \text { A-44 } \\ \text { ONOUCHI, } & \text { C-48 } \\ \text { ZNOES } & \end{array}$

Zenshirou

ORII, Tadao

ORIMO, Hajime

ORIMO, Hideo

OSAME, Mitsuhiro

OSAWA, Makiko

OSAWA, Yukiko

OSHIMA; Hiroyuki

OSHIMA, Junko

OSHIMURA, Mitsuo

OSOEGAWA,

Kazutoyo

OSUGA, Hitoshi B-40

OTSUKA, Takeshi B-3

OU, Trista $Y$.

OWADA, Makoto

OYANAGI,

Kazuhiko

OZAKI, Mamoru

OZAWA, Eijiro

PL-5, A-33, B-17,

B -62

A -48

B-60

C $-51, C-68$

B-39, B-44, B-45,

C -53

B-42

A-1

A -65

LS-6, S-I-4, B-10

B-23

$B-40$
$B-3$

A $-40, A-41, A-42$

A -44

B-55

C -29

B-43

$\begin{array}{ll}\text { PAN, I. - Hung } & \text { A-32 } \\ \text { PARK, Kyung Sook } & \text { A-32 } \\ \text { R } & \end{array}$

RAPPOLD, Gudrun B-25, B-26 
S

\begin{tabular}{|c|c|}
\hline SAGAWA, Tadashi & $C-59$ \\
\hline SAHARA, Naruhiko & $\mathrm{C}-67$ \\
\hline SAIGA, Okiyoshi & B-61 \\
\hline SAITO, Izumu & $A-73$ \\
\hline SAITO, Kayoko & $\begin{array}{l}\text { B-39, B-42, B-44, } \\
\text { B-45, C-53 }\end{array}$ \\
\hline SAITO, Masaaki & $\mathrm{B}-36, \mathrm{C}-54$ \\
\hline SAITO, Shiro & B-64 \\
\hline SAITO, Susumu & $A-63$ \\
\hline $\begin{array}{l}\text { SAITO-OHARA, } \\
\text { Fumiko }\end{array}$ & $A-56, C-52$ \\
\hline SAITOH, Shinji & $B-66, B-67$ \\
\hline SAJI, Fumitaka & $\mathrm{C}-29$ \\
\hline SAKAI, Harumi & $B-40$ \\
\hline SAKAI, Jun & $C-70$ \\
\hline SAKAI, Toshiaki & $\mathrm{C}-70$ \\
\hline $\begin{array}{l}\text { SAKAKURA, } \\
\text { Chohei }\end{array}$ & $A-52, A-53$ \\
\hline SAKATA, Toshiie & B-59 \\
\hline $\begin{array}{l}\text { SAKISAKA, } \\
\text { Yumiko }\end{array}$ & A-38 \\
\hline SAKUMA, Hitoshi & $A-12$ \\
\hline $\begin{array}{l}\text { SAKURAGAWA, } \\
\text { Norio }\end{array}$ & $A-10, A-74, B-65$ \\
\hline SAKURAI, Akihiro & $A-61$ \\
\hline SAKURAI, Koyo & B-74 \\
\hline SASAKI, Hiroki & A -56 \\
\hline SASAKI, Hiroshi & $\mathrm{C}-7$ \\
\hline SASAKI, Hiroyuki & B $-69, C-6$ \\
\hline SASAKI, Kiminori & $C-32$ \\
\hline SASAKI, Koubou & A-57 \\
\hline SASAKI, Masao S. & $A-71$ \\
\hline SASAKI, Mitsuyo & $C-15, C-19$ \\
\hline SASAKI, Nozomu & B-52 \\
\hline SASAKI, Tohru & $\mathrm{C}-58$ \\
\hline SASAOKA, Tasishi & B-49 \\
\hline SATO, Akira & $A-44$ \\
\hline SATO, Kodo & $C-28, C-30$ \\
\hline SATO, Manatsu & B- 49 \\
\hline SATO, Masato & $C-46$ \\
\hline SATO, Seiji & B-60 \\
\hline SATOH, Chiyoko & $A-62, B-28$ \\
\hline SATOH, Tetsuya & $C-69$ \\
\hline SATOU, Takaaki & $C-1$ \\
\hline SAYA, Hideyuki & $A-5, A-6$ \\
\hline $\begin{array}{l}\text { SCHELLENBERG, } \\
\text { G.D. }\end{array}$ & $A-65$ \\
\hline SEGAWA, Masaya & B-2 \\
\hline SEINO, Yoshiki & $\begin{array}{l}C-9, C-17, C-31 \\
C-43\end{array}$ \\
\hline SEKI, Naohiro & B-18 \\
\hline
\end{tabular}

\begin{tabular}{|c|c|}
\hline $\begin{array}{l}\text { SEKIGUCHI, } \\
\text { Mutsuo }\end{array}$ & PL -2 \\
\hline SEMURA, Rie & $A-23$ \\
\hline SENGOKU, Kazuo & B-71 \\
\hline $\begin{array}{l}\text { SENJU, Midori } \\
\text { Asada }\end{array}$ & $A-21$ \\
\hline $\begin{array}{l}\text { SERMSUVITAYA- } \\
\text { WONG, Kannika }\end{array}$ & B-48 \\
\hline SETO, Masao & $A-49, A-59$ \\
\hline SHIDO, Koichi & $A-43, C-61$ \\
\hline $\begin{array}{l}\text { SHIGEMOTO, } \\
\text { Kazuhiro }\end{array}$ & $A-35, C-47$ \\
\hline SHIMADA, Takashi & B-60 \\
\hline SHIMADA, Tsutomu & A -25 \\
\hline SHIMAKURA, Yae & $\mathrm{C}-75$ \\
\hline SHIMIZU, Kiichi & $C-19$ \\
\hline $\begin{array}{l}\text { SHIMIZU, } \\
\text { Nobuyoshi }\end{array}$ & $\begin{array}{l}\text { B-22, B-23, B-24, } \\
\text { B- } 76, \text { C- } 23\end{array}$ \\
\hline SHIMIZU, Yoshiko & B -23 \\
\hline $\begin{array}{l}\text { SHIMOZAWA, } \\
\text { Nobuyuki }\end{array}$ & B-62 \\
\hline SHINDOH, Nobuaki & B-23 \\
\hline SHINKA, Toshikatsu & B-31 \\
\hline $\begin{array}{l}\text { SHINOHARA, } \\
\text { Nozomi }\end{array}$ & B-58 \\
\hline $\begin{array}{l}\text { SHINOHARA, } \\
\text { Yukito }\end{array}$ & $B-40$ \\
\hline $\begin{array}{l}\text { SHINOMIYA, } \\
\text { Hiroichi }\end{array}$ & B-13 \\
\hline $\begin{array}{l}\text { SHINOMIYA, } \\
\text { Takashi }\end{array}$ & $A-50, A-51, A-52$ \\
\hline SHINTAKU, Yuko & $C-16$ \\
\hline SHIODA, Kyoko & $C-28, C-30$ \\
\hline $\begin{array}{l}\text { SHIRAHAMA, } \\
\text { Shuya }\end{array}$ & $A-63, A-67$ \\
\hline SHIRAIWA, Yumi & $B-42, B-45$ \\
\hline $\begin{array}{l}\text { SHIRASAWA, } \\
\text { Takuji }\end{array}$ & $C-67$ \\
\hline $\begin{array}{l}\text { SHIROSHITA, } \\
\text { Yoshiko }\end{array}$ & $\mathrm{C}-50$ \\
\hline $\begin{array}{l}\text { SHISHIKURA, } \\
\text { Akihiro }\end{array}$ & $A-1$ \\
\hline $\begin{array}{l}\text { SHISHIKURA, } \\
\text { Keiko }\end{array}$ & B-42 \\
\hline SOEDA, Eiichi & $\mathrm{B}-23$ \\
\hline SOEJIMA, Hidenobu & $C-58$ \\
\hline SOEJIMA, Mikiko & A-24 \\
\hline SOFUNI, Toshio & $\mathrm{C}-2$ \\
\hline SOHDA, Satoshi & $A-40, A-4 I$ \\
\hline SONG, Xiang-Qian & $B-17$ \\
\hline SONTA, Shin-ichi & $\mathrm{C}-4$ \\
\hline SOUDA, Masakazu & $C-32$ \\
\hline SUEOKA, KOU & $C-26$ \\
\hline SUGAHARA. Yoko & $C-45$ \\
\hline
\end{tabular}




\begin{tabular}{|c|c|}
\hline SUGIMOTO, Jun & $B-16$ \\
\hline SUGITA, Minoru & $A-47, C-66, C-73$ \\
\hline SUGIURA, Isao & $\mathrm{C}-38$ \\
\hline SUGIURA, Yasuo & $C-34, C-38$ \\
\hline $\begin{array}{l}\text { SUKEGAWA } \\
\text { Kazuko }\end{array}$ & A -33 \\
\hline SUMIMOTO, Hideki & $A-22$ \\
\hline $\begin{array}{l}\text { SUTHERLAND, } \\
\text { G.R. }\end{array}$ & $C-56$ \\
\hline SUTO, Yumiko & B-9, B-19 \\
\hline SUWA, Kiyotaka & $A-55$ \\
\hline SUYAMA, Itsujin & B-51 \\
\hline SUZUKI, Haruko & B-42 \\
\hline SUZUKI, Koichi & A- 17 \\
\hline SUZUKI, Mikiko & B-13 \\
\hline SUZUKI, Takashi & B- 36 \\
\hline SUZUKI, Tomokazu & $A-21, A-37$ \\
\hline SUZUKI, Yasuyuki & B-62 \\
\hline SUZUMORI, Kaoru & $C-27$ \\
\hline $\begin{array}{l}\text { SUZUMORI, } \\
\text { Nobuhiro }\end{array}$ & $C-27$ \\
\hline SZUZKI, Kumiko & $A-44$ \\
\hline \multicolumn{2}{|l|}{$\mathbf{T}$} \\
\hline TACHI, Nobutada & B-38 \\
\hline TACHIBANA, Hisao & A -57 \\
\hline TADA, Katsuhiko & $C-31$ \\
\hline TADA, Mitsuhiro & $A-7$ \\
\hline TADOKORO, Kenji & B- 8, B-9 \\
\hline TAJIMA, Toshihiro & B- 58 \\
\hline TAJIRI, Munemasa & $A-43$ \\
\hline $\begin{array}{l}\text { TAKABAYASHI, } \\
\text { Toshifumi }\end{array}$ & $C-6, C-16$ \\
\hline TAKADA, Goro & B-53 \\
\hline TAKADA, Kensuke & $A-43$ \\
\hline TAKAGI, Nobuo & $\mathrm{S}-\mathrm{I}-3$ \\
\hline TAKAGI, Yuzo & B- 60 \\
\hline $\begin{array}{l}\text { TAKAHASHI, } \\
\text { Ei-ichi }\end{array}$ & B- $13, \mathrm{~B}-19$ \\
\hline $\begin{array}{l}\text { TAKAHASHI, } \\
\text { Eihiko }\end{array}$ & $\mathrm{C}-55$ \\
\hline $\begin{array}{l}\text { TAKAHASHI, } \\
\text { Hiroaki }\end{array}$ & $\mathrm{C}-29$ \\
\hline $\begin{array}{l}\text { TAKAHASHI, } \\
\text { Megumi }\end{array}$ & B- 49 \\
\hline $\begin{array}{l}\text { TAKAHASHI, } \\
\text { Toshio }\end{array}$ & A -53 \\
\hline $\begin{array}{l}\text { TAKAHASHI, } \\
\text { Yoshiatsu }\end{array}$ & $A-34$ \\
\hline TAKAHASHI, Yuji & $A-16$ \\
\hline TAKAICHI, Ako & $B-13$ \\
\hline TAKAKUBO, Fumie & $A-35, C-46, C-47$ \\
\hline TAKAMI, Hideki & $B-10$ \\
\hline TAKAMI, Hiroshi & $A-67$ \\
\hline
\end{tabular}

\begin{tabular}{|c|c|}
\hline TAKAMI, Satoshi & $A-50$ \\
\hline TAKANO, Hideaki & A-73 \\
\hline TAKANO, J. Kaoru & $\mathrm{C}-1$ \\
\hline TAKANO, Takako & $C-1, C-67$ \\
\hline TAKAO, Atsuyoshi & $C-21, C-23$ \\
\hline $\begin{array}{l}\text { TAKASHIMA, } \\
\text { Hiroshi }\end{array}$ & $C-68$ \\
\hline $\begin{array}{l}\text { TAKASHIMA, } \\
\text { Teruyuki }\end{array}$ & A -49 \\
\hline $\begin{array}{l}\text { TAKAYANAGI, } \\
\text { Toshimitsu }\end{array}$ & $B-12$ \\
\hline TAKE, Hiroshi & $C-40$ \\
\hline TAKEBE, Hiraku & LS-3, B-6I \\
\hline TAKEDA, Misako & $A-13, A-14$ \\
\hline $\begin{array}{l}\text { TAKENAKA, } \\
\text { Michiko }\end{array}$ & $A-16$ \\
\hline $\begin{array}{l}\text { TAKENAKA, } \\
\text { Tsunehisa }\end{array}$ & $C-35$ \\
\hline TAKETA, Kazuhisa & $B-60$ \\
\hline TAMURA, Akiyoshi & $A-17$ \\
\hline TAMURA, Shu & $A-57$ \\
\hline TANABE, Hideyuki & $C-2$ \\
\hline TANAKA, Hajime & B-36, B-44, C-54 \\
\hline TANAKA, Keiji & $A-6$ \\
\hline TANAKA, Keiko & $C-54$ \\
\hline TANAKA, Kimio & $A-58, A-59$ \\
\hline TANAKA, Kiyoji & $A-68$ \\
\hline TANAKA, Mari & $A-45, C-74$ \\
\hline TANAKA, Yosuke & B-3 \\
\hline $\begin{array}{l}\text { TANEMURA, } \\
\text { Mitsuyo }\end{array}$ & $\mathrm{C}-27$ \\
\hline $\begin{array}{l}\text { TANIGUCHI, } \\
\text { Miyako }\end{array}$ & $B-53$ \\
\hline $\begin{array}{l}\text { TANIMURA, } \\
\text { Masako }\end{array}$ & $A-2, A-3$ \\
\hline $\begin{array}{l}\text { TANIMURA, } \\
\text { Tsuyoshi }\end{array}$ & B-61 \\
\hline $\begin{array}{l}\text { TANIWAKI, } \\
\text { Masafumi }\end{array}$ & $A-49, A-60$ \\
\hline TARONI, Franco & $B-56$ \\
\hline TATEISHI, Kyoko & $A-30$ \\
\hline TAUCHI, Hiroshi & $B-10$ \\
\hline TERADA, Masaaki & A-56 \\
\hline TERAOKA, Michio & $C-9, C-31$ \\
\hline $\begin{array}{l}\text { THANGAVEL, } \\
\text { Ramasamy }\end{array}$ & $A-74$ \\
\hline TODA, Tatsushi & $\begin{array}{l}\text { B-29, B-30, B-31, } \\
\text { B-32, B-33, B-44, } \\
\text { B- } 45, \text { B- } 46\end{array}$ \\
\hline TOHMA, Takaya & $\mathrm{C}-8$ \\
\hline TOHSEN, Tohichi & $A-67$ \\
\hline $\begin{array}{l}\text { TOKUNAGA } \\
\text { Katsushi }\end{array}$ & $\begin{array}{l}\text { A-16, B-5, B-8, B-9, } \\
\text { B-29, B-30, B-31, } \\
\text { B-32, B-33, B-46 }\end{array}$ \\
\hline
\end{tabular}




\begin{tabular}{|c|c|}
\hline $\begin{array}{l}\text { TOKUNAGA, } \\
\text { Katsusi }\end{array}$ & B- 6 \\
\hline TOMATSU, Shunji & $A-33$ \\
\hline TOMITA, Keiko & $B-31, C-10$ \\
\hline TOMITA, Masafumi & A -20 \\
\hline TOMURA, Shigeo & $A-45, C-74$ \\
\hline TONOKI, Hidefumi & $A-7, B-37, C-58$ \\
\hline TORU, Michio & $C-71$ \\
\hline TOYAMA, Keiko & B -48 \\
\hline TSUBOI, Ayuchi & $B-30$ \\
\hline TSUCHIYA, Shigeru & $A-45, C-74, C-76$ \\
\hline $\begin{array}{l}\text { TSUCHIYA, } \\
\text { Terumasa }\end{array}$ & $B-7, C-62$ \\
\hline TSUDA, Hitoshi & A- -51 \\
\hline $\begin{array}{l}\text { TSUGANE, } \\
\text { Mizuyo H. }\end{array}$ & $C-12, C-13$ \\
\hline TSUJI, Hiroko & $A-17$ \\
\hline TSUJI, Kazushiro & $C-43$ \\
\hline TSUJI, Masahiro & $A-27, A-28$ \\
\hline TSUJI, Shoji & B-36, B-44, C-54 \\
\hline TSUJI, Takahiro & A-62, B-28 \\
\hline TSUJI, Yoshiro & B $-11, B-12, B-65$ \\
\hline TSUJITA, Takahiro & $C-72$ \\
\hline $\begin{array}{l}\text { TSUKAHARA, } \\
\text { Masato }\end{array}$ & $C-25, C-44$ \\
\hline $\begin{array}{l}\text { TSUKAMOTO, } \\
\text { Kazuhiro }\end{array}$ & A -48 \\
\hline $\begin{array}{l}\text { TSUKIKAWA, } \\
\text { Susumu }\end{array}$ & A-44 \\
\hline TSUKINO, Ryuichi & $C-15, C-19$ \\
\hline $\begin{array}{l}\text { TSUNEKAWA, } \\
\text { Bunkichi }\end{array}$ & B-30 \\
\hline TSUNODA, Shoko & $C-25$ \\
\hline TSURUTA, Motoko & B - 37 \\
\hline \multicolumn{2}{|l|}{$\mathbf{U}$} \\
\hline $\begin{array}{l}\text { UCHIKAWA, } \\
\text { Makoto }\end{array}$ & A-16 \\
\hline UEDA, Satoshi & A-52 \\
\hline UEDA, Shintaroh & $C-2$ \\
\hline UEDA, Yutaka & A-49 \\
\hline UEHARA, Shigeki & $C-6, C-16$ \\
\hline UEKE, Tsuyoshi & $C-34$ \\
\hline URABE, Takeshi & $C-33$ \\
\hline USHIKU, Hideo & $C-10$ \\
\hline USHIZIMA, Hiroshi & $\mathrm{C}-14$ \\
\hline UTATSU, Yasuhiko & $C-68$ \\
\hline UYAMA, Eiichiro & $C-54$ \\
\hline UZAWA, Narikazu & $A-71$ \\
\hline $\mathbf{V}$ & \\
\hline VANIER, Marie T. & $B-53$ \\
\hline VERMA, I.C. & B-73 \\
\hline
\end{tabular}

\section{W}

\begin{tabular}{|c|c|}
\hline WADA, Takahito & B-66 \\
\hline WADA, Yoshinao & $A-21$ \\
\hline $\begin{array}{l}\text { WAKAMATSU, } \\
\text { Nobuaki }\end{array}$ & B-63, B-64 \\
\hline WAKUI, Keiko & $\begin{array}{l}C-10, C-20, C-24, \\
C-25, C-27\end{array}$ \\
\hline WANG, Huiru & B-8 \\
\hline WANG, Xudong & B-48 \\
\hline WANG, Yimin & B-22, B-24 \\
\hline $\begin{array}{l}\text { WATANABE, } \\
\text { Hisashi }\end{array}$ & B -60 \\
\hline $\begin{array}{l}\text { WATANABE, } \\
\text { Takeshi }\end{array}$ & B-13 \\
\hline $\begin{array}{l}\text { WATANABE, } \\
\text { Yoriko }\end{array}$ & $C-45$ \\
\hline $\begin{array}{l}\text { WATANABE, } \\
\text { Yoshihisa }\end{array}$ & B-6 \\
\hline WATAYA, Kaoru & $B-56$ \\
\hline WEEMAES, C. & B- 10 \\
\hline
\end{tabular}

YABE, Ryuichi $\quad$ A-I

YABE, Toshio B-9

YAGINUMA, Asagi C-14

YAHASHI, A-36

Yoshitsugu

YAJIMA, Akira $\quad$ C-6, C-16

YAJIMA, Toshihiro A-12

YAKUSHIJI, B-54

Michiaki

YAMADA, A-44

Hidekazu

YAMADA, Hideto C-59

YAMADA, Kiyomi A-54

YAMADA, Masao A-15, A-75, B-41

YAMADA, Naoki A-40, A-41, A-42

YAMADA, Naoto A-33

YAMADA, B-57

Yasukazu

YAMAGATA, A-39, A-46, A-47

Zentaro

YAMAGISHI, A-33

Atsushi

YAMAGISHI, $\quad$ C-21, C-22

Hiroyuki

YAMAGISHI, B-61

Nobuyuki

YAMAGUCHI, Seiji B-17, C-11

YAMAGUCHI, A-53

Toshiharu

YAMAKAWA-K., A-41 


\begin{tabular}{|c|c|}
\hline YAMAKI, Akiko & B-23 \\
\hline YAMAKI, Emi & $\mathrm{A}-27, \mathrm{~A}-28$ \\
\hline $\begin{array}{l}\text { YAMAKIDO, } \\
\text { Michio }\end{array}$ & A -62 \\
\hline $\begin{array}{l}\text { YAMAMOTO, } \\
\text { Hideki }\end{array}$ & $A-30, C-65$ \\
\hline $\begin{array}{l}\text { YAMAMOTO, } \\
\text { Hidenao }\end{array}$ & $A-57$ \\
\hline $\begin{array}{l}\text { YAMAMOTO, } \\
\text { Kiyomi }\end{array}$ & $C-44$ \\
\hline $\begin{array}{l}\text { YAMAMOTO, } \\
\text { Mitsutoshi }\end{array}$ & A-35 \\
\hline YAMAMOTO, Nao & $C-76$ \\
\hline YAMAMOTO, Ritu & $C-60$ \\
\hline $\begin{array}{l}\text { YAMAMOTO, } \\
\text { Tomoko }\end{array}$ & $B-45$ \\
\hline $\begin{array}{l}\text { YAMAMURA, } \\
\text { Ken-ichi }\end{array}$ & B-34, B-35 \\
\hline YAMANA, Kei & $C-74$ \\
\hline $\begin{array}{l}\text { YAMANAKA, } \\
\text { Hidetoshi }\end{array}$ & $C-35$ \\
\hline $\begin{array}{l}\text { YAMANOUCHI, } \\
\text { Yasuko }\end{array}$ & $C-1, C-67$ \\
\hline $\begin{array}{l}\text { YAMAOKA, } \\
\text { Kunihiro }\end{array}$ & $B-3$ \\
\hline $\begin{array}{l}\text { YAMASAKI, } \\
\text { Toshiko }\end{array}$ & $A-20$ \\
\hline $\begin{array}{l}\text { YAMASHITA, } \\
\text { Haruo }\end{array}$ & $A-43$ \\
\hline $\begin{array}{l}\text { YAMASHITA, } \\
\text { Sumimasa }\end{array}$ & B-38 \\
\hline $\begin{array}{l}\text { YAMAZAKI, } \\
\text { Hiroshi }\end{array}$ & $A-25, A-54$ \\
\hline YANAGI, Hisako & $\begin{array}{l}A-45, C-74, C-75, \\
C-76\end{array}$ \\
\hline $\begin{array}{l}\text { YANAGISAWA, } \\
\text { Hiroko }\end{array}$ & $A-15, B-41$ \\
\hline YANASE, Toshihiko & $B-59$ \\
\hline YANASE, Toshiyuki & PL-3 \\
\hline YANO, Koichi & $C-36$ \\
\hline YANO, Shoji & $C-45$ \\
\hline YANO, Tamami & $B-53$ \\
\hline YASUDA, Mineo & $C-12, C-13$ \\
\hline
\end{tabular}

\begin{tabular}{|c|c|}
\hline YASUDA, Norio & $A-50$ \\
\hline $\begin{array}{l}\text { YASUKOCHI, } \\
\text { Yukio }\end{array}$ & $B-7, C-62$ \\
\hline YASUNAGA, Seigo & B-59 \\
\hline$Y E, \operatorname{Lin}$ & $A-65, A-66, C-69$ \\
\hline YOKOTA, Shouhei & $A-60$ \\
\hline $\begin{array}{l}\text { YOKOYAMA } \\
\text { Yasunobu }\end{array}$ & $A-9, A-10$ \\
\hline YOKOYAMA, Yuji & $\begin{array}{l}C-9, C-17, C-31, \\
C-43, C-56\end{array}$ \\
\hline YONEDA, Hiroshi & $C-70$ \\
\hline YONEDA, Yoshihiro & $C-51$ \\
\hline YORIFUJI, Tohru & $\mathrm{C}-7$ \\
\hline YOSHIDA, Ichiro & B-56 \\
\hline YOSHIDA, Ikuya & $S-I-3$ \\
\hline YOSHIDA, Kibo & $C-46$ \\
\hline YOSHIDA, Mikiharu & $B-43$ \\
\hline $\begin{array}{l}\text { YOSHIDA, } \\
\text { Mitsuaki A. }\end{array}$ & $\mathrm{A}-1, \mathrm{~A}-71$ \\
\hline YOSHIIWA, Aoi & $A-30, C-65$ \\
\hline $\begin{array}{l}\text { YOSHIKAWA, } \\
\text { Yasuhiro }\end{array}$ & $A-74$ \\
\hline $\begin{array}{l}\text { YOSHIMOTO, } \\
\text { Masataka }\end{array}$ & $A-4$ \\
\hline $\begin{array}{l}\text { YOSHIMURA, } \\
\text { Yasuhide }\end{array}$ & $C-63$ \\
\hline $\begin{array}{l}\text { YOSHIMURA, } \\
\text { Yasunori }\end{array}$ & $C-26$ \\
\hline YOSHINO, Makoto & B- $54, \mathrm{~B}-56, \mathrm{C}-45$ \\
\hline $\begin{array}{l}\text { YOSHIZAWA, } \\
\text { Toshihiro }\end{array}$ & A-37 \\
\hline YU, Chang-En & $A-65$ \\
\hline $\begin{array}{l}\text { YUBISUI, } \\
\text { Toshitsugu }\end{array}$ & $A-22$ \\
\hline $\mathbf{Z}$ & \\
\hline ZAMA, Kiyoshi & $\mathrm{B}-5$ \\
\hline ZHANG, Jing & B-32 \\
\hline ZHANG, Wei & $C-62$ \\
\hline ZHANG, Yingning & $A-39, A-46, A-47$ \\
\hline ZHANG, Zhongyi & $\mathrm{B}-62$ \\
\hline ZHAO, Jia & $C-3$ \\
\hline ZUBAIR, Mohamad & B-69 \\
\hline
\end{tabular}




\section{SUBJECT INDEX}

\section{A}

\begin{tabular}{|c|c|}
\hline$\alpha$-D-mannosidase & B-63, B-64 \\
\hline$\alpha$-mannosidosis & B-64 \\
\hline$\alpha$-satellite & $A-9$ \\
\hline a lung tumor & $A-62$ \\
\hline $\mathrm{A}_{2}$ phenotype & $A-16$ \\
\hline $\mathrm{ABO}$ & $A-16, A-17$ \\
\hline ACAT2 & $B-17$ \\
\hline accumulation & B-53 \\
\hline $\mathrm{ACDK}$ & $A-1$ \\
\hline $\mathrm{ACE}$ & $A-39$ \\
\hline $\begin{array}{l}\text { adeno-associated } \\
\text { virus }\end{array}$ & $A-75$ \\
\hline adhalin gene & $C-51$ \\
\hline $\begin{array}{l}\text { adrenal hypoplasia } \\
\text { congenita }\end{array}$ & B-58 \\
\hline alcoholism & $S-1 I-3$ \\
\hline ALDH & S-II-3 \\
\hline Alport's syndrome & $C-11$ \\
\hline Alu element & $\mathrm{A}-70$ \\
\hline Alzheimer & $A-30, C-65$ \\
\hline Alzheimer disease & A -37 \\
\hline Alzheimer's disease & $C-66$ \\
\hline ambulant & B-44 \\
\hline amelogenin & B-30 \\
\hline amenorrhea & $C-16$ \\
\hline amniocentesis & $C-30$ \\
\hline amniotic cells & $A-74$ \\
\hline Angelman syndrome & B- 66, B -67 \\
\hline $\begin{array}{l}\text { angiotensin type I } \\
\text { receptor }\end{array}$ & $C-61$ \\
\hline angiotensinogen & LS- $2, A-40, C-61$ \\
\hline anhaptoglobinemia & $\mathrm{A}-24$ \\
\hline anomaly & $C-41$ \\
\hline anticipation & $C-70$ \\
\hline aortic root dilatation & $C-45$ \\
\hline APC & $A-64$ \\
\hline Apolipoprotein $\mathrm{E}$ & $C-73$ \\
\hline $\begin{array}{l}\text { Apolipoprotein E } \\
\text { allele }\end{array}$ & $C-66$ \\
\hline apolipoprotein A-I & $C-76$ \\
\hline apoptosis & LS-1, C-1 \\
\hline Arrestin (S-Ag) & $A-12$ \\
\hline $\begin{array}{l}\text { arylamine } \\
\text { N-acetyltransferase } \\
\text { (NAT2) }\end{array}$ & A-37 \\
\hline$A S C L 2$ & B-70 \\
\hline association & $A-47$ \\
\hline association study & $A-35, A-48$ \\
\hline ATR-X & $C-42$ \\
\hline
\end{tabular}

azoospermia

B-32

B

$\beta$-globin gene

A-23

$\beta$-ketothiolase deficiency

BAC

PL -5

BAC/cosmid contig B-22

BChEA199V A-20

BChEY 128C A-20

blastomere C-26

bone dysplasias $\quad \mathrm{C}-34$

bone marrow B-12

plantation

BPES C-48

BRCA1 S-II-1

BRCA2 S-II-1

breakpoint DNA C-57

breast cancer S-II-1, A-4, A-47,

A -51

buccal smear B-62

Buerger's disease $\quad$ B-7

BWS S-I-2

\section{C}

\begin{tabular}{|c|c|}
\hline ance & A-5 \\
\hline cancer cells & A -5 \\
\hline $\begin{array}{l}\text { candidate gene } \\
\text { analysis }\end{array}$ & \\
\hline $\begin{array}{l}\text { carbamylphosphate } \\
\text { synthetase-I }\end{array}$ & \\
\hline rcinogenesis & \\
\hline yopathy & \\
\hline rnitin & \\
\hline
\end{tabular}

palmitoyltransferase II

cat eye syndrome $\quad$ B-22

cataract $\quad$ B-52

CATCH22 B-21, C-21, C-22

(CCG)n repeat $\quad \mathrm{C}-43$

cDNA B-18

cDNA selection A-10

CE-D-CE gene A-18

cell death $\mathrm{C}-1$

cell differentiation $\quad$ A-57

centromere dot C-3

cerebral dominance $\quad \mathrm{C}-14$

$\mathrm{CGH}$ A $-52, \mathrm{~A}-53$

CGH method A-54

childhood A-2

CHM gene A-13 


choroideremia
chromosomal
aberration
chromosomal
aberrations
chromosomal
heteromorphisms
chromosome

chromosome 2
chromosome $6 \mathrm{p}$
chromosome $6 \mathrm{q} 27$
chromosome 9
chromosome 14
chromosome
aberration
chromosome change
chromosome $\mathrm{Y}$
clinical genetics
clinical heterogeneity
clinical spectrum
clinical subtypes
clinicopathological
parameter

A-13

C-8

A-50, A-52

C-32

S-I-3, B-18, B-69,

$\mathrm{C}-11, \mathrm{C}-17, \mathrm{C}-22$,

C $-25, \mathrm{C}-27, \mathrm{C}-28$,

C-30

B-19

B-39

A -63

C-2, C-54

B- $16, C-65$

A-61

A- 1

C -10

B-74

B- 44, C -51

$\mathrm{C}-22$

B-1

A-4

A- $62, \mathrm{~B}-48$

B-36

C -46

C -47

B-16

A-33

B-10

C -19

B-38

complex translocation

congenital

hypomyelination

neuropathy

congenital

insensitivity to pain

connexin43

consensus survey

contiguous gene

syndrome

contractile element

coronary heart

disease

cosmid contig

$\mathrm{CpG}$ island

crossing-over

cryptic deletion

cryptic translocation

CYP2C19

CYP2C9

cytochrome P450IA 1
B-37

B-15

B-73

C -36

B-49

S-II-2, A-42

B-32

B-30

C -4

C-58

C -25

A -25

A -25

A-35

$\begin{array}{ll}\text { D-phenotype } & \text { A-18 } \\ \text { database } & \text { B-76 } \\ \text { DAX-1 } & \text { B-58 } \\ \text { deficiency } & \text { B-54 } \\ \text { del22ql1.2 syndrome } & \text { C-23 } \\ \text { deletion } & \text { B-21, C-20 } \\ \text { dementia } & \text { C-38, C-68 } \\ \text { dermatoglyphics } & \text { C-13 } \\ \text { Di George syndrome } & \text { B-12 } \\ \text { dic(Yq) } & \text { C-9 } \\ \text { dicentric chromosome } & \text { C-3 } \\ \text { differential display } & \text { B-33 } \\ \text { differentiation } & \text { A-74 } \\ \text { DMD } & \text { C-50 } \\ \text { DMD/BMD } & \text { C-53 } \\ \text { DNA polymorphism } & \text { A-28, C-47 } \\ \text { DNA repair } & \text { A-68 } \\ \text { DNA-PK cs } & \text { B-20 } \\ \text { DNA marker } & \text { A-8 } \\ \text { dopamine } & \text { S-1I-3 } \\ \text { Down syndrome } & \text { B-23, B-75, C-14, } \\ & \text { C-15 } \\ \text { Down's syndrome } & \text { C-13 } \\ \text { DRD2 } & \text { C-71 } \\ \text { DRPLA } & \text { B-41 } \\ \text { DXYS241 } & \text { B-29 } \\ \text { dysmyelination } & \text { B-35 } \\ \text { dystrophin } & \text { B-43 } \\ \text { dystrophin mRNA } & \text { C-53 } \\ & \end{array}$

E

$\begin{array}{ll}\text { E6AP } & \text { A-6 } \\ \text { ecNOS gene } & \text { A-36 } \\ \text { ecogenetics } & \text { PL-3 } \\ \text { ectopia lentis } & \text { C-45 } \\ \text { education } & \text { B-73 } \\ \text { embryogenesis } & \text { B-34 } \\ \text { endocrinology } & \text { B-59 } \\ \text { enhancer } & \text { B-69 } \\ \text { erythropoietin } & \text { C-62 } \\ \text { essential hypertension } & \text { LS-2 } \\ \text { estrogen receptor } & \text { A-46 } \\ \text { estrogen receptor gene } & \text { A-47 } \\ \text { ethics } & \text { LS-3 } \\ \text { eugenics } & \text { B-72 } \\ \text { evaluation } & \text { A-54 } \\ \text { evolution } & \text { LS-4, B-19 } \\ \text { exon skipping } & \text { A-19 } \\ \text { exon trapping } & \text { A-63 } \\ \text { eye } & \text { C-55 }\end{array}$

Jpn J Human Genet 


\begin{tabular}{|c|c|}
\hline \multicolumn{2}{|l|}{$\mathbf{F}$} \\
\hline $\begin{array}{l}\text { familial } 15 p \\
\text { tetrasomy }\end{array}$ & C-59 \\
\hline familial case & $C-40$ \\
\hline $\begin{array}{l}\text { familial hypercho- } \\
\text { lesterolemia }\end{array}$ & $\mathrm{A}-27, \mathrm{~A}-28$ \\
\hline family history & $A-3$ \\
\hline FAP & A- 64 \\
\hline FBN 1 & $\mathrm{C}-17$ \\
\hline FCGRT & $B-4$ \\
\hline fetal akinesia & $C-39$ \\
\hline fiber-FISH & $A-56$ \\
\hline Finland & $\mathrm{PL}-4$ \\
\hline FISH & $\begin{array}{l}\text { S-I-1, A-9, A-26, } \\
\text { A-49, A-50, A-58, } \\
\text { A-59, B-4, B-9, B-14, } \\
\text { B-15, B-19, C-2, C-5, } \\
\text { C-23, C-24, C-25, } \\
\text { C-27, C-29, C-33, } \\
\text { C-59, C-67 }\end{array}$ \\
\hline FK 506 & $A-73$ \\
\hline fluorescence & $C-50$ \\
\hline FMTC & $A-67$ \\
\hline foveal hypoplasia & $A-15$ \\
\hline FRAXE & $C-43$ \\
\hline frequency & $C-18$ \\
\hline Fukuyama type CMD & B- $44, B-45$ \\
\hline $\begin{array}{l}\text { Fukuyama-type } \\
\text { congenital } \\
\text { muscular dystrophy } \\
\text { (FCMD) }\end{array}$ & B -46 \\
\hline \multicolumn{2}{|l|}{$\mathbf{G}$} \\
\hline galactokinase & B-52 \\
\hline $\begin{array}{l}\text { galactose-1-phosphate } \\
\text { uridyltransferase }\end{array}$ & $\mathrm{B}-51$ \\
\hline galactosemia & $B-5 I$ \\
\hline gametogenesis & $A-18$ \\
\hline gastric cancer & $A-53$ \\
\hline GATA-TF & $C-62$ \\
\hline gene amplification & $A-56, A-58$ \\
\hline gene analysis & $A-21, B-48, B-60$ \\
\hline gene deletion & $A-24$ \\
\hline gene expression & $\mathrm{B}-28$ \\
\hline gene family & $A-5$ \\
\hline gene mapping & B-13 \\
\hline gene polymorphism & A -39 \\
\hline gene regulation & $C-62, C-63$ \\
\hline gene structure & B- 63 \\
\hline gene targeting & B- 35 \\
\hline gene therapy & $A-73, A-74$ \\
\hline $\begin{array}{l}\text { genetic disease } \\
\text { discrimination }\end{array}$ & B- 72 \\
\hline
\end{tabular}

\begin{tabular}{|c|c|}
\hline genetic etiology & \\
\hline $\begin{array}{l}\text { genetic etiology } \\
\text { genetic heterogeneity }\end{array}$ & $\mathrm{S}-\mathrm{II}-2$ \\
\hline $\begin{array}{l}\text { genetic heterogeneity } \\
\text { genetic mutation }\end{array}$ & $\begin{array}{l}B-49 \\
B-55\end{array}$ \\
\hline $\begin{array}{l}\text { genetic physical EST } \\
\text { map }\end{array}$ & A-66 \\
\hline genetic service & $B-74$ \\
\hline genetics & B- 5, B -47 \\
\hline genome & $P L-3$ \\
\hline genome mapping & S-I-1 \\
\hline genomic imprinting & $S-I-2, B-66, B-67$ \\
\hline genomic sequencing & B-22 \\
\hline $\begin{array}{l}\text { geographical } \\
\text { variation }\end{array}$ & B- -50 \\
\hline$G J A l$ & B-15 \\
\hline GL12 & B-14 \\
\hline GM2 ganglioside & $B-53$ \\
\hline growth gene $(s)$ & B-25 \\
\hline \multicolumn{2}{|l|}{$\mathbf{H}$} \\
\hline H19 gene & B-71 \\
\hline habitual abortion & $C-16$ \\
\hline haplotype mapping & B-46 \\
\hline haptoglobin & $A-24$ \\
\hline $\mathrm{HbH}$ inclusions & $C-42$ \\
\hline HDL-cholesterol & $C-76$ \\
\hline helicase & A- 65 \\
\hline hepatic gene therapy & A-75 \\
\hline hepatoma & $A-57$ \\
\hline hereditary disorder & $\mathrm{C}-38$ \\
\hline $\begin{array}{l}\text { hereditary methemoglo- } \\
\text { binemia }\end{array}$ & A -22 \\
\hline heredity & B-73 \\
\hline $\begin{array}{l}\text { high density } \\
\text { lipoprotein }\end{array}$ & $C-74$ \\
\hline history & PL-3 \\
\hline HLA & B-5, B-6, C-69 \\
\hline HLA class I alleles & B-8 \\
\hline HLA haplotypes & B-8 \\
\hline HLA-DNA typing & B-7 \\
\hline HLA-DQ & B-2 \\
\hline HLA-DR & $\mathrm{B}-1$ \\
\hline Holt-Oram syndrome & $C-40$ \\
\hline homeobox gene & $\mathrm{LS}-5$ \\
\hline Homodysteine & $A-41, A-42$ \\
\hline homology & $A-26$ \\
\hline HPRT & B-57 \\
\hline HUGO & LS-3 \\
\hline human & $B-71$ \\
\hline human genome & LS-3 \\
\hline $\begin{array}{l}\text { human genomic } \\
\text { library }\end{array}$ & B-24 \\
\hline hybrid cell & $S-I-3$ \\
\hline hydronephrosis & $C-35$ \\
\hline hypercholesterolemia & S-II-2, C-75 \\
\hline
\end{tabular}




\begin{tabular}{|c|c|c|c|}
\hline hypermethioninemia & $B-55$ & LIPA gene & $B-65$ \\
\hline hypertension & $A-39$ & lipoprotein lipase & $C-74$ \\
\hline hypertrophic & B-49 & gene & \\
\hline cardiomyopathy & & lipoprotein (a) & $C-73$ \\
\hline hypoalphalipopro- & $\mathrm{C}-76$ & liver & LS-1 \\
\hline teinemia & & liver tumor & $A-55$ \\
\hline hypophosphatasia & $B-60, B-6 I$ & localization & B-25, B-26, B-27 \\
\hline hypoplastic thumb & $C-41$ & $\mathrm{LOH}$ & $A-4$ \\
\hline hypothyroidism & $C-15$ & low-grade & $A-51$ \\
\hline hypotransferrinemia & $A-21$ & lymphogenic gene (s) & B-27 \\
\hline I & \multicolumn{3}{|c|}{$\mathbf{M}$} \\
\hline identical twins & $\mathrm{C}-24$ & macular degeneration & $A-14$ \\
\hline $\operatorname{idic}(Y p)$ & $C-10$ & malformation & $A-2, C-34$ \\
\hline IGCR & $\mathrm{C}-72$ & mantle cell & $A-49$ \\
\hline IL-2 receptor $\gamma$ chain & B-3 & lymphoma & \\
\hline immunogenetics & $B-11, B-12$ & mapping & $\mathrm{A}-11, \mathrm{~B}-4, \mathrm{~B}-10$ \\
\hline imprinting & B- 68, B- 69, B-70 & & B- $14, B-18$ \\
\hline in situ hybridization & $B-40, C-52$ & mass screening & $B-52$ \\
\hline inborn errors of & $B-60$ & maternal serum & $B-75$ \\
\hline metabolism & & $\mathrm{MCA} / \mathrm{MR}$ & $\mathrm{C}-42$ \\
\hline insertional mutation & B-38 & meiosis & $C-4$ \\
\hline Interleukin-4 & B-3 & membrane & $A-9$ \\
\hline internet & $B-76$ & MEN1 & $A-61$ \\
\hline interstitial deletion & $C-19$ & MEN2 & $A-67$ \\
\hline inv dup (15) & $C-31$ & mental retardation & $\mathrm{B}-26, \mathrm{C}-23, \mathrm{C}-58$ \\
\hline inversion & $A-72, C-4$ & meta-analysis & $C-66$ \\
\hline ischemic stroke & A-36 & methionine adenosyl- & $B-55$ \\
\hline isochromosome $18 \mathrm{q}$ & $C-33$ & transferase & \\
\hline & & methylation & B-68 \\
\hline J & & methylation imprint & B-71 \\
\hline Japanese & B-8 & microangiopathy & $A-34$ \\
\hline juvenile myoclonic & B-39 & microdissection & $A-10$ \\
\hline epilepsy & & micrognathia & $C-41$ \\
\hline 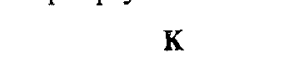 & & microsatellite & $\begin{array}{l}\text { A-34, B-29, C-50, } \\
\text { C- } 69\end{array}$ \\
\hline K562 & $A-10$ & microsatellite & $A-60$ \\
\hline Kabuki make-up & $C-36$ & instability & \\
\hline syndrome & & microsatellite markers & $A-48$ \\
\hline Kawasaki syndrome & B-6 & mineral bone density & $A-44$ \\
\hline kidney & $C-55$ & minibrain & $B-23$ \\
\hline knockout mouse & $A-68$ & mirror hands/feet & $C-57$ \\
\hline $\mathbf{T}$ & & missense mutation & A-70 \\
\hline L & & mitochondria & $A-29, A-30, A-31$ \\
\hline LDL receptor & $A-27$ & mitochondrial DNA & $A-32$ \\
\hline LDL receptor gene & A-28 & mixoploid & $C-32$ \\
\hline LEC rat & $A-7$ & MLL gene & A-59 \\
\hline Leigh's syndrome & A-29 & molecular & $S-1-1$ \\
\hline leukemia & B-16 & cytogenetics & \\
\hline leukemia/lymphoma & $A-58$ & monocyte & B-3 \\
\hline leukoencephalopathy & $C-68$ & monozygotic twins & $C-21, C-34$ \\
\hline linkage & $C-54, C-75$ & mortality & $\mathrm{B}-50$ \\
\hline linkage analysis & $B-36, B-39$ & mosaicism & $\mathrm{C}-7, \mathrm{C}-18, \mathrm{C}-24$, \\
\hline linkage study & LS $-2, C-68$ & & $C-31$ \\
\hline
\end{tabular}




\begin{tabular}{|c|c|c|c|}
\hline mtDNA & $A-33$ & ovarian cancer & A-63 \\
\hline MTHFR & $A-42$ & \multirow{2}{*}{\multicolumn{2}{|c|}{$\mathbf{P}$}} \\
\hline mucopolysacchari- & PL-5 & & \\
\hline doses & & pl5 & $A-71$ \\
\hline mucopolysacchari- & $A-33$ & pl6 & $A-71$ \\
\hline dosis & & $\mathrm{p} 21$ (Wafl/Cipl) & $A-57$ \\
\hline multiple sclerosis & B-1 & $\mathrm{p} 53$ & $A-6, A-7$ \\
\hline muscular dystrophy & B-43 & paired domain & $A-15$ \\
\hline mutagenesis & PL-2 & palatal rugae & $\mathrm{C}-12$ \\
\hline mutation & $A-22, A-27, A-69$, & Parkinson's disease & $A-35$ \\
\hline & B- $51, \mathrm{~B}-56, \mathrm{~B}-57$ & $\mathrm{PAX} 2$ & $C-55, C-56$ \\
\hline & B- 59, B- 64, B- 76 & PAX6 & A- 15 \\
\hline & $C-51$ & Pax-6 mutant & $\mathrm{C}-12$ \\
\hline mutations & PL-4, A-23 & PCR & $C-7, C-26, C-43$ \\
\hline myasthenia gravis & B-2 & PCR-PIRA & $A-20$ \\
\hline myelination & $B-34$ & PCR-RFLP & B-7 \\
\hline myelodysplastic & $A-60$ & PCR-SSCP & A -64 \\
\hline syndrome & & PCR/SSCP & $A-69$ \\
\hline myopathy & C-54 & peopling of Japan & $A-32$ \\
\hline myotonic dystrophy & $C-52$ & peripherin/RDS & $A-14$ \\
\hline $\mathbf{N}$ & & peroxisomes & B-62 \\
\hline $\mathbf{N}$ & & phenylketonuria & $A-73$ \\
\hline NADH-cytochrome & A -22 & phylogenetic analysis & $A-32$ \\
\hline b5 reductase & & physical map & $C-48$ \\
\hline NAIP & B-40 & physical mapping & $B-17$ \\
\hline NAIP gene & B-42 & PO gene & B-38 \\
\hline narcolepsy & $C-69$ & point mutation & $B-47$ \\
\hline nerve growth factor & B-37 & polymorphism & $\mathrm{A}-11, \mathrm{~A}-16, \mathrm{~A}-25$ \\
\hline neural crest & LS-5 & & A-36, A-40, A-41, \\
\hline neuroblastoma & $A-3$ & & A-43, A-44, A-45, \\
\hline $\begin{array}{l}\text { neurodegenerative } \\
\text { disorder }\end{array}$ & B-4l & & $\begin{array}{l}\text { A-46, B-31, B-56, } \\
\text { C-74 }\end{array}$ \\
\hline $\begin{array}{l}\text { neuroectodermal } \\
\text { tumor }\end{array}$ & $A-52$ & $\begin{array}{l}\text { polymorphism } \\
\text { analysis }\end{array}$ & $B-45$ \\
\hline neuropathogenesis & PL-4 & positional cloning & $A-72, C-57$ \\
\hline newborn infants & $C-35$ & PRADI & $A-49$ \\
\hline NF1 & $A-69$ & Prader-Willi & B-67 \\
\hline NIDDM & $A-34, A-38$ & syndrome & \\
\hline Niemann-Pick & $B-53$ & preeclampsia & $A-41$ \\
\hline Disease type $\mathrm{C}$ & & pregnancy induced & $A-40$ \\
\hline NK receptor & B-9 & hypertension & \\
\hline NOS II & $A-26$ & $\begin{array}{l}\text { pregnancy-induced } \\
\text { hypertention }\end{array}$ & $S-I I-4, C-6 I$ \\
\hline O & & prenatal diagnosis & B-45, B-54, B-61, \\
\hline $\begin{array}{l}\mathrm{O}^{6} \text {-methylguanine- } \\
\text { DNA }\end{array}$ & $A-37$ & & $\begin{array}{l}\mathrm{C}-27, \mathrm{C}-29, \mathrm{C}-31 \\
\mathrm{C}-33\end{array}$ \\
\hline methyltransferase & & prenatal screening & $\mathrm{B}-75$ \\
\hline (MGMT) & & presenilin 1 & $C-65, C-67$ \\
\hline optic nerve & $\mathrm{C}-56$ & presenilin 2 & $C-67$ \\
\hline coloboma-renal & & pressure & $C-1$ \\
\hline disease & & prevention & S-II-4 \\
\hline oral cancer & $A-71$ & primates & $\mathrm{C}-2$ \\
\hline Osteodysplasia & $\mathrm{C}-38$ & processing & $A-31$ \\
\hline osteoporosis & $A-45, A-46, A-48$ & promoter & B- $63, C-71$ \\
\hline
\end{tabular}




\begin{tabular}{|c|c|c|c|}
\hline $\begin{array}{l}\text { pseudoautosomal } \\
\text { region }\end{array}$ & $B-25$ & $\begin{array}{l}\text { Smith-Magenis } \\
\text { syndrome }\end{array}$ & $C-49$ \\
\hline purine metabolism & $B-48$ & SMN gene & $B-42$ \\
\hline PWS/AS & $S-1-2$ & somatic mutation & $A-70$ \\
\hline \multirow{2}{*}{\multicolumn{2}{|c|}{$\mathbf{Q}$}} & sperm & $C-5$ \\
\hline & & splicing & B-57 \\
\hline QTLmethod & $C-75$ & spontaneous abortion & $C-28$ \\
\hline quaking & B-34, B-35 & SRY & B- $31, \mathrm{~B}-33, \mathrm{C}-9, \mathrm{C}-60$ \\
\hline \multirow{2}{*}{\multicolumn{2}{|c|}{$\mathbf{R}$}} & SSCP & A -65 \\
\hline & & supernumerary & $C-59$ \\
\hline radiosensitivity & $B-10$ & marker 15 & \\
\hline reciprocal & $\mathrm{C}-5$ & susceptibility & $\mathrm{B}-6$ \\
\hline translocation & & susceptibility gene & A-38 \\
\hline recombination & $A-17$ & syndecan-2 & $C-47$ \\
\hline renal cell carcinoma & A-1 & \multirow{2}{*}{\multicolumn{2}{|c|}{$\mathbf{T}$}} \\
\hline renal failure & A-43 & & \\
\hline $\begin{array}{l}\text { renin angiotensin } \\
\text { system }\end{array}$ & $A-43$ & $\begin{array}{l}\text { T cell epitope } \\
\text { TAM }\end{array}$ & $\begin{array}{l}\text { B-2 } \\
\text { A-72 }\end{array}$ \\
\hline repetitive & B-21 & tandem repeat & $A-11$ \\
\hline replication & PL-2 & thalassemia & $A-23$ \\
\hline reproduction & $C-28$ & thyroid function & $C-15$ \\
\hline restrictive dermopathy & $C-39$ & thyroid tumors & $A-50$ \\
\hline RET oncogene & A- 67 & tissue specificity & A-75 \\
\hline retinitis pigmentosa & A- 14 & total cholesterol & $C-73$ \\
\hline RFLP & $B-61$ & transferrin & $A-21$ \\
\hline Rh50 glycoprotein & A- 19 & translocation & $C-11, C-48, C-56$ \\
\hline rheumatoid arthritis & $B-5$ & trinucleotide repeat & $\mathrm{C}-52, \mathrm{C}-70$ \\
\hline RH null phenotype & $A-19$ & triplet repeat & B-41 \\
\hline risk factor & S-II-4 & expansion & \\
\hline IRNA & $A-30$ & trisomy $11 \mathrm{p}$ & $C-30$ \\
\hline \multirow{2}{*}{\multicolumn{2}{|c|}{1 118 }} & trisomy 16 mice & $\mathrm{C}-13$ \\
\hline & & trisomy-20 & $C-18$ \\
\hline sarcoglycan & B-43 & trisomy mice & $C-12$ \\
\hline schizophrenia & $\mathrm{C}-70, \mathrm{C}-71, \mathrm{C}-72$ & TRKA & $\mathrm{B}-37$ \\
\hline scid & B-20 & $\operatorname{tRNA}{ }^{\text {Leu }(U U R)}$ & $A-31$ \\
\hline selection & LS-4 & TRPS type I & $C-58$ \\
\hline sequence & $A-8, C-53$ & tumor & $A-2$ \\
\hline \multirow{2}{*}{$\begin{array}{l}\text { Sertoli-Leydig cell } \\
\text { tumor }\end{array}$} & $C-60$ & tumor chromosomes & A -54 \\
\hline & & tumor suppressor & A-55 \\
\hline $\operatorname{sex}$ & $C-26$ & gene & \\
\hline sex determination & B-33 & Turner Stigmata & B-27 \\
\hline sex phenotype & $\mathrm{C}-9$ & Turner syndrome & $C-7$ \\
\hline short stature & $C-10, C-20$ & twin & $C-72$ \\
\hline \multirow{2}{*}{$\begin{array}{l}\text { Shprintzen-Goldberg } \\
\text { syndrome }\end{array}$} & $C-17, C-45$ & twins & $C-46$ \\
\hline & & tyrosinemia & LS-1 \\
\hline sialophorin & $B-11$ & \multirow{2}{*}{$\mathbf{U}$} & \\
\hline sib-pair analysis & $A-38$ & & \\
\hline silver staining & $C-3$ & ubiquitin & A-6 \\
\hline single-minded & $\mathrm{B}-23$ & ubiquitin ligase & $A-5$ \\
\hline skin cancer & $A-68$ & ultrasound screening & $C-35$ \\
\hline skull & LS-5 & Upper-Limb & $C-14$ \\
\hline SMA & $B-40, B-42$ & movement & \\
\hline Smith-Lemli-Opitz & $C-44$ & & \\
\hline
\end{tabular}




\section{V}

$\begin{array}{ll}\begin{array}{l}\text { VACTERL } \\ \text { association } \\ \text { van der Woude } \\ \text { syndrome }\end{array} & \mathrm{C}-40 \\ \text { virus } & \mathrm{C}-36 \\ \text { vitamin D receptor } & \mathrm{LS}-4 \\ \text { vitamin D receptor } & \mathrm{A}-44 \\ \text { gene } & \\ \text { VNTR } & \mathrm{A}-8 \\ \text { VNTRs } & \mathrm{C}-32\end{array}$

$\mathbf{W}$

\begin{tabular}{|c|c|}
\hline Werner syndrome & $A-64, A-66$ \\
\hline Williams syndrome & $C-29$ \\
\hline Wilson disease & B-50 \\
\hline $\begin{array}{l}\text { Wiskott-Aldrich } \\
\text { syndrome }\end{array}$ & $B-11$ \\
\hline Wolman disease & B- 65 \\
\hline \multicolumn{2}{|l|}{$\mathbf{x}$} \\
\hline $\begin{array}{l}\mathrm{X} \text { chromosome } \\
\text { aberration }\end{array}$ & $C-16$ \\
\hline $\mathrm{X}$-arrestin & $A-12$ \\
\hline $\mathrm{X}$-inactivation & S-I-3, B-28 \\
\hline $\mathrm{X}$-linked inheritance & $A-13$ \\
\hline $\mathrm{Xp} 22.3$ & B-26 \\
\hline
\end{tabular}

\section{$\mathbf{Y}$}

$\mathrm{Y}$ chromosome

yeast

B-29, B-30, B- 31 ,

B- $32, \mathrm{C}-20$

A -7

$\mathbf{Z}$

Zellweger syndrome

ZNF179

PL-5, B -62

C -49

Others

Ip35-36 B-36

lq-multiplication $\cdot A-51$

$2 \mathrm{DE}$

A-62, B-28

$2 q$ medial monosomy

$2 \mathrm{q} 31$

C -8

C -8

4q-syndrome A-55

6q25.3-q26 B-17

7-dehydrocholesterol C-44

8p12-21 A-66

$9 \mathrm{q} 3 \mathrm{l} \quad \mathrm{B}-46$

Ilp15.5 B-70

11 q23 abnormalities A-59

12q partial $\quad C-19$

monosomy

$17 \mathrm{p} 11.2$

$21 \mathrm{q} 22.3$

C -49

B-24

C -21

A-29

Vol. 42, No. 1, 1997 